THIAGO CÉSAR DE SOUZA PINTO

MODELAGEM DA VELOCIDADE CRÍTICA DE TRANSPORTE DE POLPAS MINERAIS CONTENDO PARTÍCULAS GROSSAS 
THIAGO CÉSAR DE SOUZA PINTO

MODELAGEM DA VELOCIDADE CRÍTICA DE TRANSPORTE DE POLPAS MINERAIS CONTENDO PARTÍCULAS GROSSAS

Tese apresentada à Escola Politécnica da Universidade de São Paulo para obtenção do Título de Doutor em Engenharia. 


\section{MODELAGEM DA VELOCIDADE CRÍTICA DE TRANSPORTE DE POLPAS MINERAIS CONTENDO PARTÍCULAS GROSSAS}

Tese apresentada à Escola Politécnica da Universidade de São Paulo para obtenção do Título de Doutor em Engenharia.

Área de concentração:

Engenharia Mineral

Orientador:

Prof. Dr. Laurindo de Salles Leal Filho 
Este exemplar foi revisado e alterado em relação à versão original, sob responsabilidade única do autor e com a anuência de seu orientador.

São Paulo,19 de julho de 2012.

Assinatura do autor

Assinatura do orientador

FICHA CATALOGRÁFICA

Pinto, Thiago Cesar de Souza

Modelagem da velocidade crítica de transporte de polpas minerais contendo partículas grossas / T.C.S. Pinto. -- ed.rev. -São Paulo, 2012. $190 \mathrm{p}$.

Tese (Doutorado) - Escola Politécnica da Universidade de São Paulo. Departamento de Engenharia de Minas e de Petróleo.

1. Transporte em minas 2. Hematita 3. Partículas grossas 4. Apatita 5. Esfericidade 6. Mineroduto. I. Universidade de São Paulo. Escola Politécnica. Departamento de Engenharia de Minas e de Petróleo II. t. 
À minha família, pelo amor e dedicação. 


\section{AGRADECIMENTOS}

O autor gostaria de expressar seus sinceros agradecimentos:

\section{À Deus, criador de tudo.}

Ao amigo e Prof. Dr. Laurindo de Salles Leal Filho, pela orientação da tese, sempre enriquecendo com sugestões e comentários pertinentes, e por não medir esforços para que este trabalho se concluísse da melhor forma possível.

Ao amigo e Prof. Dr. Deovaldo de Moraes Júnior, por todo apoio e amizade dedicada ao longo dos anos, orientação e ensinamentos que se aplicam tanto ao lado profissional como ao lado humano. À sua esposa Marlene Silva de Moraes, pela amizade e todo apoio ao longo dos anos.

À minha família, pai, mãe e irmãos, por todo amor e suporte para que este trabalho pudesse se tornar realidade.

À Lorena Jamati, minha companheira, que sempre esteve ao meu lado, dividindo alegrias e dificuldades ao longo desses anos, sempre me apoiando e me fortalecendo para que este trabalho se concluísse.

A toda equipe do Laboratório de Operações Unitárias da UNISANTA, nas pessoas dos professores Luís Renato Bastos Lia, Carlos Alberto Amaral Moino, Aldo Ramos Santos, Karina Tamião e dos técnicos Gilmar de Alcântara, Volnei de Lemos e Irineu Penha da Ressurreição, e aos estagiários que passaram pelo laboratório ao longo destes anos.

A toda equipe do Laboratório de Fenômenos de Transporte e Química de Interfaces (LFQI), Marisa, Daniela, Simone, Ivani, Kelly, Rosendo, Adriana, Odair, pelo convívio e toda ajuda para a realização deste trabalho.

À Maria Cristina Bonésio, da Biblioteca do Departamento de Engenharia de Minas e de Petróleo (PMI), pela ajuda e paciência com as referências utilizadas neste trabalho.

À CAPES, por todo suporte financeiro. 
À Universidade Santa Cecília (UNISANTA), por todo apoio e confiança bem como por disponibilizar suas instalações para a realização de parte dos ensaios experimentais.

Às empresas Vale S.A. e Mineração Jundu, por disponibilizarem as amostras minerais utilizadas nesta tese.

A todos os amigos, que de alguma forma, me ajudaram e me apoiaram para que este projeto pudesse ser concluído. 
A busca do conhecimento é um ato diário

(Desconhecido) 


\section{RESUMO}

O dimensionamento de sistemas de transporte hidráulico de polpas minerais exige especial atenção à medida que partículas grossas apresentam um comportamento de sedimentação no interior dos tubos. Dentro desta situação, a velocidade de transporte da polpa mineral deve ter magnitude suficiente para suspender $e$ transportar os sólidos, evitando que os mesmos se depositem na base da tubulação. O bombeamento de polpas minerais em tubos horizontais contendo partículas grossas constituiu o objeto desta tese. Um levantamento sobre a literatura corrente foi realizado e, através de procedimentos experimentais, obteve-se um banco de dados para o modelamento da velocidade crítica $\left(\mathrm{V}_{\mathrm{C}}\right)$, isto é, a velocidade mínima em que ocorre a formação de um leito móvel na base do tubo, apresentando magnitude ligeiramente superior à velocidade de deposição $V_{D}$, caracterizada pelo início da deposição das partículas na base dos dutos. Para a realização dos ensaios, foram construídas duas unidades experimentais de bombeamento de polpa mineral, onde foram estudadas as seguintes variáveis: i) gradiente de pressão por metro de tubo horizontal $(\Delta \mathrm{P} / \mathrm{L})$, ii) velocidade média do fluxo $(\mathrm{V})$, iii) perfil de concentração de sólidos ao longo da seção transversal, iv) fator de forma através da função de esfericidade das partículas $(\Psi)$, v) densidade do sólido e do líquido, vi) concentração volumétrica da polpa mineral, vii) granulometria dos sólidos e viii) diâmetro da tubulação. A primeira unidade experimental foi montada com tubulação em PVC transparente de diâmetro nominal de $25,4 \mathrm{~mm}$ e a segunda unidade foi construída em PVC branco com um trecho de $2 \mathrm{~m}$ em acrílico transparente, apresentando diâmetro nominal de 50,8mm. A velocidade critica $\left(V_{C}\right)$ para cada condição estudada foi determinada visualmente, através das seções transparentes da tubulação. As amostras utilizadas neste trabalho foram: concentrados de apatita e hematita e o mineral quartzo. As frações granulométricas estudadas foram inseridas em duas classes de tamanho, sendo a primeira classe passante em $297 \mu \mathrm{m}$ e retida em $249 \mu \mathrm{m}$ e a segunda classe passante em $149 \mu \mathrm{m}$ e retida em $105 \mu \mathrm{m}$. Os resultados permitiram determinar um novo modelo semiempírico para $\mathrm{V}_{\mathrm{C}}$, alcançando desvios menores que $10 \%$ para as velocidades preditas em relação aos valores de velocidades observadas experimentalmente.

Palavras-chave: Mineroduto. Partículas grossas. Apatita. Hematita. Esfericidade. 


\begin{abstract}
The design of hydraulic systems of slurry transport demands a special attention due to coarse particles present a settling behavior inside the pipes. In this situation, the transport velocity should have order of magnitude sufficient to promote the suspension and the transport of particles, avoiding the solids deposition at the bottom of pipe. The transport of mineral slurries containing coarse particles was the primary goal of the thesis. A survey of the available literature was done and through the experimental tests could be possible to raise a data bank in order to develop a new best fit correlation for the critical velocity $\left(V_{C}\right)$ which included the particle shape effect, through the sphericity function. $V_{C}$ could be defined as the minimum velocity where a moving bed of particles takes place at the bottom of the horizontal pipe and it is slightly above the deposition velocity $V_{D}$, which could be characterized by a bed of stationary particles at the bottom of pipe. The research was conducted using two recirculating pipe test rigs with transparent PVC pipe of $25.4 \mathrm{~mm}$ and $50.8 \mathrm{~mm}$ internal diameter with slurry concentrations from $8 \%$ up to $27 \%$ by volume. The material used was apatite and hematite concentrates and quartz mineral, clustered in two classes of size range $(-0.297+0.210 \mathrm{~mm} ;-0.149+0.105 \mathrm{~mm})$, where the variables were: i) Head losses per meter of horizontal pipe $(\Delta P / L)$, ii) Mean transport velocity $(V)$, iii) solids distribution profile, iv) particle shape effect, through the sphericity function $(\Psi)$, v) density of particles and liquid, vi) Volumetric concentration of slurries, vii) particles size and viii) pipe diameter. The critical velocity $\left(\mathrm{V}_{\mathrm{C}}\right)$, for each studied condition, was visually determined through the transparent sections of the pipes. The results have yielded a new semi empirical model to predict the critical velocity, yielding a deviation of less than $10 \%$ from the observed values of experimental data for $\mathrm{V}_{\mathrm{C}}$.
\end{abstract}

Keywords: Pipeline. Coarse particles. Apatite. Hematite. Sphericity. 


\section{LISTA DE ILUSTRAÇÕES}

\section{Capítulo 2}

Figura 2.1-Faixa de tamanho de partículas adequado ao ótimo desempenho de operações unitárias do processamento mineral.

Figura 2.2-Diâmetro esférico equivalente de um cilindro através de seu volume. .28

Figura 2.3-Esfericidade de formas regulares. 34

Figura 2.4-Fluido entre placas planas paralelas. 39

Figura 2.5-Relação da taxa e tensão de cisalhamento para fluidos Newtonianos e não Newtonianos.

Figura 2.6-Componentes da força de resistência hidrodinâmica

Figura 2.7-Balanço de forças em uma partícula esférica imersa em meio fluido. .50

Figura 2.8-Coeficiente de arrasto em função do Número de Reynolds para partículas de diferentes esfericidades.

Figura 2.9-Distribuição dos perfis de velocidade e cisalhamento .54

Figura 2.10-Classificação das bombas de deslocamento positivo. .56

Figura 2.11-Classificação das turbobombas. .57

Figura 2.12-Comparação da potência requerida $(\mathrm{P})$, pressão $(H)$ e eficiência $(\eta)$ para operação de bombeamento de polpa e água. 58

Figura 2.13-Comportamento da perda de carga em função da velocidade para escoamento heterogêneo $(A)$ e homogêneo $(B)$.

Figura 2.14-Regime de fluxo, (1) velocidade subcrítica $\left(\mathrm{V}_{<} \mathrm{V}_{\mathrm{d}}\right)$; (2) suspensão total $\left(\mathrm{V}>\mathrm{V}_{\mathrm{d}}\right)$ 
Figura 2.15-Comparação de 6 modelos para a velocidade crítica de deposição para quartzo com concentração de $1 \% \mathrm{v} / \mathrm{v}$.

Figura 2.16-Variação do parâmetro $F_{L}$ em função da granulometria de sólidos e da concentração.

Figura 2.17-Nomográfico para determinação da velocidade limite de

deposição

Figura 2.18-Diagrama de Moody 70

\section{Capítulo 3}

Figura 3.1-Esboço do aparato experimental para a determinação da esfericidade de partículas minerais 80

Figura 3.2-Esboço da Unidade experimental de bombeamento de polpas minerais.

Figura 3.3-Unidade experimental de bombeamento de polpas minerais $(D=25,4 \mathrm{~mm})$. 82

Figura 3.4-Unidade experimental de bombeamento de polpas minerais $(\mathrm{D}=50,8 \mathrm{~mm})$. 83

Figura 3.5-Bomba centrifuga e seus componentes ( $D=25,4 \mathrm{~mm})$ (1) Carcaça, (2) selo, (3) rotor semiaberto. 84

Figura 3.6-Bomba centrifuga para polpas minerais da marca-IMBIL $(\mathrm{D}=50,8 \mathrm{~mm})$. 84

Figura 3.7-Agitador com 2 impelidores axiais ( $D=25,4 \mathrm{~mm})$ .85

Figura 3.8-Agitador com impelidores axiais ( $D=50,8 \mathrm{~mm})$ .85

Figura 3.9-Tubo de 25,4cm de diâmetro em PVC transparente. 86

Figura 3.10- Lâmpadas instaladas ao longo da tubulação. 86

Figura 3.11-Manômetro em U e válvulas. 


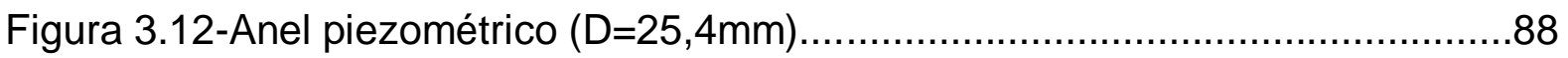

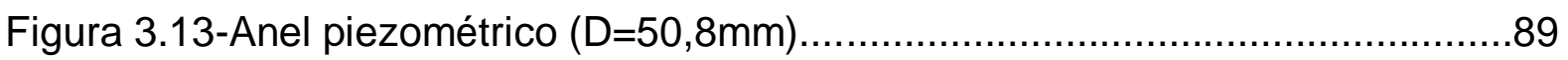

Figura 3.14-(a) Calha distribuidora, (b) vista frontal da divisão do tubo.....................89

Figura 3.15-Caixa de amostragem de polpa (a) Compartimento acoplado; (b) Compartimento individualizado...........................................................90

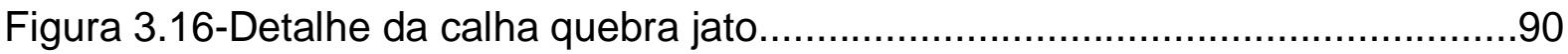

Figura 3.17-Representação da distância do centro de cada setor em relação ao

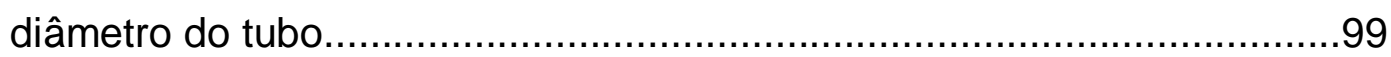

\section{Capítulo 4}

Figura 4.1-Gradiente de pressão em função da velocidade de fluxo para concentrado de apatita em dutos de $25,4 \mathrm{~mm}$ de diâmetro

Figura 4.2-Gradiente de pressão em função da velocidade de fluxo para concentrado de apatita em dutos de $25,4 \mathrm{~mm}$ de diâmetro 116

Figura 4.3-Gradiente de pressão em função da velocidade de fluxo para concentrado de apatita em dutos de $50,8 \mathrm{~mm}$ de diâmetro 116

Figura 4.4-Gradiente de pressão em função da velocidade de fluxo para concentrado de apatita em dutos de $50,8 \mathrm{~mm}$ de diâmetro.

Figura 4.5-Gradiente de pressão em função da velocidade de fluxo para concentrado de hematita em dutos de $25,4 \mathrm{~mm}$ de diâmetro.

Figura 4.6-Gradiente de pressão em função da velocidade de fluxo para concentrado de hematita em dutos de $25,4 \mathrm{~mm}$ de diâmetro

Figura 4.7-Gradiente de pressão em função da velocidade de fluxo para concentrado de hematita em dutos de 50,8mm de diâmetro.

Figura 4.8-Gradiente de pressão em função da velocidade de fluxo para concentrado de hematita em dutos de $50,8 \mathrm{~mm}$ de diâmetro 
Figura 4.9-Gradiente de pressão em função da velocidade de fluxo para quartzo em dutos de 25,4mm de diâmetro

Figura 4.10-Gradiente de pressão em função da velocidade de fluxo para quartzo em dutos de $25,4 \mathrm{~mm}$ de diâmetro

Figura 4.11-Gradiente de pressão em função da velocidade de fluxo para quartzo em dutos de $50,8 \mathrm{~mm}$ de diâmetro.

Figura 4.12-Gradiente de pressão em função da velocidade de fluxo para quartzo em dutos de 50,8mm de diâmetro.

Figura 4.13-Hábito das partículas de hematita. .124

Figura 4.14-Concentrado de hematita obtido no fluxo da calha da base. 126

Figura 4.15- Concentrado de hematita obtido no fluxo da calha do meio...... .127

Figura 4.16- Concentrado de hematita obtido no fluxo da calha do topo 128

\section{Capítulo 5}

Figura 5.1-Influência do número de Reynolds modificado sobre $\mathrm{V}_{\mathrm{C}}$. 132

Figura 5.2-Influência do grupo adimensional da esfericidade sobre $\mathrm{V}_{\mathrm{C}}$ .134

Figura 5.3-Efeito da concentração volumétrica em $\mathrm{V}_{\mathrm{C}}$ para o quartzo. .135

Figura 5.4-Efeito da concentração volumétrica em $V_{C}$ para o concentrado de apatita. 136

Figura 5.5-Efeito da concentração volumétrica em $V_{C}$ para o concentrado de hematita. 136

Figura 5.6- Resíduos versus valores previstos para $\mathrm{V}_{\mathrm{C}}$

Figura 5.7- Método dos mínimos quadrados para o grupo NRe modificado.

Figura 5.8- Método dos mínimos quadrados para o grupo da esfericidade. 140

Figura 5.9- Método dos mínimos quadrados para a concentração. 142 
Figura 5.10- Método dos mínimos quadrados para a constante da concentração.................................................................................143

Figura 5.11- Comparação entre a velocidade crítica calculada pelo modelo e a velocidade crítica observada experimentalmente................................145 


\section{LISTA DE TABELAS}

\section{CAPÍTULO 2}

Tabela 2.1-Técnicas de análise de tamanho de partículas. .29

Tabela 2.2-Dimensões e magnitude da viscosidade dinâmica. .40

Tabela 2.3-Classificação dos fluidos quanto à reologia. 41

Tabela 2.4-Correlações para viscosidade de polpas concentradas. 46

\section{CAPÍTULO 3}

Tabela 3.1- Caracterização do concentrado de apatita........................................76

Tabela 3.2- Teores apresentados para o concentrado de apatita..........................76

Tabela 3.3- Caracterização do concentrado de hematita...................................78

Tabela 3.4- Teores do concentrado de hematita................................................78

Tabela 3.5-Caracterização da fase sólida do quartzo......................................79

Tabela 3.6- Componentes da unidade experimental......................................82

Tabela 3.7- Válvulas constituintes do manômetro................................................87

Tabela 3.8- Propriedades da polpa mineral de concentrado de apatita para ensaios

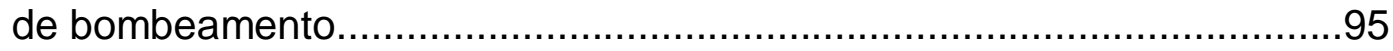

Tabela 3.9- Propriedades da polpa mineral de concentrado de hematita para ensaios de bombeamento .95

Tabela 3.10- Propriedades da polpa mineral de quartzo para ensaios de bombeamento. .96 


\section{CAPÍTULO 4}

Tabela 4.1- Velocidade crítica para polpas de concentrado de apatita...................104

Tabela 4.2- Velocidade crítica para polpas de concentrado de hematita................105

Tabela 4.3- Velocidade crítica para polpas de mineral de quartzo.........................107

Tabela 4.4- Desvios para a velocidade crítica em relação aos valores previstos por Wilson e Judge (1976)..................................................................110

Tabela 4.5- Desvios para a velocidade crítica em relação aos valores previstos por

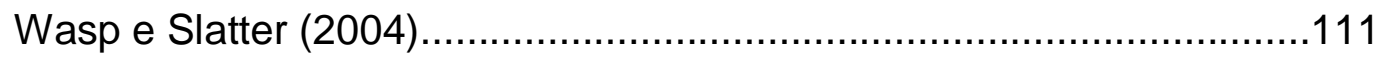

Tabela 4.6- Desvios para a velocidade crítica em relação aos valores previstos por Turian (1987) ...........................................................................112

Tabela 4.7- Desvios para a velocidade crítica em relação aos valores preditos por Schiller e Herbich (1991) 113

Tabela 4.8- Desvio médio em relação aos valores de $V_{C}$ experimentais e previsto por modelos da literatura corrente. 114

Tabela 4.9-Esfericidade na seção transversal do duto de 50,8mm. 125

\section{CAPÍTULO 5}

Tabela 5.1- Análise do resíduo normalizado (Z) ...........................................138

Tabela 5.2- Resultados para análise do teste t de Student...................................138

Tabela 5.3- Método dos mínimos quadrados para o grupo NRe modificado...........140

Tabela 5.4- Método dos mínimos quadrados para o grupo da esfericidade............141

Tabela 5.5- Método dos mínimos quadrados para o grupo da esfericidade............142

Tabela 5.6- Método dos mínimos quadrados para a constante da concentração. 


\section{LISTA DE SÍMBOLOS}
A
Área $\left[\mathrm{L}^{2}\right]$
$\mathrm{C}_{\mathrm{D}}$
coeficiente de arraste [-]
$C_{\mathrm{f}}$
perímetro da figura plana $[\mathrm{L}]$
$\mathrm{C}_{f}$
perímetro de um círculo de mesma área da figura plana [L]
$C_{m}$
concentração mássica da polpa mineral [-]
$C_{m / m}$
concentração em massa (\%) [-]
$C_{v / v}$
concentração em volume [-]
D
diâmetro da tubulação [L]
$D_{v}$
diâmetro volumétrico [L]
$D_{p}$
diâmetro médio de Sauter [L]
d
diâmetro da partícula [L]
$d_{p}$
diâmetro da esfera [L]
$d_{50}$
granulometria em que $50 \%$ é passante $[L]$
F
força aplicada a placa móvel $\left[\mathrm{MLT}^{-2}\right]$
$F_{D}$
força de arraste ou resistiva $\left[\mathrm{MLT}^{-2}\right]$
$\mathrm{F}_{\mathrm{L}}$
força de sustentação $\left[\mathrm{MLT}^{-2}\right]$
$f_{w}$
fator de atrito de Darcy [-]
g
aceleração da gravidade $\left[\mathrm{L} \mathrm{T} \mathrm{T}^{-2}\right]$
$\mathrm{H}$
carga da bomba [L]
perda de carga da polpa [L]
$i_{w} \quad$ perda de carga do líquido puro [L] 


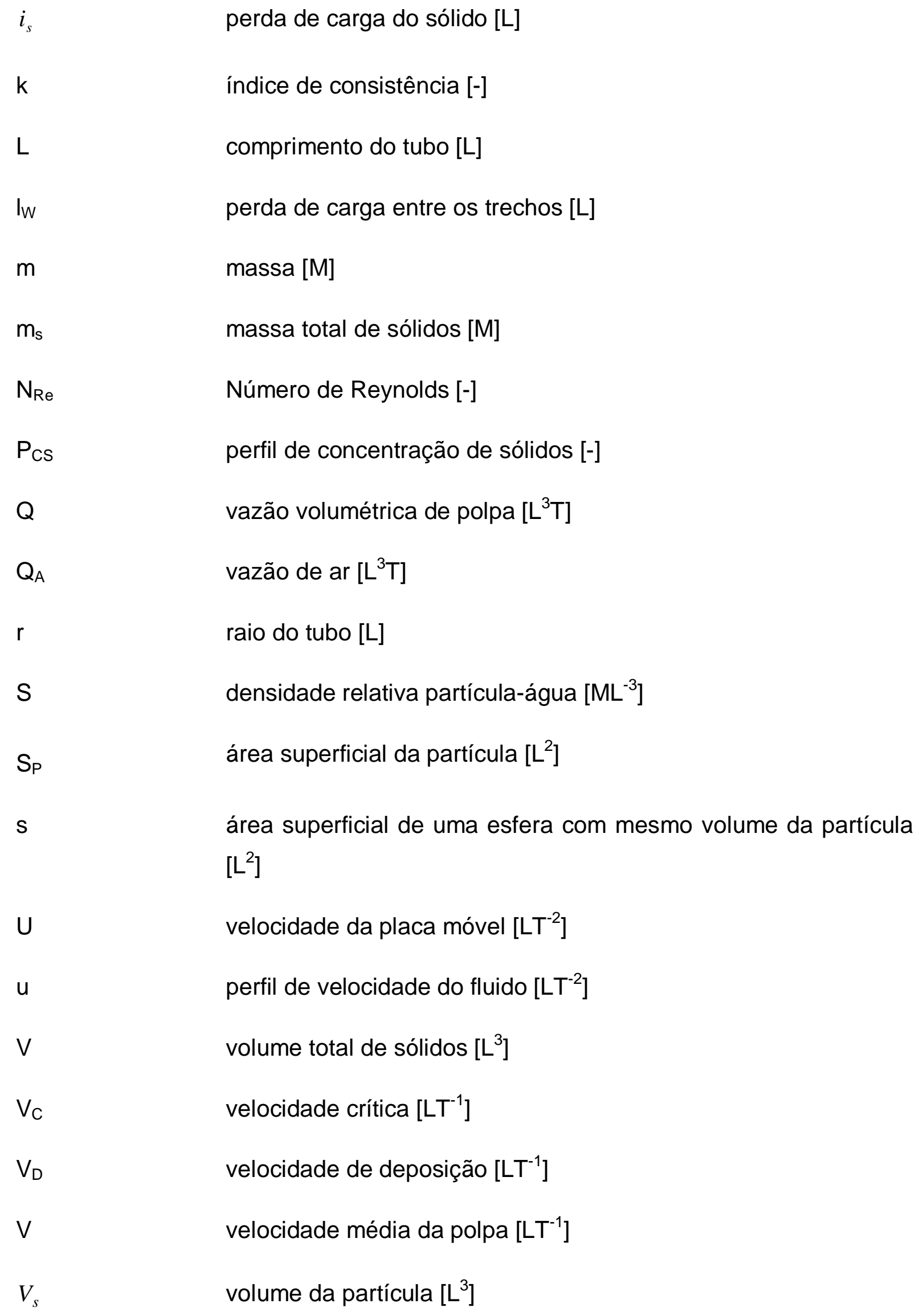




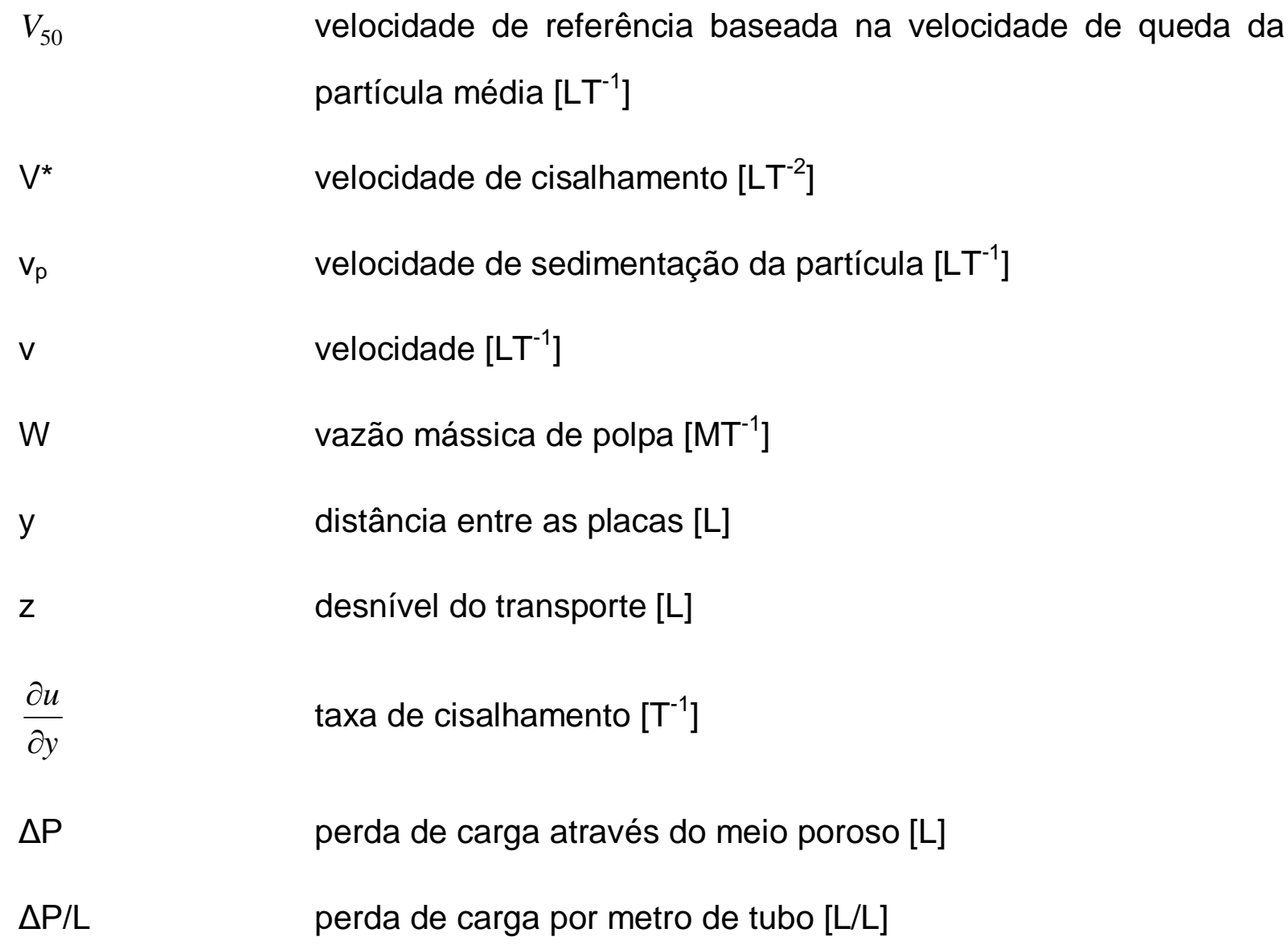

\section{Letras gregas}

$\begin{array}{ll}\gamma & \text { peso específico }\left[\mathrm{ML}^{-2} \mathrm{~T}^{-2}\right] \\ \delta & \text { espessura da subcamada viscosa }[\mathrm{L}] \\ \varepsilon & \text { porosidade do meio [-] } \\ \mu & \text { viscosidade dinâmica }\left[\mathrm{ML}^{-1} \mathrm{~T}^{-1}\right] \\ \mu_{A} & \text { viscosidade aparente }\left[\mathrm{ML}^{-1} \mathrm{~T}^{-1}\right] \\ \pi & \text { relação entre o comprimento e o diâmetro da circunferência } \\ v & \text { viscosidade cinemática da água }\left[\mathrm{L}^{2} \mathrm{~T}^{-1}\right] \\ \rho_{\mathrm{f}} & \text { massa específica do líquido }\left[\mathrm{ML}^{-3}\right] \\ \rho_{\mathrm{s}} & \text { massa específica do sólido }\left[\mathrm{ML}^{-3}\right]\end{array}$


tensão de cisalhamento $\left[\mathrm{ML}^{-1} \mathrm{~T}^{2}\right]$

$\tau_{w}$

tensão de cisalhamento na parede do tubo $\left[\mathrm{ML}^{-1} \mathrm{~T}^{2}\right]$

$\Phi$

incremento do gradiente de pressão da polpa [-]

$\phi$

concentração volumétrica [-]

$\psi$

grau de esfericidade [-]

$\Omega$

circularidade [-] 


\section{SUMÁRIO}

CAPÍTULO 1- Introdução, Relevância e Objetivos.............................23

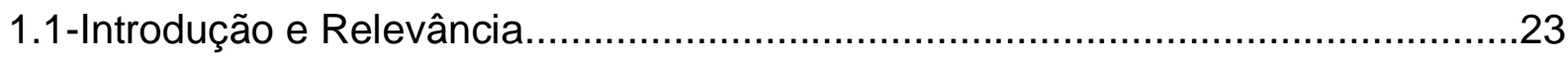

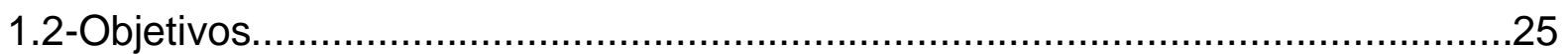

CAPÍTULO 2- Revisão da Literatura.................................................26

2.1-Caracterização de forma e tamanho de partículas minerais..............................27

2.2-Técnicas para determinação do tamanho de partículas......................................29

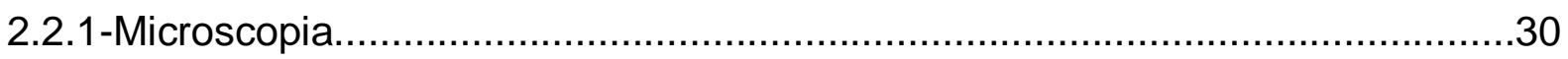

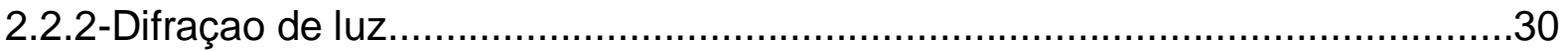

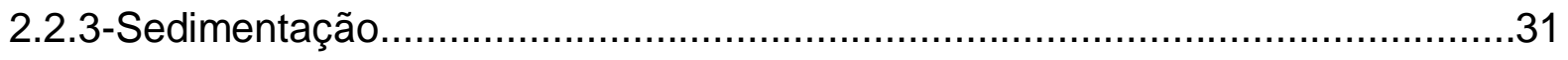

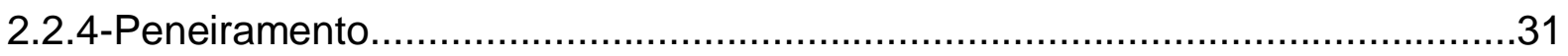

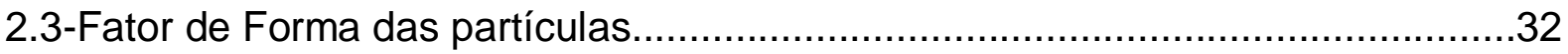

2.3.1-Determinação da esfericidade de partículas através da permeametria............34

2.4-Fluidodinâmica de partículas sólidas............................................................37

2.4.1-Reologia

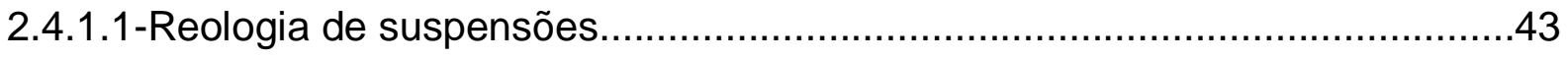

2.4.2-Sólidos imersos em meio fluido................................................................47

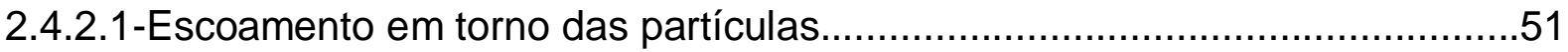

2.5-Transporte hidráulico de polpas minerais....................................................53

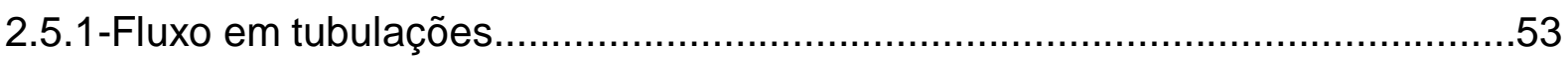

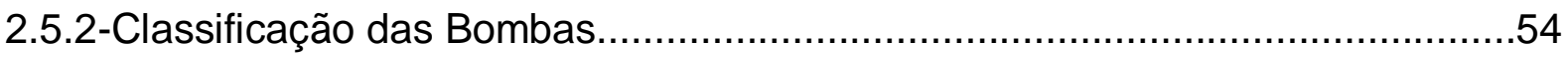

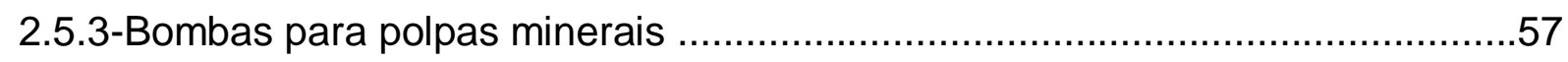


2.5.5-Classificação de polpas minerais quanto ao fluxo.....................................60

2.5.6-Velocidade crítica de transporte...................................................62

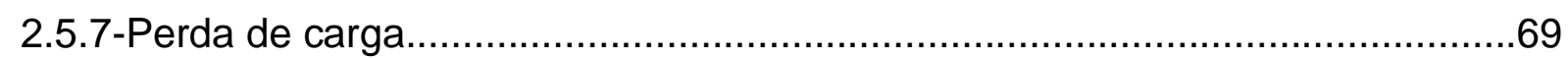

CAPÍTULO 3- Materiais e Métodos......................................................74

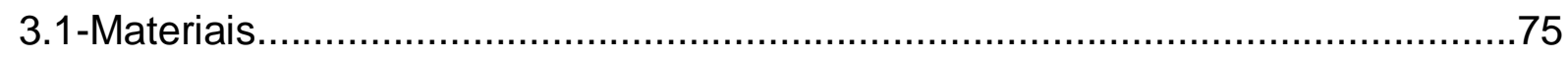

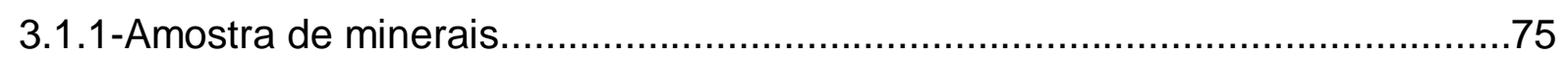

3.1.2-Unidade experimental para determinação da esfericidade...........................79

3.1.3-Unidade experimental para o bombeamento de polpas minerais...................80

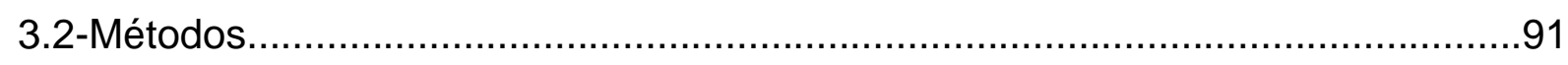

3.2.1-Determinação da esfericidade das partículas minerais..............................91

3.2.2-Ensaios de bombeamento de polpas minerais....................................93

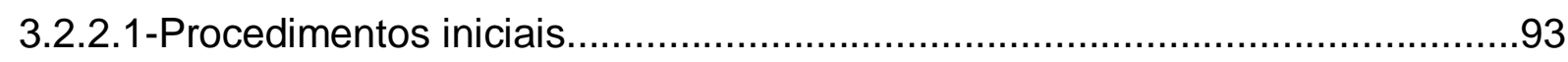

3.2.2.2-Determinação da velocidade crítica................................................96

3.2.2.3-Determinação da Perda de Carga....................................................97

3.2.2.4-Determinação experimental do gradiente de fluxo de sólidos ....................98

3.2.2.5-Levantamento da curva da perda de carga por metro de tubo horizontal em função da velocidade de fluxo da polpa..............................................100

CAPÍTULO 4 - Resultados e Discussões: ensaios experimentais de bombeamento..............................................................101

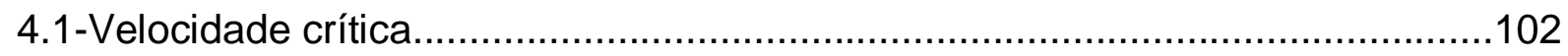

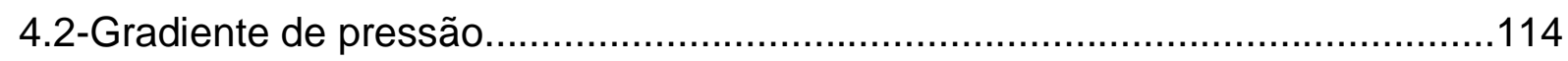


4.3-Segregação de partículas de hematita nos tubos durante 0

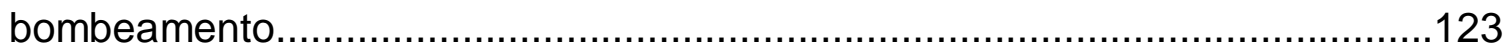

CAPÍTULO 5- Resultados e Discussões: modelagem da velocidade crítica $\left(\mathrm{V}_{\mathrm{c}}\right)$

5.1-Efeito de $N R_{E}$ modificado.

5.2-Efeito do grupo adimensional da esfericidade. 133

5.3-Efeito da densidade dos sólidos. 134

5.4-Efeito da concentração de sólidos. 134

5.5-Validação estatística do modelo proposto. 137

5.6-Ajuste dos parâmetros do modelo proposto. 139

5.7-Modelo proposto final.

CAPÍTULO 6- Conclusões e Sugestões 146

Referências bibliográficas 149

\section{Apêndices}

Apêndice A159

A1-Curvas do perfil de distribuição de sólidos. 159

Apêndice B.171

B1-Dados de gradiente de pressão e velocidade de fluxo .171 


\section{CAPÍTULO 1}

\section{INTRODUÇÃO, RELEVÂNCIA E OBJETIVO}

\subsection{Introdução e Relevância}

Na primeira década do século XXI, os grandes superávits apresentados pela balança comercial brasileira foram devidos, principalmente, à exportação de commodities agrícolas e minerais. Neste contexto, destaca-se a grande produção de concentrados de minério de ferro (compostos predominantemente de hematita) e também a crescente e intensiva demanda por fertilizantes fosfatados, cuja produção depende da oferta de concentrados de apatita. Para manter sua atual competitividade no cenário internacional, é necessário que a indústria mineral brasileira reduza não somente os custos de produção, mas também o impacto ambiental de suas atividades produtivas. Neste caso, a substituição de ferrovia ou rodovia pelo transporte hidráulico de concentrados minerais pode constituir uma valiosa contribuição no sentido de baratear custos e diminuir a poluição do ar e solo pela geração de poeira.

Concentrados de hematita (sinter feed) e apatita comumente produzidos nas usinas brasileiras de beneficiamento são constituídos em mais de $20 \%$ de sua massa total por partículas grossas (diâmetro $>0,105 \mathrm{~mm}$ ). Tais partículas, quando transportadas em dutos, na forma de polpas com alta porcentagem de sólidos, necessitam estar em adequado estado de suspensão para não sedimentar e, eventualmente, obstruir o fluxo de polpa através do duto. Deste modo, o sucesso do transporte hidráulico de concentrados minerais, que contêm partículas grossas em suspensão, demanda conhecimentos técnicos adequados a tal aplicação. Esta constitui a justificativa para o desenvolvimento desta tese.

O fluxo de polpa mineral em um duto difere do fluxo de um líquido homogêneo porque este último pode ocorrer sob uma ampla faixa de velocidades e regimes de escoamento, enquanto que o fluxo de polpa contendo partículas grossas 
está restrito a uma faixa especial de velocidades que devem, obrigatoriamente, ser maiores que um valor crítico que é denominado "velocidade de deposição" ( $\left.\mathrm{V}_{\mathrm{D}}\right)$. Isto porque, para velocidades de fluxo menores ou iguais a $V_{D}$, um leito fixo de partículas é criado no fundo do duto horizontal, indicando a necessidade de um aumento na turbulência do sistema para evitar a obstrução da tubulação o que, fatalmente, trará danos à operação (Wilson et al, 2006). Deste modo, a magnitude do parâmetro $V_{D}$ constitui uma informação de primordial importância tanto para o projeto quanto para operação de minerodutos. Outra condição importante para o dimensionamento, bem como a operação de bombeamento de polpas minerais, é a velocidade crítica $\left(\mathrm{V}_{\mathrm{C}}\right)$, que apresenta magnitude ligeiramente maior que $V_{D}$, em que o fluxo apresenta um leito móvel de partículas no interior dos dutos.

A modelagem do fluxo de polpas em dutos data de meados do século $X X$, através da publicação do trabalho pioneiro de Durand (DURAND, 1952). Tal modelo consiste na correlação entre queda de pressão $(\Delta P)$ por unidade de comprimento $(L)$ horizontal de duto, também chamado de gradiente de pressão $(\Delta P / L)$, com a velocidade média do fluxo (V), permitindo que, por observação visual, se determine a magnitude da velocidade mínima de deposição $\left(\mathrm{V}_{\mathrm{D}}\right)$. Deste modo, a magnitude de $V_{D}$ pôde ser relacionada à concentração de sólidos na polpa, assim como a algumas de suas características intrínsecas, como tamanho de partículas e densidade dos sólidos presentes (WASP et al, 1977; SLATTER, 1999).

Após quase 60 anos de existência do modelo pioneiro de Durand, muitos outros modelos têm sido reportados pela literatura corrente. Todos eles apresentam duas características comuns: todos se baseiam em diagramas $(\Delta P / L)$ em função de $\mathrm{V}$ para determinação de curvas especificas de bombeamento e não abordam a influência da forma das partículas no desempenho do sistema de transporte hidráulico. 


\subsection{Objetivos}

Esta tese teve como objetivo geral projetar e montar duas unidades experimentais com diâmetros de tubulação diferentes $\left(D_{1}=25,4 \mathrm{~mm}\right.$ e $\left.D_{2}=50,8 \mathrm{~mm}\right)$, para quantificar a influência das principais variáveis envolvidas na operação de bombeamento de polpas minerais. Os objetivos específicos foram a determinação experimental e, por consequência, a modelagem da velocidade crítica de transporte $\left(\mathrm{V}_{\mathrm{C}}\right)$ inserindo a forma de partículas grossas (diâmetro $>0,105 \mathrm{~mm}$ ) através da função esfericidade, para concentrados de apatita e hematita e do mineral quartzo. Este esforço encontra-se inserido na linha de trabalho do Grupo de Pesquisa em Tratamento de Minérios da Escola Politécnica da USP, sob a atual liderança do orientador desta tese. 


\section{CAPÍTULO 2}

\section{REVISÃO DA LITERATURA}

Este capítulo aborda os principais métodos utilizados pela tecnologia mineral para caracterizar forma e tamanho das partículas sólidas (seção 2.1-2.3) que, misturados à água, constituem polpas ou suspensões que são submetidas ao transporte hidráulico em tubulações. Forma e tamanho das partículas minerais influenciam sua velocidade de sedimentação, regime de fluxo, coeficiente de arrasto e a reologia das suspensões, assim a seção 2.4 aborda aspectos relativos ao comportamento de partículas sólidas dispersas em meio aquoso. Tais variáveis integram direta ou indiretamente os vários modelos matemáticos reportados pela literatura que relacionam perda de carga na tubulação e/ou velocidade de deposição com variáveis fundamentais, como tamanho, forma e densidade das partículas minerais (seção 2.5). 


\subsection{Caracterização da forma e tamanho de partículas minerais}

Partículas minerais são geradas por processos de cominuição que utilizam a energia mecânica na forma de compressão, impacto e cisalhamento. Uma vez que estes mecanismos não são adequadamente controlados, o produto gerado é constituído de uma população de partículas a qual apresenta ampla distribuição granulométrica, cuja caracterização provê informações muito importantes para o controle de processos e na escolha e/ou dimensionamento de equipamentos. Isto porque, cada operação unitária do tratamento mineral opera, em sua máxima eficiência, dentro de uma determinada faixa de tamanho, conforme ilustra a Figura 2.1.
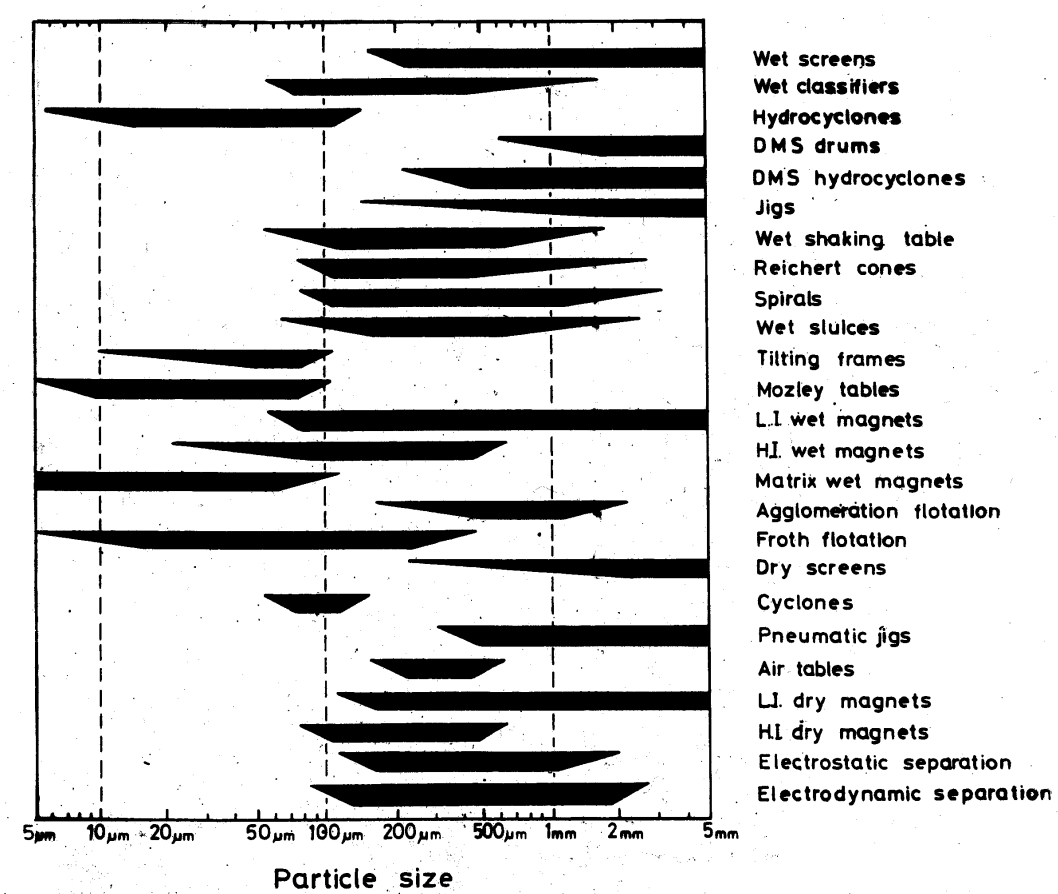

Figura 2.1- Faixa de tamanho de partículas adequado ao ótimo desempenho de operações unitárias do processamento mineral (KELLY E SPOTTSWOOD, 1982).

O tamanho de uma partícula esférica é função exclusiva de seu diâmetro, já que este apresenta o mesmo comprimento ao longo dos três eixos do espaço tridimensional (WADELL, 1935). Para partículas que apresentam formas regulares e 
não esféricas, seu tamanho pode ser caracterizado pelas dimensões de seus três eixos. Todavia, para partículas de forma arbitrária, seu tamanho pode ser definido através de um diâmetro esférico equivalente ou nominal (ALLEN, 1997; RAWLE, 2002). Ele pode ser determinado através de propriedades da partícula como, por exemplo, volume, área superficial, ou ainda em condições mais específicas como a sedimentação em meio fluido, o que permite relacionar o diâmetro real da partícula ao de uma esfera de mesma densidade e que apresenta mesma velocidade de sedimentação. Neste caso, tal variável é denominada de diâmetro equivalente esférico ou diâmetro hidráulico.

De acordo com Allen (1997) e Kelly e Spottswood (1982), a partir da definição do modelo adotado para a medida de tamanho das partículas, é importante a realização de uma caracterização que retrate a magnitude do diâmetro médio de uma população.

lacocca e German (1997) destacam que, dependendo da propriedade da partícula adotada para se determinar o diâmetro da esfera equivalente, diferentes respostas são obtidas, sendo que todas são corretas, apesar de trazerem valores diferentes em função da propriedade da partícula que foi utilizada para tal medida. Rawle (2002) esclarece que não se devem comparar resultados entre as técnicas utilizadas, a não ser que sejam partículas esféricas. O que o autor sugere é comparar a mesma técnica realizada por diferentes instrumentos de medição.

Conforme se observa na Figura 2.2, um cilindro de altura de $150 \mu \mathrm{m}$ e diâmetro de $30 \mu \mathrm{m}$, exibe um diâmetro equivalente de $59 \mu \mathrm{m}$.
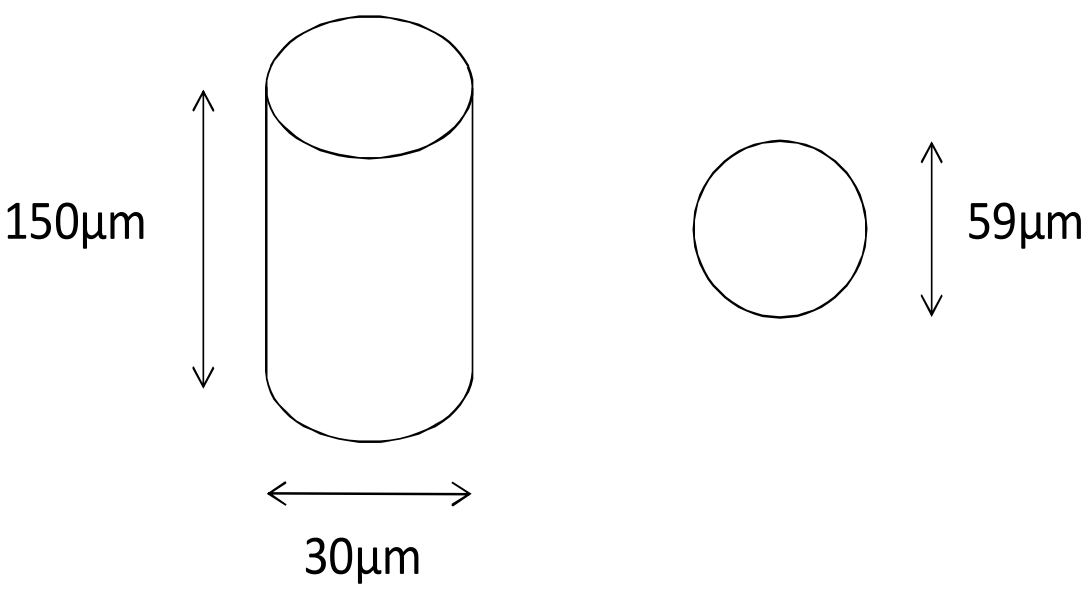

Figura 2.2- Diâmetro esférico equivalente de um cilindro através de seu volume. 


\subsection{Técnicas para determinação do tamanho de partículas}

Várias técnicas podem ser empregadas para a obtenção de informação quantitativa (ou semi-quantitativa) sobre o tamanho das partículas que compõem uma amostra, assim como a distribuição de frequência com que ocorrem os diferentes tamanhos, ou classes de tamanhos (CHATTERJEE, 1998). Assim, a reprodutibilidade de uma analise é fator de primordial importância para a credibilidade dos resultados e sua interpretação (JILLAVENKATESA, 2001 apud PAPINI, 2003). A Tabela 2.1 apresenta algumas técnicas de análises usualmente empregadas.

Tabela 2.1-Técnicas de análise de tamanho de partícula (lacocca e German, 1997).

Peneiramento

Microscopia Quantitativa

Espalhamento de luz; Turbidimetria (espalhamento de luz de pequeno ângulo)

Contadores ópticos de partículas

Velocimetria

Espalhamento de nêutrons/raios $X$

Cromatografia por exclusão de tamanho; Cromatografia hidrodinâmica

Fracionamento de campo de fluxo (FFF)

FFF elétrico; FFF por sedimentação

Sensoriamento de zona elétrica

Centrifugação/Ultra centrifugação/Sedimentação

Tempo de vôo aerodinâmico

Dentre as várias técnicas disponíveis para a determinação de um diâmetro médio para uma população de partículas, este trabalho apresenta uma breve discussão sobre a microscopia, espalhamento ou difração de luz e a sedimentação, devido ao fato de serem estas as técnicas mais utilizadas no âmbito da tecnologia mineral. 


\subsubsection{Microscopia}

A microscopia é a única técnica de medida direta, muito utilizada como medida padrão. Além do tamanho, também é possível caracterizar a forma das partículas, utilizando parâmetros como circularidade e esfericidade. As imagens projetadas pelo microscópio são bidimensionais e dependem da orientação das mesmas (IACOCCA E GERMAN, 1997).

Microscópios podem ser óticos, de varredura ou de transmissão. Os intervalos granulométricos para cada tipo podem variar de $2 \mathrm{~nm}$ para 0 de transmissão, $20 \mathrm{~nm}$ para varredura e $3 \mu \mathrm{m}$ para o ótico, tendo um tamanho máximo comum de partículas, de $1 \mathrm{~mm}$ (ALLEN, 1997).

\subsubsection{Difração de luz}

O espalhamento ou difração de luz faz parte de um conjunto de técnicas em que as partículas são dispersas em meio fluido e a medida é realizada de forma dinâmica. As descontinuidades verificadas na transmissão de luz que atravessa uma suspensão são detectadas e sua magnitude é correlacionada com o diâmetro das partículas presentes na suspensão.

A luz pode sofrer 4 tipos de fenômenos (difração, refração, absorção ou reflexão) (HILDEBRAND, 1999). Os detectores dos equipamentos medem a intensidade e o ângulo do espalhamento e então é realizada uma conversão para a distribuição de tamanhos.

De acordo com Allen (1997) e lacocca e German (1997), a difração pode ocasionar um aumento na dispersão do tamanho das partículas com a diminuição da circularidade das mesmas. Sendo assim, medidas de esfericidade não são possíveis já que o diâmetro médio não corresponde ao diâmetro da esfera de mesmo volume. Variações nas medidas por espalhamento de luz também sofrem diferenças referentes ao equipamento com que se realizam as medidas, devido a parâmetros óticos (índices de refração) e softwares de análise. 


\subsubsection{Sedimentação}

A sedimentação é controlada pela velocidade de deposição em meio fluido. O regime de escoamento deve ser laminar e a velocidade das mesmas deve obedecer à Lei de Stokes. Alguns problemas devem ser observados para medidas de tamanho através da sedimentação, como o efeito da forma da partícula, haja vista que quanto mais a partícula se afasta de uma esfera, maior o número de anomalias na trajetória de queda (ALMENDRA, 1979). Partículas coloidais $(<1 \mu \mathrm{m})$, por apresentarem dificuldade de sedimentação, demandam maior tempo de sedimentação, bem como partículas grosseiras fogem do regime laminar $\left(\mathrm{N}_{\mathrm{Re}}\right.$ partícula> 0,2).

\subsubsection{Peneiramento}

Esta técnica visa separar os sólidos em frações de tamanhos uniformes de acordo com um gabarito. Este gabarito se constitui na abertura da peneira, que define o diâmetro de corte. O produto gerado em cada peneira apresenta partículas retidas e passantes de acordo com a abertura utilizada. A operação pode ocorrer a seco ou a úmido e de forma estática ou dinâmica. O número de Tyler (\#) é utilizado para caracterizar o gabarito das peneiras, constituindo o número de furos em linha reta por polegada linear. Assim, quanto maior o número de mesh Tyler, maior o número de furos, e por consequência, mais fina a partícula passante em um dado mesh de uma peneira.

Barreiros et al. (1996) apresentaram um trabalho onde foi analisado o efeito da forma das partículas utilizando técnicas de sedimentação, difração e microscopia, com esferas de vidro, vidro moído e micas. Como conclusão, os autores afirmam que para partículas de forma irregular, a microscopia apresentou os maiores valores para o diâmetro e a sedimentação os menores, sendo que a difração apresentou resultados intermediários. Para partículas esféricas, os autores concluem que não há discrepância significativa entre as técnicas. Assim, fica evidenciado que o efeito 
da forma das partículas exerce influência significativa em relação à técnica escolhida para a medida do tamanho das mesmas.

\subsection{Forma das partículas}

O fator forma das partículas é importante em uma série de situações, pois afeta diretamente propriedades como área superficial, densidade de suspensões, principalmente para concentrações volumétricas acima de $30 \%$, velocidade terminal de sedimentação e coeficiente de arraste, além de influenciar o desempenho de operações unitárias, como escoamento em tubos, tanques com agitação, células de flotação e leitos porosos (KELLY E SPOTTSWOOD, 1982; SOUZA PINTO et al., 2009).

Wadell (1932) discute sobre a confiabilidade da classificação direta da forma das partículas em regulares e irregulares a partir da semelhança com formas padrão, afirmando que tal processo envolve opiniões pessoais e não permite manter um padrão ao se analisar materiais diferentes.

A classificação de tamanhos de partículas irregulares é geralmente baseada na média aritmética ou geométrica do maior, intermediário e menor diâmetro, o que em qualquer situação apresenta relação direta com dois principais fatores, forma e volume. Ao se comparar uma partícula de forma irregular com uma esfera, estas podem apresentar um mesmo tamanho e diferirem quanto à forma, volume e área superficial.

Wadell (1933) propôs o fator de circularidade $(\Omega)$, que expressa um fator de forma para figuras planas (bidimensional), com o objetivo de se comparar partículas de formas diferentes, conforme descrito na Equação 2.1.

$$
\Omega=\frac{c_{f}}{C_{f}}
$$


Sendo:

$\Omega \circ$ grau de circularidade

$c_{f}$ o perímetro de um círculo de mesma área da figura plana e;

$C_{f}$ o perímetro da figura plana.

Muitas equações que descrevem o comportamento das partículas (velocidade terminal de queda, coeficiente de arraste, fator de fricção) baseiam-se no comportamento de formas esféricas. Wadell (1935) foi quem apresentou a definição do grau ou coeficiente de esfericidade das partículas como a razão entre a área superficial de uma esfera, que apresenta o mesmo volume da partícula, e a área superficial da partícula (Equação 2.2). Fernandez et al. (2010) também apresentam e discutem o conceito de esfericidade.

$$
\psi=\frac{s}{S_{p}}
$$

Sendo:

$\psi$ o grau de esfericidade;

$s$ a área superficial de uma esfera com mesmo volume da partícula e;

$S_{p}$ a área superficial da partícula.

A esfericidade das partículas apresenta valor máximo na unidade $(\psi=1)$ para partículas perfeitamente esféricas, diminuindo conforme a forma se afasta desta. Logo, partículas isométricas ou de geometria definida têm sua esfericidade facilmente determinada pela equação 2.2, pois é possível conhecer sua área superficial. A Figura 2.3 apresenta a esfericidade de algumas formas isométricas.

Segundo Massarani (2002), o diâmetro volumétrico $\left(D_{v}\right)$ pode ser adotado como dimensão característica e a esfericidade como a caracterização da forma. Sendo assim, a esfericidade pode ser definida, dentro do conceito descrito através da Equação 2.2, de acordo com a Equação 2.3. 

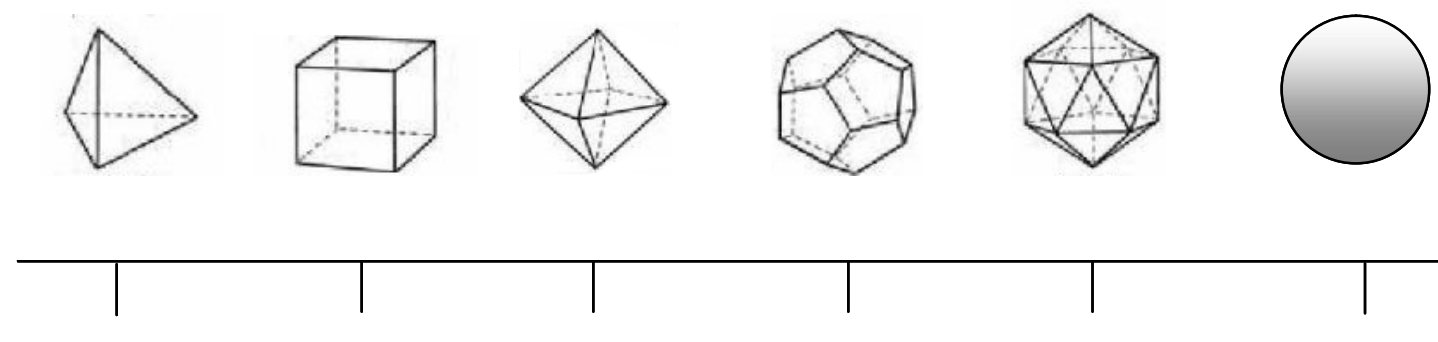

0.91

0.94

1.00

Tetraedro Hexaedro Octaedro Dodecaedro Icosaedro Esfera

Figura 2.3-Esfericidade de sólidos isométricos e geometria definida

(Souza Pinto et al, 2009).

$$
\psi=\frac{\pi \cdot D_{V}^{2}}{S_{P}}
$$

Sendo:

$\psi$ o coeficiente de esfericidade;

$\pi \cdot D_{V}^{2}$ a área superficial de uma esfera com mesmo volume da partícula e; $S_{P}$ a área superficial da partícula.

\subsubsection{Determinação da esfericidade de partículas através da permeametria}

Segundo Heywood (1954) a área superficial é uma das propriedades mais importantes de materiais particulados, é há muitas técnicas para sua medida direta.

Schultz (1974) afirma que a resistência oferecida por um leito de partículas ao fluxo de um fluido é função da região da fronteira entre o fluxo e o leito estacionário de partículas. O modelo proposto por Kozeny-Carman, em 1952, expressa esta relação para a determinação da área superficial de materiais particulados. 
Segundo Massarani (2002), a superfície específica da matriz porosa (Sv) é função de um fator de forma $B$, associado à superfície, e um fator $C$, associado ao volume da partícula. Logo a área específica da matriz porosa pode ser definida de acordo com a Equação 2.4.

$$
S_{V}=\frac{6 .(1-\varepsilon)}{D_{p} \cdot \psi}
$$

Sendo:

$\varepsilon$ a porosidade do meio;

$D_{p}$ o diâmetro médio de Sauter (volume de superfície), $m$.

A permeametria é uma técnica que permite a determinação da esfericidade de materiais particulados (MASSARANI, 2002; SCHULTZ, 1974; ERGUN, 1952) e pode ser determinada através da perda de carga do escoamento de um fluido através de um leito poroso, o qual tem sua constante de permeabilidade (k) determinada conforme Equação 2.5 (McCABE, 2001), baseada na Lei de Darcy.

$$
-\frac{\Delta P}{L}=\frac{\mu}{K} \cdot \frac{Q}{A}
$$

Sendo:

$\triangle \mathrm{P}$ a perda de carga através do meio poroso, $\mathrm{Pa}$

$Q$ a vazão de ar, $\mathrm{m}^{3} / \mathrm{s}$

$\mu$ a viscosidade dinâmica do fluido a $20^{\circ} \mathrm{C}$, Pa.s

A a área da seção do leito, $\mathrm{m}^{2}$

$\mathrm{L}$ o comprimento do leito, $\mathrm{m}$.

Segundo McCabe (2005), a porosidade do meio $(\varepsilon)$ pode ser definida como a razão entre o volume de espaços vazios pelo volume total do leito (vazio+sólidos). 
Assim, se um leito de volume (V), for preenchido por certa massa de partículas (m) apresentando massa específica $\rho_{\mathrm{s}}$, a porosidade do meio pode ser definida segundo Equação 2.6.

$$
m_{s}=(1-\varepsilon) \cdot \rho_{s} \cdot V
$$

Em que:

$\mathrm{m}_{\mathrm{s}}$ é a massa total de sólidos, $\mathrm{kg}$

$\varepsilon$ é a porosidade do meio;

$\checkmark$ é o volume total de sólidos, $\mathrm{m}^{3}$.

Com as características do sistema, tais como, porosidade, diâmetro da partícula, perda de carga por altura de leito e a velocidade média do fluido, o modelo de Kozeny-Carmam apresenta a esfericidade de acordo com a Equação 2.7. Ergun (1952) também discute e apresenta tal modelo, (McCABE, 2001).

$$
-\frac{\Delta P}{L} \cdot \frac{\left(D_{p} \psi\right)^{2}}{\overline{V_{0}} \cdot \mu} \cdot \frac{\varepsilon^{2}}{(1-\varepsilon)^{2}}=150
$$

Sendo:

$D_{P}$ o diâmetro médio de Sauter; $m$

$V_{0}$ a velocidade média do fluido, $\mathrm{m} / \mathrm{s}$

Rearranjando a Equação 2.7, combinada com a Equação 2.5, tem-se o modelo apresentado através da Equação 2.8 (MCCABE, 1985; SOUZA PINTO et al., 2009). 


$$
K=\frac{\left(D_{p} \psi\right)^{2} \varepsilon^{3}}{150 .(1-\varepsilon)^{2}}
$$

\subsection{Fluidodinâmica de partículas sólidas}

Heider e Levenspiel (1989), Trang-Cong et al. (2004), Yow et al. (2005) evidenciam a importância da relação da velocidade de sedimentação da partícula com seu coeficiente de arraste e o Número de Reynolds. Muitos trabalhos (Haider e Levenspiel, 1989; Concha e Barrientos, 1985, Concha e Almendra, 1979) têm revelado a dificuldade em se trabalhar com partículas não esféricas, apresentando fatores de correção para a correta previsão da velocidade terminal de queda e coeficientes de arraste das mesmas.

A magnitude da velocidade terminal de queda das partículas minerais tem importância fundamental dentro do universo do tratamento mineral. Operações de concentração gravimétrica, bombeamento de polpas, flotação, são exemplos em que a sedimentação das partículas deve ser um fenômeno controlado e analisado para o propósito de modelamento e otimização.

Com base nos modelos para a determinação da velocidade terminal de queda, inicialmente realizados através dos trabalhos de Stokes, sua aplicação é exclusivamente para partículas esféricas, já que estas possuem as mesmas dimensões, independente de sua orientação (WADELL, 1933).

Muitos autores (HEIDER E LEVENSPIEL 1989; CONCHA E BARRIENTOS, 1986; TRANG-CONG ET AL 2004; YOW ET AL 2005) têm trabalhado com o objetivo de se determinar um modelo matemático que busque a correta previsão da velocidade terminal de partículas de forma arbitrária, sendo Wadell (1935), através do conceito de esfericidade, busca um fator que exprima uma relação entre a partícula e a esfera de mesmo tamanho. Tal fator tem se revelado de importância significativa e, através de modelos ou representações gráficas, tem sido utilizado por meio de correlações com a velocidade terminal e o coeficiente de arraste das mesmas. 


\subsubsection{Reologia}

Fluidos podem ser definidos como corpos que se deformam continuamente quando submetidos à ação de uma força cisalhante, e a reologia provê bases teóricas e experimentais necessárias para classificar os fluidos quanto ao seu comportamento, quando submetidos a tal força, permitindo o modelamento e controle de processo (MACOSKO, 1993; MORAES, 2011).

Toda substância está sujeita a sofrer deformação quando submetida a uma tensão de cisalhamento $(\tau)$, isto é, a razão entre a magnitude da força cisalhante $(F)$ e a área (A) sobre a qual tal esforço é aplicado $(\tau=\mathrm{F} / \mathrm{A})$. Quando $\tau$ é aplicado sobre um corpo sólido, a extensão de sua deformação é controlada pelo módulo de elasticidade do material. Todavia, quando líquidos e gases são submetidos a um esforço de cisalhamento, eles se deformam continuamente sendo, por esta razão, denominados de fluidos. Com base nestas premissas, defini-se reologia como a ciência que estuda a deformação e fluidez da matéria (HARRIS, 1977; BARNES, 1989). A diferença entre deformação para sólidos, líquidos e gases pode ser observada através dos trabalhos descritos abaixo:

i. Quando se enfocou sólidos, enfatizou-se a sua deformação elástica produzida, em observação às forças deformantes, publicada por R. Hooke, através da Teoria da Elasticidade, em 1676.

ii. Quando se abordam os líquidos e gases, enfatiza-se a fluidez. Este é um foco da Reologia, haja vista que Isaac Newton publicou "PRINCIPIA" em 1687 com base no comportamento dos líquidos.

Isaac Newton propôs um modelo baseado em um fluido confinado entre duas placas planas de mesma área $(A)$, separadas por uma distancia $(Y)$, de acordo com a Figura 2.4. Fixando-se a placa inferior e impondo uma força $(F)$ à placa superior, que desenvolve velocidade $(U)$, as diversas camadas do fluido se movem com velocidades constantes, que variam de um valor máximo (u), junto à placa superior e de mesmo valor de (U), e zero junto à parede da placa inferior. Logo, a força necessária para manter uma diferença de velocidade entre as placas, por unidade de área $(F / A)$, é diretamente proporcional ao gradiente de velocidade 
formado através do fluido e inversamente proporcional à distância entre as placas $(\mathrm{y})$ (MUNSON et al., 2004; BARNES, 1989).

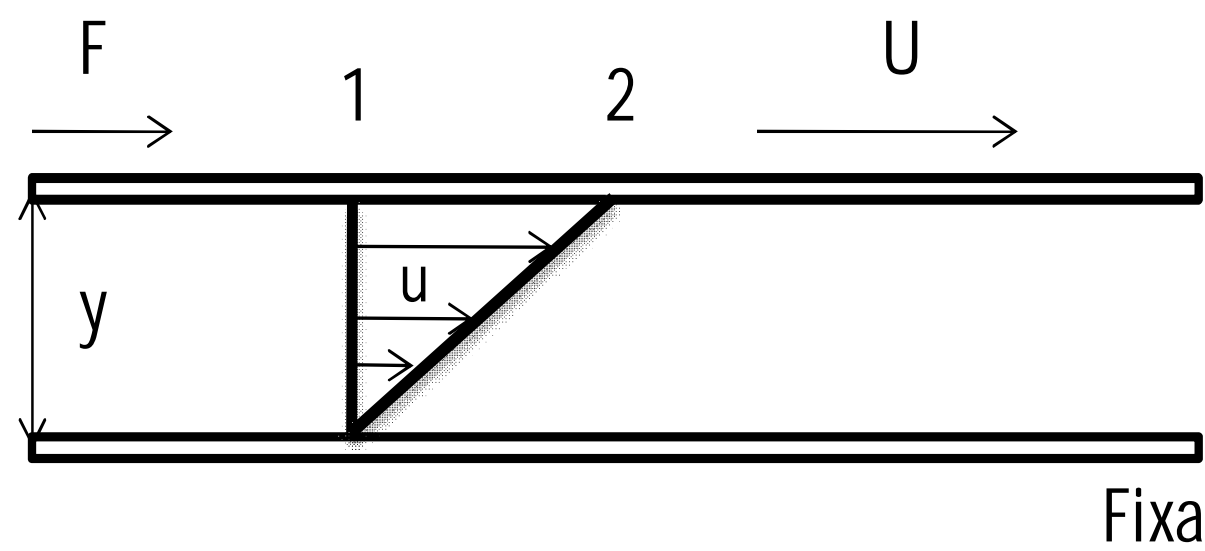

Figura 2.4-Fluido entre placas planas paralelas

Sendo:

y a distância entre as placas;

F a força aplicada a placa móvel;

U a velocidade da placa móvel,

u o perfil de velocidade do fluido,

1-2 a distância percorrida pela placa.

A resistência que este fluido apresenta ao escoamento, isto é, a fricção interna de suas camadas, pode ser definida através de uma propriedade denominada viscosidade. A tensão cisalhante $(\tau)$ produzida é diretamente proporcional à taxa de cisalhamento $\left(\frac{\partial u}{\partial y}\right)$ e a constante de proporcionalidade $(\mu)$ pode ser definida como a viscosidade, conforme ilustra a Equação 2.9.

A lei de Newton para viscosidade apresenta relação linear para a tensão e a taxa de cisalhamento, sendo assim, fluidos que obedecem a esta relação de proporcionalidade são classificados como fluidos Newtonianos e, aqueles que fogem da relação linear podem ser definidos como fluidos não-Newtonianos (BIRD ET AL., 1960). 


$$
\tau=\mu \cdot \frac{\partial u}{\partial y}
$$

Em que:

$\tau$ é a tensão de cisalhamento; $\mathrm{Pa}$

$\frac{\partial u}{\partial y}$ é taxa de cisalhamento; $\mathrm{s}^{-1}$

$\mu$ é a viscosidade dinâmica, Pa.s

Conforme se verifica na Equação 2.9, viscosidade é uma variável que possui as dimensões e unidades apresentadas de acordo com a Tabela 2.2.

Tabela 2.2- Dimensões e magnitude da viscosidade dinâmica (Perry et al, 1997).

\begin{tabular}{c|c|c}
\hline $\begin{array}{c}\text { Sistema de } \\
\text { unidades }\end{array}$ & Unidades & $\begin{array}{c}\text { Magnitude para água a 20} \mathbf{C} \\
\left(\mathbf{1 0 ^ { - 3 } )}\right.\end{array}$ \\
\hline SI & Pa.s $\left(\mathrm{N} . \mathrm{s} / \mathrm{m}^{2}\right)$ & 1,0000 \\
\hline CGS & Poise $\left(\right.$ dina.s $\left./ \mathrm{cm}^{2}\right)$ & 10,0000 \\
\hline INGLES & $\mathrm{lbf} . \mathrm{s} / \mathrm{ft}^{2}$ & 0,0209 \\
\hline MKS & $\mathrm{kgf.s} / \mathrm{m}^{2}$ & 0,1020 \\
\hline
\end{tabular}

Segundo Somasundaran (1980), Moudgil (1988) e Klimpel (1982), fluidos nãoNewtonianos apresentam modelos empíricos que descrevem seu comportamento baseado na taxa em função da tensão de cisalhamento. Os fluidos não-Newtonianos são dependentes da taxa de cisalhamento e independentes do tempo de atuação da mesma. A exceção são fluidos classificados como tixotrópicos e reopéticos, que também apresentam dependência do tempo. A Tabela 2.3 apresenta a classificação dos fluidos quanto à reologia. Os fluidos apresentam diferentes comportamentos reológicos em função da relação da tensão e taxa de cisalhamento, conforme ilustrado na Figura 2.5 (somente fluidos cuja reologia é independente do tempo).

Tabela 2.3- Classificação dos fluidos quanto à reologia (Adaptado Moraes Jr et al., 2011). 


\begin{tabular}{|c|c|c|c|}
\hline $\begin{array}{c}\text { CLASSIFICAÇÃO } \\
\text { DOS FLUIDOS }\end{array}$ & DEFINIÇÃO & EXEMPLOS & MODELO \\
\hline $\begin{array}{l}\text { Plástico de } \\
\text { Bingham }\end{array}$ & $\begin{array}{c}\text { Tem um comportamento } \\
\text { de sólido até exceder uma } \\
\text { tensão cisalhante mínima, } \\
\text { assumindo comportamento } \\
\text { de fluido }\end{array}$ & $\begin{array}{l}\text { Creme dental, } \\
\text { margarina, óleos } \\
\text { e algumas } \\
\text { polpas minerais }\end{array}$ & $\tau=\tau_{0}+\mu \cdot \frac{\partial u}{\partial y}$ \\
\hline Pseudoplástico & $\begin{array}{c}\text { Classe mais ampla dos } \\
\text { fluidos não-Newtonianos, } \\
\text { sendo sua curva no } \\
\text { reograma côncava para } \\
\text { baixo, passando pela } \\
\text { origem }\end{array}$ & $\begin{array}{l}\text { Maionese, } \\
\text { graxas, látex, } \\
\text { polímeros de } \\
\text { celulose, sabão, } \\
\text { detergente. }\end{array}$ & $\begin{array}{c}\tau=\mu_{A}\left(\frac{\partial u}{\partial y}\right) \\
\mu_{A}=K\left(\frac{\partial u}{\partial y}\right)^{n-1} \\
\mathrm{n}<1\end{array}$ \\
\hline Newtoniano & $\begin{array}{l}\text { Relação linear entre } \\
\text { tensão e taxa de } \\
\text { cisalhamento, e a reta } \\
\text { passa pela origem do } \\
\text { reograma }\end{array}$ & $\begin{array}{l}\text { Água, ar e } \\
\text { gasolina }\end{array}$ & $\tau=\mu \cdot \frac{\partial u}{\partial y}$ \\
\hline Dilatante & $\begin{array}{c}\text { A curva da tensão de } \\
\text { cisalhamento versus taxa } \\
\text { de deformação passa pela } \\
\text { origem e tem concavidade } \\
\text { para cima e é praticamente } \\
\text { linear a altas taxas } \\
\text { cisalhantes }\end{array}$ & $\begin{array}{l}\text { Goma arábica, } \\
\text { suspensões de } \\
\text { mica e areia }\end{array}$ & $\begin{array}{c}\tau=\mu_{A}\left(\frac{\partial u}{\partial y}\right) \\
\mu_{A}=K\left(\frac{\partial u}{\partial y}\right)^{n-1} \\
\mathrm{n}>1\end{array}$ \\
\hline Reopético & $\begin{array}{c}\text { Mesmo com a aplicação } \\
\text { de uma força constante, a } \\
\text { viscosidade aumenta com } \\
\text { o tempo, e cessando a } \\
\text { força a estrutura original é } \\
\text { recuperada }\end{array}$ & $\begin{array}{c}\text { Suspensão de } \\
\text { gesso e } \\
\text { bentonita }\end{array}$ & - \\
\hline Tixotrópico & $\begin{array}{l}\text { Mesmo com a variação da } \\
\text { força cisalhante, a } \\
\text { viscosidade diminui, e sua } \\
\text { estrutura original é } \\
\text { recuperada com a cessão } \\
\text { da tensão. }\end{array}$ & $\begin{array}{l}\text { Vernizes, lodo } \\
\text { de esgoto, tintas }\end{array}$ & - \\
\hline Viscoelástico & $\begin{array}{l}\text { A resistência à deformação } \\
\text { é proporcional ao efeito } \\
\text { viscoso acrescido de um } \\
\text { efeito elástico (tensão } \\
\text { tangencial e normal) }\end{array}$ & $\begin{array}{l}\text { Líquidos } \\
\text { poliméricos }\end{array}$ & - \\
\hline
\end{tabular}




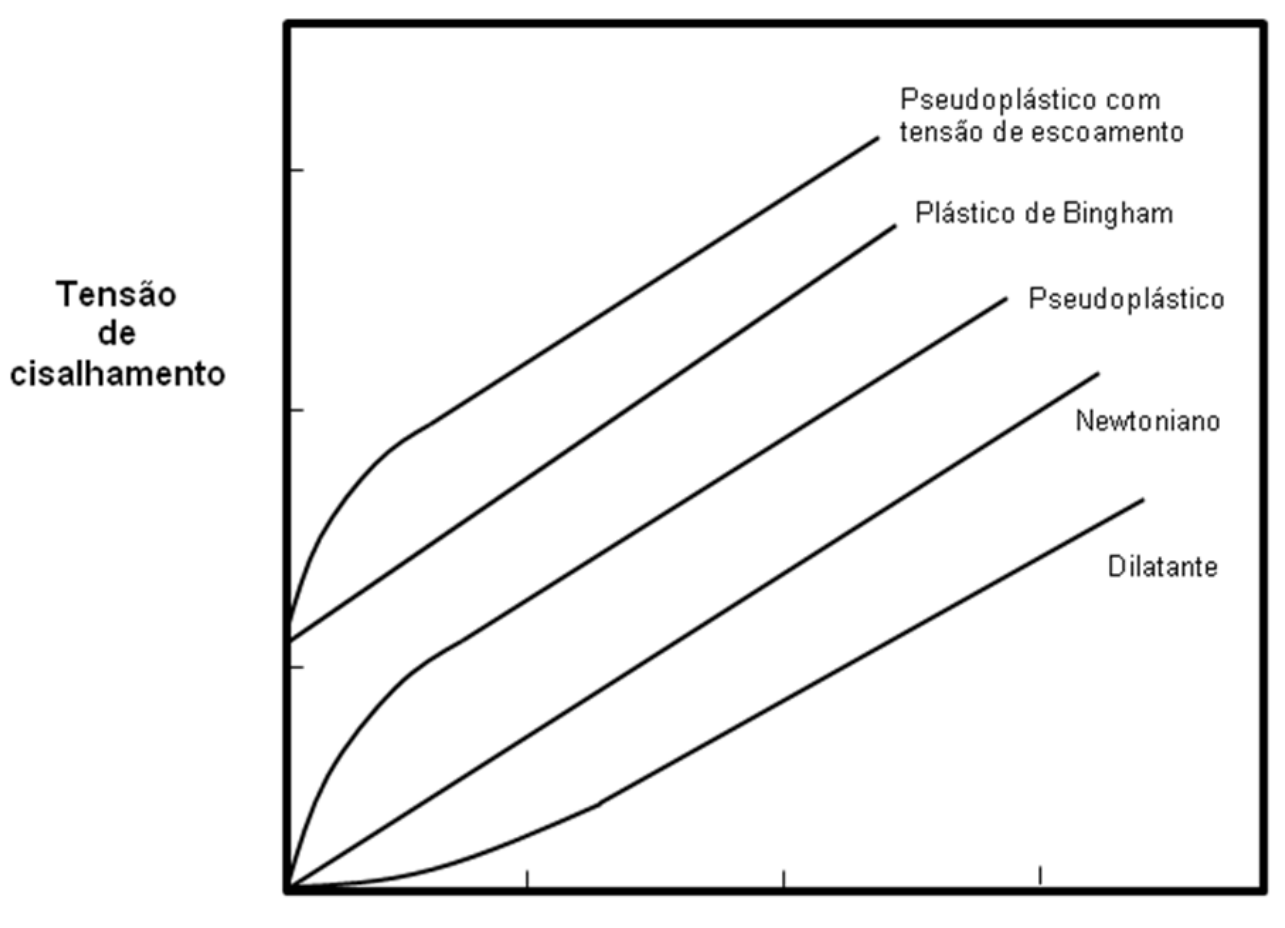

Taxa de cisalhamento

Figura 2.5-Relação da taxa e tensão de cisalhamento para fluidos Newtonianos e não Newtonianos (Moraes Jr, 2011).

Observando a Figura 2.5, pode-se notar que para altos valores de taxa de cisalhamento (eixo das abscissas), a variação da tensão cisalhante (eixo das ordenadas) passa a obedecer a uma variação linear. Fluidos Newtonianos partem da origem, isto é, atingem valores nulos para a tensão e a taxa de cisalhamento, enquanto plásticos de Bingham e pseudoplástico apresentam uma tensão de cisalhamento mínima.

Barnes et al. (1989) e Mingzhao et al. (2004) reportam que as variáveis que apresentam maior influência sobre a viscosidade são: a taxa de cisalhamento, temperatura, pressão e o tempo em que o material é submetido ao cisalhamento.

A taxa de cisalhamento aproximada pode ser estimada dividindo-se a velocidade média do fluxo pela dimensão característica da geometria do material em que o fluido se encontra escoando, como por exemplo, o raio de um tubo ou a espessura de uma subcamada (SHAHEEN, 1971). Em reômetros do modelo Brookfield, $\frac{\partial u}{\partial y}$ é a frequência da rotação do spindle no interior do líquido. 
Líquidos Newtonianos apresentam um decréscimo na viscosidade com 0 aumento da temperatura, aproximadamente com a relação de Arrhenius. E quanto maior a viscosidade mais forte a dependência sobre a temperatura.

A viscosidade de líquidos aumenta exponencialmente com a pressão isotrópica. O único caso de exceção é água a $30^{\circ} \mathrm{C}$, em que a viscosidade inicialmente diminui para depois aumentar, sendo importante ressaltar que as variações na viscosidade são muito pequenas para valores de variação da pressão atmosférica \pm 1 bar (BARNES et al., 1989).

\subsubsection{Reologia de suspensões}

A reologia de suspensões se mostra como um campo importante das ciências de engenharia, baseando-se na variedade de aplicações industriais, como por exemplo, na indústria química, petróleo e mineral, dentre outras (SHAHEEN, 1971). De acordo com Whiten et al. (1993) a adição de partículas sólidas no meio aquoso acarreta num aumento de dissipação de energia por unidade de volume da polpa. Logo para uma taxa de deformação constante, a manutenção da igualdade entre a taxa e a tensão de cisalhamento deve-se haver um aumento da viscosidade.

Dentro da indústria mineral, Slatter (1999) relata que a reologia pode ser abordada pelas características viscosas da polpa, através da relação entre a tensão e a taxa de cisalhamento, apresentando curvas entre essas grandezas conhecidas como reograma.

Para a caracterização reológica da polpa mineral, Slatter (1999) e Whiten et al. (1993) afirmam que medidas em viscosímetros de tubo são mais realistas e os resultados mais reprodutivos, já que este tipo de viscosímetro minimiza o efeito de segregação das partículas, utilizando a perda de carga e fatores de fricção conhecidos para o levantamento do reograma de uma polpa mineral.

Pawlik e Laskowski (1999) ressaltam a relação de dependência que existe entre reologia e as forças hidrodinâmicas que atuam na superfície das partículas. Os mecanismos que regem a suspensão de partículas em meio fluido pode ser descrito basicamente por 3 princípios: 
i) O primeiro é de origem coloidal, onde a polaridade governa o fenômeno. As forças envolvidas resultam em atração ou repulsão e são resultados de cargas eletrostáticas bem como das forças de London-Van der Waals presentes.

ii) O segundo surge do movimento Browniano, onde as forças promovem uma movimentação randômica das partículas, ressaltando que a forma e o tamanho têm influência significativa sobre a mesma. Assim partículas menores que $1 \mu \mathrm{m}$ sofrem forte influência do movimento Browniano.

iii) Em terceiro estão as forças viscosas que atuam nas partículas. Estas forças são proporcionais à diferença na velocidade local da partícula e do fluido que a cerca. Logo as partículas representam uma interrupção no contínuo do fluido, acarretando num aumento da viscosidade. Para partículas que formam agregados (floculação/coagulação), a influência passa a ser mais significativa, pois também são aprisionados fluidos, gerando um aumento mais expressivo na viscosidade aparente (BARNES, 1989).

Einstein, através de sua publicação em 1906, foi o pioneiro na investigação de viscosidade de suspensões. Seus trabalhos foram para polpas diluídas em fluidos newtonianos (menos de 1\% em volume) e o autor mostrou que a influência de uma única partícula esférica ocasiona um aumento na viscosidade, pois os sólidos ocasionam uma mudança no perfil de distribuição de velocidade do fluido (MACOSKO, 1993), conforme ilustrado na Equação 2.10. O modelo proposto pelo autor não considera a posição nem o tamanho da partícula.

$$
\mu=\mu_{f} .(1+2,5 \phi)
$$

\section{Em que:}

$\mu$ é a viscosidade da suspensão;

$\mu_{f}$ é a viscosidade do liquido; e

$\phi$ é a concentração volumétrica de sólidos. 
A partir dos estudos de Einstein, muitos trabalhos surgiram (ROBINSON, 1957; MOONEY, 1951) com o objetivo de se modificar o modelo para polpas mais concentradas.

De acordo com Cox e Brenner (1970), quando se leva em conta as interações entre partículas, o comportamento e a caracterização reológica da suspensão implicam em maior complexidade.

Tomas (1965) apresenta uma vasta discussão sobre a viscosidade de suspensões concentradas. A análise de dados de literatura, segundo o autor, indica uma negligência de variáveis que podem influenciar a viscosidade de suspensões concentradas tais como, distribuição do tamanho de partículas, tensão de cisalhamento e fenômenos de superfície, que determinam a molhabilidade, aglutinação e dispersão. He et al. (2004) indica que tal fato pode levar a erros na viscosidade de $20 \%$ em polpas que apresentam concentração em volume $(\phi=0,2)$ e $50 \%$ para polpas com concentração volumétrica $(\phi=0,5)$.

Um conceito importante, segundo Shook e Bartosik (1994) vem a ser o máximo empacotamento da polpa $\left(\phi_{m}\right)$, isto é, quando a adição de sólidos chega a um ponto tal que torna o escoamento impossível e a viscosidade tende ao infinito. As variáveis que afetam $\left(\phi_{m}\right)$ são a distribuição granulométrica e a forma das partículas. Partículas não esféricas e floculadas apresentam baixo grau de empacotamento, já partículas simétricas apresentam valores maiores para $\left(\phi_{m}\right)$.

De acordo com He et al. (2004), polpas diluídas apresentam comportamento Newtoniano ( $1 \%$ em volume) e, com o aumento da concentração de sólidos, o efeito aglomerativo se torna mais pronunciado, o que acarreta um acréscimo no valor da viscosidade, gerando um comportamento não-Newtoniano para a maioria das polpas minerais (USUl et al., 2001). Modelos empíricos que predizem a viscosidade de suspensões a partir de correlações com a viscosidade do líquido carreador são apresentadas na Tabela 2.4 .

Para avaliar a utilidade e/ou aplicabilidade das equações apresentadas na Tabela 2.4, adota-se uma porcentagem de sólidos volumétrica de $20 \%$, ou seja, $\phi=0,2$. Para esta situação, os valores da viscosidade encontrados pelas expressões da mesma tabela indicam que a relação $\mu / \mu_{\mathrm{f}}$ converge para a faixa de 1,8 a 2,1. Isto significa que, em termos práticos, para uma porcentagem de sólidos volumétrica de $20 \%$, a polpa mineral é duas vezes mais viscosa que a água. 
Slatter (1999) afirma que o modelamento reológico de polpas minerais pode ser realizado de forma satisfatória através dos modelos pseudoplástico e de plástico de Bingham, em que cada modelo apresenta $\tau_{y}=0$ e $n=1$, respectivamente. $O$ autor ressalta a importância de que os modelos só são validos para condições em que o fluxo apresenta regime laminar.

Tabela 2.4- Correlações para viscosidade de polpas concentradas.

\begin{tabular}{cl}
\hline Autor & Modelo \\
\hline Roscoe (1954) & $\frac{\mu}{\mu_{f}}=\frac{1}{(1-\phi)^{2,5}}$ \\
Krieger e Dougherty (1959) & $\frac{\mu}{\mu_{f}}=\left(1-\frac{\phi}{\phi_{m}}\right)^{\mu \cdot \phi_{m}}$ \\
Tomas (1965) & $\frac{\mu}{\mu_{f}}=1+2,5 \phi+10,05 \phi^{2}+0,00273 e^{16,6 \phi}$ \\
Heiskanen e Laapas (1979) & $\frac{\mu}{\mu_{f}}=1+2,5 \phi+14,1 \phi^{2}+0,00273 e^{16,6 \phi}$ \\
Shook e Roco (1991) & $\frac{\mu}{\mu_{f}}=1+2,5 \phi+10 \phi^{2}+0,0019 e^{20 \phi}$ \\
Senepati et al. (2009) & $\frac{\mu}{\mu_{f}}=\frac{10 C_{u}}{d_{50}}\left[1+\frac{\mu}{\gamma^{0,4}} \cdot\left(\frac{\phi}{\phi_{m}-\phi}\right)\right]^{3,5}$
\end{tabular}

Sendo para os modelos da Tabela 2.4:

$\Phi$ a concentração volumétrica de sólidos;

$\phi_{m}$ o máximo empacotamento da suspensão;

$C_{u}$ o coeficiente de uniformidade;

$d_{50}$ a granulometria em que 50\% é passante;

$\gamma$ a taxa de cisalhamento. 


\subsubsection{Sólidos imersos em meio fluido}

Todo corpo ou partícula que se movimenta através de um fluido está sujeito a forças promovidas pela interação partícula-fluido e a forças devidas a um campo externo, como gravidade e força centrífuga. As que atuam na interface partículafluido podem ser descritas em função dos efeitos viscosos ou efeitos de pressão enquanto que as forças devidas ao campo externo podem ser atribuídas a um campo gravitacional ou centrífugo (BROWN, 1950, GEANKOPLIS, 1993; MUNSON et al., 2004).

O balanço de forças apresenta como resultante do campo externo $\left(F_{g}\right)$, como por exemplo, o campo gravitacional, uma parcela devido à força peso $\left(\mathrm{F}_{\mathrm{P}}\right)$ da partícula e outra parcela devido ao empuxo $\left(\mathrm{F}_{\mathrm{E}}\right)$, conforme ilustra a Equação $2.11 \mathrm{e}$ 2.12. Para ações externas que não à do campo gravitacional, o balanço é válido levando-se em conta as acelerações em questão (MUNSON et al., 2004; ALMENDRA, 1979).

$$
\begin{aligned}
& \mathrm{F}_{\mathrm{g}}=\mathrm{F}_{\mathrm{P}}-\mathrm{F}_{\mathrm{E}} \\
& F_{g}=\rho_{s} V_{s} g-\rho_{f} V_{s} g
\end{aligned}
$$

Sendo:

$\rho_{\mathrm{s}}$ a massa específica do sólido; $\mathrm{kg} / \mathrm{m}^{3}$

$\rho_{\mathrm{f}}$ a massa específica do líquido; $\mathrm{kg} / \mathrm{m}^{3}$

$V_{s}$ o volume da partícula; $\mathrm{m}^{3}$

$\mathrm{g}$ a aceleração da gravidade, $\mathrm{m} / \mathrm{s}^{2}$

O balanço das forças hidrodinâmicas, que ocorre na interface partículafluido, apresenta uma resultante na direção do movimento, porém em sentido contrário, conhecida como força de arraste ou resistiva $\left(F_{D}\right)$ e outra perpendicular à 
direção do movimento, de sustentação $\left(\mathrm{F}_{\mathrm{L}}\right)$, (Figura 2.6), que para partículas esféricas apresenta valor nulo.

A força de arraste pode ser descrita pelo atrito partícula-fluido em função da distribuição de forças de cisalhamento (efeitos viscosos) denominado de arraste superficial e das distribuições de pressão em torno da partícula, conhecido como arraste de forma, devido à forte dependência sobre a forma da partícula (ALMENDRA 1979, CHIN ET AL., 1986).

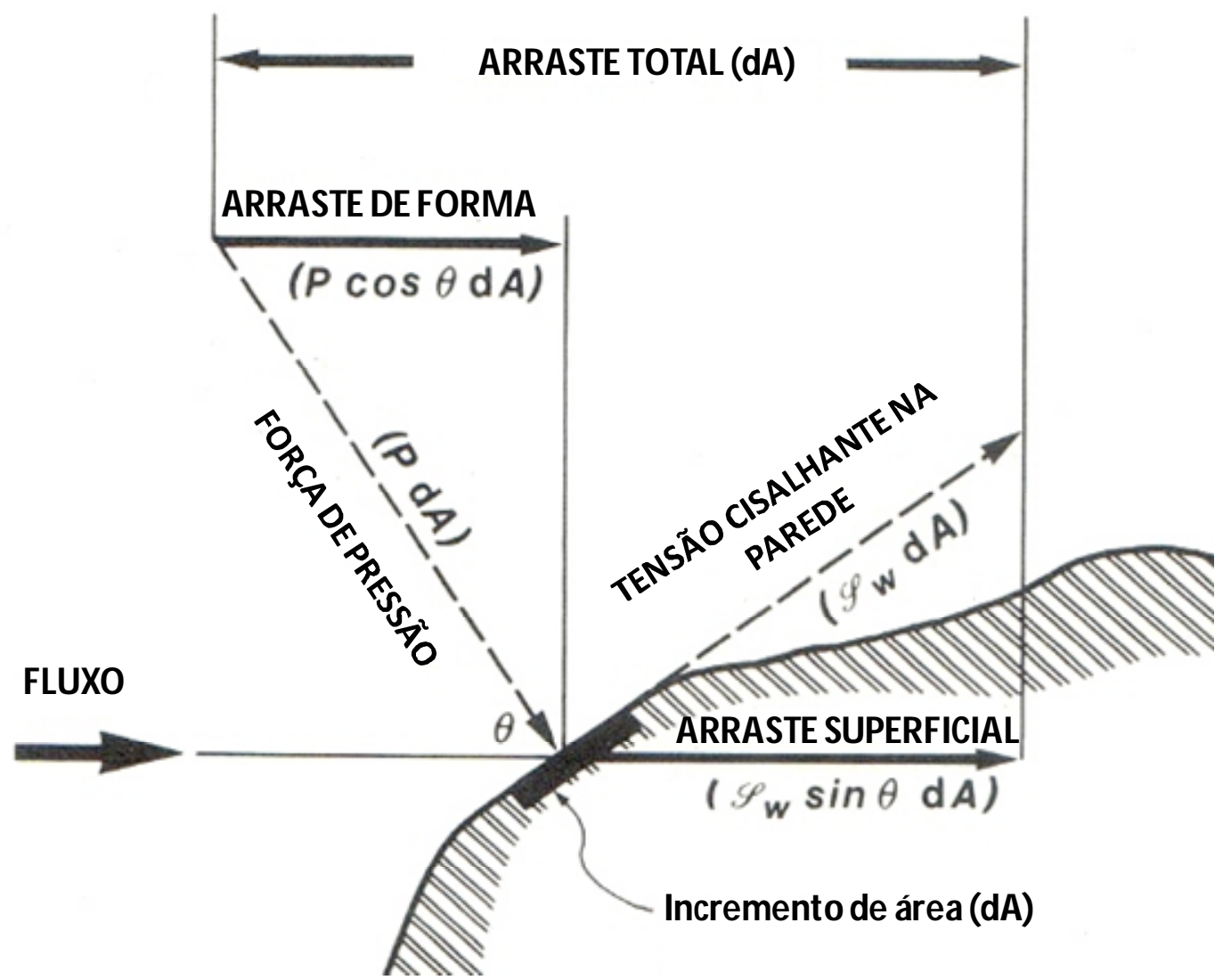

Figura 2.6-Componentes da força de resistência hidrodinâmica.

(Sampaio e Tavares, 2005)

O arraste superficial aumenta com o aumento da viscosidade do fluido e da velocidade relativa partícula-fluido, válido para o escoamento laminar. O arraste de forma surge do ângulo da partícula com o fluido, isto é, a orientação da partícula devido ao efeito causado pela forma da mesma (HEISKANEN, 1993). Assim o 
coeficiente de arraste apresenta como campo de forças, o balanço conforme Equação 2.13.

$$
C_{D}=\frac{\text { momentum total transferido }}{\text { momentum total transferido pela turbulência }}
$$

Fox et al. (2006) e Munson et al. (2004) reportam que para se determinar o arraste em uma partícula se faz necessário conhecer as distribuições das tensões de cisalhamento e de pressão ao longo da mesma, e os autores destacam a dificuldade de se obter tais distribuições.

Tendo em vista a complexidade em se determinar pressões e a tensão cisalhante, uma alternativa muito utilizada é a definição adimensional de um coeficiente de arraste $\left(C_{D}\right)$, que tem sido realizada através de análises simplificadas experimentais ou técnicas numéricas (MUNSON et al., 2004).

De acordo Waddel (1934), a Lei de Newton da resistência fornece o balanço de forças, que pode ser definido de acordo com a Equação 2.14.

$$
F=m \frac{\partial u}{\partial t}+u \frac{\partial m}{\partial t}
$$

Sendo:

$\mathrm{F}$ a força que age no fluido; $\mathrm{N}$

$\mathrm{m}$ a massa de fluido; $\mathrm{kg}$

$\mathrm{u}$ velocidade do fluido, $\mathrm{m} / \mathrm{s}$

Assumindo que a partícula sólida se move com velocidade constante e igual a $(v)$, a velocidade do fluido deslocado passa a ser independente do tempo ao longo da trajetória da partícula. Brown (1950) afirma que o termo $\frac{\partial \mathrm{m}}{\partial \mathrm{t}}$ (Equação 2.14) pode 
ser representado pela área projetada da partícula $(A)$ e da distância percorrida em função do tempo $\left(\frac{\partial \mathrm{h}}{\partial \mathrm{t}}\right)$, isto é, a velocidade.

Segundo Brown (1950); Pettyjohn e Christiansen (1948), através da análise dimensional das forças que atuam na partícula (Figura 2.7), o balanço se faz em função do Número de Reynolds. Analisando a interface sólido-líquido, assume-se que a velocidade do fluido (u), tem o mesmo módulo da velocidade da partícula (v), o que leva à igualdade proposta através da Equação 2.15.

$$
F=\rho_{f} A_{p} v^{2} \cdot f(R e)
$$

Pettyjohn e Christiansen (1948) e Fox e McDonalds (1998) discutem sobre a similaridade do termo $\rho_{\mathrm{f}} \mathrm{v}^{2}$ com a relação geral para escoamentos de fluidos em tubulações $\frac{u^{2} \rho}{2}$, objetivando se tornar conhecida a pressão dinâmica. Substituindo e rearranjando os termos da Equação 2.15, tem-se o coeficiente de arraste $\left(C_{D}\right)$, também como função do Número de Reynolds (Re) (Equação 2.16).

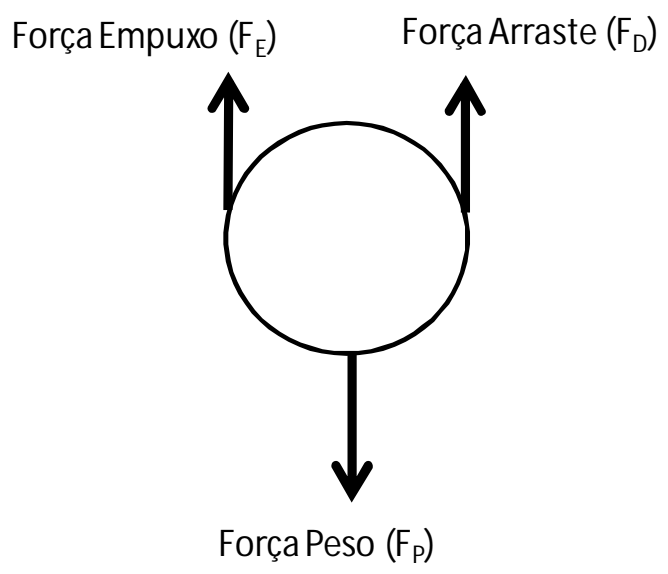

Figura 2.7- Balanço de forças em uma partícula esférica imersa em meio fluido. 


$$
C_{D}=\frac{F_{D}}{\frac{\rho_{f} A_{p} v^{2}}{2}}=f(\mathrm{Re})
$$

\subsubsection{Escoamento em torno das partículas}

As características de escoamento em torno de corpos ou partículas submersas são fortemente influenciadas por parâmetros como granulometria, forma da partícula, velocidade relativa, massa especifica, orientação da partícula e propriedades do fluido (LAREO et al, 1997; LOTH, 2007).

Muitos autores explicitam a dependência do arraste em função do regime de escoamento em que a partícula se encontra (MUNSON et al., 2004, ALMENDRA, 1979; PERRY et al.; 1999; FLEMMER E BANKS, 1986). Para tanto, o Número de Reynolds, um parâmetro adimensional que caracteriza o regime de escoamento do fluxo, representando a razão entre os efeitos viscosos e os efeitos inerciais, permite a caracterização efetiva do tipo de escoamento, conforme explicita a Equação 2.17 (GEANKOPLIS, 1993).

$$
\operatorname{Re}=\frac{\rho_{\mathrm{f}} \mathrm{v}_{\mathrm{p}} \mathrm{d}_{\mathrm{p}}}{\mu}
$$

Sendo:

$\rho_{\mathrm{f}}$ a massa específica do fluido; $\mathrm{kg} / \mathrm{m}^{3}$

$\mathrm{v}_{\mathrm{p}}$ a velocidade de sedimentação da partícula; $\mathrm{m} / \mathrm{s}$

$d_{p}$ o diâmetro da esfera; $m$

$\mu$ a viscosidade do fluido, Pa.s 
Heiskanen (1993), Allen (1997), Perry et al., (1999) fazem uma análise do escoamento em torno da partícula, de acordo com a caracterização de fluxo abaixo descrita, em função do número de Reynolds da partícula:
a) Laminar: $\operatorname{Re}<0,2$
b) Transição: $0,2<\operatorname{Re}<1000$
c) Turbulento: $\operatorname{Re}>1000$

A Figura 2.8 apresenta a relação do coeficiente de arrasto em função do número de Reynolds, levando-se em conta o efeito da forma de cada partícula, através da esfericidade das mesmas.

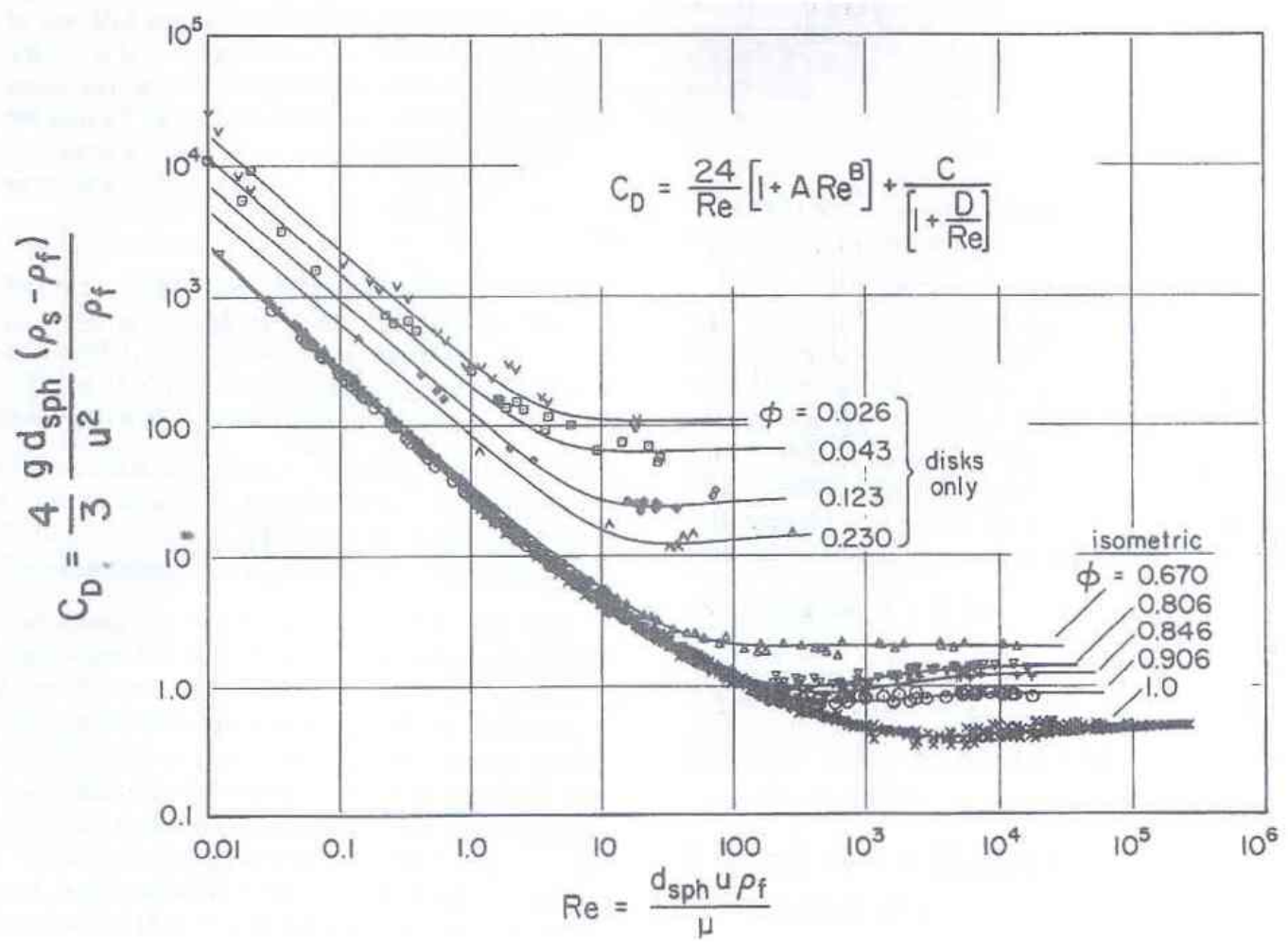

Figura 2.8- Coeficiente de arrasto em função do Número de Reynolds para partículas de diferentes esfericidades (Fox e McDonalds, 1998) 


\subsection{Transporte hidráulico de polpas minerais}

\subsubsection{Fluxo em tubulações}

O transporte hidráulico dentro do universo mineral pode se dar por gravidade ou sob pressão, isto é, por bombeamento.

Segundo Kotzé (2007) o transporte de polpas que apresentam comportamento não-Newtoniano tem papel importante na indústria mineral. Estas polpas tem se tornado cada vez mais concentradas, seja devido à preocupação com o uso racional da água ou por limites de produção, tornando a caracterização reológica destas um difícil desafio.

Slatter (2008) afirma que, para o levantamento de dados acerca do comportamento reológico da polpa mineral se faz necessário estabelecer a relação da tensão $(\tau)$ e da taxa de cisalhamento $\left(\frac{d v}{d y}\right)$ para uma dada amostra.

Existem dois tipos principais de viscosímetros que permitem tal classificação: rotacionais e os de tubo. O primeiro utiliza o torque e a rotação e o segundo a diferença de pressão para se determinar o comportamento reológico da polpa, sendo que o autor destaca que para polpas não-Newtonianas o modelo de tubo é preferido.

Considerando um regime laminar, após atingido o regime estacionário, e eliminando efeitos de entrada e saída, isto é, regime plenamente desenvolvido, o balanço de forças pode ser descrito de acordo com as Equações 2.18 e 2.19.

A Figura 2.9 apresenta um perfil de velocidade e de taxa de cisalhamento no interior de um tubo.

$$
\tau_{w}=\frac{D \Delta P}{4 L}
$$




$$
\tau=\frac{\Delta P}{L} \cdot \frac{r}{2}
$$

Em que:

$\frac{\Delta P}{L}$ é a perda de carga por metro de tubo, $\mathrm{Pa} / \mathrm{m}$

r é o raio do tubo, $m$

L é o comprimento do tubo, $m$

$\tau$ e $\tau_{w}$ são as tensões de cisalhamento no centro e na parede do tubo, respectivamente, $\mathrm{Pa}$

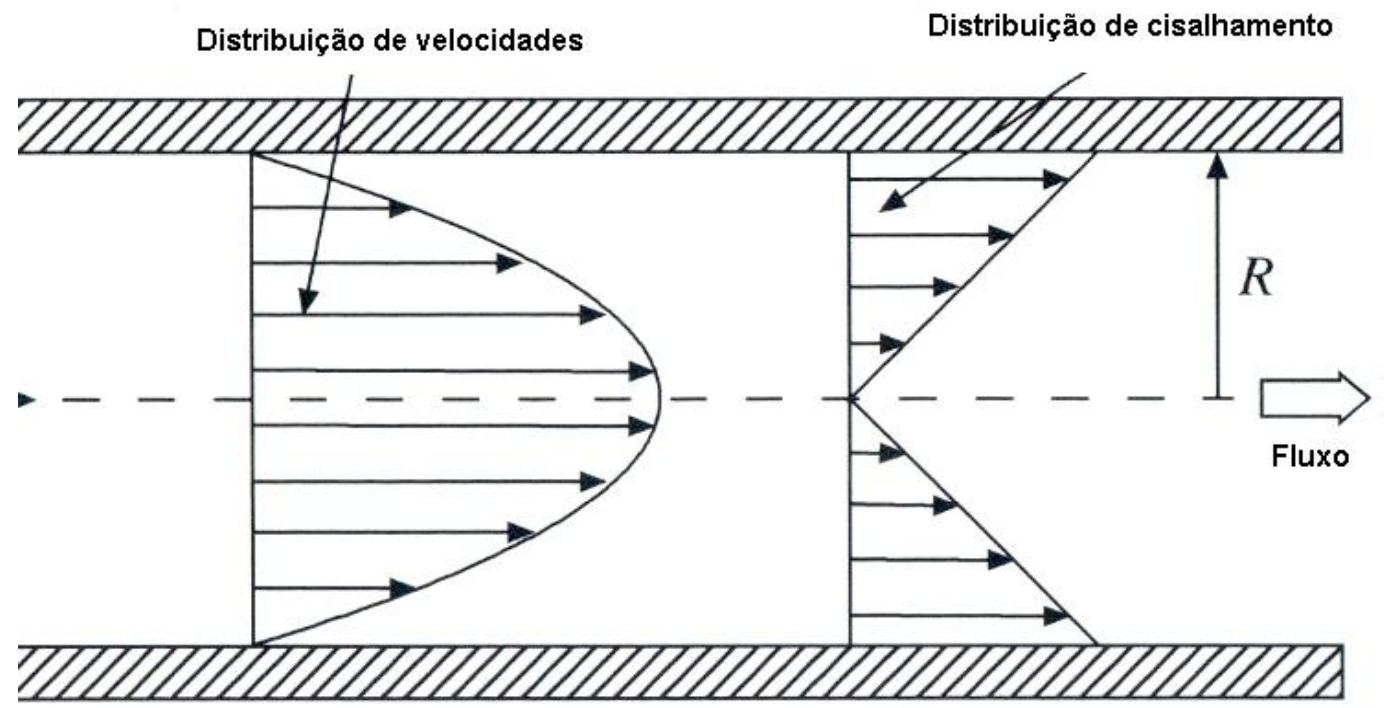

Figura 2.9- Distribuição dos perfis de velocidade e cisalhamento (Kotzé, 2007).

\subsubsection{Classificação das bombas}

Macintyre (1987) e Moraes Jr. et al. (2011) classificam bombas como máquinas geratrizes que promovem o escoamento de líquidos puros, pastas e 
suspensões. Para tanto, as bombas recebem trabalho de um motor, e transferem esta energia ao fluido a ser bombeado na forma de energia cinética.

A classificação geral das bombas geralmente é realizada pelo modo como esta opera. Assim, de forma geral as bombas podem ser classificadas em:
a) Bombas de deslocamento positivo;
b) Turbobombas ou rotodinâmica;
c) Bombas especiais.

De acordo com Foust et al. (1982); Perry e Green (1980) bombas de deslocamento positivo transmitem um volume bem definido de fluido a cada volta ou golpe e o fluido é expelido na mesma direção que a do órgão que está em contato. Podem ser classificadas como alternativas, onde são utilizados pistão ou sistemas recíprocos, em que o escoamento é preponderantemente intermitente; ou rotativa, com escoamento contínuo.

As bombas alternativas operam a altas pressões (100atm ou mais) e apresentam vazão constante com volume relativamente baixo. Nesse tipo de bomba o fluido recebe a ação das forças diretas do pistão ou sistema recíproco, já para bombas rotativas, o fluido recebe a ação de uma ou mais peças dotadas de movimento de rotação.

A Figura 2.10 apresenta a classificação geral das bombas de deslocamento positivo. 


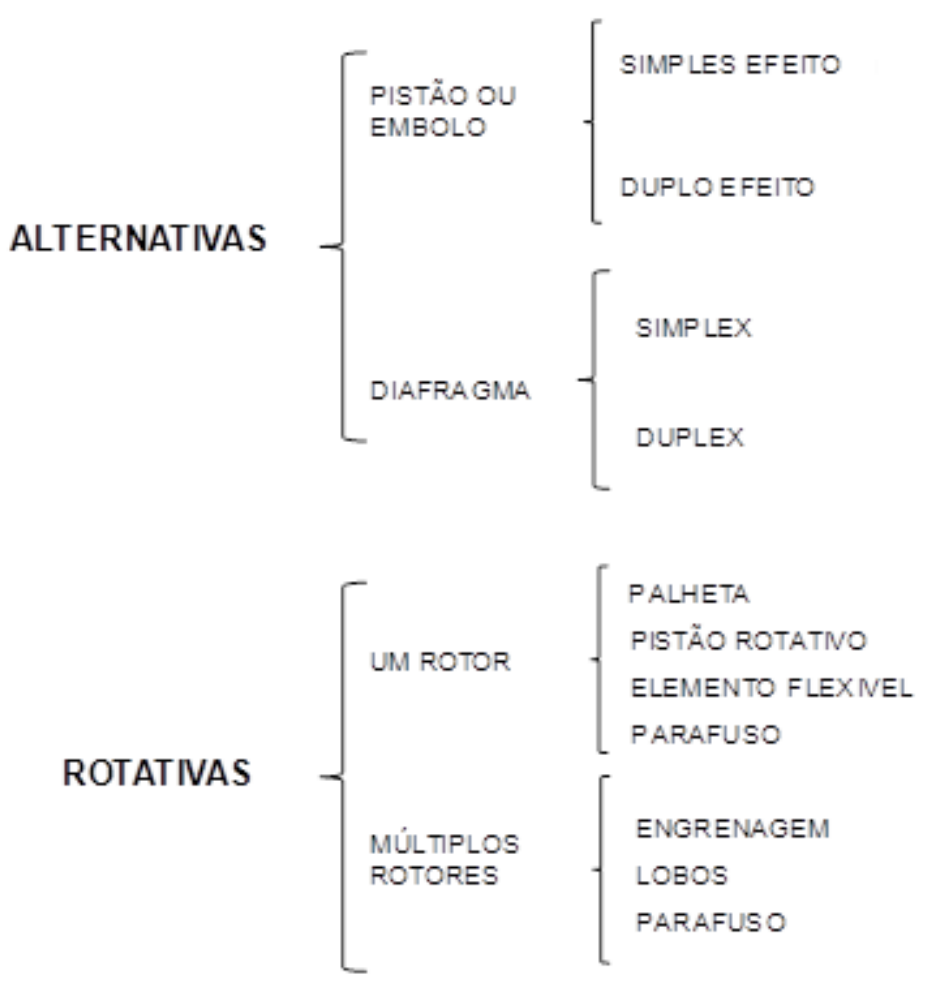

Figura 2.10-Classificação das bombas de deslocamento positivo (adaptado de Moraes Jr, et al. 2011).

As bombas rotodinâmicas ou turbobombas, segundo Moraes Júnior et al. (2011), podem ser caracterizadas por apresentarem um componente rotativo dotado de pás (rotor ou impelidor), que transforma a energia mecânica em energia cinética através de sua aceleração. Neste tipo de bomba o líquido a ser bombeado não apresenta a mesma direção do rotor ou impelidor. A função dos rotores é fornecer aceleração ao fluido bombeado e estes podem ser classificados como aberto, semiaberto ou fechado (MACINTYRE, 1987). Uma breve classificação das turbobombas pode ser observada na Figura 2.11. 


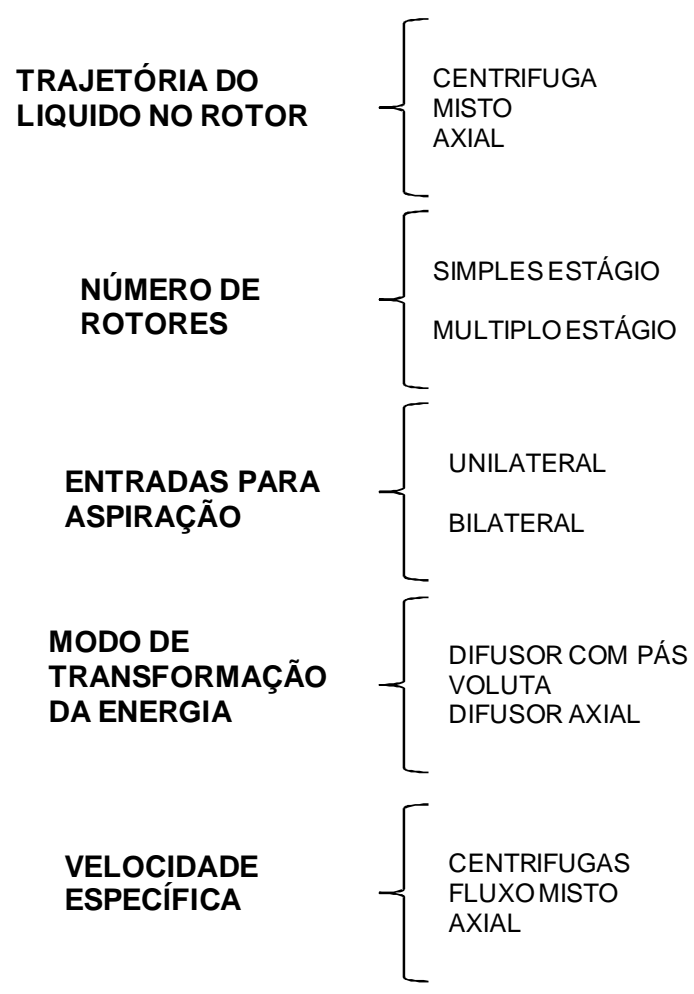

Figura 2.11-Classificação das turbobombas (adaptado de Moraes Jr., 2011).

\subsubsection{Bombas para polpas minerais}

De acordo com Jacobs (1991) o dimensionamento e a escolha da bomba de polpa não dependem somente de propriedades como vazão e altura manométrica, condições do sistema, como qualquer aplicação de bombeamento, mas depende muito das características da polpa mineral, tais como concentração de sólidos, tamanho de partículas, viscosidade aparente, abrasividade, entre outras, o que leva as bombas de polpa a apresentarem construção em materiais resistentes à abrasão e ao uso de revestimentos internos visando ao aumento da vida útil do equipamento.

Bombas centrífugas geralmente são preferidas para aplicações que demandam altas vazões e baixas alturas manométricas, enquanto bombas de deslocamento positivo tendem a ser utilizadas para um fluxo menor e aplicações a alta pressão, usualmente longas distâncias. Vale ressaltar que o arranjo de turbobombas em série permite um ganho considerável de pressão. Driver (2003) destaca que bombas centrífugas são livres de pulsos, isto é, o fluxo é bombeado 
constantemente, o que para bombas de deslocamento positivo, de acordo com o número de pistões utilizados, a operação apresenta fluxo pulsante.

Sellgren e Addie (1993) destacam que o bombeamento de polpas reduz a altura manométrica e a eficiência da operação, a um fluxo constante, conforme ilustrado na Figura 2.12. Entende-se por (n) a razão entre a energia total que a bomba recebe do motor pela energia que a mesma foi capaz de transferir ao fluido.

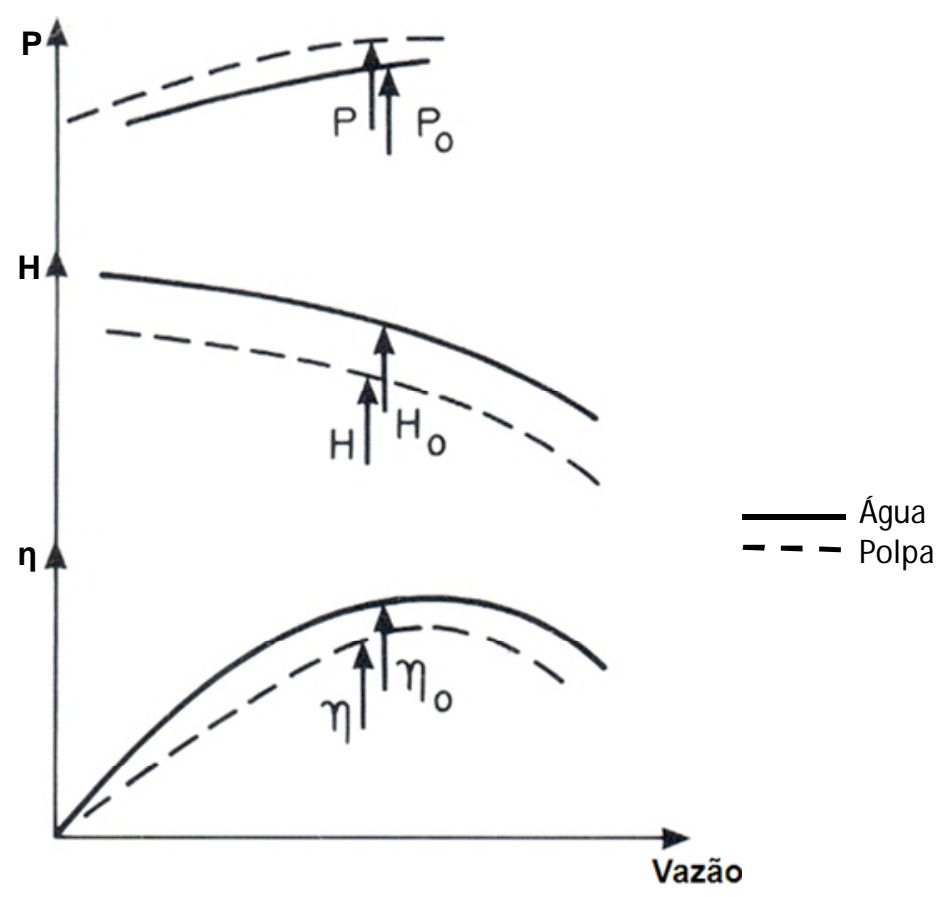

Figura 2.12-Comparação da potência requerida $(P)$, pressão $(H)$ e eficiência $(\eta)$ para operação de bombeamento de polpa e água (Adaptado de Sellgren e Addie, 1993).

\subsubsection{Propriedades físicas de polpas minerais}

Polpas minerais são suspensões constituídas de duas fases sendo uma líquida e outra sólida. De acordo com Gaudin (1939) e Kelly e Sposttiswood (1982), dentro do universo da indústria mineral, o fluido carreador universalmente utilizado é a água. 
Segundo Brown e Heywood (1993), os atributos que geralmente são utilizados para caracterizar fisicamente as polpas são: a massa específica das fases constituintes (sólido e líquido) e da polpa, concentração de sólidos, distribuição granulométrica, forma e tamanho das partículas e a viscosidade da polpa. A Equação 2.20 ilustra a caracterização da massa específica da polpa e as Equações 2.21 e 2.22 apresentam a concentração mássica e volumétrica, respectivamente.

$$
\rho_{p}=\frac{100}{\frac{C_{m}}{\rho_{S}}+\frac{100-C_{m}}{\rho_{L}}}
$$

Em que:

$\rho_{p}$ é a massa específica da polpa mineral; $\mathrm{kg} / \mathrm{m}^{3}$

$C_{m}$ é a concentração mássica da polpa mineral;

$\rho_{S}$ é a massa específica do sólido, $\mathrm{kg} / \mathrm{m}^{3}$

$\rho_{L}$ é a massa específica do líquido, $\mathrm{kg} / \mathrm{m}^{3}$

$$
\begin{aligned}
C_{m / m}= & \frac{m_{S}}{m_{S}+m_{L}} \cdot 100 \\
C_{v / v}= & \frac{\frac{m_{S}}{\rho_{S}}}{\frac{m_{S}}{\rho_{S}}+\frac{m_{L}}{\rho_{L}}} \cdot 100
\end{aligned}
$$

Em que:

$C_{m / m}$ é a concentração em massa; (\%)

$C_{v / v}$ é a concentração em volume; (\%) 
$m_{S}$ é a massa de sólido, $\mathrm{kg}$

$m_{L}$ é a massa de líquido, $\mathrm{kg}$

\subsubsection{Classificação de polpas minerais quanto ao fluxo}

De acordo com Wasp et al. (1977) e Jacobs (1991), o comportamento de suspensões contendo partículas sólidas difere do comportamento de um fluido simples quando submetidos a bombeamento em tubos. A caracterização da natureza do fluxo para líquidos pode ser determinada a partir das propriedades físicas do líquido e do sistema de bombeamento, sendo que a operação permite alcançar uma completa faixa de velocidades (laminar, transição ou turbulento). Já para sistemas de polpas minerais, Brown e Heywood (1991) e Nayyar (1999) abordam a dificuldade em se caracterizar um sistema de bombeamento devido às alterações provocadas pelos sólidos e pelo comportamento da polpa quando submetida a diferentes condições de operação.

Polpas minerais podem ser classificadas quanto ao comportamento como homogênea ou heterogênea. A primeira classe apresenta suspensões com partículas finas, em que o líquido carreador e os sólidos são considerados como um fluido pseudo-homogêneo. As partículas conseguem ser suspensas com a operação normal de bombeamento e a velocidade de sedimentação, neste tipo de polpa mineral, inexiste ou é muito baixa, somente havendo sedimentação no tubo com a interrupção da operação. Os efeitos inerciais são menores e há um aumento na viscosidade da polpa em relação ao líquido puro, que geralmente apresenta comportamento não-Newtoniano. Wilson et al. (1992) afirmam que não existe uma faixa granulométrica bem definida para classificar a polpa como pseudo-homogênea, mas usualmente adota-se como base partículas com diâmetros menores que $100 \mu \mathrm{m}$.

A segunda classe pode ser caracterizada por polpas que apresentam comportamento em que as partículas sólidas sedimentam, apresentando um fluxo heterogêneo, em que os sólidos são mal distribuídos ao longo da seção transversal do tubo, mesmo em altas velocidades de transporte, e os efeitos inerciais das partículas são mais pronunciados (WASP et al., 1977; WILSON et al., 1992). Os 
sólidos produzem uma perda de carga adicional por atrito com as paredes, e de acordo com Jacobs et al. (1991), são encontradas partículas com diâmetro superior a $150 \mu \mathrm{m}$.

O comportamento destes dois tipos de polpas minerais diferem entre elas. Enquanto polpas pseudo-homogêneas permitem uma variação na velocidade de transporte, do regime laminar ao turbulento, polpas heterogêneas necessitam de uma velocidade mínima para que não ocorra deposição de partículas na base da tubulação, conforme ilustrado na Figura 2.13 (BROWN E HEYWOOD, 1991; DORON et al., 1987).

Para polpas heterogêneas, a velocidade do fluxo impelido pode caracterizar a distribuição dos sólidos ao longo da seção transversal da tubulação, de acordo com a ilustração apresentada na Figura 2.14.

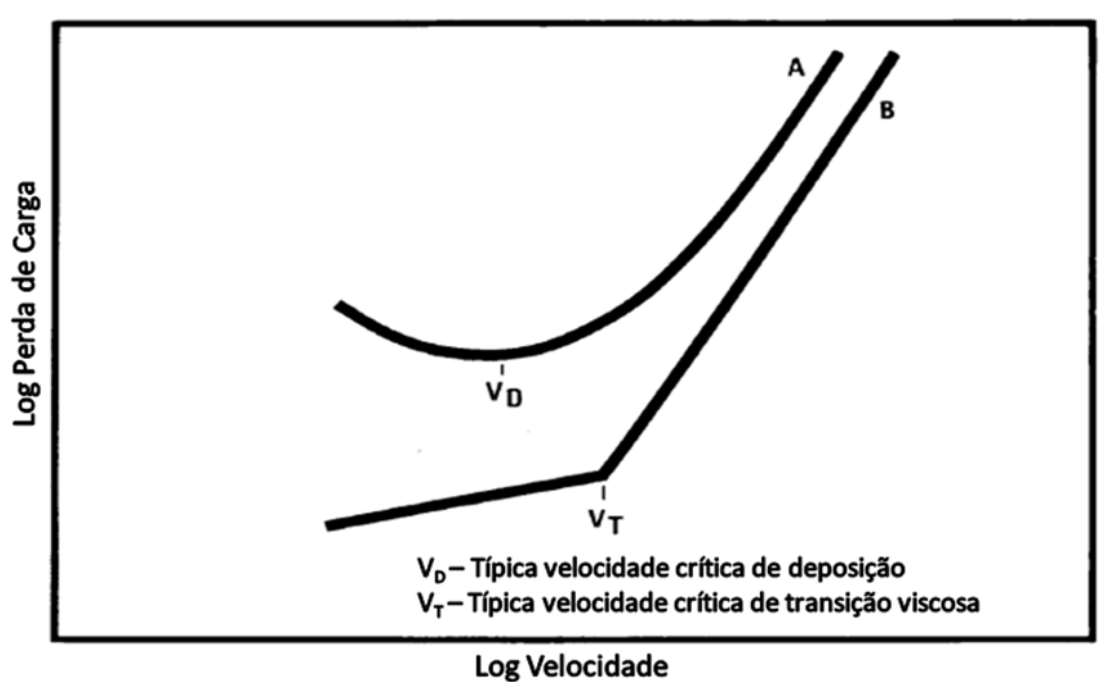

Figura 2.13-Comportamento da perda de carga em função da velocidade para escoamento heterogêneo (A) e homogêneo (B). (Adaptado de Wasp et al., 1977) 


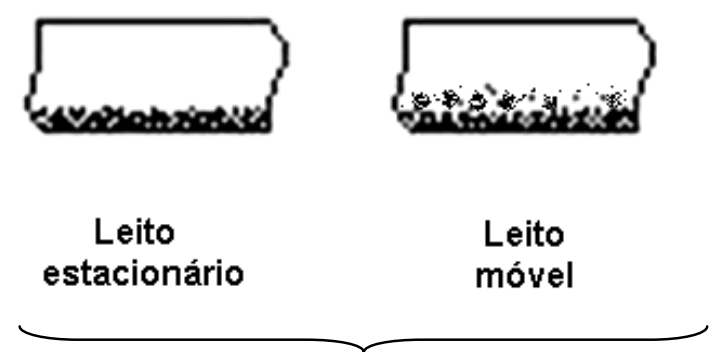

(1)
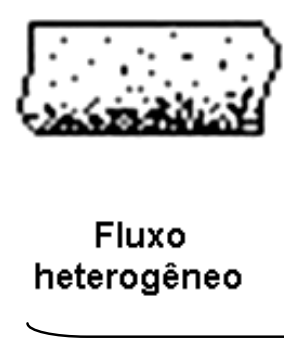

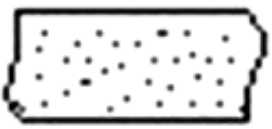

Fluxo homogêneo

Figura 2.14- Regime de fluxo, (1) velocidade subcrítica $\left(V_{<} V_{d}\right)$;

(2) suspensão total $\left(V>V_{d}\right)$.

No que diz respeito ao dimensionamento de sistemas de bombeamento de polpas que contem partículas grossas, Gillies (1993) constatou que diferentes modelos existentes na literatura preveem valores muito discrepantes para propriedades fundamentais, como: velocidade de deposição $\left(V_{D}\right)$, perda de carga, viscosidade aparente da polpa e tensão crítica de cisalhamento. Tal autor sugere que outras variáveis (rugosidade da tubulação e forma das partículas) além das tradicionais (diâmetro dos dutos, tamanho médio das partículas grossas, concentração volumétrica de sólidos na polpa, densidade relativa sólido/líquido e viscosidade do fluido carreador) devem ser abordadas para se obter modelos mais realistas.

Ainda de acordo com Gilles (1993), os parâmetros supracitados normalmente constam nos modelos descritos na literatura utilizados para prever perda de carga e velocidade de transporte. O destaque são variáveis que são omitidas e apresentam importância significativa, tais como rugosidade de tubulação e a forma das partículas.

\subsubsection{Velocidade crítica de transporte}

Para o transporte de polpas que apresentam comportamento heterogêneo, ou seja, polpas que contém partículas grossas, o critério de velocidade crítica de transporte apresenta um papel de fundamental importância, pois operações de bombeamento abaixo desta velocidade irão comprometer de forma significativa a operação (GILLIES, 1993). 
Carleton e Cheng (1974) apresentam uma revisão, onde são destacadas mais de 50 correlações para predizer a velocidade crítica de deposição, e Gillies (1993) destaca que muitas outras foram propostas depois dos trabalhos de Carleton e Cheng. Por outro lado, Wasp e Slatter (2004) afirmam haver muita discordância entre os modelos propostos, devido ao fato de as correlações não apresentarem suas faixas de aplicabilidade bem definidas. A Figura 2.15 apresenta uma série de correlações e a discrepância entre cada uma delas para uma dada condição.

Durand (1953) apresenta um modelo clássico para predizer a velocidade crítica de deposição (Equação 2.23) que varia de sistema para sistema em função do tamanho de partículas e da concentração de sólidos. De acordo com Wasp et al. (1977) e Kaushal et al. (2001), o parâmetro $F_{L}$ se mostra aplicável para partículas que apresentam tamanhos de até $1 \mathrm{~mm}$ (Figura 2.16), diminuindo sua influência na velocidade para polpas que apresentam uma distribuição não uniforme de partículas.

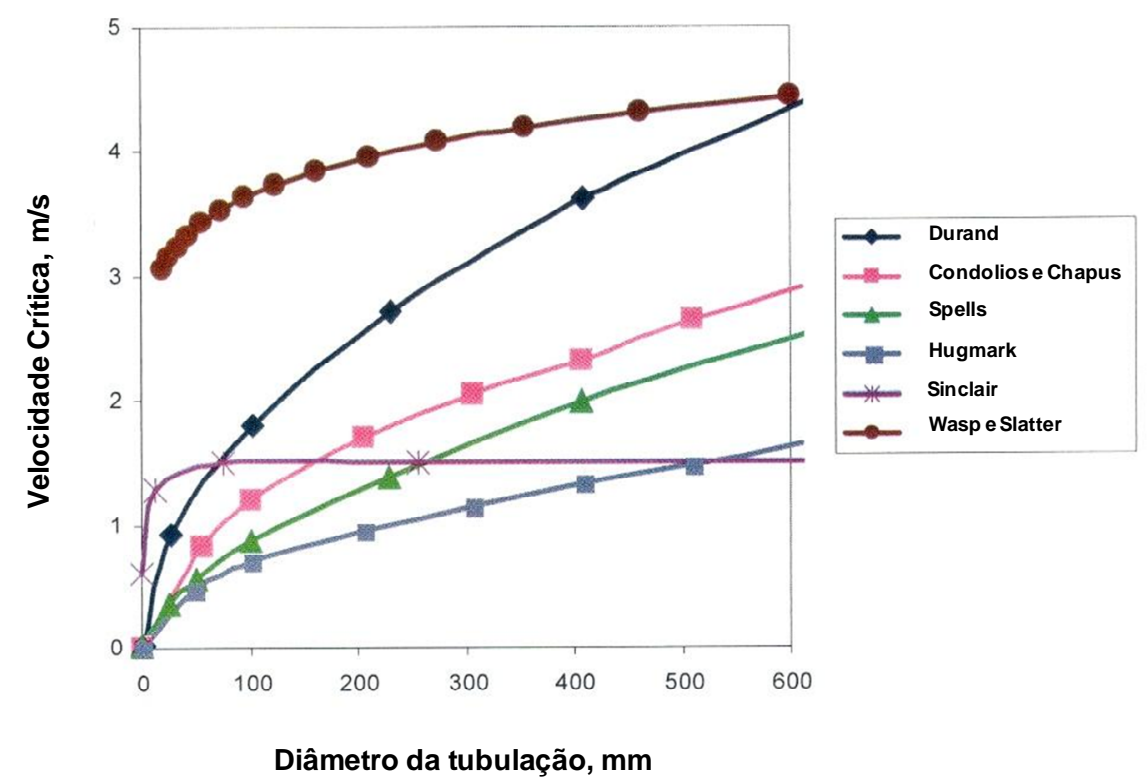

Figura 2.15- Comparação de 6 modelos para a velocidade crítica de deposição para quartzo com concentração de 1\%v/v, (Wasp e Slatter, 2004)

$$
V_{D}=F_{L} \cdot[2 g D(S-1)]^{0,5}
$$


Sendo:

$\mathrm{V}_{\mathrm{D}}$ a velocidade crítica de deposição, em $\mathrm{m} / \mathrm{s}$;

$F_{L}$ o fator, função da granulometria e da diluição polpa.

$\mathrm{g}$ a aceleração da gravidade, em $\mathrm{m} / \mathrm{s}^{2}$;

D o diâmetro da tubulação, em m;

$\rho_{\mathrm{s}}$ a massa específica dos sólidos, em $\mathrm{kg} / \mathrm{m}^{3}$;

$\rho_{\text {I }}$ a massa específica do líquido de transporte, $\mathrm{kg} / \mathrm{m}^{3}$;

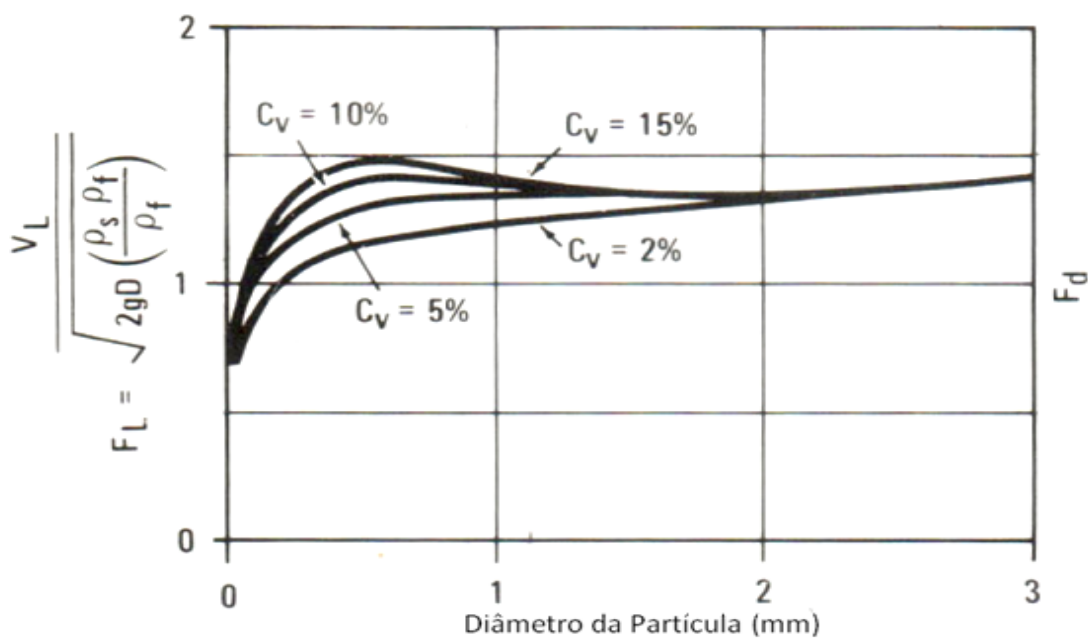

Figura 2.16- Variação do parâmetro $F_{L}$ em função da granulometria de sólidos e da concentração.

Para concentrações mais altas, Wasp et al. (1977), a partir da modificação do modelo de Durand (1953), apresentam uma correlação para a velocidade crítica de deposição, descrita segundo a Equação 2.24 (KAUSHAL et al., 2002).

$$
V_{D}=4 \cdot\left(\frac{d}{D}\right)^{\frac{1}{16}} \cdot\left(C_{V}\right)^{\frac{1}{5}} \sqrt{2 g D(S-1))}
$$




\section{Em que:}

$\mathrm{C}_{\mathrm{v}}$ é a concentração volumétrica da polpa.

$\mathrm{g}$ é a aceleração da gravidade, em $\mathrm{m} / \mathrm{s}^{2}$;

D é o diâmetro interno da tubulação, em m;

d é o diâmetro da partícula, m;

S é a densidade relativa partícula-água.

Após o clássico trabalho de Durand (1952), merece destaque o trabalho realizado por Thomas (1965), que relacionou a velocidade de sedimentação das partículas em repouso (w) com a velocidade de deposição de partículas suspensas em um fluido sob bombeamento, gerando um modelo descrito pela Equação 2.25 e 2.26 .

O modelo proposto por Thomas (1965) falhou para polpas que contêm partículas que exibem tamanho maior que a espessura da subcamada viscosa, conforme ponderações reportadas por Wasp e Slatter (2004). Assim, a aplicabilidade do modelo se restringe a partículas finas, que resultam em polpas classificadas como homogêneas.

$$
\begin{aligned}
& \frac{w}{u_{0}}=4,90 \cdot\left(\frac{d \cdot u_{0}}{v}\right) \cdot\left(\frac{v}{D \cdot u_{0}}\right)^{0,60}(S-1)^{0,23} \\
& \frac{u_{C}}{u_{0}}=1+2,8 \cdot\left(\frac{w}{u_{0}}\right)^{\frac{1}{3}} \phi^{0,5}
\end{aligned}
$$

Em que:

$w$ é a velocidade de sedimentação das partículas em líquido em repouso;m/s $u_{0}$ é a velocidade deposição em condições diluídas; $\mathrm{m} / \mathrm{s}$ $u_{C}$ é a velocidade deposição em uma dada concentração; $\mathrm{m} / \mathrm{s}$ 
$\phi$ é a fração volumétrica de sólidos;

D é o diâmetro interno da tubulação; $m$

d é o diâmetro da partícula; $m$

$v$ é a viscosidade cinemática da água; $\mathrm{m}^{2} / \mathrm{s}$.

Após o empirismo que caracterizou os modelos desenvolvidos nas décadas de 50 e 60 do século XX, como os de Durand (1952) e Thomas (1965); observou-se, a partir dos anos 70 , uma progressiva integração de princípios físicos e as correlações empíricas para gerar novos modelos que foram capazes de prever com maior acurácia a velocidade de deposição de partículas suspensas na polpa. Dentre os vários novos modelos, Gillies e colaboradores (2000) destacam o trabalho de Wilson e Judge (1979), apresentado na Equação 2.27 e também o de Thomas (1979), conforme Equação 2.28. Estes modelos contemplaram um amplo espectro de diâmetros de tubos e propriedades do fluido.

O modelo de Wilson e Judge (1979) se aplica a partículas maiores que $0,15 \mathrm{~mm}$ e tubos com diâmetros superiores a $100 \mathrm{~mm}$. Os resultados também podem ser representados na forma de um "ábaco nomográfico" (termo aportuguesado a partir do vocábulo inglês nomograph chart), conforme ilustra a Figura 2.17.

O nomográfico foi inicialmente construído para partículas de quartzo e prediz o limite da velocidade de deposição com boa precisão, porém Wilson et al. (2006) indicam que seu uso é restrito às condições estudadas. Uma correção para o uso desta figura para partículas de diferentes densidades relativas pode ser realizada, no entanto com menor precisão do que para partículas de quartzo. Inicialmente entra-se com o valor do diâmetro da tubulação e alinha-se uma reta com o tamanho da partícula, rebatendo para a coluna central que indica a velocidade. Para correção para polpas minerais que não utilizam o quartzo, o procedimento é o mesmo, porém após achar a velocidade do quartzo, projeta-se uma reta a partir da velocidade indicada para o quartzo cruzando com a densidade relativa em questão, assim obtendo-se o novo limite de velocidade na coluna da direita.

Como exemplo, Wilson et al. (2006) utilizam um diâmetro de tubo de $0,3 \mathrm{~m}$ com partículas de quartzo de $1 \mathrm{~mm}$, obtendo uma velocidade de deposição de $3,5 \mathrm{~m} / \mathrm{s}$. Corrigindo este limite de velocidade para partículas que apresentam densidade relativa de 1,5 , o novo limite de velocidade é de $1,9 \mathrm{~m} / \mathrm{s}$. 


$$
V_{D}=2.0+0.3 \log \left(\frac{d}{D \cdot C_{D}}\right) \cdot[2 \cdot g \cdot D(S-1)]^{0.5}
$$

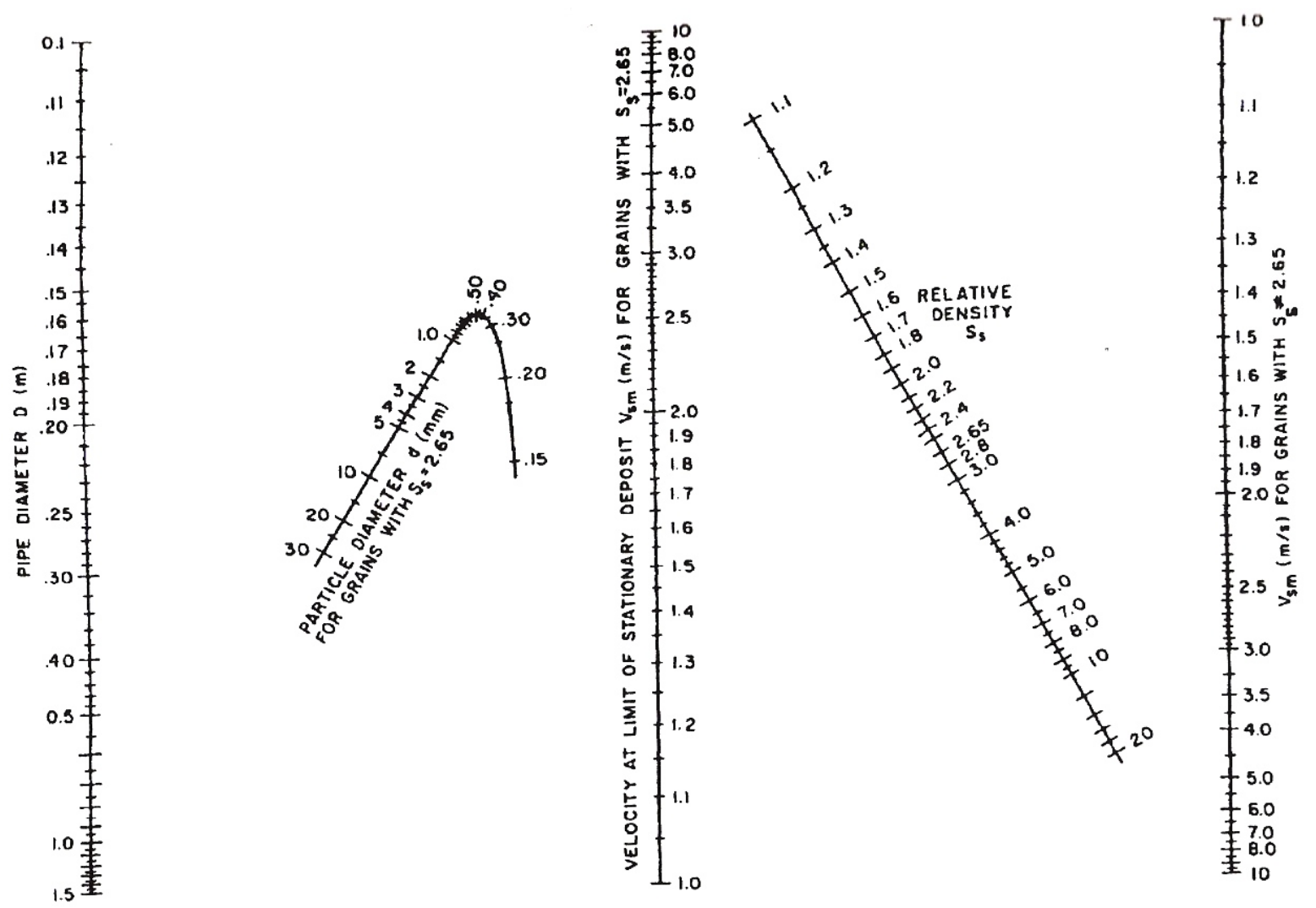

Figura 2.17- Nomográfico para determinação da velocidade limite de deposição, Wilson (1979). Fonte: Wilson et al. (2006).

Como demostrado por Thomas (1979), o efeito das partículas finas, menores que a espessura da subcamada viscosa (Equação 2.29), apresenta efeito significativo na magnitude da velocidade de deposição $\left(\mathrm{V}_{\mathrm{D}}\right)$. A velocidade de cisalhamento $\left(\mathrm{V}^{\star}\right)$, conceitualmente é diretamente proporcional às regiões turbulentas, e definida segundo a Equação 2.30.

$$
\frac{V_{D}}{V^{*}}=0.068 .\left(\frac{d \cdot V^{*} \rho}{\mu}\right)^{2}
$$




$$
\begin{gathered}
\delta=\frac{5 \mu}{\rho V^{*}} \\
V^{*}=V_{b u l k} \sqrt{\frac{\tau_{o}}{\rho}}
\end{gathered}
$$

Sendo:

$\delta$ a espessura da subcamada viscosa, $\mathrm{mm}$

$\mathrm{V}^{*}$ a velocidade cisalhante, $\mathrm{m} / \mathrm{s}$

$\tau_{0}$ a tensão de cisalhamento na camada do fluido, $\mathrm{Pa}$

Outra importante contribuição foi observada através dos trabalhos de Wasp e Slatter (2004), que desenvolveram um modelo preditivo para a velocidade de deposição, baseado em operações industriais de bombeamento de polpas minerais, com diâmetros de tubo que variam de $203.2 \mathrm{~mm}$ a $459.7 \mathrm{~mm}$. O modelo apresenta uso prático, pois utiliza variáveis de fácil obtenção. O modelo proposto pode ser observado na Equação 2.31.

$$
V_{D}=0,18 \cdot(S-1)^{0,5} \cdot\left(\frac{d_{95 .} \rho_{s} \cdot \sqrt{g D}}{\mu_{f}}\right)^{0,22} e^{4.34 \cdot C_{V}}
$$

\section{Em que:}

d95 é o diâmetro da partícula em que 95\% é passante;

$S$ é a densidade relativa sólido/líquido

D é o diâmetro do duto, $m$

$\rho_{\mathrm{s}}$ é a densidade do sólido, $\mathrm{kg} / \mathrm{m}^{3}$

$\mu_{\mathrm{f}}$ é a viscosidade do fluido carreador, Pa.s

$\mathrm{C}_{\mathrm{v}}$ é a concentração volumétrica de sólidos;

Turian (1987) apresenta uma correlação para prever a velocidade crítica de deposição, conforme descrito na Equação 2.32. 


$$
V_{D}=1,7951 . C_{V}^{0,1087}\left(1-C_{V}\right)^{0,2401} \cdot\left(\frac{d_{95 .} \rho_{F} \sqrt{g D}(S-1)}{\mu_{f}}\right)^{0,00179} \cdot\left(\frac{d}{D}\right)^{0,06623} \cdot \sqrt{2 g D(S-1)}
$$

Schiller e Herbich (1991) propõem um modelo baseado nos trabalhos de Durand (1953) baseado no d(50) das partículas, conforme ilustrado pela Equação 2.33 .

$$
V_{D}=1,3 C_{V}^{0,125}\left[1-e^{-6,9 \cdot d}\right] \sqrt{2 g D(S-1)}
$$

Assim, dados recorrentes na literatura revelam as limitações $e$ as discrepâncias nos modelos que predizem a velocidade mínima de transporte para que os sólidos não sedimentem na base da tubulação. Um novo modelo semiempírico para a velocidade crítica, que apresenta um leito móvel na base do tubo e velocidade de fluxo ligeiramente maior que a velocidade de deposição, baseado em dados experimentais e inserindo o efeito da forma das partículas através da esfericidade se constitui o objetivo desta tese.

\subsubsection{Perda de carga}

Fluidos que escoam em tubulações invariavelmente requerem um gradiente de pressão para manter a operação no regime estacionário. No que diz respeito aos fluidos homogêneos, o gradiente de pressão ocorre por dois mecanismos. Dissipação viscosa (cisalhamento entre camadas de fluido e paredes de dutos) e inercial (variação da velocidade média de fluxo). Equações e modelos que predizem a queda de pressão em tubulações onde escoa um líquido puro são bem definidas na literatura, destacando-se o modelo proposto por Darcy-Weisbach, válido para diâmetro de duto constante, horizontal e em regime estacionário plenamente desenvolvido (MUNSON et al. 2004), conforme descrito na Equação 2.34. A Figura 
2.18 apresenta o Diagrama de Moody, para a determinação do fator de atrito de Darcy $(f)$, que apresenta magnitude 4 vezes maior que o fator de Fanning.

$$
i_{w}=f_{w} \frac{L}{D} \frac{v^{2}}{2 g}
$$

Em que:

$i_{w}$ é perda de carga do líquido puro; mcl

$f_{w}$ é o fator de atrito de Darcy;

$D$ é o diâmetro do tubo; $\mathrm{m}$

$L$ é o comprimento do tubo; $m$

$v$ é a velocidade do liquido; $\mathrm{m} / \mathrm{s}$, e

$g$ é a aceleração da gravidade $\mathrm{m} / \mathrm{s}^{2}$.

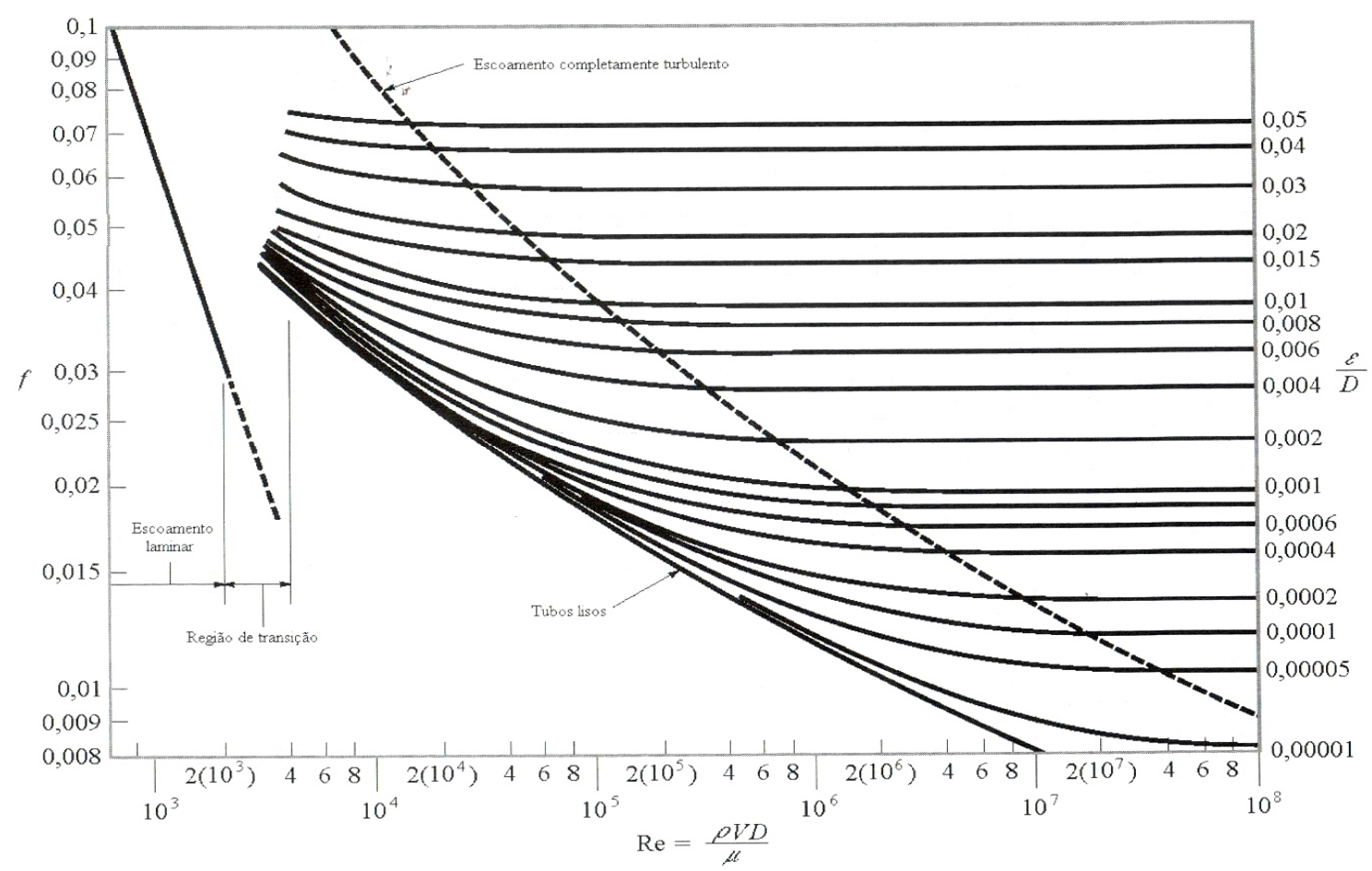

Figura 2.18-Diagrama de Moody. (Munson e outros, 2004) 
Gillies (1993) reporta sobre a importância do trabalho publicado por Durand e Condolios (1952), em que os autores trouxeram grande contribuição sobre o entendimento do efeito dos sólidos na perda de carga para o escoamento de polpas minerais.

Diferentemente dos fluidos homogêneos, para se estudar o gradiente de pressão desenvolvido em sistemas que bombeiam fluidos heterogêneos, também há que se levar em conta a influência da presença de sólidos na formação deste gradiente. Já em 1952, Durand e Condolios (1952) propuseram a existência de um incremento no gradiente de pressão $(\Phi)$ quando se bombeiam polpas minerais. De acordo com a Equação 2.35, tal incremento contém uma contribuição do líquido carreador $\left(\mathrm{i}_{\mathrm{w}}\right)$ e outra atribuída a presença das partículas solidas (i). Outro parâmetro importante é o das variáveis independentes, ilustrado pela Equação 2.36

$$
\begin{gathered}
\Phi=\frac{i-i_{w}}{C_{V} \cdot i_{w}} \\
\Psi=\frac{V^{2} \sqrt{C_{D}}}{g D(S-1)}
\end{gathered}
$$

Sendo:

$\Phi$ o excesso do gradiente de pressão; $m$

$\Psi$ o adimensional das variáveis independentes;

$C_{D}$ o coeficiente de arraste;

$S$ a densidade relativa sólido-líquido;

$C_{V}$ a concentração volumétrica, expressa em fração.

$i$ a perda de carga da polpa, m.

Segundo Wasp et al. (1977), a forma usual do excesso do gradiente de pressão, o qual pode ser aplicado para velocidades acima da velocidade crítica de deposição, se encontra descrito de acordo com a Equação 2.37. Muitos autores 
apresentaram modelos para prever o gradiente de pressão baseados nos trabalhos de Durand e Condolios (WASP et al., 1970; NEWITT et al., 1955; SHOOK et al., 1982; ZANDI E GOVATOS, 1967).

$$
\Phi=81 . \Psi^{-\frac{3}{2}}
$$

Newitt et al. (1955), através de relações empíricas, estabeleceram modelos para predizer o excesso do gradiente de pressão em diferentes condições de fluxo (pseudo-homogêneo, heterogêneo e leito móvel), baseados na contribuição da massa imersa de partículas à perda de carga do sistema. A Equação 2.38 traz a relação proposta pelos autores para condições em que há a formação de um leito móvel na base da tubulação.

$$
\Phi=\frac{66 . g D(S-1)}{V^{2}}
$$

Wilson et al. (1990) e Wilson et al. (2002) discutem a relação do gradiente de pressão ocasionado pelos sólidos e pelo fluido carreador para polpas heterogêneas. Os autores apresentam um modelo para a perda ocasionada pelos sólidos, baseados em dados recorrentes na literatura (Equação 2.39). O que é muito comum na maioria dos modelos propostos, é que o efeito dos sólidos $\left(i-i_{w}\right)$ é proporcional ao efeito da concentração, sendo que os autores supracitados revelam que isto não é valido para condições em que as polpas minerais são altamente concentradas (C>0,3 em volume).

$$
i=i_{w}+(S-1)\left[0,22 \cdot V_{50}{ }^{M}\right] V_{M}{ }^{-M}
$$




\section{Em que}

$V_{50}$ é uma velocidade de referência baseada na velocidade de queda da partícula média

$V_{M}$ é a velocidade média da polpa

M é um fator baseado na distribuição granulométrica da polpa mineral.

Para polpas que apresentam um intervalo granulométrico estreito, o valor de $M$ é aproximadamente $-1,7$, tendo valores menores conforme 0 intervalo granulométrico fica mais amplo. O modelo apresentado pela Equação 2.39 constitui a base para o scale-up de sistemas de mineroduto (WILSON et al., 2006). 


\section{CAPÍTULO 3}

\section{MATERIAIS E MÉTODOS}

Neste capítulo são apresentadas as características e propriedades dos materiais utilizados (seção 3.1) bem como os procedimentos experimentais adotados (seção 3.2). Os minérios utilizados neste trabalho foram concentrados de apatita, hematita e 0 quartzo. As características dos equipamentos utilizados são apresentadas na seção 3.1 .2 e 3.1.3.

Os procedimentos adotados em cada etapa do trabalho estão descritas em detalhe na seção 3.2, onde se encontram os procedimentos para a determinação da esfericidade das partículas minerais (seção 3.2.1) e os ensaios de bombeamento de polpas minerais (seção 3.2.2). 


\subsection{Materiais}

\subsubsection{Amostras minerais}

a) Concentrado de apatita

O concentrado de apatita utilizado neste trabalho foi fornecido pela empresa Bunge Fertilizantes, atual Valefert, sendo o produto final da flotação da usina de processamento mineral, situada no município de Cajati-SP.

O material foi recebido e peneirado a úmido, utilizando-se peneiras vibratórias com malhas nas aberturas de $297 \mu \mathrm{m}, 210 \mu \mathrm{m}, 149 \mu \mathrm{m}$ e $105 \mu \mathrm{m}$, com identificação em mesh Tyler de 48\#, 65\#, 100\# e 150\#, respectivamente. O procedimento foi realizado no Laboratório de Tratamento de Minérios (LTM) do Departamento de Engenharia de Minas e de Petróleo da Escola Politécnica da USP.

As amostras utilizadas nos ensaios de bombeamento de polpas foram divididas em duas frações granulométricas grossas. A primeira fração é passante em $297 \mu \mathrm{m}$ e retida em $210 \mu \mathrm{m}$ (-48+65\# mesh Tyler) e a segunda fração é passante em $149 \mu \mathrm{m}$ e retida em $105 \mu \mathrm{m}(-100+150 \#$ mesh Tyler). O diâmetro médio de Sauter $\left(D_{3,2}\right)$ foi utilizado para retratar o diâmetro médio da população de partículas, com análises realizadas no Laboratório de Caracterização Tecnológica (LCT) do mesmo departamento na EPUSP, através da técnica de difração de laser, no equipamento Mastersize S-2.19, da Malvern. O concentrado de apatita foi então submetido a uma separação magnética a seco, utilizando um imã de mão de terras raras, com campo magnético de 6.500 Gauss. A massa específica da amostra foi determinada por picnometria, em triplicata.

Cada uma das frações granulométricas do concentrado de apatita foi submetida a uma difração de raios-X para a identificação da mineralogia qualitativa, no equipamento PANalytical, modelo X'Pert PRO e os resultados se encontram descritos na Tabela 3.1. Já os teores de cálcio, magnésio, sílica, fósforo e ferro foram determinados por fluorescência de raios- $X$, através do equipamento da marca PANalytical, modelo Axios Advanced cujos resultados são apresentados na Tabela 3.2. 
Tabela 3.1- Caracterização do concentrado de apatita

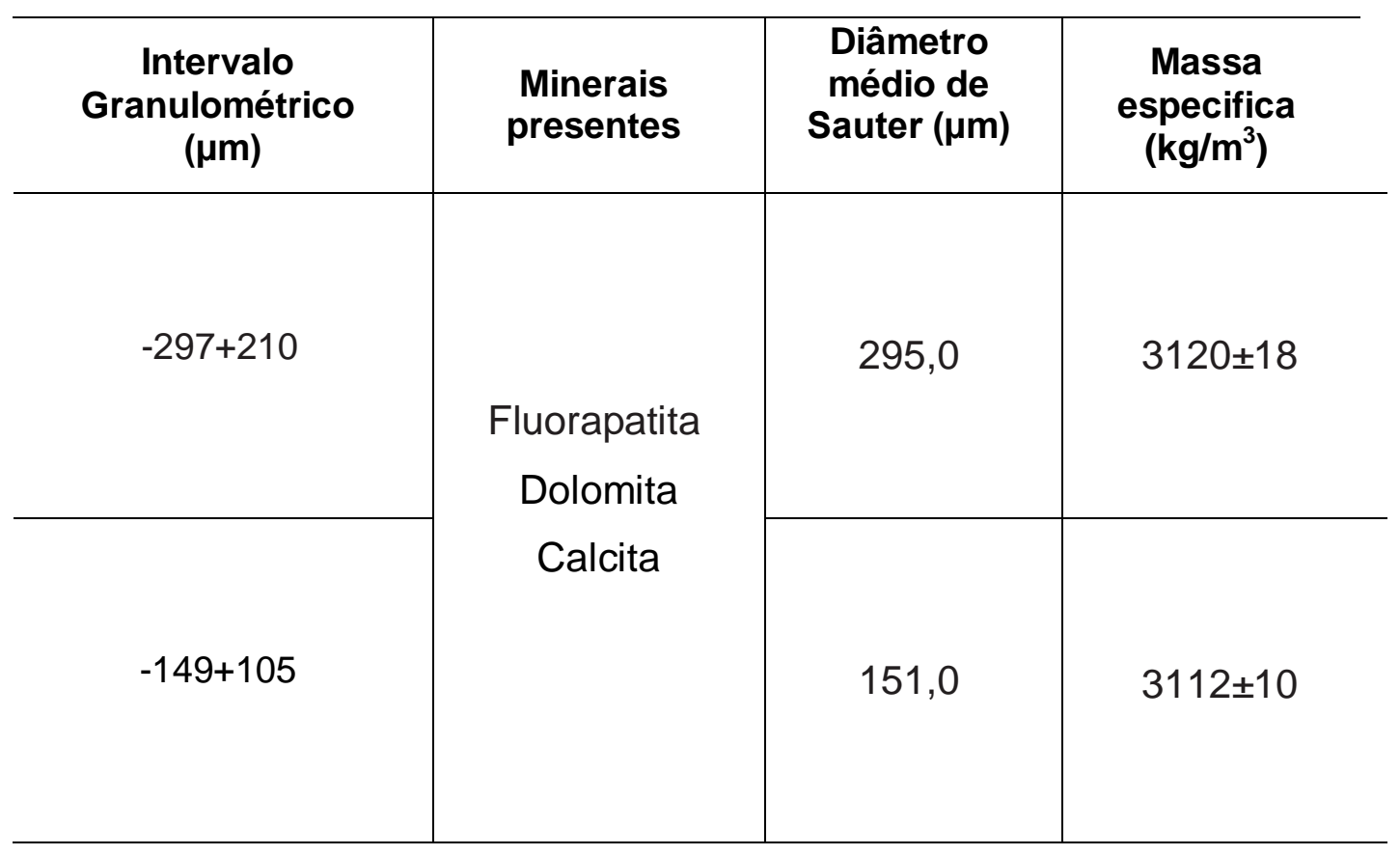

Tabela 3.2- Teores apresentados para o concentrado de apatita.

\begin{tabular}{|c|c|}
\hline $\begin{array}{c}\text { Teores, \% } \\
(-297+210 \mu \mathrm{m})\end{array}$ & $\begin{array}{c}\text { Teores, } \% \\
(-149+105 \mu \mathrm{m})\end{array}$ \\
\hline $\mathrm{P}_{2} \mathrm{O}_{5}=40,0$ & $\mathrm{P}_{2} \mathrm{O}_{5}=38,4$ \\
\hline $\mathrm{CaO}=54,6$ & $\mathrm{CaO}=53,8$ \\
\hline $\mathrm{MgO}=0,42$ & $\mathrm{MgO}=0,68$ \\
\hline $\mathrm{SiO}_{2}=0,51$ & $\mathrm{SiO}_{2}=0,60$ \\
\hline $\mathrm{Fe}_{2} \mathrm{O}_{3}=0,28$ & $\mathrm{Fe}_{2} \mathrm{O}_{3}=0,47$ \\
\hline
\end{tabular}


b) Concentrado de hematita

A amostra do concentrado de hematita é oriunda da usina de concentração localizada na Planta Industrial de Andrade, do município de Andrade-MG e foi fornecida pela Vale S.A.

O material foi peneirado a úmido, utilizando-se peneiras vibratórias em aberturas de $297 \mu \mathrm{m}, 210 \mu \mathrm{m}, 149 \mu \mathrm{m}$ e $105 \mu \mathrm{m}$, no Laboratório de Tratamento de Minérios (LTM) do Departamento de Engenharia de Minas e de Petróleo da EPUSP.

Após o peneiramento, as amostras foram divididas em duas frações granulométricas grossas, sendo a primeira passante em $297 \mu \mathrm{m}$ e retida em $210 \mu \mathrm{m}$ e a segunda fração granulométrica foi passante em $149 \mu \mathrm{m}$ e retida em $105 \mu \mathrm{m}$. O diâmetro médio da população de partículas foi caracterizado através do diâmetro médio de Sauter, com análises realizadas no Laboratório de Caracterização Tecnológica (LCT) do mesmo departamento na EPUSP, utilizando difração de laser no equipamento Mastersize S-2.19 da Malvern. A massa específica das amostras foi determinada por picnometria, em triplicata.

Cada uma das frações granulométricas do concentrado de hematita foram submetidas a uma difração de raios-X, no equipamento PANalytical, modelo X'Pert PRO para a determinação da mineralogia qualitativa, e a caracterização da fase sólida para hematita se encontra descrita na Tabela 3.3. Já os teores de cada elemento (Ferro, Silício e Alumínio) foi determinados por fluorescência de raios-X no equipamento da marca PANalytical, modelo Axios Advanced, tendo seus resultados apresentados nas Tabela 3.4. 
Tabela 3.3- Caracterização do concentrado de hematita.

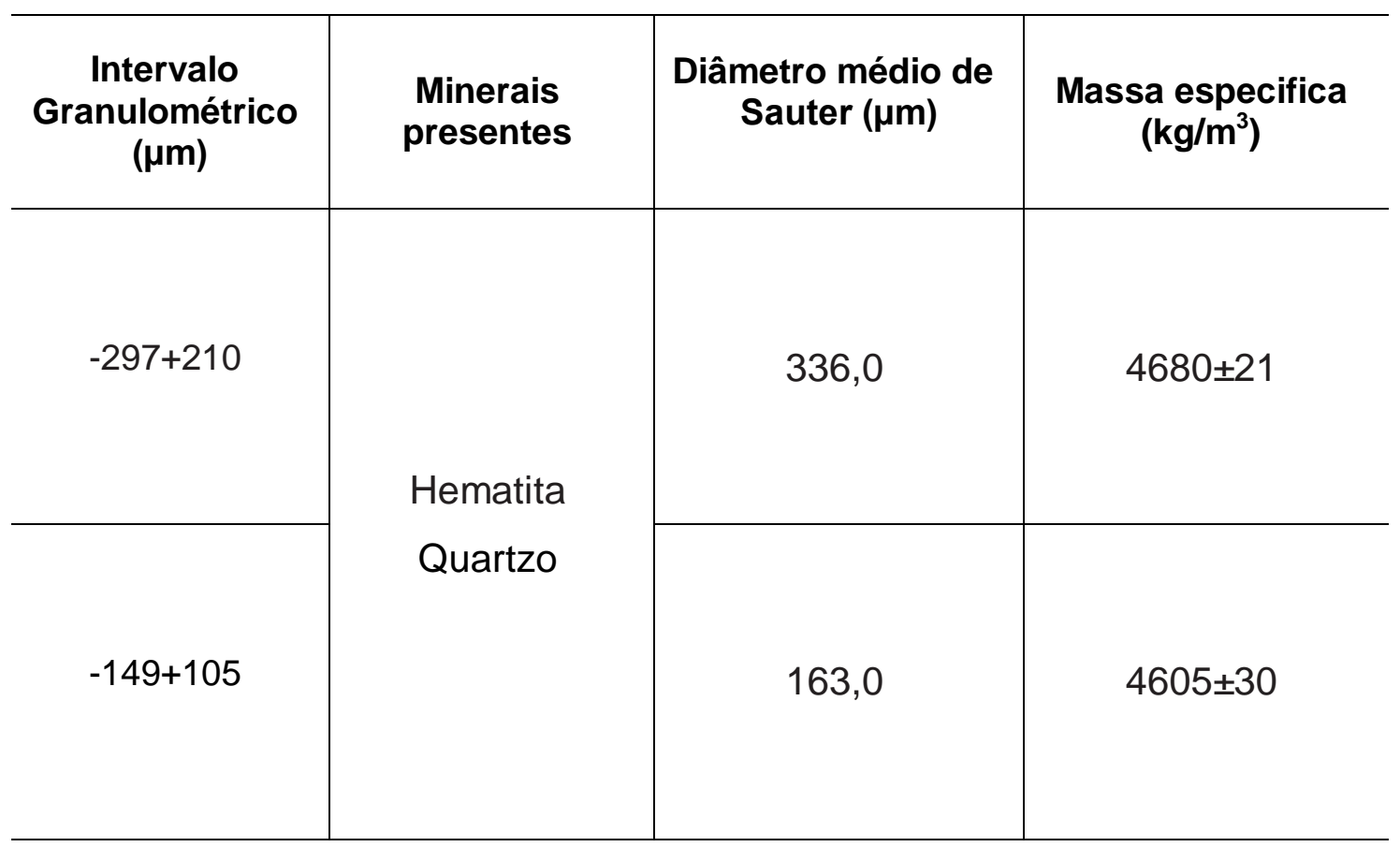

Tabela 3.4- Teores do concentrado de hematita.

\begin{tabular}{|c|c|}
\hline $\begin{array}{c}\text { Teores, \% } \\
(-297+210 \mu m)\end{array}$ & $\begin{array}{c}\text { Teores, } \% \\
(-149+105 \mu m)\end{array}$ \\
\hline $\mathrm{Fe}_{2} \mathrm{O}_{3}=60,0$ & $\mathrm{Fe}_{2} \mathrm{O}_{3}=63,9$ \\
\hline $\mathrm{SiO}_{2}=12,9$ & $\mathrm{SiO}_{2}=15,1$ \\
\hline $\mathrm{Al}_{2} \mathrm{O}_{3}=0,23$ & $\mathrm{Al}_{2} \mathrm{O}_{3}=0,18$ \\
\hline
\end{tabular}

c) Quartzo

A amostra de quartzo utilizada neste trabalho foi cedida pela empresa Mineração Jundu, da mina situada no município de Analândia-SP. O material foi recebido e peneirado a úmido, utilizando-se peneiras vibratórias com malhas nas 
aberturas de $297 \mu \mathrm{m}, 210 \mu \mathrm{m}, 149 \mu \mathrm{m}$ e $105 \mu \mathrm{m}$, sendo realizado no Laboratório de Tratamento de Minérios (LTM) do Departamento de Engenharia de Minas e de Petróleo da Escola Politécnica da USP.

O material utilizado para os ensaios foi dividido em duas frações granulométricas grossas. A primeira fração é passante em $297 \mu \mathrm{m}$ e retida em $210 \mu \mathrm{m}$ e a segunda fração é passante em $149 \mu \mathrm{m}$ e retida em $105 \mu \mathrm{m}$. O diâmetro médio de Sauter $\left(D_{3,2}\right)$ foi utilizado para retratar o diâmetro médio da população de partículas, com análises realizadas no laboratório de Caracterização Tecnológica (LCT) do mesmo departamento na EPUSP, através da técnica de difração de laser, no equipamento Mastersize S-2.19, da Malvern. A massa específica da amostra foi determinada por picnometria, em triplicata. Os resultados estão descritos na Tabela 3.5

Tabela 3.5-Caracterização da fase sólida do quartzo.

\begin{tabular}{c|c|c}
\hline $\begin{array}{c}\text { Intervalo } \\
\text { Granulométrico } \\
(\boldsymbol{\mu m})\end{array}$ & $\begin{array}{c}\text { Diâmetro médio de } \\
\text { Sauter }(\boldsymbol{\mu m})\end{array}$ & $\begin{array}{c}\text { Massa especifica } \\
\left(\mathbf{k g} / \mathbf{m}^{3}\right)\end{array}$ \\
\hline$-297+210$ & 265,0 & \\
\hline$-149+105$ & 132,0 & \\
\hline
\end{tabular}

\subsubsection{Unidade experimental para determinação da esfericidade}

O aparato experimental utilizado em ensaios para a determinação da esfericidade das amostras dos concentrados de hematita, apatita e mineral de quartzo tem seu esboço ilustrado na Figura 3.1. 
A unidade é composta de um funil de Buchner, com volume total de 43,06 $\mathrm{cm}^{3}$, com diâmetro interno (D) igual a 48,5mm e altura (L) de $23,3 \mathrm{~mm}$, um kitassato de $500 \mathrm{ml}$, bomba de vácuo marca FANEM, modelo 089, um rotâmetro de área variável para ar, da Dwyer (0-10NIpm), e um manômetro em U, utilizando água como fluido manométrico. Um tampão, com saída em $\mathrm{T}$, foi utilizado para vedar o kitassato e permitir o acoplamento da linha ao medidor de pressão.

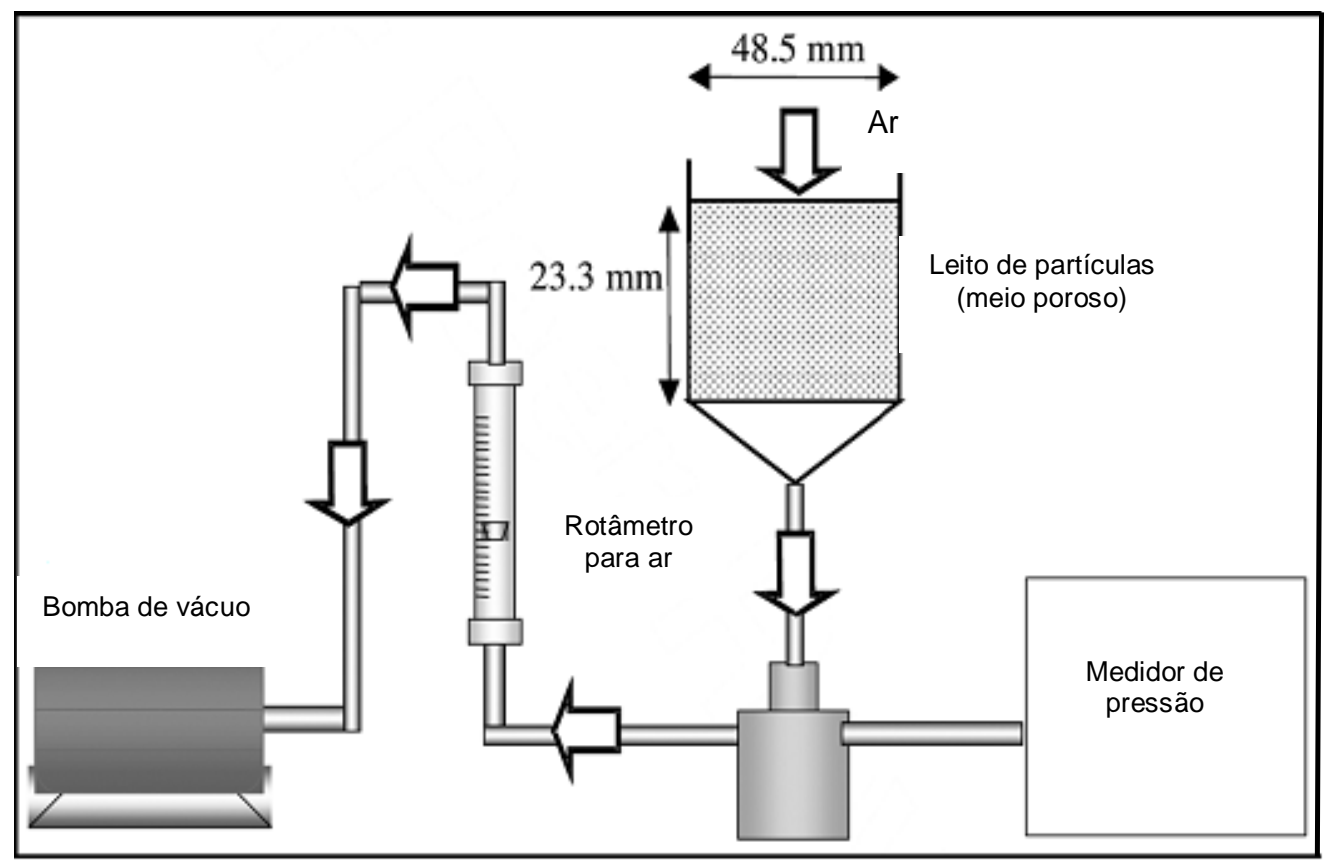

Figura 3.1- Esboço do aparato experimental para a determinação da esfericidade de partículas minerais

\subsubsection{Unidade experimental para o bombeamento de polpas minerais}

Para os ensaios de bombeamento dos concentrados de apatita, hematita e mineral de quartzo, foram dimensionadas e construídas duas unidades experimentais de bombeamento com reciclo fechado, com diferentes diâmetros. A unidade com maior diâmetro apresenta $D=50,8 \mathrm{~mm}$ e se encontra localizada no Laboratório de Fenômenos de Transporte e Físico-química de Interfaces do Departamento de Engenharia de Minas e de Petróleo da EPUSP. Já a unidade de 
menor diâmetro possui $\mathrm{D}=25,4 \mathrm{~mm}$ e se encontra no Laboratório de Operações Unitárias da Faculdade de Engenharia Química da UNISANTA, Santos-SP.

As unidades experimentais são semelhantes e têm seu esboço apresentado na Figura 3.2, e as partes constituintes do aparato estão descritas na Tabela 3.6. As Figuras 3.3 e 3.4 apresentam a foto das unidades experimentais, com diâmetro de $25,4 \mathrm{~mm}$ e $50,8 \mathrm{~mm}$, respectivamente.

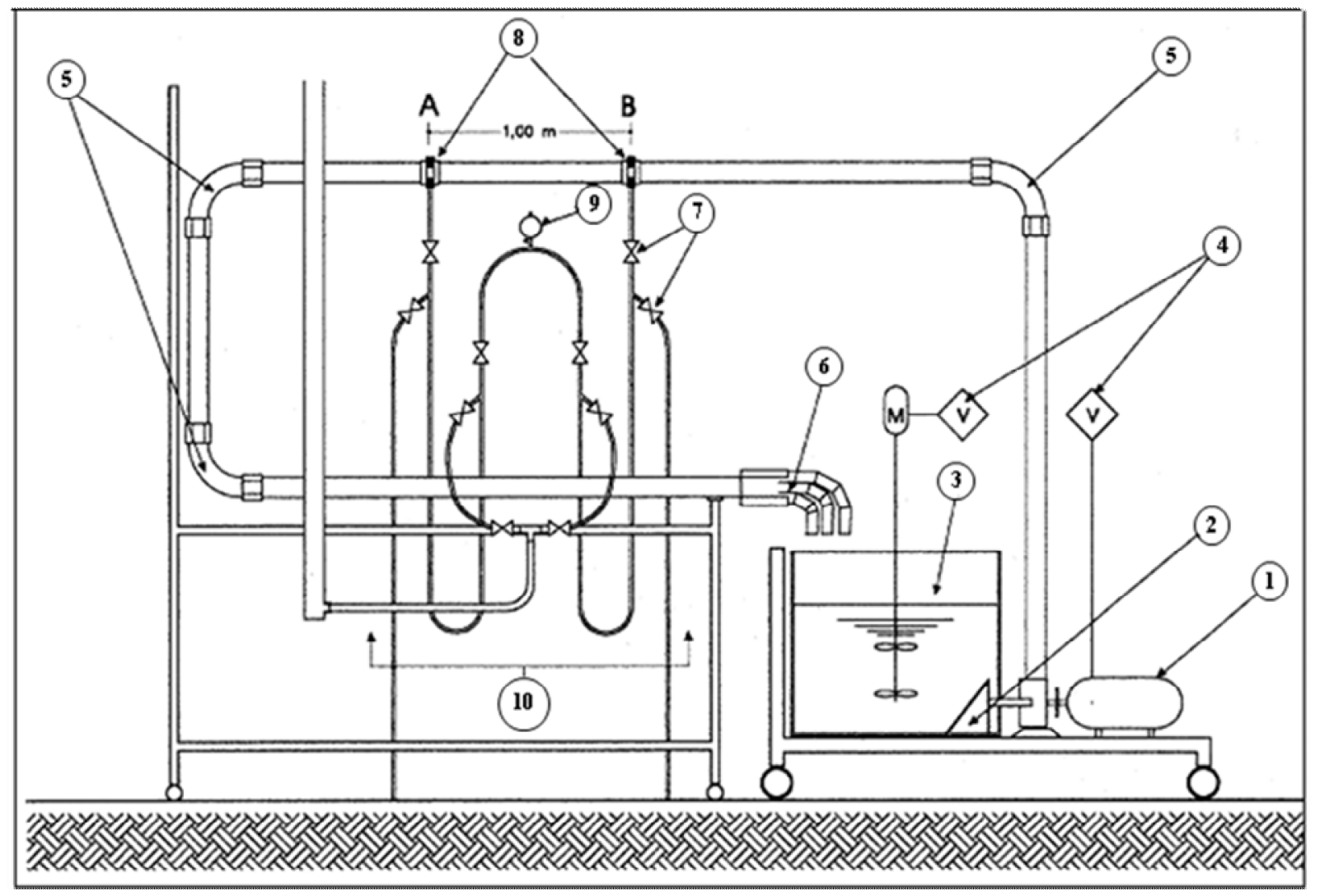

Figura 3.2- Esboço da Unidade experimental de bombeamento de polpas minerais. 
Tabela 3.6- Componentes da unidade experimental.

\begin{tabular}{c|c}
\hline Item & Descrição \\
\hline 01 & Bomba Centrífuga \\
\hline 02 & Dispositivo quebra-bolha \\
\hline 03 & Tanque de alimentação com agitação \\
\hline 04 & Inversores de freqüência \\
\hline 05 & Calha distribuidora \\
\hline 06 & Válvulas do manômetro em U \\
\hline 07 & Anéis piezométricos \\
\hline 08 & Sistema de pressurização do manômetro em U \\
\hline 09 & Tubos de saída para limpeza do manômetro \\
\hline 10 & \\
\hline
\end{tabular}

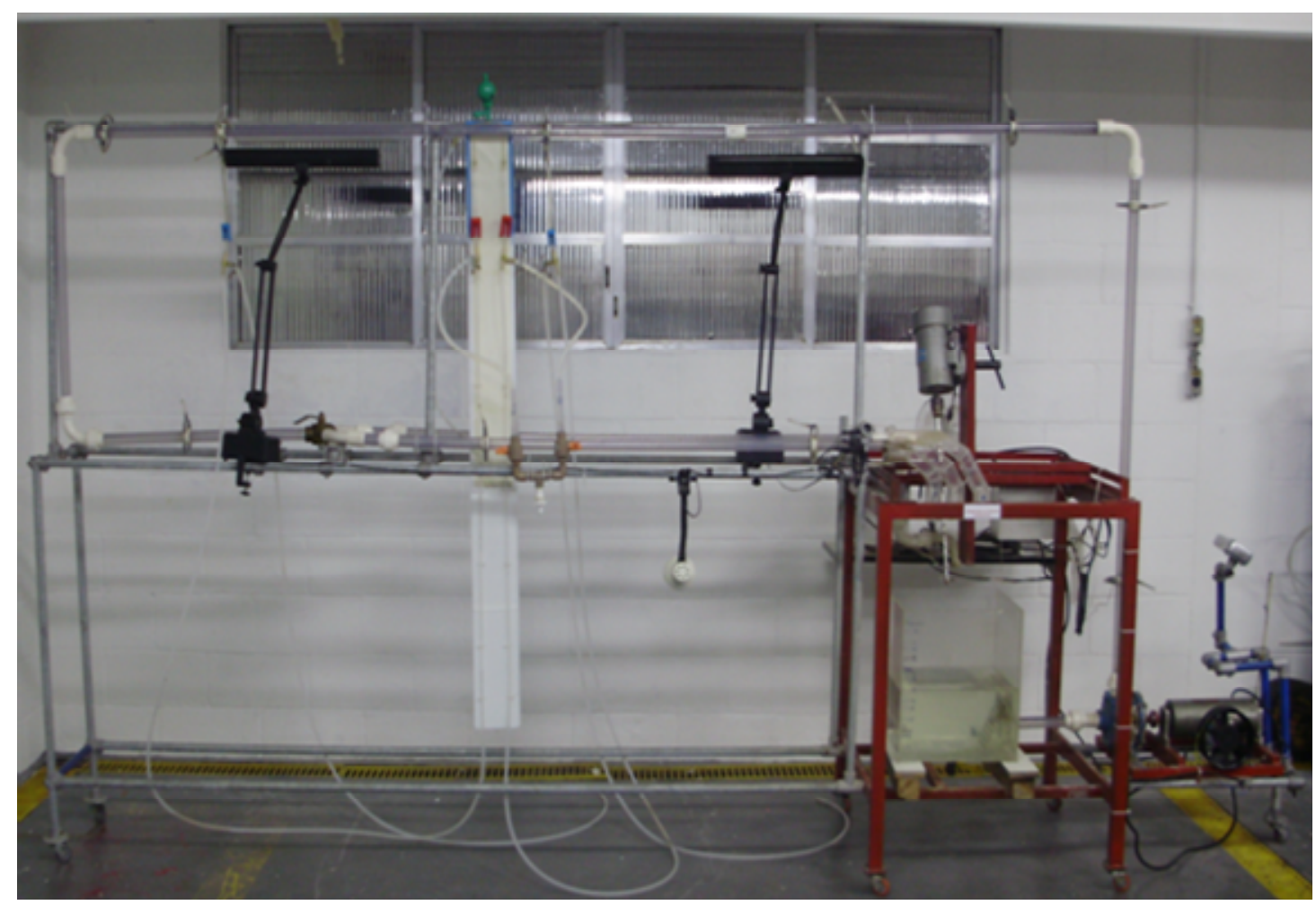

Figura 3.3- Unidade experimental de bombeamento de polpas minerais $(\mathrm{D}=25,4 \mathrm{~mm})$. 


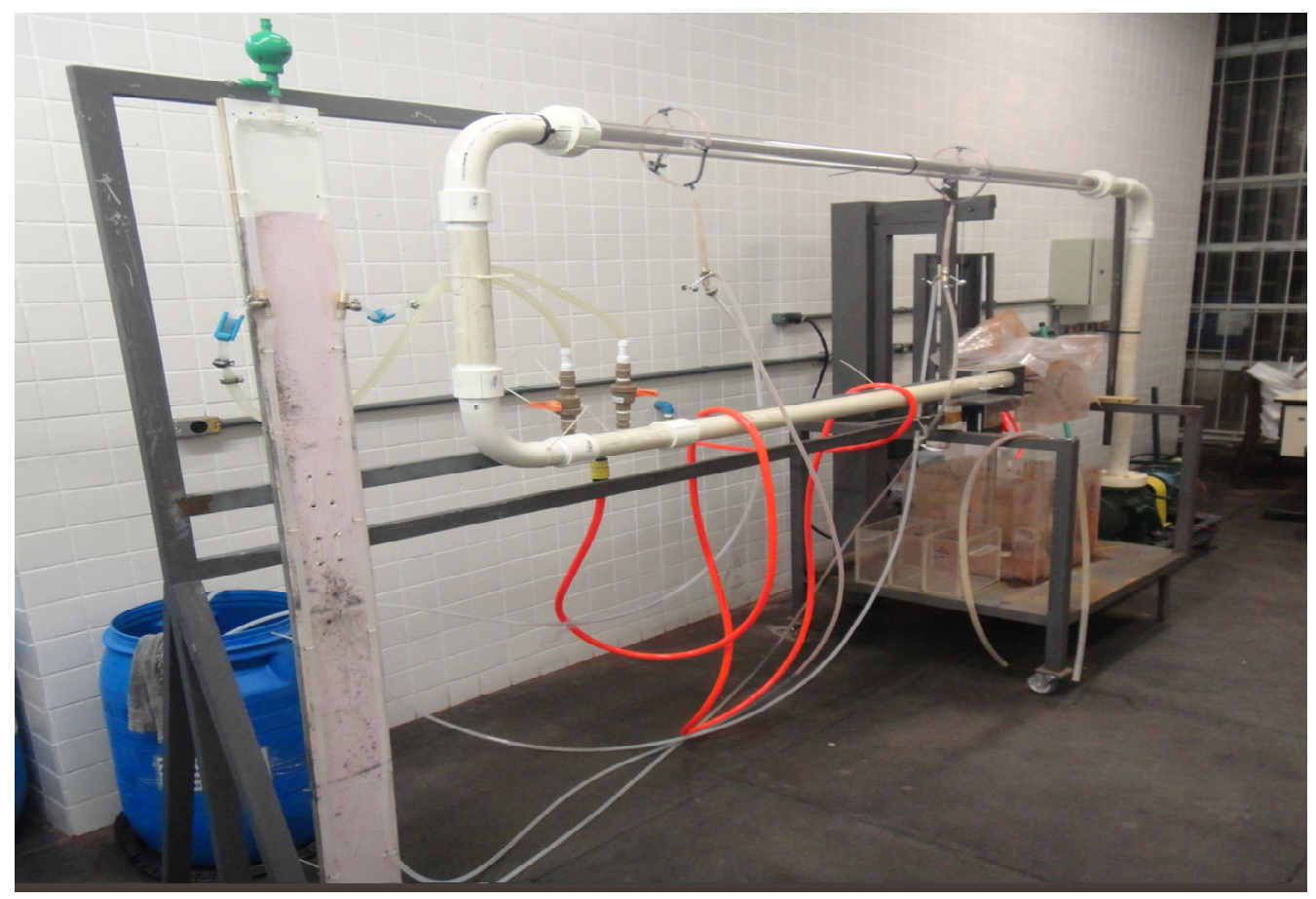

Figura 3.4- Unidade experimental de bombeamento de polpas minerais $(\mathrm{D}=50,8 \mathrm{~mm})$.

A unidade com diâmetro interno de 25,4mm de diâmetro apresenta uma bomba centrífuga da marca Jaccuzi, modelo 1091-M, com potência de 750 W, já a unidade com maior diâmetro apresenta bomba centrífuga para polpa da Marca IMBIL, com $3750 \mathrm{~W}$ de potência. Ambos os motores se encontram em balanço, mancalizado em 2 rolamentos, com o objetivo de se medir a potência útil. As duas bombas centrífugas se encontram nas Figuras 3.5 e 3.6. O rotor utilizado para a bomba centrífuga de $750 \mathrm{~W}$ é semiaberto e possui selo mecânico. A voluta é separada do corpo da bomba e a carcaça é bipartida, o que permite fácil manutenção. Já a bomba centrífuga com motor de $3750 \mathrm{~W}$ de potência apresenta rotor semi aberto com revestimento de borracha natural e carcaça bipartida. Inversores de frequência foram acoplados a cada agitador e bomba, permitindo o controle da rotação dos mesmos. Os impelidores para cada unidade experimental apresentam motor WEG com $750 \mathrm{~W}$ de potência e se encontram nas Figuras 3.7 e 3.8.

A tubulação de $25,4 \mathrm{~cm}$ de diâmetro é toda feita em PVC transparente, o que permite a visualização do interior dos tubos (Figura 3.9). Lâmpadas foram instaladas ao longo da tubulação (Figura 3.10) para melhor visualização do fluxo, permitindo 
identificar com clareza o comportamento dos sólidos no interior dos tubos durante a operação de bombeamento. A unidade com diâmetro de 50,8mm apresenta uma seção com $2 \mathrm{~m}$ de comprimento de tubos em acrílico transparente, onde foram localizadas as tomadas de pressão, permitindo assim a visualização do fluxo.

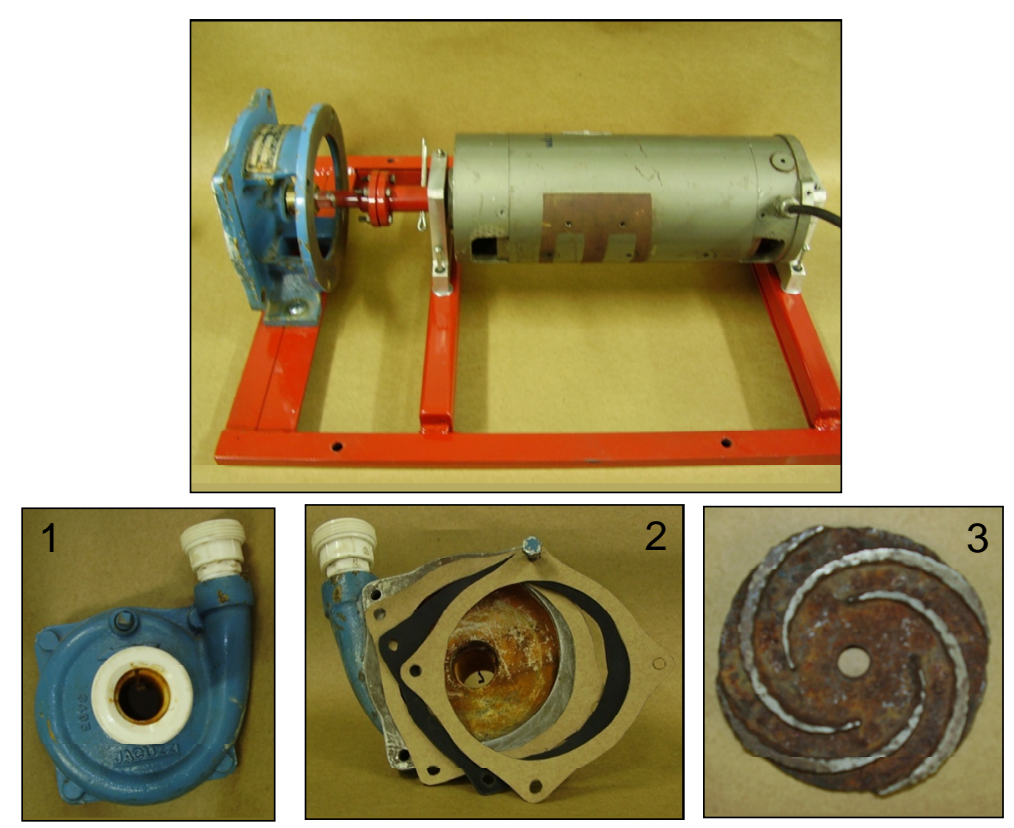

Figura 3.5- Bomba centrifuga e seus componentes ( $D=25,4 \mathrm{~mm})$

(1) Carcaça, (2) selo, (3) rotor semiaberto.

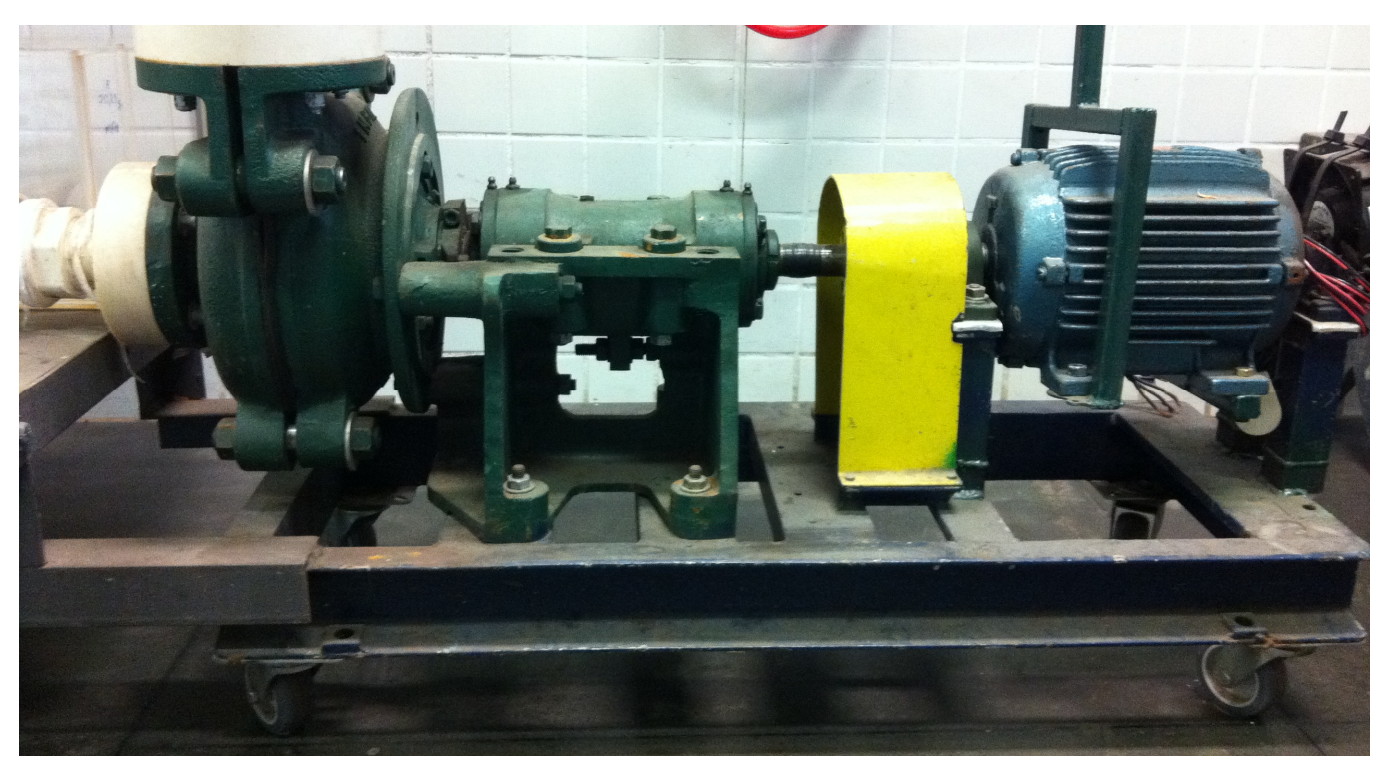

Figura 3.6- Bomba centrifuga para polpas minerais da marca-IMBIL ( $D=50,8 \mathrm{~mm})$. 


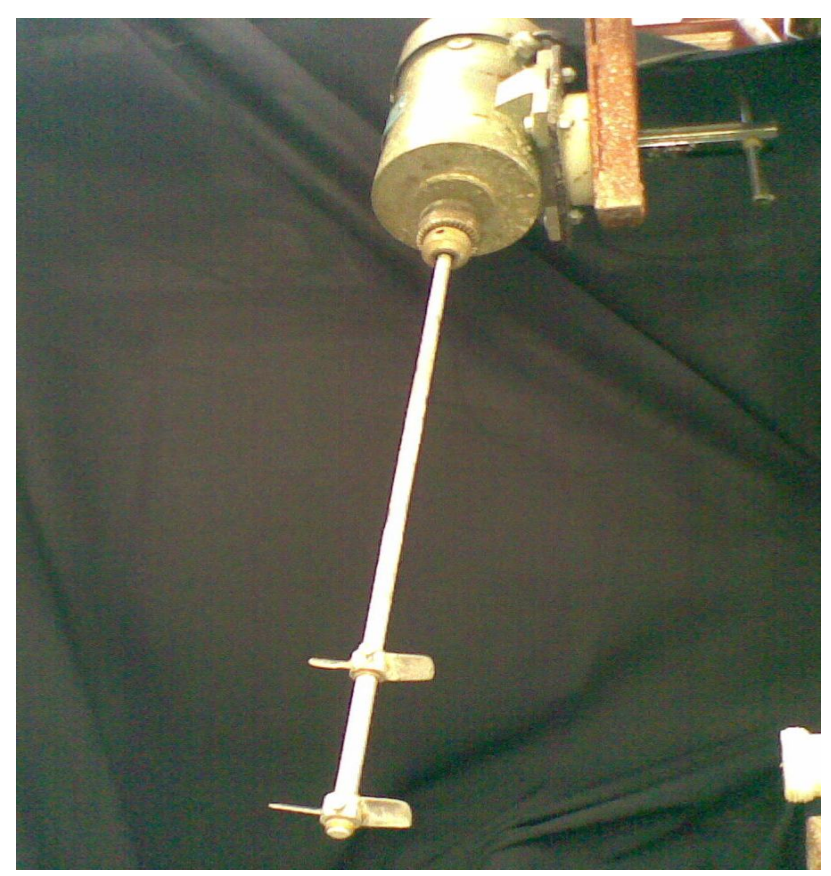

Figura 3.7- Agitador com 2 impelidores axiais $(D=25,4 \mathrm{~mm})$

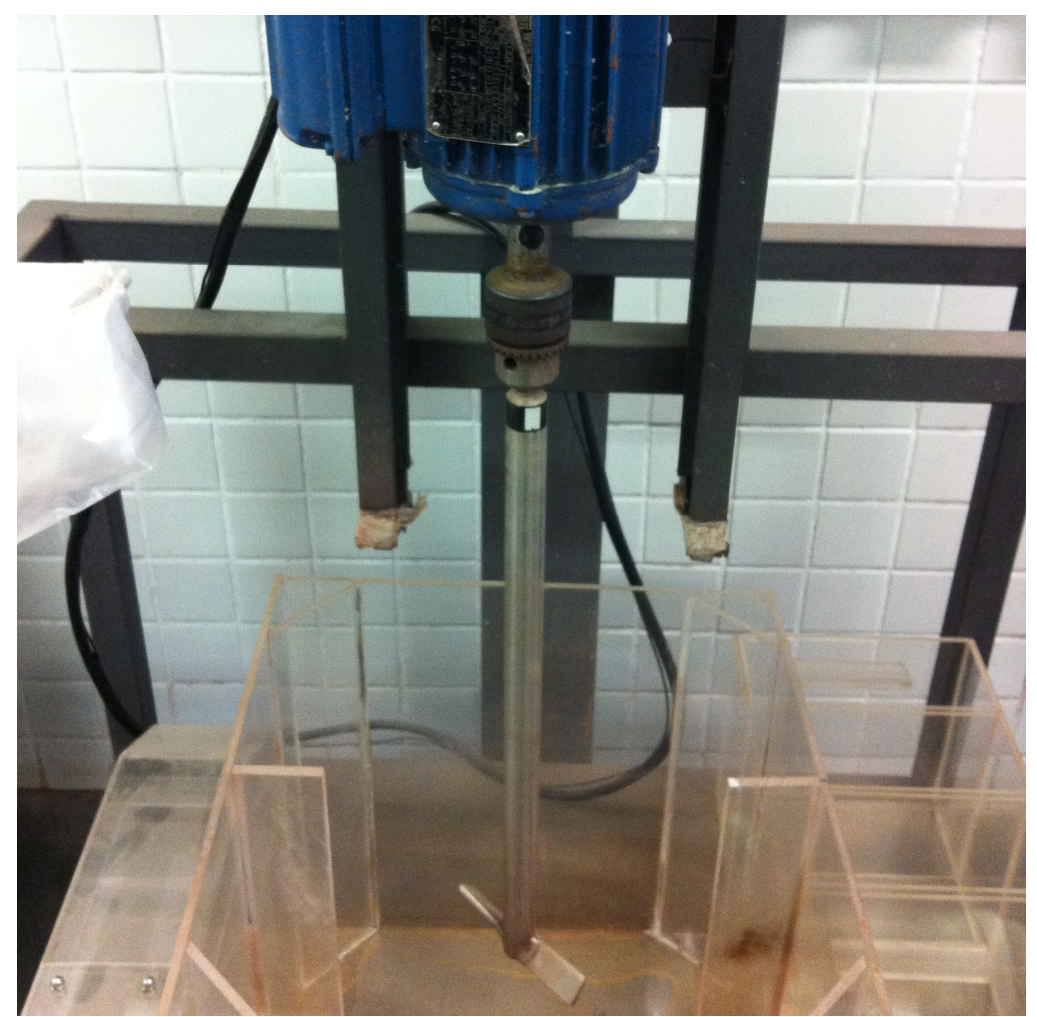

Figura 3.8- Agitador com impelidor axiais $(D=50,8 \mathrm{~mm})$ 


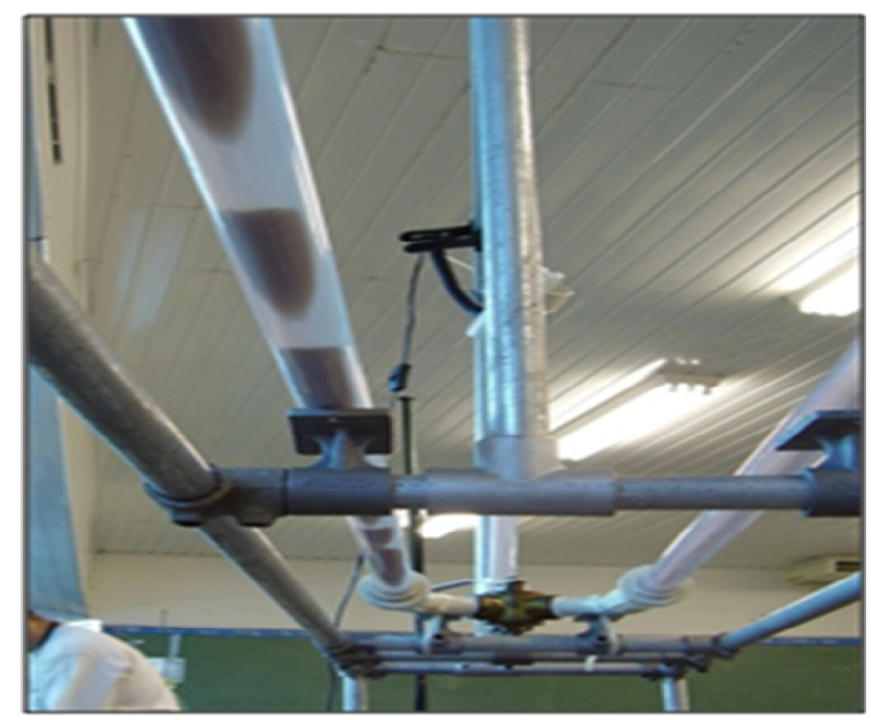

Figura 3.9- Tubo de 25,4cm de diâmetro em PVC transparente.

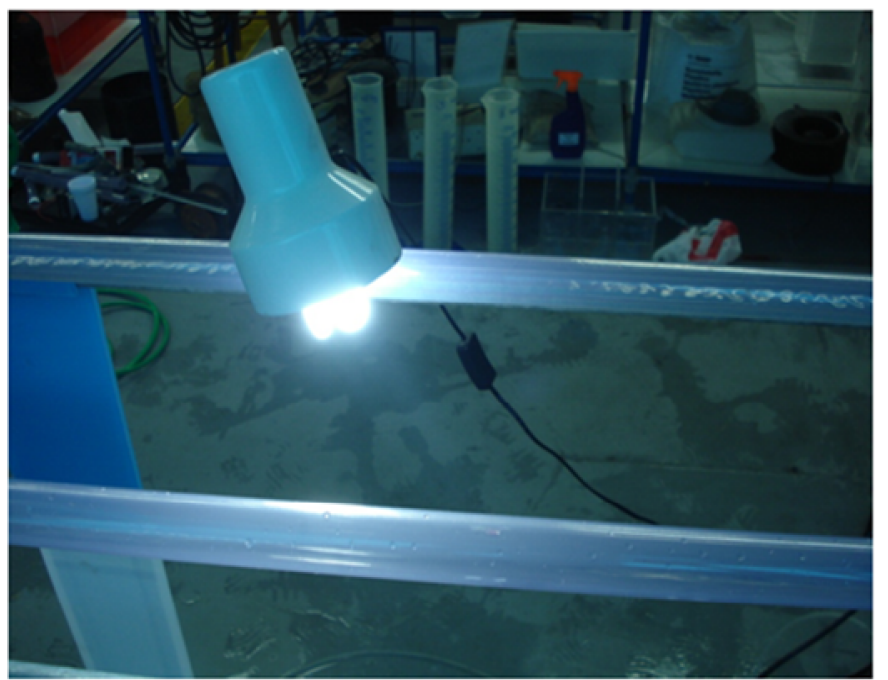

Figura 3.10- Lâmpadas instaladas ao longo da tubulação.

Um manômetro em U, invertido e pressurizado com ar, tendo água como fluido manométrico, foi utilizado para a leitura da perda da carga em ambas as unidades experimentais. Os tubos do manômetro apresentam diâmetro de 0,0095m, feitos em poliflux. Um jogo de válvulas foi instalado para permitir seu preenchimento com água e permitir possíveis manutenções (limpeza e desentupimento), mesmo 
durante a operação de bombeamento, conforme ilustra a Figura 3.11. Os constituintes do manômetro se encontram na Tabela 3.7.

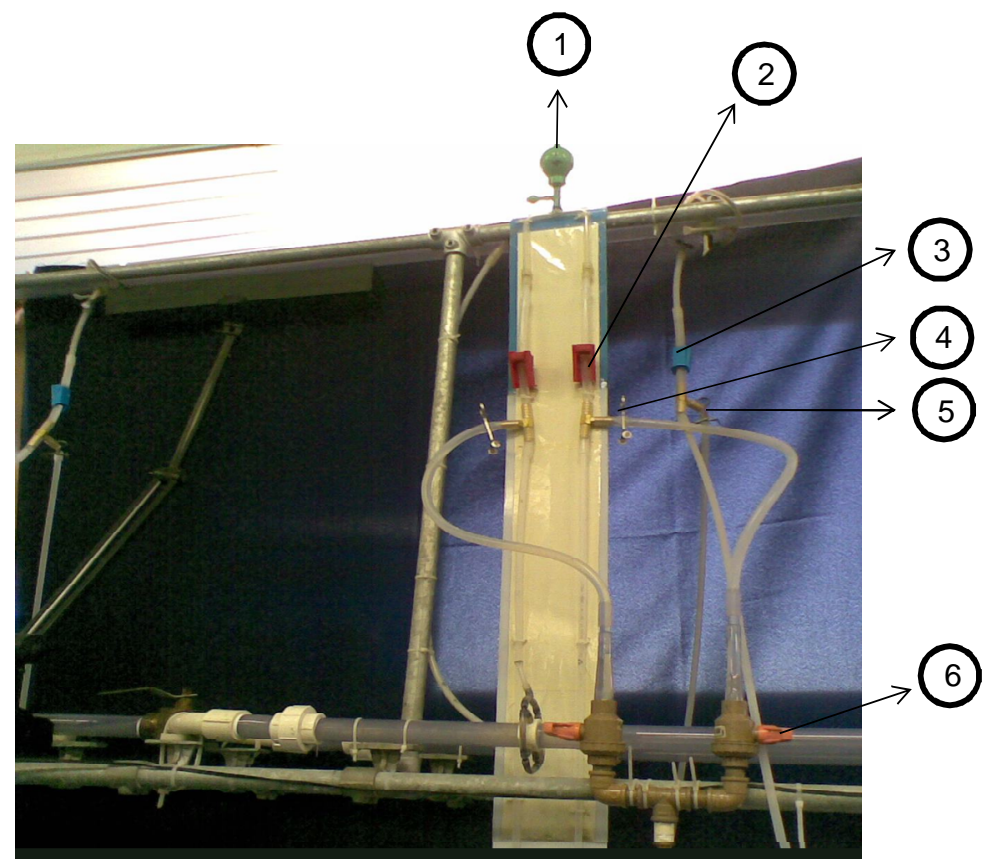

Figura 3.11- Manômetro em U e válvulas

Tabela 3.7- Válvulas constituintes do manômetro.

\begin{tabular}{c|c}
\hline Item & Descrição \\
\hline 1 & Pêra para pressurização do manômetro \\
\hline 2 & Válvula para preenchimento do manômetro \\
\hline 3 & Válvula de controle para o fluxo interno do tubo \\
\hline 5 & Válvula da entrada de água de lavagem \\
\hline 6 & Válvula para controle da entrada de água de lavagem \\
\hline
\end{tabular}


Anéis piezométricos, para medidas de pressão estática, foram utilizados ao longo da tubulação, com configuração de tomadas cruzadas (Figura 3.12 e Figura 3.13), para se evitar ao máximo o entupimento das mesmas pelos sólidos. Os anéis foram feitos de PVC, colados por cima do tubo, utilizando "Ts" e mangueiras flexíveis de silicone como conectores.

Uma calha distribuidora, feita em acrílico (Figura 3.14), e que divide a área do tubo em 3 seções, foi instalada na descarga do sistema para a identificação do perfil de concentração de sólidos no interior da tubulação. As áreas da seção transversal dos setores 1, 2 e 3, são respectivamente $1,86 \mathrm{~cm}^{2}, 1,93 \mathrm{~cm}^{2}$ e 1,92cm², para um diâmetro interno nominal de 25,7mm. O tubo de maior diâmetro apresenta diâmetro interno nominal de $50,15 \mathrm{~mm}$ e as áreas dos setores da calha distribuidora são respectivamente $6,58 \mathrm{~cm}^{2}, 6,63 \mathrm{~cm}^{2}$, e $6,61 \mathrm{~cm}^{2}$.

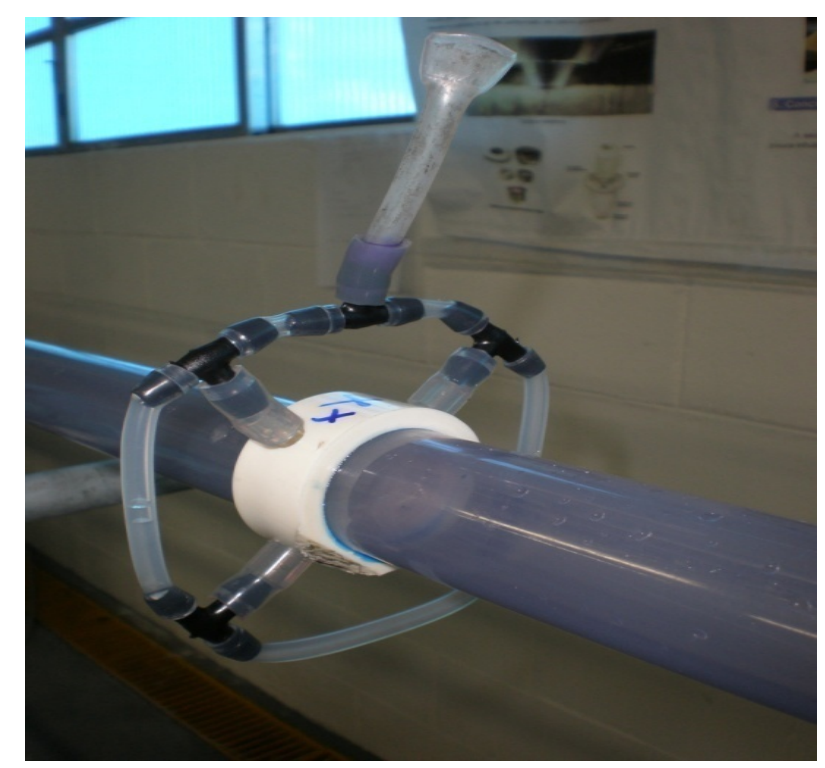

Figura 3.12- Anel piezométrico ( $D=25,4 \mathrm{~mm})$ 


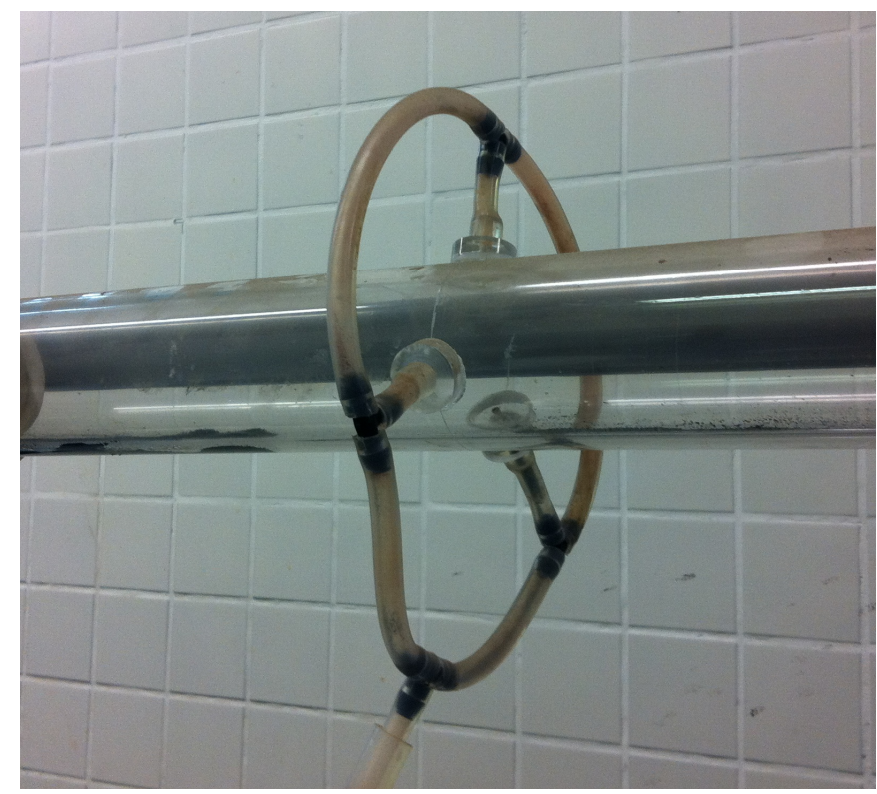

Figura 3.13- Anel piezométrico ( $D=50,8 \mathrm{~mm})$

Para a coleta das amostras na saída do sistema, foi construída uma caixa em acrílico, com divisões independentes (Figura 3.15), para permitir a amostragem simultânea nas seções individuais da calha distribuidora. Cada compartimento da caixa coletora apresenta uma marcação volumétrica, o que permite a leitura do volume bem como a determinação da massa de polpa amostrada em cada seção do tubo.
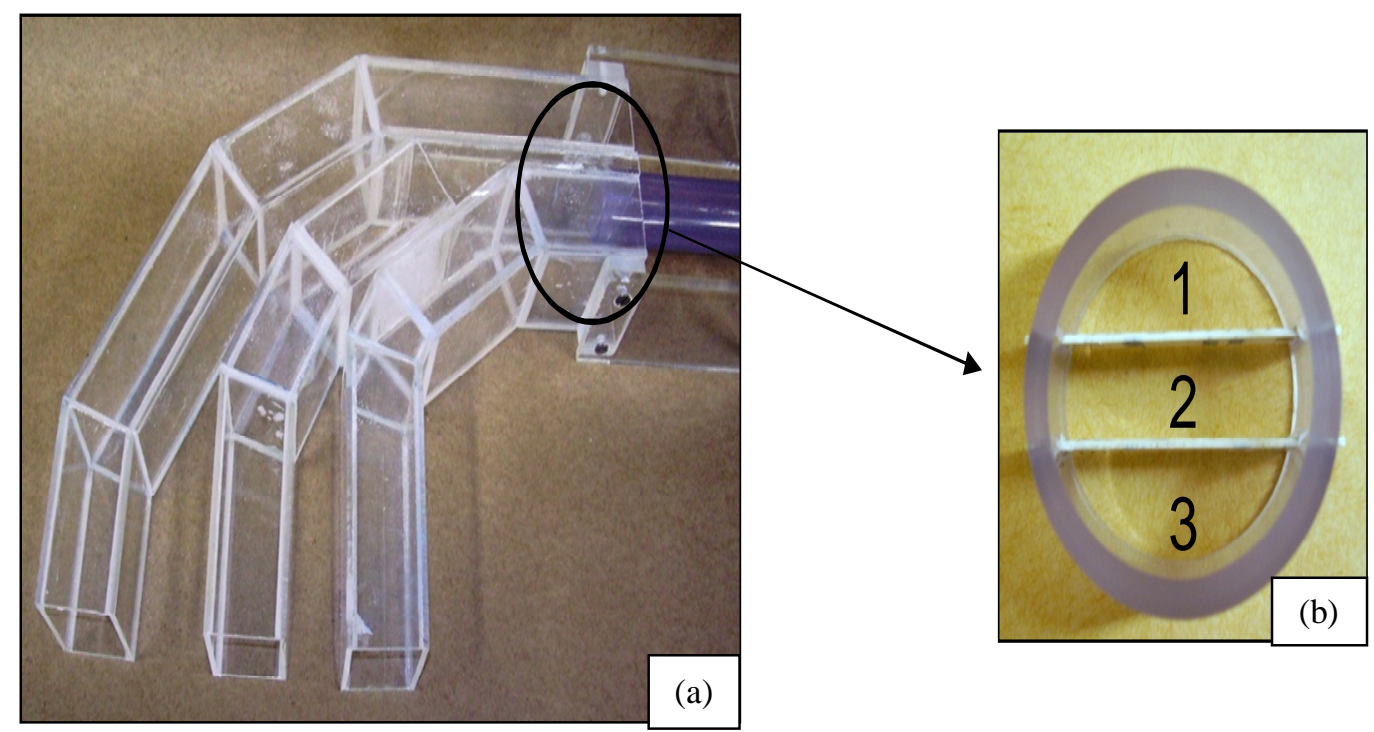

Figura 3.14- (a) Calha distribuidora, (b) vista frontal da divisão do tubo. 


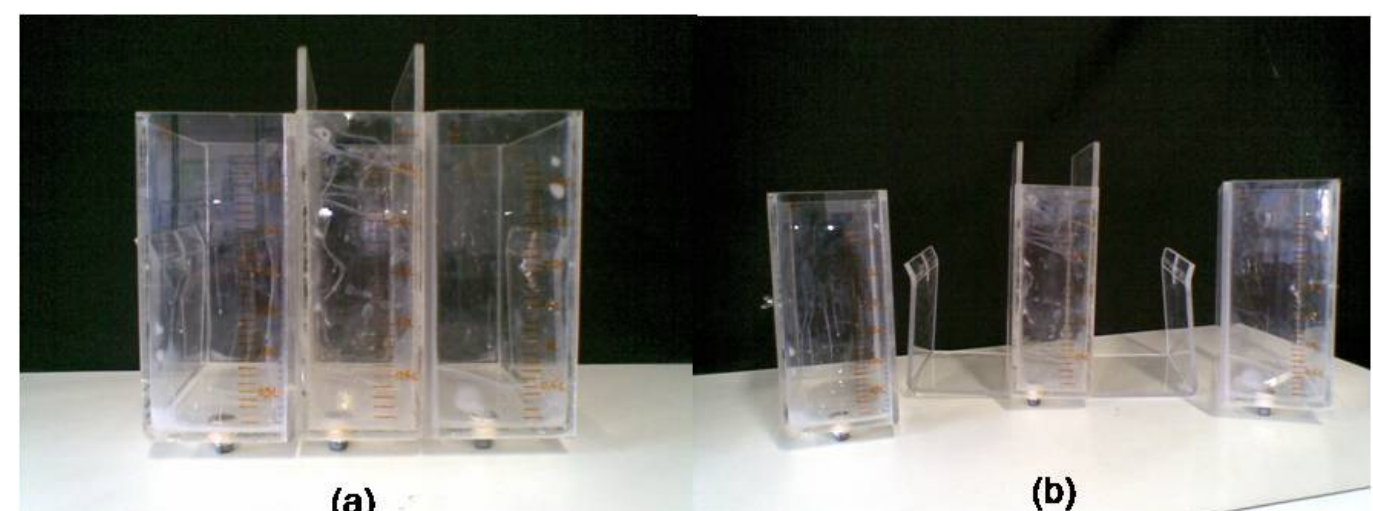

(a)

(b)

Figura 3.15- Caixa de amostragem de polpa

(a) Compartimento acoplado; (b) Compartimento individualizado

Uma calha quebra-jato (Figura 3.16) foi utilizada durante os ensaios na descarga do sistema para que o retorno da polpa ao tanque de alimentação fosse suavizado, evitando prejudicar as linhas de fluxo de agitação, assim conservando os sólidos suspensos e a polpa homogeneizada.

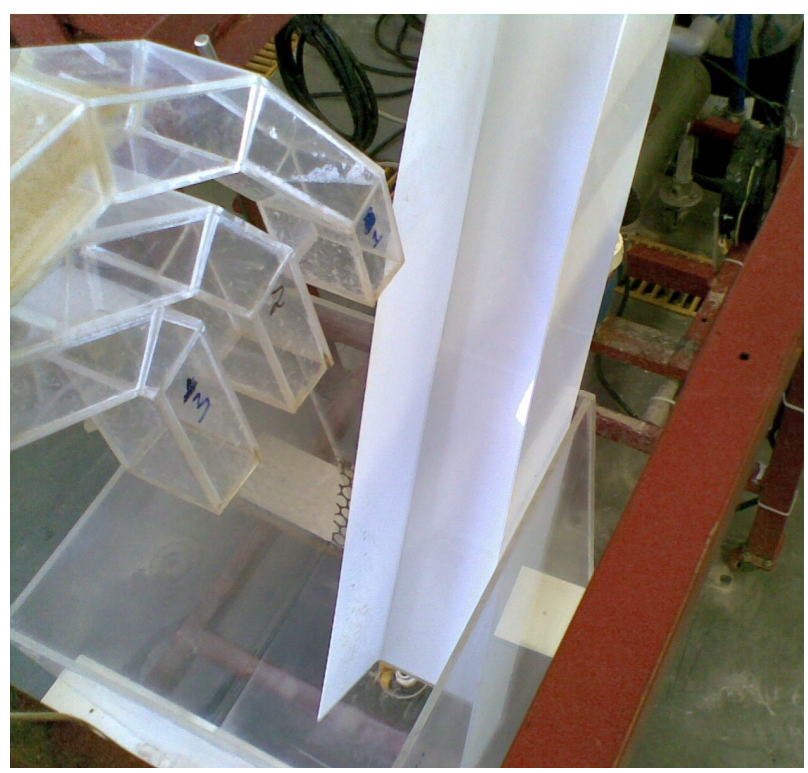

Figura 3.16- Detalhe da calha quebra-jato. 


\subsection{Métodos}

\subsubsection{Determinação da esfericidade das partículas minerais}

Após a montagem do aparato experimental descrito na seção 3.1.2, o funil de Buchner foi preenchido com as amostras minerais utilizadas para cada intervalo granulométrico proposto. Com o leito empacotado, o excesso de partículas foi retirado, através de uma haste de madeira.

Com o acionamento da bomba de vácuo, localizada no final do sistema, o ar foi forçado a percolar o leito poroso, tendo sua vazão monitorada através do rotâmetro de área variável, para valores no intervalo de 1 a $4 \mathrm{~L} / \mathrm{min}$, variando na unidade, e a perda de carga foi monitorada através do manômetro em $\mathrm{U}$, utilizando água como fluido manométrico, para cada valor de vazão de ar.

A constante de permeabilidade do leito $(K)$, que atende ao regime laminar, foi determinada através da Lei de Darcy, de acordo com a Equação 3.1.

$$
-\frac{\Delta P}{L}=\frac{\mu}{K} \cdot \frac{Q}{A}
$$

Sendo:

$\Delta \mathrm{P}$ a perda de carga através do meio poroso;

$Q$ a vazão de ar;

$\mu$ a viscosidade dinâmica do ar a $20^{\circ} \mathrm{C}$.

A porosidade do meio $(\varepsilon)$, definida como a razão entre o volume de espaços vazios pelo volume total do leito (vazio e sólidos), pode ser definida segundo a Equação 3.2. 


$$
\varepsilon=\frac{V_{\text {vazios }}}{V_{\text {leito }}}
$$

\section{Em que:}

$\mathrm{m}_{\mathrm{s}}$ é a massa total de sólidos;

$\varepsilon$ é a porosidade do meio;

$\checkmark$ é o volume total de sólidos.

A partir das características do sistema, tais como, porosidade, diâmetro da partícula, perda de carga por altura de leito, viscosidade do fluido e a velocidade média do fluido, o modelo de Kozeny-Carmam apresenta a esfericidade de acordo com a Equação 3.3, para regime laminar (McCabe, 1985).

$$
-\frac{\Delta P}{L} \cdot \frac{\left(D_{p} \psi\right)^{2}}{\overline{V_{0}} \cdot \mu} \cdot \frac{\varepsilon^{2}}{(1-\varepsilon)^{2}}=150
$$

Sendo:

$\mathrm{D}_{\mathrm{P}} \mathrm{O}$ diâmetro médio volumétrico;

$V_{0}$ a velocidade média do fluido

Rearranjando a Equação 3.1 e 3.3, o modelo utilizado para a determinação da esfericidade das partículas minerais é apresentado conforme a Equação 3.4.

$$
K=\frac{\left(D_{p .} \psi\right)^{2} \varepsilon^{3}}{150 .(1-\varepsilon)^{2}}
$$




\subsubsection{Ensaios de bombeamento de polpas minerais}

\subsubsection{Procedimentos iniciais}

Inicialmente foram determinadas as massas de sólido e líquido a fim de adequar a concentração da polpa ao volume útil do tanque de alimentação. As concentrações volumétricas das polpas utilizadas foram determinadas de acordo com a Equação 3.5. A massa específica da polpa foi obtida empregando-se a Equação 3.6.

$$
C_{v / v}=\frac{\frac{m_{S}}{\rho_{S}}}{\frac{m_{S}}{\rho_{S}}+\frac{m_{L}}{\rho_{L}}} \cdot 100
$$

Em que:

$C_{v / v}$ é a concentração em volume (\%);

$m_{S}$ é a massa de sólido, $\mathrm{kg}$

$m_{L}$ é a massa de líquido, $\mathrm{kg}$

$\rho_{S}$ é a massa específica do sólido, $\mathrm{kg} / \mathrm{m}^{3}$

$\rho_{L}$ é a massa específica do líquido. $\mathrm{kg} / \mathrm{m}^{3}$

$$
\rho_{p}=\frac{100}{\left(\frac{C_{w}}{\rho_{S}}+\frac{100-C_{w}}{\rho_{L}}\right)}
$$




\section{Em que:}

$\mathrm{C}_{\mathrm{w}}$ é a concentração mássica de sólidos em porcentagem

$\rho_{p}$ é a massa específica da polpa mineral, $\mathrm{kg} / \mathrm{m}^{3}$

$\rho_{S}$ é a massa específica do sólido, $\mathrm{kg} / \mathrm{m}^{3}$

$\rho_{L}$ é a massa específica do líquido, $\mathrm{kg} / \mathrm{m}^{3}$

As Tabelas 3.8, 3.9 e 3.10 apresentam as condições propostas para os ensaios de bombeamento com os concentrados de apatita e hematita e o mineral quartzo, respectivamente.

O tanque de alimentação foi então preenchido com o volume de água determinado para o ajuste da concentração, e a massa de sólidos pesada. Logo após a pesagem dos sólidos foi realizado o preenchimento do manômetro em $\mathrm{U}$ com água.

Um jogo de válvulas foi especialmente montado com o objetivo de isolar o manômetro do sistema de bombeamento, para que os ensaios não precisassem ser interrompidos devido a erros de leitura de pressão, ocasionados devido a obstrução dos tubos do manômetro pelos sólidos, durante a operação de bombeamento.

Após o preenchimento do manômetro, os sólidos são adicionados ao tanque de alimentação e o agitador foi acionado para a homogeneização da polpa.

As lâmpadas ao longo da tubulação foram ligadas e, com a verificação de toda suspensão dos sólidos no tanque de alimentação acionou-se o motor da bomba centrífuga e colocou-se a calha quebra-jato no tanque de alimentação. 
Tabela 3.8- Propriedades do concentrado de apatita para ensaios de bombeamento.

\begin{tabular}{|c|c|c|c|c|}
\hline $\begin{array}{c}\text { Diâmetro } \\
\text { médio de } \\
\text { Sauter, } \mu \mathrm{m}\end{array}$ & $\begin{array}{c}\% \text { sólidos em } \\
\text { massa }\end{array}$ & $\begin{array}{c}\% \text { sólidos em } \\
\text { volume }\end{array}$ & $\begin{array}{c}\text { Diâmetro } \\
\text { interno do } \\
\text { duto, } \mathrm{mm}\end{array}$ & $\begin{array}{c}\text { Densidade } \\
\text { relativa da } \\
\text { polpa }\end{array}$ \\
\hline \multirow{2}{*}{295} & $\begin{array}{l}30 \\
40 \\
50\end{array}$ & $\begin{array}{l}12 \\
18 \\
24\end{array}$ & 27,0 & $\begin{array}{l}1.257 \\
1.374 \\
1.516\end{array}$ \\
\hline & $\begin{array}{l}30 \\
40 \\
50\end{array}$ & $\begin{array}{l}12 \\
18 \\
24\end{array}$ & 50,15 & $\begin{array}{l}1.257 \\
1.374 \\
1.516\end{array}$ \\
\hline \multirow{2}{*}{151} & $\begin{array}{l}30 \\
40 \\
50\end{array}$ & $\begin{array}{l}12 \\
18 \\
24\end{array}$ & 27,0 & $\begin{array}{l}1.257 \\
1.374 \\
1.516\end{array}$ \\
\hline & $\begin{array}{l}30 \\
40 \\
50\end{array}$ & $\begin{array}{l}12 \\
18 \\
24\end{array}$ & 50,15 & $\begin{array}{l}1.257 \\
1.374 \\
1.516\end{array}$ \\
\hline
\end{tabular}

Tabela 3.9- Propriedades do concentrado de hematita para ensaios de bombeamento

\begin{tabular}{|c|c|c|c|c|}
\hline $\begin{array}{l}\text { Diâmetro } \\
\text { médio de } \\
\text { Sauter, } \mu \mathrm{m}\end{array}$ & $\begin{array}{c}\text { \% sólidos em } \\
\text { massa }\end{array}$ & $\begin{array}{c}\% \text { sólidos em } \\
\text { volume }\end{array}$ & $\begin{array}{l}\text { Diâmetro do } \\
\text { duto, } \mathrm{mm}\end{array}$ & $\begin{array}{c}\text { Densidade } \\
\text { relativa da } \\
\text { polpa }\end{array}$ \\
\hline \multirow{6}{*}{336} & 30 & 8 & \multirow{3}{*}{27,0} & 1.314 \\
\hline & 40 & 12 & & 1.467 \\
\hline & 50 & 17 & & 1.661 \\
\hline & 30 & 8 & \multirow{3}{*}{50,15} & 1.314 \\
\hline & 35 & 12 & & 1.386 \\
\hline & 40 & 17 & & 1.467 \\
\hline \multirow{6}{*}{163} & 30 & 8 & \multirow{3}{*}{27,0} & 1.314 \\
\hline & 40 & 12 & & 1.467 \\
\hline & 50 & 17 & & 1.661 \\
\hline & 30 & 8 & \multirow{3}{*}{50,15} & 1.314 \\
\hline & 40 & 12 & & 1.467 \\
\hline & 50 & 17 & & 1.661 \\
\hline
\end{tabular}


Tabela 3.10- Propriedades do mineral de quartzo para ensaios de bombeamento.

\begin{tabular}{|c|c|c|c|c|}
\hline $\begin{array}{c}\text { Diâmetro } \\
\text { médio de } \\
\text { Sauter , } \mu \mathrm{m}\end{array}$ & $\begin{array}{c}\% \text { sólidos em } \\
\text { massa }\end{array}$ & $\begin{array}{c}\% \text { sólidos em } \\
\text { volume }\end{array}$ & $\begin{array}{l}\text { Diâmetro do } \\
\text { duto, } \mathrm{mm}\end{array}$ & $\begin{array}{c}\text { Densidade } \\
\text { relativa da } \\
\text { polpa }\end{array}$ \\
\hline \multirow{2}{*}{265} & $\begin{array}{l}30 \\
40 \\
50\end{array}$ & $\begin{array}{l}14 \\
20 \\
27\end{array}$ & 27,0 & $\begin{array}{l}1.226 \\
1.326 \\
1.444\end{array}$ \\
\hline & $\begin{array}{l}30 \\
40 \\
50\end{array}$ & $\begin{array}{l}14 \\
20 \\
27\end{array}$ & 50,15 & $\begin{array}{l}1.226 \\
1.326 \\
1.444\end{array}$ \\
\hline \multirow{2}{*}{132} & $\begin{array}{l}30 \\
40 \\
50\end{array}$ & $\begin{array}{l}14 \\
20 \\
27\end{array}$ & 27,0 & $\begin{array}{l}1.226 \\
1.326 \\
1.444\end{array}$ \\
\hline & $\begin{array}{l}30 \\
40 \\
50\end{array}$ & $\begin{array}{l}14 \\
20 \\
27\end{array}$ & 50,15 & $\begin{array}{l}1.226 \\
1.326 \\
1.444\end{array}$ \\
\hline
\end{tabular}

\subsubsection{Determinação da velocidade crítica}

A determinação experimental de $V_{C}$ se iniciava com a adequação da concentração volumétrica da polpa no tanque de alimentação e acionando-se o agitador para manter os sólidos em suspensão. Por meio de inversor de frequência fixava-se uma rotação na bomba centrífuga para que os sólidos não se depositassem na tubulação. A partir disto, a rotação da bomba foi diminuída até o ponto em que havia a formação de um leito móvel na base dos dutos. A identificação de tal ponto foi feita visualmente, através das seções transparentes das tubulações, com o auxílio das lâmpadas instaladas ao longo dos dutos e a rotação da bomba é medida diretamente no eixo da mesma através de um tacômetro digital.

Após a determinação do ponto de velocidade crítica de deposição (leito móvel), foram realizadas amostragens da polpa na descarga do sistema, onde se monitorou o tempo de amostragem e a massa total de polpa, para a determinação da vazão mássica (Equação 3.7). A partir da massa especifica da polpa, foi determinada a vazão volumétrica da mesma, de acordo com a Equação 3.8. 


$$
W=\frac{m_{p}}{t}
$$

Sendo:

W a vazão mássica de polpa, $\mathrm{kg} / \mathrm{s}$;

$\mathrm{m}$ a massa, $\mathrm{kg}$;

t o tempo, s.

$$
Q=\frac{W}{\rho_{p}}
$$

Em que:

$Q$ é a vazão volumétrica de polpa, $\mathrm{m}^{3} / \mathrm{s}$;

W é a vazão mássica de polpa, $\mathrm{kg} / \mathrm{s}$;

$\rho_{p}$ é a massa específica da polpa, $\mathrm{kg} / \mathrm{m}^{3}$.

Com a definição da vazão volumétrica, foi possível determinar a velocidade média (V) de fluxo da polpa segundo a Equação 3.9.

$$
v=\frac{Q}{A}
$$

\subsubsection{Determinação da Perda de Carga}

Com a determinação da velocidade crítica $\left(\mathrm{V}_{\mathrm{C}}\right)$ e da vazão volumétrica $(\mathrm{Q})$, realizou-se a medida da perda de carga por metro de tubulação horizontal $(\triangle P / L)$ utilizando-se os anéis piezométricos e o manômetro em U. 
A análise do escoamento bifásico foi realizada através da Equação de Bernoulli com o termo da perda de carga (3.10).

$$
\frac{P_{A}}{\gamma}+\frac{v_{A}{ }^{2}}{2 g}+z_{A}+H=\frac{P_{B}}{\gamma}+\frac{v_{B}{ }^{2}}{2 g}+z_{B}+l_{W, B-A}
$$

Em que:

$P$ é a pressão, em $\mathrm{N} / \mathrm{m}^{2}$;

$\gamma$ é o peso específico, em $\mathrm{N} / \mathrm{m}^{3}$;

$v$ é velocidade do fluido, em $\mathrm{m} / \mathrm{s}$;

z é o nível do transporte, em m;

H é a carga da bomba, em m;

Iw é a perda de carga entre os trechos $A-B$, em m.

O balanço de energia mecânica entre os pontos (A-B) permite rearranjar a Equação 3.10 conforme a Equação 3.11, sendo que não há trabalho de eixo entre os pontos, não há variação de área no tubo e ambos se encontram no mesmo nível. Assim, o desnível no manômetro apresenta diretamente a perda de carga por metro de tubulação horizontal.

$$
\frac{\Delta P_{B-A}}{\gamma}=l_{W, B-A}
$$

\subsubsection{Determinação experimental do gradiente de fluxo de sólidos}

O perfil do gradiente de fluxo de sólidos ao longo da secção transversal da tubulação é um parâmetro importante que auxilia na caracterização do fluxo 
(heterogêneo ou pseudo-homogêneo), bem como permite a análise de efeitos de abrasão e desgaste da tubulação.

A determinação do perfil de concentração foi realizada através da calha distribuidora, localizada na descarga do sistema, que dividia a seção do tubo em 3 seções. Uma caixa coletora, que se ajusta às saídas individuais da calha, foi utilizada para a determinação da concentração mássica em cada setor. A amostragem foi realizada coletando-se a polpa na descarga do sistema em função do tempo. Os recipientes eram individualizados, para cada setor do tubo, e foi possível determinar o volume bem como a massa de polpa. As coletas foram simultâneas, o que minimizava os erros ao se determinar os parâmetros supracitados para todos os setores.

As distâncias $\left(d_{1} ; d_{2} ; d_{3}\right)$, ilustradas na Figura 3.17, relacionam o centro de cada setor em relação ao diâmetro do tubo (D) seguindo as relações de 0,2D, 0,5D e $0,8 \mathrm{D}$, da base ao topo e se aplica para ambas as unidades experimentais.

O perfil de concentração de sólidos foi determinado com base na concentração de cada setor relacionado com a área do mesmo, conforme ilustrado na Equação 3.12.

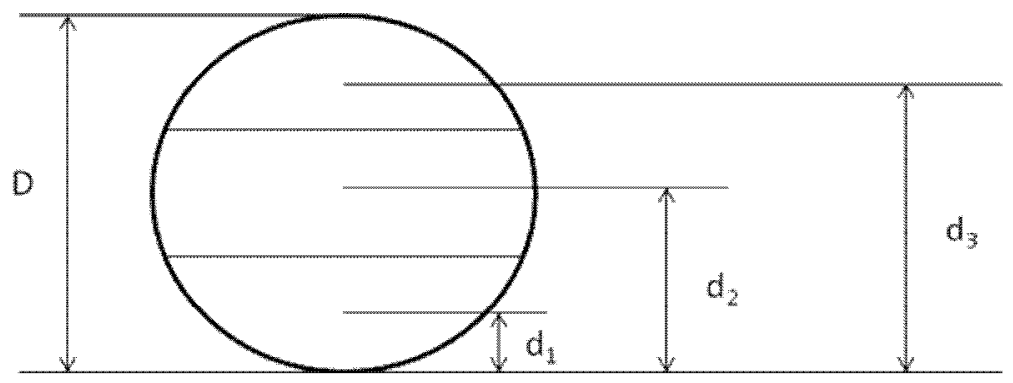

Figura 3.17 - Representação da distância do centro de cada setor em relação ao diâmetro do tubo.

$$
P_{C S}=\frac{\frac{C i}{A i}}{\sum_{i=1-3}^{n} \frac{C i}{A i}} \cdot 100
$$

Em que:

$P_{\text {CS }}$ é o perfil de concentração de sólidos, \%; 
C é a concentração mássica, \% (massa seca/massa polpa);

A é a área de cada setor $(n=1 ; 2 ; 3)$.

\subsubsection{Levantamento da curva da perda de carga por metro de tubo em função} da velocidade de fluxo da polpa

Para a construção da curva foram utilizados 5 pontos, sendo 4 pontos acima da velocidade crítica $\left(\mathrm{V}_{\mathrm{C}}\right)$ e um ponto abaixo desta velocidade, onde havia a formação de um leito fixo na base da tubulação, gerando acúmulo de partículas na base das mesmas. Todos os pontos foram determinados em função da rotação da bomba em que ocorre a formação de um leito móvel na base do tubo, variando a velocidade da bomba por um inversor de frequência em intervalos determinados, tanto acima como abaixo da rotação em que o fluxo atende $\mathrm{V}_{\mathrm{c}}$. Para cada rotação utilizada, observou-se a perda de carga associada e a velocidade do fluxo para dada condição. 


\section{CAPÍTULO 4}

\section{RESULTADOS E DISCUSSÃO: ENSAIOS EXPERIMENTAIS DE BOMBEAMENTO}

Neste capítulo são apresentados os resultados obtidos experimentalmente utilizando as duas unidades de bombeamento com "loop" para polpas minerais. A seção 4.1 traz os valores da velocidade crítica de transporte para os materiais estudados, que se constitui no objeto de estudo desta tese. Ainda são ilustradas as condições experimentais para cada ensaio, como o diâmetro médio de Sauter, concentração volumétrica e a densidade da polpa. A seção 4.2 ilustra as curvas de bombeamento ( $\triangle P / L$ em função de $V)$ para todas as condições propostas de estudo, e é discutido o comportamento para cada material bombeado. Nesta seção também são discutidas a distribuição axial de sólidos ao longo da seção transversal do duto. As figuras são apresentadas no anexo $B$. $A$ seção 4.3 apresenta $O$ confronto de modelos teóricos que predizem a velocidade de deposição com as velocidades críticas obtidas a partir dos ensaios experimentais e os desvios para cada modelo testado. 
Ensaios experimentais de bombeamento foram realizados em circuito fechado (loop) com água pura (líquido carreador) e também com suspensões aquosas dos minerais apatita, hematita e quartzo, utilizando dutos de $25,4 \mathrm{~mm}$ e $50,8 \mathrm{~mm}$ de diâmetro.

As Tabelas 4.1-4.3 apresentam um sumário das condições dos experimentos realizados com polpa de apatita (Tabela 4.1), hematita (Tabela 4.2) e quartzo (Tabela 4.3). Nestas tabelas, D é o diâmetro do duto, dSAUTER é o diâmetro médio de Sauter da partícula, $\rho_{p}$ é a densidade da partícula, C é a concentração volumétrica, $\Psi$ é a esfericidade e $\mathrm{V}_{\mathrm{C}}$ é a velocidade crítica.

Para cada condição operacional determinou-se a velocidade crítica de transporte $\left(\mathrm{V}_{\mathrm{C}}\right)$, assim como o gradiente de pressão por metro de duto horizontal $(\Delta P / L)$. Deste modo, os resultados são apresentados neste capítulo sob a abordagem da velocidade crítica (Seção 4.1) e do gradiente de pressão (Seção 4.2).

\subsection{Velocidade crítica de Transporte $\left(\mathrm{V}_{\mathrm{C}}\right)$}

Conforme se abordou na Seção 3.2.2.2 desta tese, a velocidade de fluxo sob a qual se forma um leito móvel de partículas na base da tubulação é denominada de $\mathrm{V}_{\mathrm{C}}$, que é determinada visualmente durante ensaios de bombeamento. Para isto se faz necessário utilizar uma seção de tubulação que seja transparente, conforme aparato experimental descrito no Capítulo 3. Durante os experimentos, um observador sabe que o fluxo atingiu sua velocidade crítica de transporte quando as partículas existentes no fundo da tubulação não se encontram paradas, mas se movem através de um leito cuja espessura permanece estável. Além disto, em diagramas que relacionam gradiente de pressão $\left(\frac{\Delta F}{L}\right)$ com velocidade de fluxo $(\mathrm{V})$, a magnitude de $\mathrm{V}_{\mathrm{C}}$ está associada a um ponto de mínima pressão. Tal situação, por propiciar a formação de um leito móvel com a mínima queda de pressão constitui uma condição altamente desejada para um sistema de bombeamento.

Uma vez que a determinação de $V_{C}$ está associada à identificação visual da formação de leito móvel, tal condição pode ser aferida através da determinação da concentração de sólidos na entrada versus saída do "loop" de bombeamento: se a concentração de saída for menor que a de entrada, trata-se de um indício de que o 
leito móvel se transformou em leito fixo, evidenciando acúmulo de partículas no fundo da tubulação. Para não incorrer neste erro, em todas as determinações visuais, somente se validava um valor de $V_{C}$ (visualmente observado) se a concentração de sólidos na entrada fosse igual à de saída.

A Tabela 4.1 exibe resultados de $V_{C}$ para polpas de apatita que exibiam de 12 a $24 \%$ de sólidos (em volume) e que foram bombeadas em tubulação com diâmetro de $25,4 \mathrm{~mm}$ e $50,8 \mathrm{~mm}$. Nesta tabela, é importante ressaltar:

a) Em dutos de 25,4mm, para partículas de maior diâmetro ( $\mathrm{d}_{\text {sauter }}=0,295 \mathrm{~mm}$ ), a magnitude de $V_{C}$ cresceu de $1,5 \mathrm{~m} / \mathrm{s}$ para $1,9 \mathrm{~m} / \mathrm{s}$ quando a concentração de sólidos subiu de 12\% para 24\%; enquanto que para as partículas de menor diâmetro $\left(d_{\text {Sauter }}=0,151 \mathrm{~mm}\right) \quad V_{C}$ cresceu de $1,2 \mathrm{~m} / \mathrm{s}$ para $1,5 \mathrm{~m} / \mathrm{s}$. Este comportamento ilustra o efeito da concentração de sólidos sobre $V_{C}$ : polpas mais concentradas demandam maior velocidade de fluxo para se atingir a tão almejada condição de leito móvel;

b) Na mesma condição experimental descrita no item (a), o efeito do tamanho da partícula sobre a magnitude de $\mathrm{V}_{\mathrm{C}}$ pode ser evidenciado: partículas menores demandam menor velocidade de fluxo pelo fato de exibirem menor velocidade de sedimentação. De fato, partículas maiores demandam maior turbulência para serem transportadas em condição de leito móvel do que as mais finas;

c) Em dutos de $50,8 \mathrm{~mm}$, para partículas de maior diâmetro ( $\mathrm{d}_{\text {Sauter }}=0,295 \mathrm{~mm}$ ), a magnitude de $V_{C}$ cresceu de $1,8 \mathrm{~m} / \mathrm{s}$ para $2,2 \mathrm{~m} / \mathrm{s}$ quando a concentração de sólidos subiu de 12\% para 24\%; enquanto que para as partículas de menor diâmetro $\left(\mathrm{d}_{\text {Sauter }}=0,151 \mathrm{~mm}\right) \mathrm{V}_{\mathrm{C}}$ cresceu de $1,5 \mathrm{~m} / \mathrm{s}$ para $1,9 \mathrm{~m} / \mathrm{s}$. Comparandose tais valores de $V_{C}$ com aqueles obtidos para tubo de menor diâmetro $(25,4 \mathrm{~mm})$, observa-se que nos tubos maiores é necessário maior velocidade de fluxo devido à maior espessura exibida pelo leito móvel (Doron e Barnea, 1993). 
Tabela 4.1- Velocidade crítica para polpas de concentrado de apatita.

\begin{tabular}{|c|c|c|c|c|c|}
\hline$\underset{(\mathrm{mm})}{\mathrm{D}}$ & $\begin{array}{c}\mathbf{d}_{\text {Sauter }} \\
(\mathbf{m m})\end{array}$ & $\underset{\left(k g / m^{3}\right)}{\rho_{p}}$ & $\underset{(v / v)}{C}$ & $\Psi$ & $\underset{(m / s)}{V_{C}}$ \\
\hline \multirow{3}{*}{25,4} & \multirow{6}{*}{0,295} & 1.257 & 0,12 & \multirow{6}{*}{0,635} & 1,5 \\
\hline & & 1.374 & 0,18 & & 1,7 \\
\hline & & 1.516 & 0,24 & & 1,9 \\
\hline \multirow{3}{*}{50,8} & & 1.257 & 0,12 & & 1,8 \\
\hline & & 1.374 & 0,18 & & 2,0 \\
\hline & & 1.516 & 0,24 & & 2,2 \\
\hline \multirow{3}{*}{25,4} & \multirow{6}{*}{0,151} & 1.257 & 0,12 & \multirow{6}{*}{0,645} & 1,2 \\
\hline & & 1.374 & 0,18 & & 1,3 \\
\hline & & 1.516 & 0,24 & & 1,5 \\
\hline \multirow{3}{*}{50,8} & & 1.257 & 0,12 & & 1,5 \\
\hline & & 1.374 & 0,18 & & 1,7 \\
\hline & & 1.516 & 0,24 & & 1,9 \\
\hline
\end{tabular}

A Tabela 4.2 apresenta resultados de $V_{C}$ para polpas de hematita que exibiam de 8 a 17\% de sólidos (em volume) e que foram bombeadas em tubulação com diâmetro de 25,4mm versus 50,8mm. Nesta tabela, é importante ressaltar:

a) Em dutos de 25,4mm, para partículas de maior diâmetro ( $d_{\text {sauter }}=0,336 \mathrm{~mm}$ ), a magnitude de $V_{C}$ cresceu de $2,0 \mathrm{~m} / \mathrm{s}$ para $2,2 \mathrm{~m} / \mathrm{s}$ quando a concentração de sólidos variou de 8 a 17\% (em volume); enquanto que para as partículas de menor diâmetro $\left(d_{\text {Sauter }}=0,163 \mathrm{~mm}\right) V_{C}$ cresceu de $1,6 \mathrm{~m} / \mathrm{s}$ para $2,0 \mathrm{~m} / \mathrm{s}$. Este comportamento corroborou o que se observou com as polpas de apatita;

b) $\mathrm{Na}$ mesma condição experimental descrita no item (a), o efeito do tamanho das partículas sobre a magnitude de $V_{C}$ também corroborou o que se tinha 
observado com relação à apatita: partículas menores demandam menor velocidade de fluxo pelo fato de exibirem menor velocidade de sedimentação;

c) Em dutos de 50,8mm, para partículas de maior diâmetro ( $\mathrm{d}_{\text {Sauter }}=0,336 \mathrm{~mm}$ ), a magnitude de $\mathrm{V}_{\mathrm{C}}$ cresceu de $2,3 \mathrm{~m} / \mathrm{s}$ para $2,8 \mathrm{~m} / \mathrm{s}$ quando a concentração de sólidos subiu de $8 \%$ para $17 \%$; enquanto que para as partículas de menor diâmetro $\left(d_{\text {Sauter }}=0,163 \mathrm{~mm}\right) \mathrm{V}_{\mathrm{C}}$ cresceu de $1,9 \mathrm{~m} / \mathrm{s}$ para $2,3 \mathrm{~m} / \mathrm{s}$. Comparandose tais valores de $\mathrm{V}_{\mathrm{C}}$ com aqueles obtidos para tubo de menor diâmetro $(25,4 \mathrm{~mm})$, observa-se que nos tubos maiores é necessário maior velocidade de fluxo devido à maior espessura exibida pelo leito móvel (Doron e Barnea, 1993).

Tabela 4.2- Velocidade crítica para polpas de concentrado de hematita.

\begin{tabular}{|c|c|c|c|c|c|}
\hline$\underset{(\mathrm{mm})}{\mathrm{D}}$ & $\begin{array}{c}\mathbf{d}_{\text {Sauter }} \\
(\mathrm{mm})\end{array}$ & $\underset{\left(k g / m^{3}\right)}{\rho_{p}}$ & $\underset{(v / v)}{C}$ & $\Psi$ & $\underset{(m / s)}{V_{C}}$ \\
\hline \multirow{3}{*}{25,4} & \multirow{6}{*}{0,336} & 1.314 & 0,08 & \multirow{6}{*}{0,375} & 2,0 \\
\hline & & 1.467 & 0,12 & & 2,1 \\
\hline & & 1.661 & 0,17 & & 2,2 \\
\hline \multirow{3}{*}{50,8} & & 1.314 & 0,08 & & 2,3 \\
\hline & & 1.467 & 0,12 & & 2,4 \\
\hline & & 1.661 & 0,17 & & 2,8 \\
\hline \multirow{3}{*}{25,4} & \multirow{6}{*}{0,163} & 1.314 & 0,08 & \multirow{6}{*}{0,390} & 1,6 \\
\hline & & 1.467 & 0,12 & & 1,8 \\
\hline & & 1.661 & 0,17 & & 2,0 \\
\hline \multirow{3}{*}{50,8} & & 1.314 & 0,08 & & 1,9 \\
\hline & & 1.467 & 0,12 & & 2,1 \\
\hline & & 1.661 & 0,17 & & 2,3 \\
\hline
\end{tabular}


A Tabela 4.3 ilustra resultados de $V_{C}$ para polpas de quartzo que exibiam concentração volumétrica de sólidos variando de $14 \%$ a $27 \%$ e que foram bombeadas em tubulação de diâmetro de $25,4 \mathrm{~mm}$ versus $50,8 \mathrm{~mm}$. Nesta tabela, é necessário ressaltar:

a) Em dutos de 25,4mm, para partículas de maior diâmetro ( $\mathrm{d}_{\text {Sauter }}=0,265 \mathrm{~mm}$ ), a magnitude de $\mathrm{V}_{\mathrm{C}}$ cresceu de $1,3 \mathrm{~m} / \mathrm{s}$ para $1,8 \mathrm{~m} / \mathrm{s}$ quando a concentração de sólidos variou de 14 a 27\% (em volume); \%; enquanto que para as partículas de menor diâmetro $\left(d_{\text {Sauter }}=0,132 \mathrm{~mm}\right) V_{C}$ cresceu de $1,1 \mathrm{~m} / \mathrm{s}$ para $1,4 \mathrm{~m} / \mathrm{s}$. Este comportamento corroborou o que se observou com as polpas de apatita e hematita;

b) Conforme se verificou para os sistemas experimentais que continham apatita e hematita, nas polpas de quartzo, as maiores partículas demandaram maior velocidade de fluxo para formação de leito móvel $\left(\mathrm{V}_{\mathrm{C}}\right)$ do que as partículas mais finas. Este comportamento está associado a mais baixa velocidade de sedimentação apresentada das partículas finas, implicando na demanda de menor energia para seu transporte;

c) Em dutos de $50,8 \mathrm{~mm}$, para partículas de maior diâmetro ( $\mathrm{d}_{\text {Sauter }}=0,265 \mathrm{~mm}$ ), a magnitude de $\mathrm{V}_{\mathrm{C}}$ cresceu de $1,7 \mathrm{~m} / \mathrm{s}$ para $2,0 \mathrm{~m} / \mathrm{s}$ quando a concentração de sólidos subiu de 14\% para 27\%; enquanto que para as partículas de menor diâmetro $\left(d_{\text {Sauter }}=0,132 \mathrm{~mm}\right) V_{C}$ cresceu de $1,3 \mathrm{~m} / \mathrm{s}$ para $1,7 \mathrm{~m} / \mathrm{s}$. Comparandose tais valores de $V_{C}$ com aqueles obtidos para tubo de menor diâmetro $(25,4 \mathrm{~mm})$, observa-se que nos tubos maiores é necessário maior velocidade de fluxo devido à maior espessura exibida pelo leito móvel (Doron e Barnea, 1993). Este comportamento também foi observado para polpas contendo hematita e apatita;

d) Os valores de $V_{C}$ apresentados nesta tabela $(1,3-2,0 \mathrm{~m} / \mathrm{s})$ são semelhantes àqueles reportados por Gilles (1993), que trabalhou com partículas grossas $(0,10-0,30 \mathrm{~mm})$ do mesmo mineral (quartzo), em polpas com semelhante concentração volumétrica de sólidos (15-30\%), em dutos de 50,8mm de diâmetro. 
Tabela 4.3- Velocidade crítica para polpas de mineral de quartzo.

\begin{tabular}{|c|c|c|c|c|c|}
\hline$\underset{(\mathrm{mm})}{\mathrm{D}}$ & $\begin{array}{c}d_{\text {Sauter }} \\
(\mathrm{mm})\end{array}$ & $\underset{\left(\mathrm{kg} / \mathrm{m}^{3}\right)}{\rho_{\mathrm{p}}}$ & $\underset{(\mathrm{v} / \mathrm{v})}{\mathrm{C}}$ & $\Psi$ & $\begin{array}{c}V_{c} \\
(\mathrm{~m} / \mathrm{s})\end{array}$ \\
\hline \multirow{3}{*}{25,4} & \multirow{6}{*}{0,265} & 1.226 & 0,14 & \multirow{6}{*}{0,810} & 1,3 \\
\hline & & 1.326 & 0,20 & & 1,5 \\
\hline & & 1.444 & 0,27 & & 1,8 \\
\hline \multirow{3}{*}{50,8} & & 1.226 & 0,14 & & 1,7 \\
\hline & & 1.326 & 0,20 & & 1,9 \\
\hline & & 1.444 & 0,27 & & 2,0 \\
\hline \multirow{3}{*}{25,4} & \multirow{6}{*}{0,132} & 1.226 & 0,14 & \multirow{6}{*}{0,800} & 1,1 \\
\hline & & 1.326 & 0,20 & & 1,2 \\
\hline & & 1.444 & 0,27 & & 1,4 \\
\hline \multirow{3}{*}{50,8} & & 1.226 & 0,14 & & 1,3 \\
\hline & & 1.326 & 0,20 & & 1,5 \\
\hline & & 1.444 & 0,27 & & 1,7 \\
\hline
\end{tabular}

Nas Tabelas 4.1-4.3, quando se compara $\mathrm{V}_{\mathrm{C}}$ com a densidade da polpa, é possível observar que, para um mesmo diâmetro de tubulação, partículas mais densas (hematita>apatita>quartzo) demandam maior velocidade de fluxo para se atingir a condição de leito móvel $\left(\mathrm{V}_{\mathrm{C}}\right)$.

Nesta tese, os experimentos de bombeamento focaram a determinação experimental de $V_{C}$, embora a literatura utilize a velocidade de deposição $\left(V_{D}\right)$ para o propósito de modelamento. Cabe aqui relembrar que $V_{D}$ é a velocidade de fluxo sob a qual ocorre a indesejada formação de leito fixo no fundo da tubulação. Por outro lado, quando se projeta um sistema de bombeamento, buscando escolher uma velocidade de fluxo $(\mathrm{V})$ operacional baseada em algum modelo da literatura, a prática aconselha somar ao valor de $V_{D}$ previsto por tal modelo, usualmente um incremento de $0,5 \mathrm{~m} / \mathrm{s}$ (WASP; 1977 WILSON et al, 2006). Procedendo deste modo, 
evita-se a formação de leito fixo e se favorece a formação de leito móvel. Tal recomendação não seria necessária se $V_{C}$, ao invés de $V_{D}$, alimentasse os modelos. Daí a decisão de determinar $V_{C}$ ao invés de $V_{D}$ nesta tese.

É possível confrontar os resultados de $V_{C}$ obtidos através do sistema experimental desta tese com valores de $V_{D}$ previstos por quatro modelos clássicos da literatura corrente: Wilson e Judge (1976), Wasp e Slatter (2004), Turian (1987) e Schiller e Herbich (1991). É importante ressaltar que, de acordo com a teoria, $V_{C}$ (condição crítica para formação de leito móvel) é ligeiramente superior a $V_{D}$ (formação de leito fixo). Esta comparação se fez necessária para encontrar, inicialmente, quais modelos reportados pela literatura melhor refletiam a realidade experimental desta tese.

Os valores de $V_{C}$ (determinados nesta tese), quando comparados aos valores de $V_{D}$ (previstos pelos diferentes modelos), permitiram calcular a diferença percentual $(\Delta \%)$ existente entre ambos. Estas informações são apresentadas nas Tabelas 4.4-4.8, onde se verifica que:

a) Todos os valores de $V_{D}$ previstos pelos modelos apresentaram magnitude inferior aos de $\mathrm{V}_{\mathrm{C}}$ determinados experimentalmente nesta tese, o que era de se esperar;

b) O Modelo de Wilson e Judge (Tabela 4.4) produziu $\Delta \%$ que cresce em função da concentração volumétrica de sólidos, além de apresentar os menores desvios $(\Delta \%)$, sugerindo que tal modelo é o que melhor retrata as condições experimentais adotadas nesta tese. O menor desvio encontrado foi de $\Delta=1 \%$ para o concentrado de hematita que continha partículas mais finas $\left(d_{\text {Sauter }}=0,163 \mathrm{~mm}\right)$, na concentração volumétrica de $8 \%$, em duto de $50,8 \mathrm{~mm}$;

c) O Modelo de Wasp e Slatter (Tabela 4.5) apresenta $\Delta \%$ decrescente em função da concentração volumétrica de sólidos. O menor desvio foi de $\Delta=2 \%$ para polpas de quartzo que continham partículas de maior diâmetro $\left(d_{\text {Sauter }}=0,265 \mathrm{~mm}\right)$, em dutos de 25,4mm;

d) O Modelo de Turian (Tabela 4.6), assim como o Modelo de Wilson e Judge, produziu $\Delta \%$ crescente em função da concentração volumétrica de sólidos. $O$ menor desvio foi de $\Delta=9,2 \%$, que foi obtido para o concentrado de hematita, 
com partículas de menor diâmetro $\left(d_{\text {Sauter }}=0,163 \mathrm{~mm}\right)$, em dutos de $50,8 \mathrm{~mm}$ com polpa exibindo concentração volumétrica de $8 \%$;

e) O Modelo de Schiller e Herbich (Tabela 4.7) foi o que apresentou os maiores desvios dentre os modelos submetidos à comparação. O menor desvio foi de $\Delta=47,4 \%$, o que sinaliza sua inadequação às condições experimentais adotadas nesta tese;

f) Calculando a média dos desvios obtidos por cada um dos quatro modelos, chega-se aos valores da Tabela 4.8, onde se verifica que a abordagem de Wilson e Judge foi aquela que propiciou as menores diferenças $(\Delta \%)$ entre $V_{C}$ experimental de $V_{D}$ previsto. Por isto, o modelo proposto por esta tese (Capítulo 5) adotará a mesma abordagem que Wilson e Judge utilizaram para tornar adimensional o diâmetro do tubo e das partículas. Para isto, substituise o coeficiente de arraste pelo fator de esfericidade $(\Psi)$ das partículas. A fácil determinação das variáveis propostas no modelo de Wasp e Slatter, e a base de dados obtida na indústria, reforçam o uso do modelo proposto pelos autores, tendo em vista o desvio médio aceitável em relação aos dados experimentais $\left(\mathrm{V}_{\mathrm{C}}\right)$ desta tese. 
Tabela 4.4- Desvios para a velocidade crítica em relação aos valores previstos por Wilson e Judge (1976).

\begin{tabular}{|c|c|c|c|c|}
\hline Amostra & $\begin{array}{l}\text { Diâmetro médio } \\
\text { de Sauter }(\mu \mathrm{m})\end{array}$ & $\begin{array}{c}\text { Concentração } \\
(\mathrm{v} / \mathrm{v})\end{array}$ & $\begin{array}{l}\text { Diâmetro do } \\
\text { tubo }(m)\end{array}$ & Desvio (\%) \\
\hline \multirow{4}{*}{ Quartzo } & 265 & $\begin{array}{l}14 \\
20 \\
27\end{array}$ & \multirow{2}{*}{25,4} & $\begin{array}{c}3,3 \\
13,2 \\
21,5\end{array}$ \\
\hline & 132 & $\begin{array}{l}14 \\
20 \\
27\end{array}$ & & $\begin{array}{l}18,3 \\
37,4 \\
49,0\end{array}$ \\
\hline & 265 & $\begin{array}{l}14 \\
20 \\
27\end{array}$ & \multirow{2}{*}{50,8} & $\begin{array}{l}14,4 \\
30,5 \\
39,8\end{array}$ \\
\hline & 132 & $\begin{array}{l}14 \\
20 \\
27\end{array}$ & & $\begin{array}{l}20,2 \\
47,9 \\
58,5\end{array}$ \\
\hline \multirow{4}{*}{$\begin{array}{c}\text { Concentrado de } \\
\text { apatita }\end{array}$} & 295 & $\begin{array}{l}12 \\
18 \\
24\end{array}$ & \multirow{2}{*}{25,4} & $\begin{array}{l}15,5 \\
24,5 \\
46,6\end{array}$ \\
\hline & 151 & $\begin{array}{l}12 \\
18 \\
24\end{array}$ & & $\begin{array}{c}7,7 \\
20,3 \\
43,5\end{array}$ \\
\hline & 295 & $\begin{array}{l}12 \\
18 \\
24\end{array}$ & \multirow{2}{*}{50,8} & $\begin{array}{l}16,5 \\
19,0 \\
30,7\end{array}$ \\
\hline & 151 & $\begin{array}{l}12 \\
18 \\
24\end{array}$ & & $\begin{array}{l}24,5 \\
58,8 \\
64,0\end{array}$ \\
\hline \multirow{4}{*}{$\begin{array}{l}\text { Concentrado de } \\
\text { hematita }\end{array}$} & 336 & $\begin{array}{c}8 \\
12 \\
17\end{array}$ & \multirow{2}{*}{25,4} & $\begin{array}{c}6,6 \\
14,4 \\
21,7\end{array}$ \\
\hline & 163 & $\begin{array}{c}8 \\
12 \\
17\end{array}$ & & $\begin{array}{l}25,5 \\
37,0 \\
43,5\end{array}$ \\
\hline & 336 & $\begin{array}{c}8 \\
12 \\
17\end{array}$ & \multirow{2}{*}{50,8} & $\begin{array}{c}1,0 \\
4,4 \\
13,5\end{array}$ \\
\hline & 163 & $\begin{array}{c}8 \\
12 \\
17\end{array}$ & & $\begin{array}{c}1,3 \\
13,9 \\
18,5\end{array}$ \\
\hline
\end{tabular}


Tabela 4.5- Desvios para a velocidade crítica em relação aos valores previstos por Wasp e Slatter (2004).

\begin{tabular}{|c|c|c|c|c|}
\hline Amostra & $\begin{array}{l}\text { Diâmetro médio } \\
\text { de Sauter }(\mu \mathrm{m})\end{array}$ & $\begin{array}{c}\text { Concentração } \\
(\mathbf{v} / \mathbf{v})\end{array}$ & $\begin{array}{c}\text { Diâmetro do } \\
\text { tubo (mm) }\end{array}$ & Desvio (\%) \\
\hline \multirow{4}{*}{ Quartzo } & 265 & $\begin{array}{l}14 \\
20 \\
27\end{array}$ & \multirow{2}{*}{25,4} & $\begin{array}{c}14,5 \\
7,5 \\
2,0\end{array}$ \\
\hline & 132 & $\begin{array}{l}14 \\
20 \\
27\end{array}$ & & $\begin{array}{l}24,5 \\
25,0 \\
16,5\end{array}$ \\
\hline & 265 & $\begin{array}{l}14 \\
20 \\
27\end{array}$ & \multirow{2}{*}{50,8} & $\begin{array}{l}52,0 \\
50,0 \\
37,3\end{array}$ \\
\hline & 132 & $\begin{array}{l}14 \\
20 \\
27\end{array}$ & & $\begin{array}{l}52,2 \\
47,6 \\
35,5\end{array}$ \\
\hline \multirow{4}{*}{$\begin{array}{l}\text { Concentrado de } \\
\text { apatita }\end{array}$} & 295 & $\begin{array}{l}12 \\
18 \\
24\end{array}$ & \multirow{2}{*}{25,4} & $\begin{array}{l}37,3 \\
26,5 \\
21,4\end{array}$ \\
\hline & 151 & $\begin{array}{l}12 \\
18 \\
24\end{array}$ & & $\begin{array}{l}24,1 \\
19,4 \\
25,5\end{array}$ \\
\hline & 295 & $\begin{array}{l}12 \\
18 \\
24\end{array}$ & \multirow{2}{*}{50,8} & $\begin{array}{l}67,4 \\
47,4 \\
41,3\end{array}$ \\
\hline & 151 & $\begin{array}{l}12 \\
18 \\
24\end{array}$ & & $\begin{array}{l}72,4 \\
58,5 \\
43,0\end{array}$ \\
\hline \multirow{4}{*}{$\begin{array}{l}\text { Concentrado de } \\
\text { hematita }\end{array}$} & 336 & $\begin{array}{c}8 \\
12 \\
17\end{array}$ & \multirow{2}{*}{25,4} & $\begin{array}{l}49,4 \\
46,4 \\
39,1\end{array}$ \\
\hline & 163 & $\begin{array}{c}8 \\
12 \\
17\end{array}$ & & $\begin{array}{l}72,7 \\
70,1 \\
61,0\end{array}$ \\
\hline & 336 & $\begin{array}{c}8 \\
12 \\
17\end{array}$ & \multirow{2}{*}{50,8} & $\begin{array}{l}62,2 \\
69,4 \\
48,4\end{array}$ \\
\hline & 163 & $\begin{array}{c}8 \\
12 \\
17\end{array}$ & & $\begin{array}{l}67,8 \\
71,2 \\
49,7\end{array}$ \\
\hline
\end{tabular}


Tabela 4.6- Desvios para a velocidade crítica em relação aos valores previstos por Turian (1987).

\begin{tabular}{|c|c|c|c|c|}
\hline Amostra & $\begin{array}{c}\text { Diâmetro médio } \\
\text { de Sauter }(\mu \mathrm{m})\end{array}$ & $\begin{array}{c}\text { Concentração } \\
(\mathbf{v} / \mathbf{v})\end{array}$ & $\begin{array}{c}\text { Diâmetro do } \\
\text { tubo (mm) }\end{array}$ & Desvio (\%) \\
\hline \multirow{4}{*}{ Quartzo } & 265 & $\begin{array}{l}14 \\
20 \\
27\end{array}$ & \multirow{2}{*}{25,4} & $\begin{array}{l}19,8 \\
28,5 \\
36,0\end{array}$ \\
\hline & 132 & $\begin{array}{l}14 \\
20 \\
27\end{array}$ & & $\begin{array}{l}16,5 \\
31,3 \\
42,4\end{array}$ \\
\hline & 265 & $\begin{array}{l}14 \\
20 \\
27\end{array}$ & \multirow{2}{*}{50,8} & $\begin{array}{l}28,2 \\
43,5 \\
51,4\end{array}$ \\
\hline & 132 & $\begin{array}{l}14 \\
20 \\
27\end{array}$ & & $\begin{array}{l}12,4 \\
23,5 \\
32,5\end{array}$ \\
\hline \multirow{4}{*}{$\begin{array}{l}\text { Concentrado de } \\
\text { apatita }\end{array}$} & 295 & $\begin{array}{l}12 \\
18 \\
24\end{array}$ & \multirow{2}{*}{25,4} & $\begin{array}{l}34,4 \\
40,0 \\
52,0\end{array}$ \\
\hline & 151 & $\begin{array}{l}12 \\
18 \\
24\end{array}$ & & $\begin{array}{l}11,2 \\
21,5 \\
63,0\end{array}$ \\
\hline & 295 & $\begin{array}{l}12 \\
18 \\
24\end{array}$ & \multirow{2}{*}{50,8} & $\begin{array}{l}30,2 \\
30,5 \\
41,2\end{array}$ \\
\hline & 151 & $\begin{array}{l}12 \\
18 \\
24\end{array}$ & & $\begin{array}{l}40,0 \\
46,6 \\
49,2\end{array}$ \\
\hline \multirow{4}{*}{$\begin{array}{l}\text { Concentrado de } \\
\text { hematita }\end{array}$} & 336 & $\begin{array}{c}8 \\
12 \\
17\end{array}$ & \multirow{2}{*}{25,4} & $\begin{array}{l}36,3 \\
42,0 \\
45,2\end{array}$ \\
\hline & 163 & $\begin{array}{c}8 \\
12 \\
17\end{array}$ & & $\begin{array}{l}41,3 \\
49,0 \\
50,5\end{array}$ \\
\hline & 336 & $\begin{array}{c}8 \\
12 \\
17\end{array}$ & \multirow{2}{*}{50,8} & $\begin{array}{l}19,5 \\
27,4 \\
31,2\end{array}$ \\
\hline & 163 & $\begin{array}{c}8 \\
12 \\
17\end{array}$ & & $\begin{array}{c}9,2 \\
18,2 \\
18,5\end{array}$ \\
\hline
\end{tabular}


Tabela 4.7- Desvios para a velocidade crítica em relação aos valores preditos por Schiller e Herbich (1991).

\begin{tabular}{|c|c|c|c|c|}
\hline Amostra & $\begin{array}{l}\text { Diâmetro médio } \\
\text { de Sauter }(\mu \mathrm{m})\end{array}$ & $\begin{array}{c}\text { Concentração } \\
(\mathbf{v} / \mathbf{v})\end{array}$ & $\begin{array}{c}\text { Diâmetro do } \\
\text { tubo }(\mathrm{mm})\end{array}$ & Desvio (\%) \\
\hline \multirow{4}{*}{ Quartzo } & 265 & $\begin{array}{l}14 \\
20 \\
27\end{array}$ & \multirow{2}{*}{25,4} & $\begin{array}{l}43,5 \\
50,5 \\
55,5\end{array}$ \\
\hline & 132 & $\begin{array}{l}14 \\
20 \\
27\end{array}$ & & $\begin{array}{r}91,5 \\
113,5 \\
123,1\end{array}$ \\
\hline & 265 & $\begin{array}{l}14 \\
20 \\
27\end{array}$ & \multirow{2}{*}{50,8} & $\begin{array}{l}49,5 \\
56,2 \\
65,4\end{array}$ \\
\hline & 132 & $\begin{array}{l}14 \\
20 \\
27\end{array}$ & & $\begin{array}{l}78,0 \\
91,5 \\
98,5\end{array}$ \\
\hline \multirow{4}{*}{$\begin{array}{c}\text { Concentrado de } \\
\text { apatita }\end{array}$} & 295 & $\begin{array}{l}12 \\
18 \\
24\end{array}$ & \multirow{2}{*}{25,4} & $\begin{array}{l}66,0 \\
69,5 \\
79,8\end{array}$ \\
\hline & 151 & $\begin{array}{l}12 \\
18 \\
24\end{array}$ & & $\begin{array}{r}73,0 \\
84,5 \\
112,0\end{array}$ \\
\hline & 295 & $\begin{array}{l}12 \\
18 \\
24\end{array}$ & \multirow{2}{*}{50,8} & $\begin{array}{l}49,5 \\
47,4 \\
60,0\end{array}$ \\
\hline & 151 & $\begin{array}{l}12 \\
18 \\
24\end{array}$ & & $\begin{array}{l}82,0 \\
85,5 \\
86,4\end{array}$ \\
\hline \multirow{4}{*}{$\begin{array}{l}\text { Concentrado de } \\
\text { hematita }\end{array}$} & 336 & $\begin{array}{c}8 \\
12 \\
17\end{array}$ & \multirow{2}{*}{25,4} & $\begin{array}{l}63,4 \\
67,5 \\
70,4\end{array}$ \\
\hline & 163 & $\begin{array}{c}8 \\
12 \\
17\end{array}$ & & $\begin{array}{l}115,5 \\
115,4 \\
116,5\end{array}$ \\
\hline & 336 & $\begin{array}{c}8 \\
12 \\
17\end{array}$ & \multirow{2}{*}{50,8} & $\begin{array}{l}36,5 \\
44,4 \\
54,6\end{array}$ \\
\hline & 163 & $\begin{array}{c}8 \\
12 \\
17\end{array}$ & & $\begin{array}{l}59,5 \\
70,4 \\
69,4\end{array}$ \\
\hline
\end{tabular}


Tabela 4.8- Desvio médio em relação aos valores de $\mathrm{V}_{\mathrm{C}}$ experimentais e previsto por modelos da literatura corrente.

\begin{tabular}{c|c}
\hline Modelo reportado & Desvio médio, \% \\
\hline Wilson e Judge (1979) & 25,0 \\
\hline Wasp e Slatter (2004) & 38,0 \\
\hline Turian (1987) & 37,0 \\
\hline Schiller e Herbich (1991) & 75,0 \\
\hline
\end{tabular}

\subsection{Gradiente de pressão}

As Figuras 4.1 e 4.2 apresentam a curva da perda de carga por metro de tubo horizontal $(\Delta P / L)$ em função da velocidade média de transporte $(V)$ para polpas minerais de concentrado de apatita em dutos de 25,4mm. A Figura 4.1 traz as partículas de menor diâmetro e a Figura 4.2 apresenta os resultados para as partículas com maior diâmetro. As Figuras 4.3 e 4.4 apresentam as mesmas condições, porém, para dutos de $50,8 \mathrm{~mm}$ de diâmetro. As partículas de concentrado de apatita encerram uma faixa estreita de tamanho e apresentam partículas grossas e seu fluxo dentro do duto é caracterizado como heterogêneo, conforme é possível observar no comportamento das curvas das figuras em questão. Partindo da maior velocidade de fluxo, a perda de carga diminui com a redução de $\mathrm{V}$. A partir de $\mathrm{V}_{\mathrm{C}}$, mesmo com a diminuição da velocidade é notado um aumento da perda de carga, ocasionada pelo acúmulo de sólidos no interior do duto, formando um leito fixo de partículas. Para cada concentração utilizada, as condições de fluxo apresentaram velocidade mínima onde um leito fixo de partículas na base da tubulação era formado, até velocidades maiores, o suficiente para não se observar nenhum depósito de partículas na base dos dutos. O ponto de mínima pressão das Figuras 4.1 até 4.4 apresentam a velocidade crítica de transporte, em que partículas formam um leito móvel na base da tubulação. As Figuras e Tabelas sobre a distribuição de 
sólidos ao longo da seção transversal da tubulação para todas as condições propostas se encontram no Apêndice A.

O perfil de distribuição das partículas no interior dos dutos é apresentado somente para $\mathrm{V}_{\mathrm{C}}$. É possível observar que quanto mais concentrada a polpa mineral melhor a distribuição ao longo da seção transversal, devido ao suporte intergranular das partículas. Também pode ser observado que o efeito da densidade das partículas acarreta uma maior segregação dos sólidos nos dutos, ou seja, quanto maior a densidade dos sólidos maior a segregação. Outro fato de destaque é que o diâmetro de 50,8mm, mesmo com maior $V_{C}$, apresenta maior segregação que o diâmetro de 25,4mm. Doron e Barnea (1993) e Gilles (1993), também discutem tal observação. A turbulência gerada por uma maior magnitude de $V_{C}$ não é suficiente para promover uma melhor distribuição dos sólidos ao longo da seção transversal dos dutos. Assim quanto maior o diâmetro, maior a segregação das partículas.

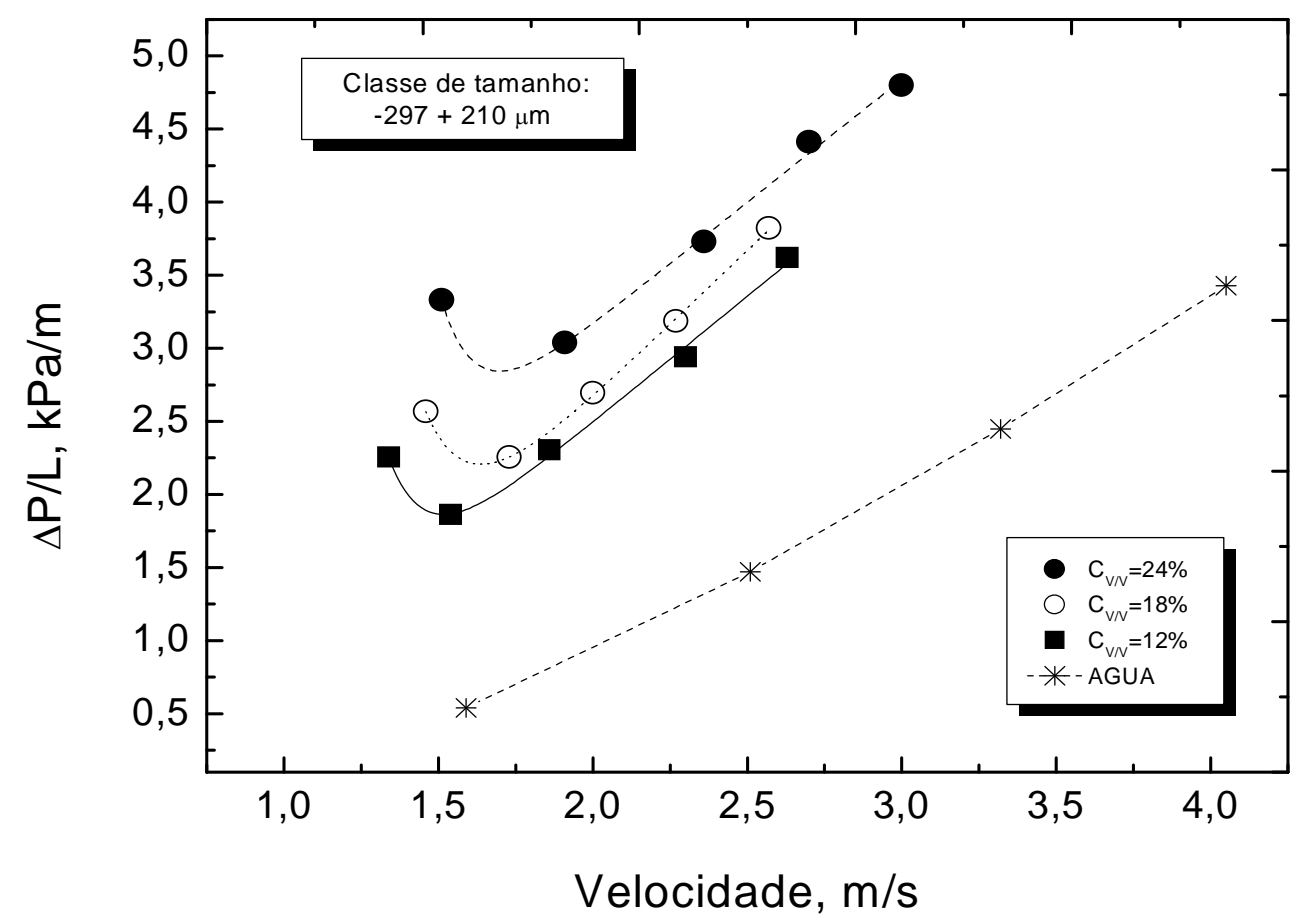

Figura 4.1- Gradiente de pressão em função da velocidade de fluxo para concentrado de apatita em dutos de $25,4 \mathrm{~mm}$ de diâmetro. 


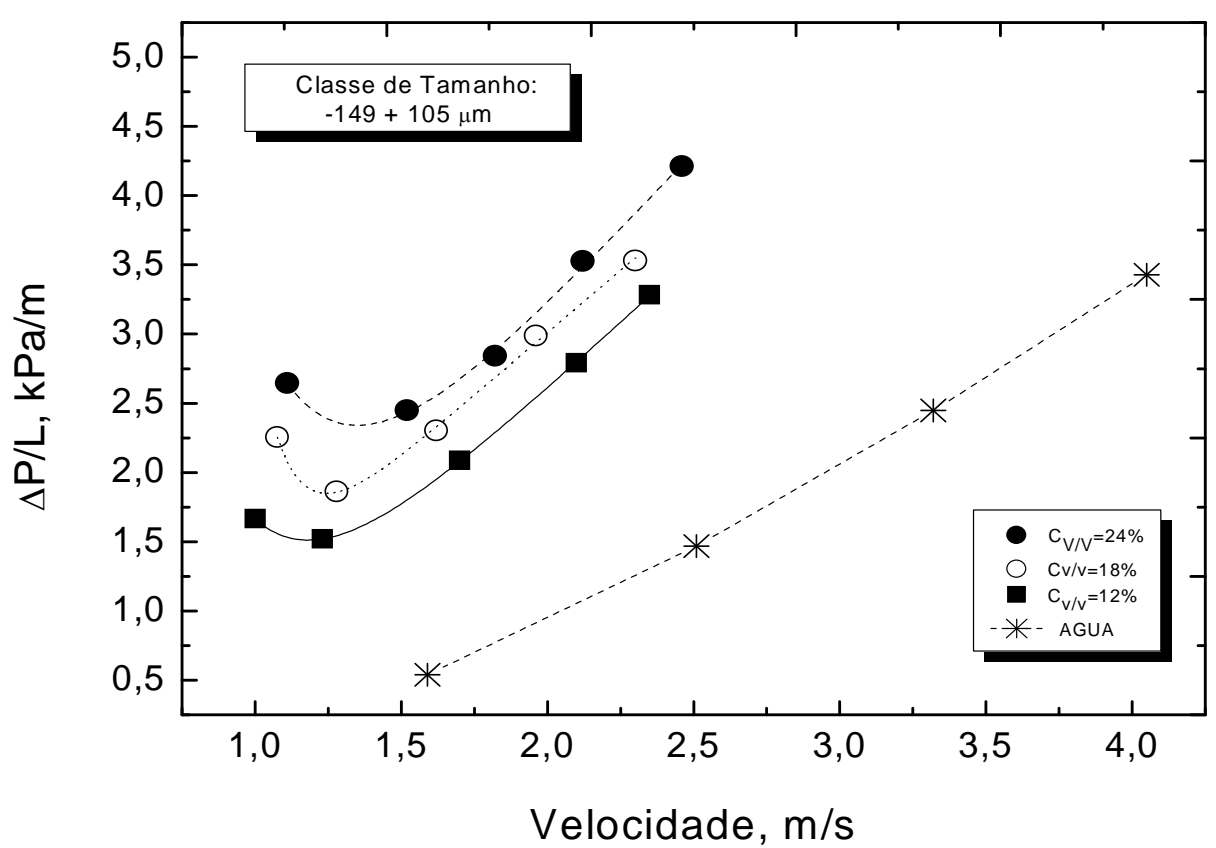

Figura 4.2- Gradiente de pressão em função da velocidade de fluxo para concentrado de apatita em dutos de $25,4 \mathrm{~mm}$ de diâmetro.

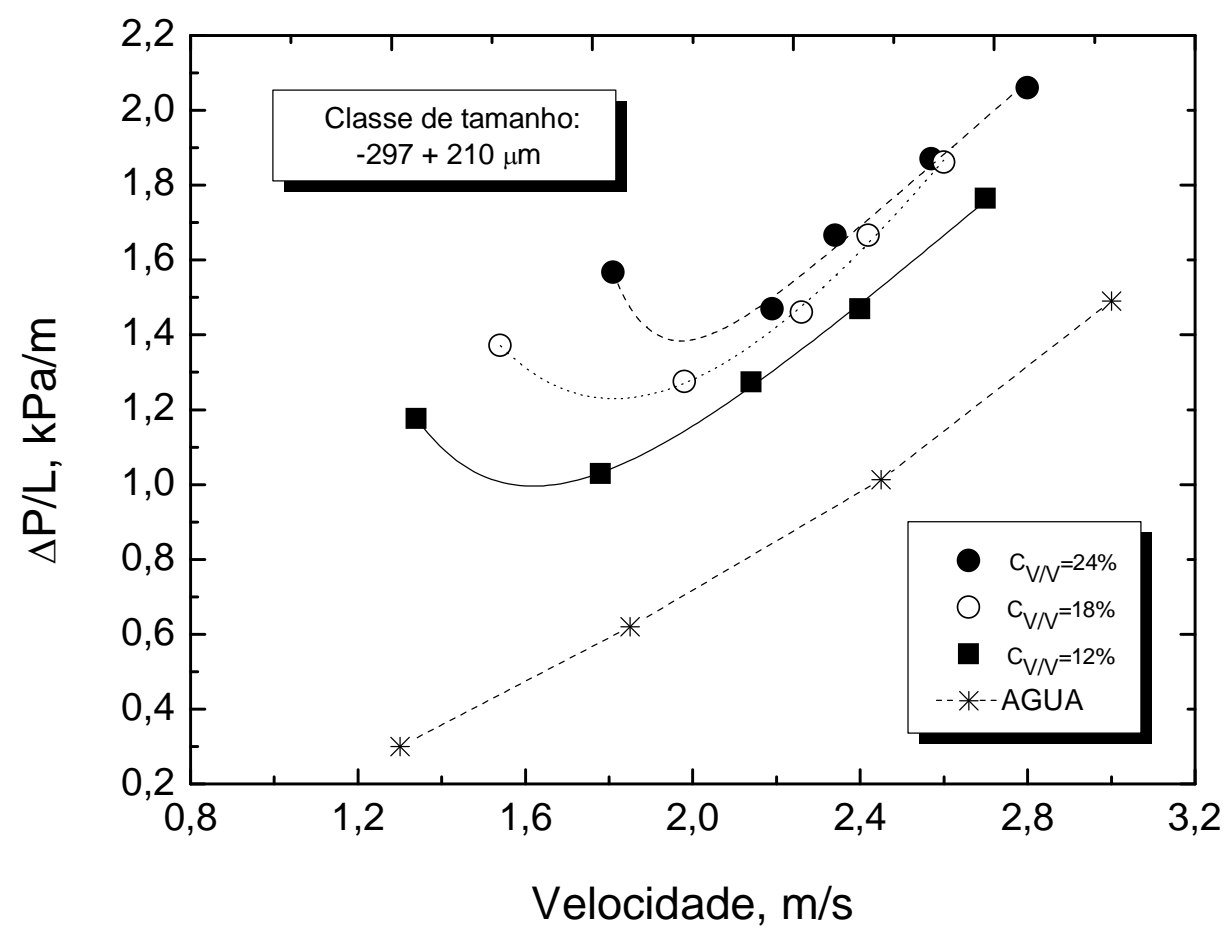

Figura 4.3- Gradiente de pressão em função da velocidade de fluxo para concentrado de apatita em dutos de 50,8mm de diâmetro. 


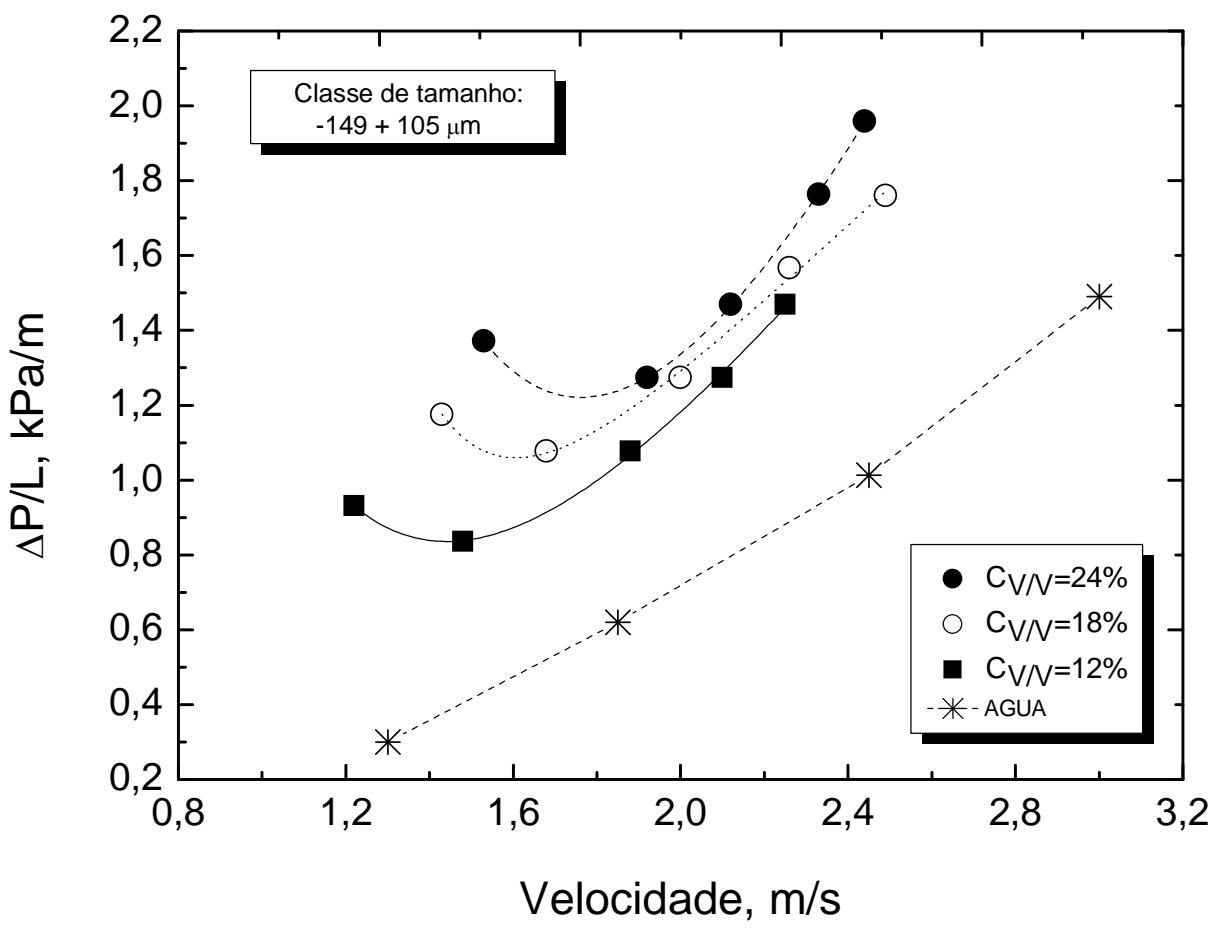

Figura 4.4- Gradiente de pressão em função da velocidade de fluxo para concentrado de apatita em dutos de 50,8mm de diâmetro.

As Figuras 4.5 e 4.6 apresentam o resultado da curva de bombeamento para concentrado de hematita em dutos com diâmetro de 25,4mm. Já as Figuras 4.7 e 4.8 apresentam os resultados para o mesmo material em dutos com $50,8 \mathrm{~mm}$ de diâmetro. A forma da curva caracteriza comportamento heterogêneo de fluxo no interior da tubulação, evidenciado pelo aumento do gradiente de pressão a partir da formação de um leito fixo de partículas na base da mesma, acarretando uma diminuição da área de fluxo da polpa e consequente aumento da pressão mesmo com a diminuição de V. As Figuras do perfil axial da distribuição de sólidos se encontram no Apêndice $\mathrm{A}$ e apresentam a distribuição da concentração de sólidos ao longo da seção transversal do tubo em condições de fluxo para $V_{C}$. Novamente ocorre uma maior segregação da polpa em menores concentrações, devido ao menor contato partícula-partícula. O maior gradiente de pressão, em condições de fluxo para $\mathrm{V}_{\mathrm{C}}$, se dá para partículas grossas em duto com $25,4 \mathrm{~mm}$ de diâmetro e a maior velocidade se apresenta na concentração de $17 \%$ em dutos com 50,8mm de diâmetro. 


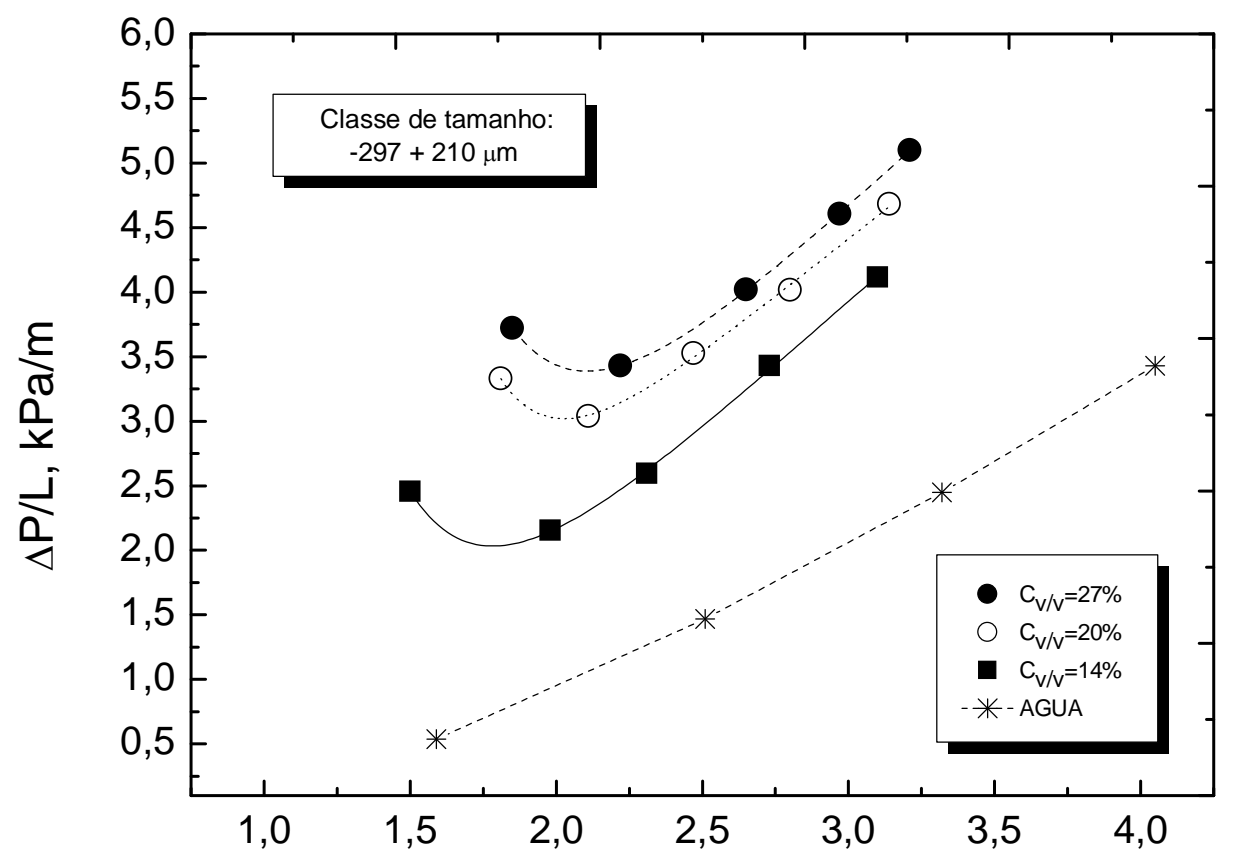

Velocidade, $\mathrm{m} / \mathrm{s}$

Figura 4.5- Gradiente de pressão em função da velocidade de fluxo para concentrado de hematita em dutos de $25,4 \mathrm{~mm}$ de diâmetro.

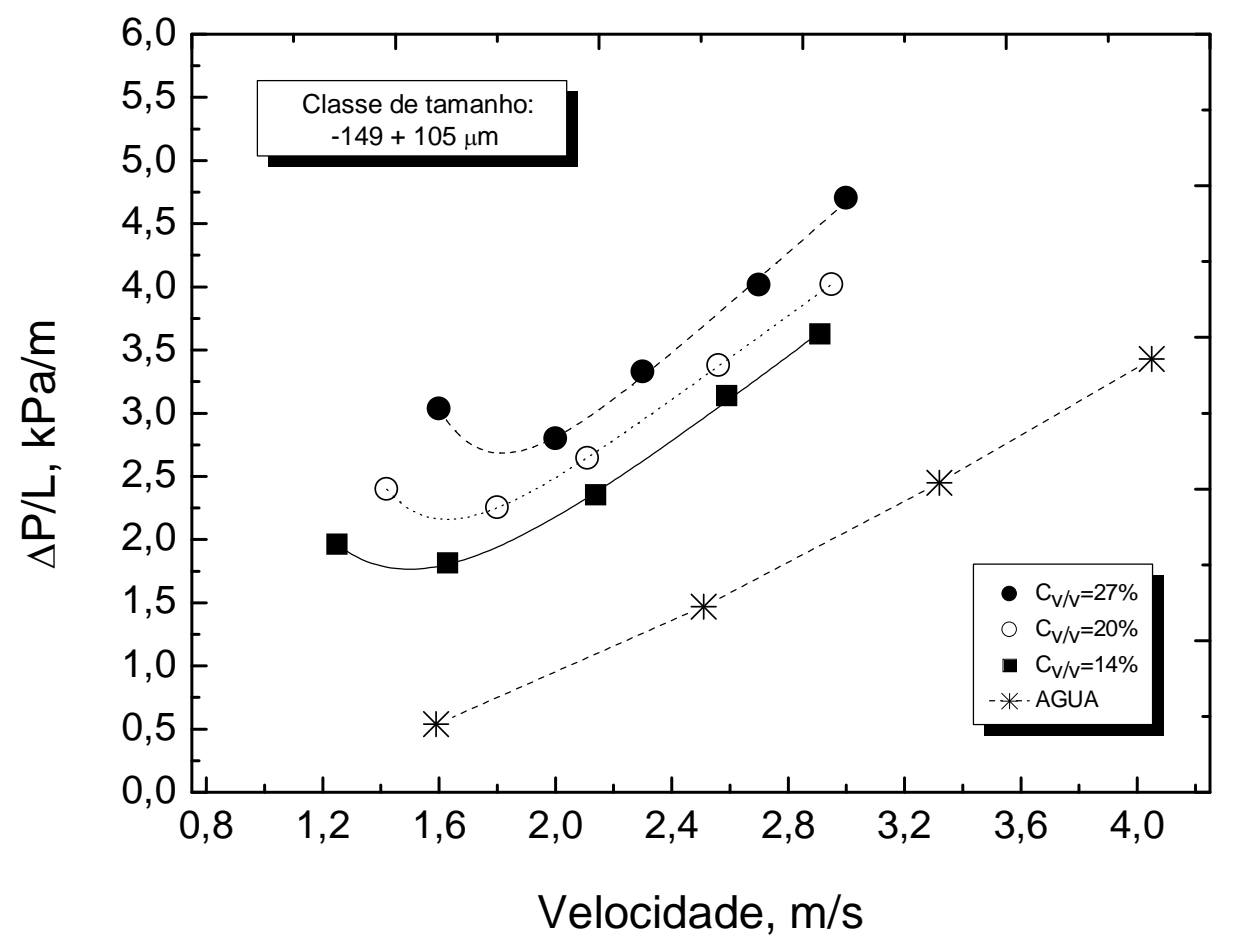

Figura 4.6- Gradiente de pressão em função da velocidade de fluxo para concentrado de hematita em dutos de $25,4 \mathrm{~mm}$ de diâmetro. 


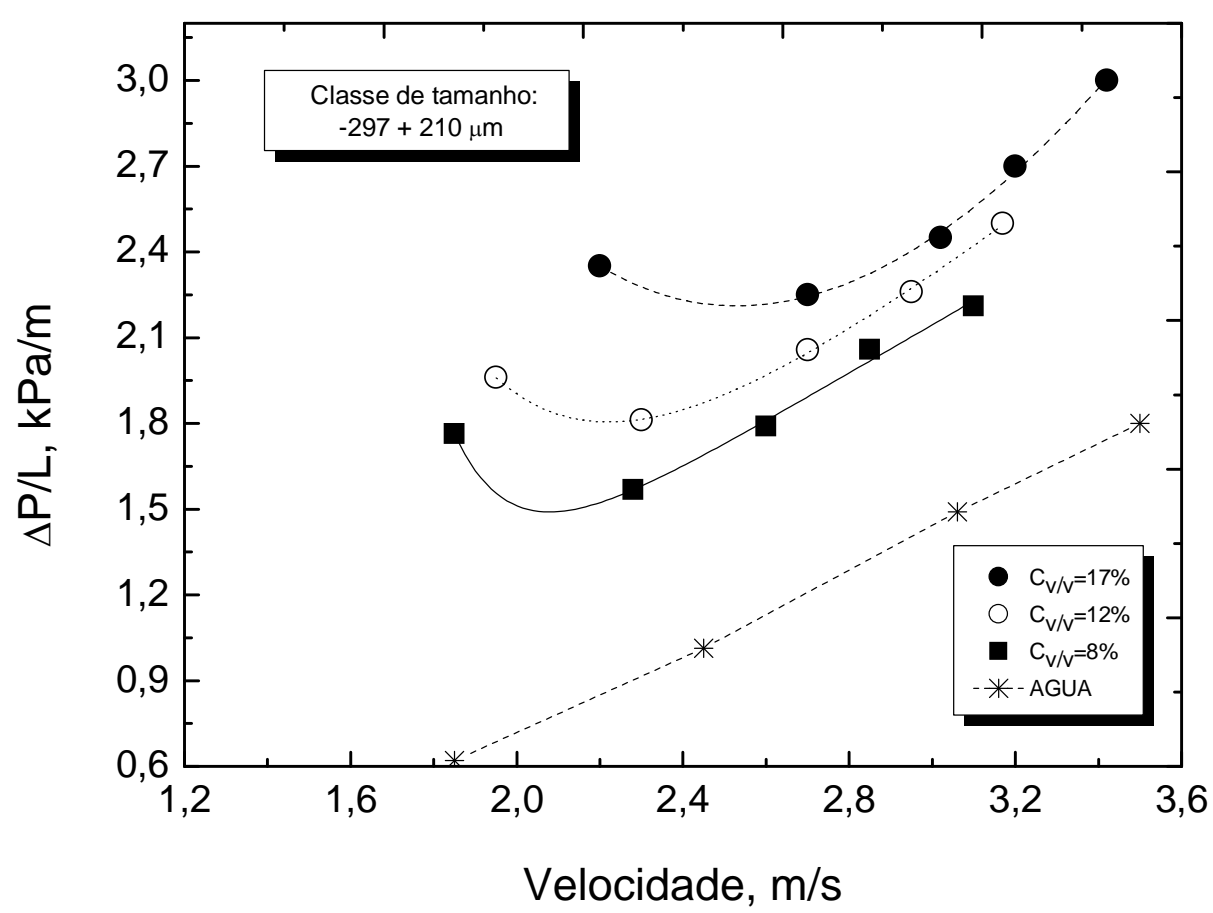

Figura 4.7- Gradiente de pressão em função da velocidade de fluxo para concentrado de hematita em dutos de $50,8 \mathrm{~mm}$ de diâmetro.

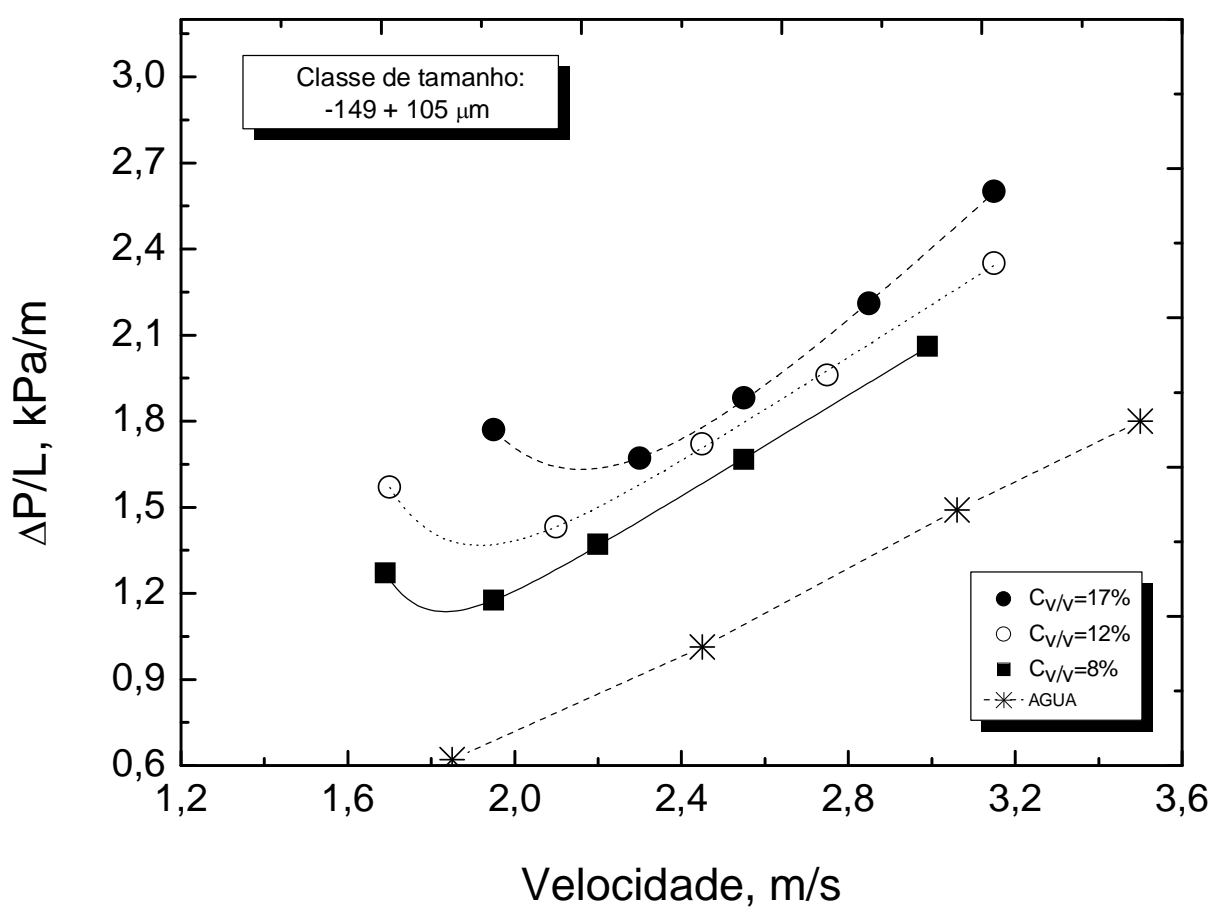

Figura 4.8- Gradiente de pressão em função da velocidade de fluxo para concentrado de hematita em dutos de $50,8 \mathrm{~mm}$ de diâmetro. 
As Figuras 4.9 e 4.10 apresentam o resultado da curva de bombeamento para o quartzo em dutos com diâmetro de 25,4mm. Já as Figuras 4.11 e 4.12 apresentam os resultados para o mesmo material em dutos com 50,8mm de diâmetro. A forma da curva $\Delta P / L$ em função de $V$ também apresenta comportamento heterogêneo, porém menos acentuado como os demais materiais estudados. O maior gradiente de pressão, em condições de fluxo para $\mathrm{V}_{\mathrm{C}}$, se dá para as partículas maiores (0,297+0,249mm) em dutos com $25,4 \mathrm{~mm}$ de diâmetro e a maior velocidade se apresenta na concentração de $27 \%$ em dutos com $50,8 \mathrm{~mm}$ de diâmetro. A magnitude da maior velocidade obtida para o quartzo, conforme ilustrado na Tabela 4.2 , apresenta valor $64 \%$ menor do que a maior $V_{C}$ obtida para hematita.

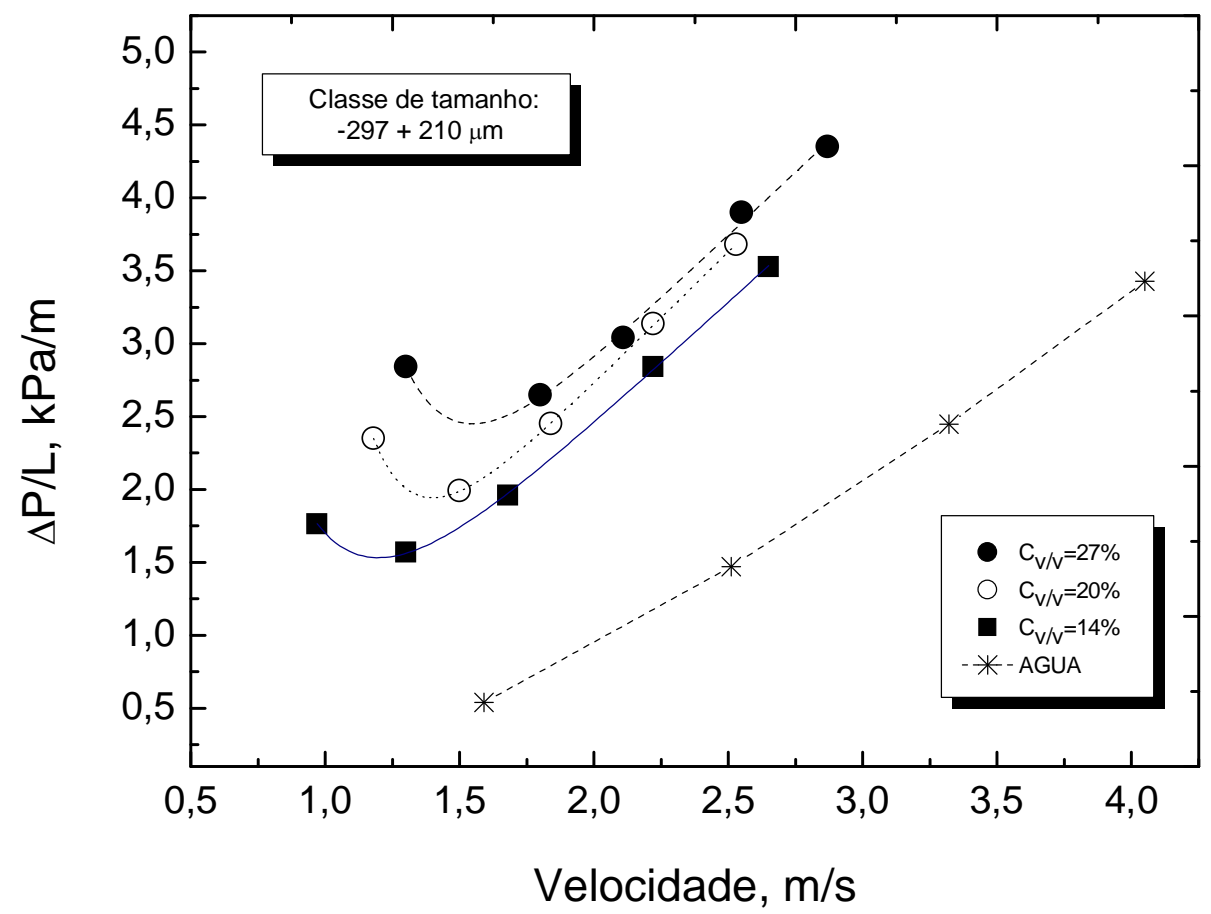

Figura 4.9- Gradiente de pressão em função da velocidade de fluxo para quartzo em dutos de $25,4 \mathrm{~mm}$ de diâmetro. 


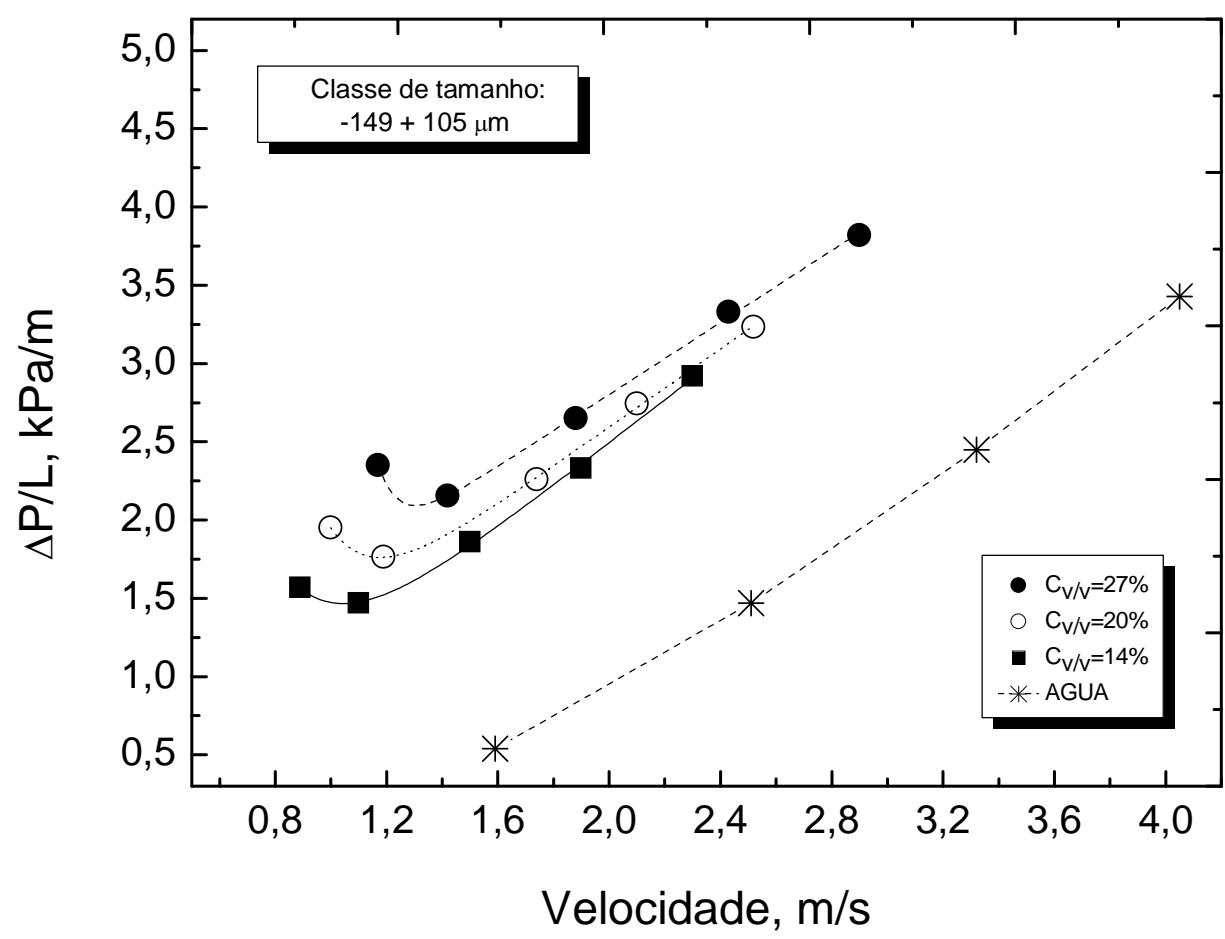

Figura 4.10- Gradiente de pressão em função da velocidade de fluxo para quartzo em dutos de 25,4mm de diâmetro.

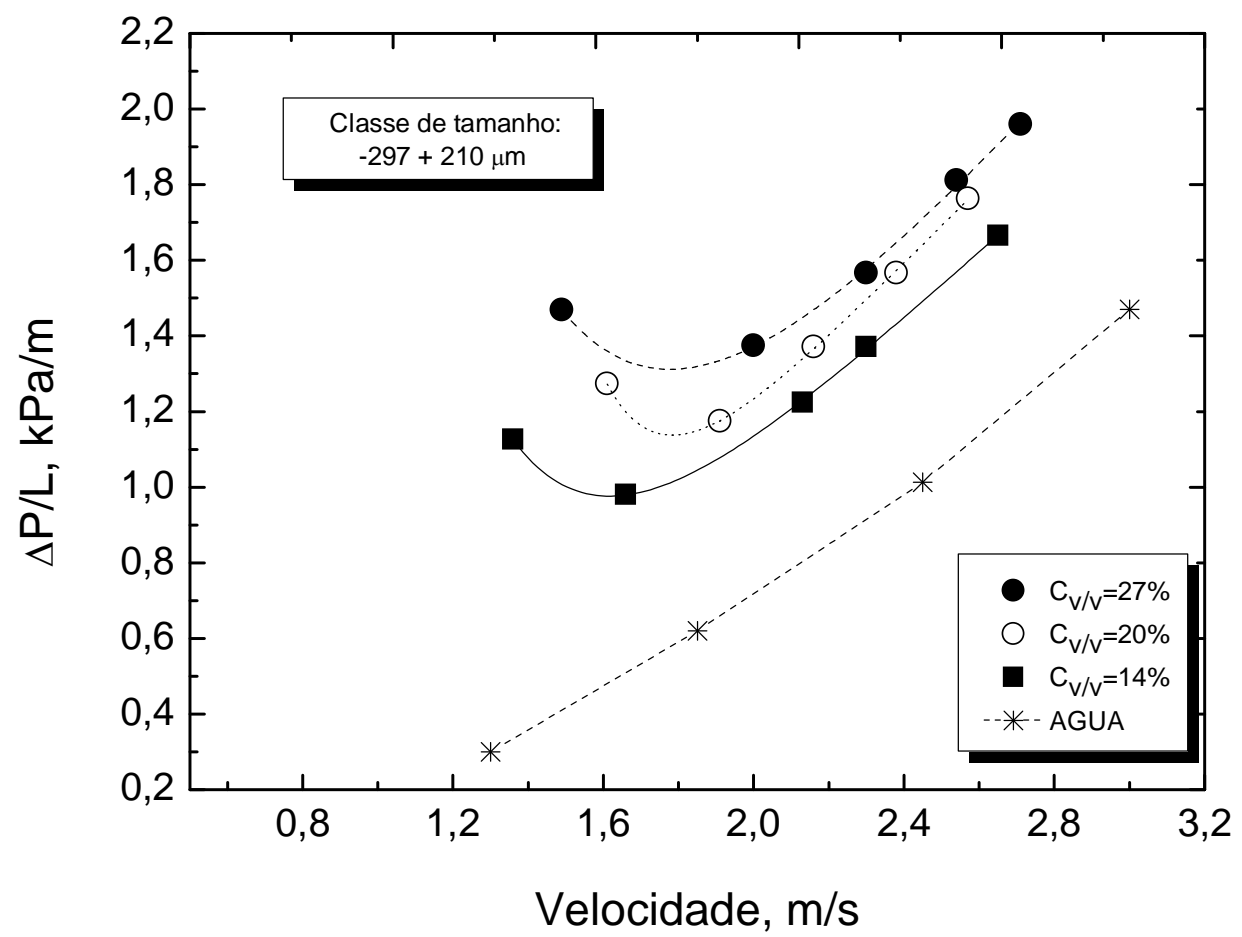

Figura 4.11- Gradiente de pressão em função da velocidade de fluxo para quartzo em dutos de 50,8mm de diâmetro. 


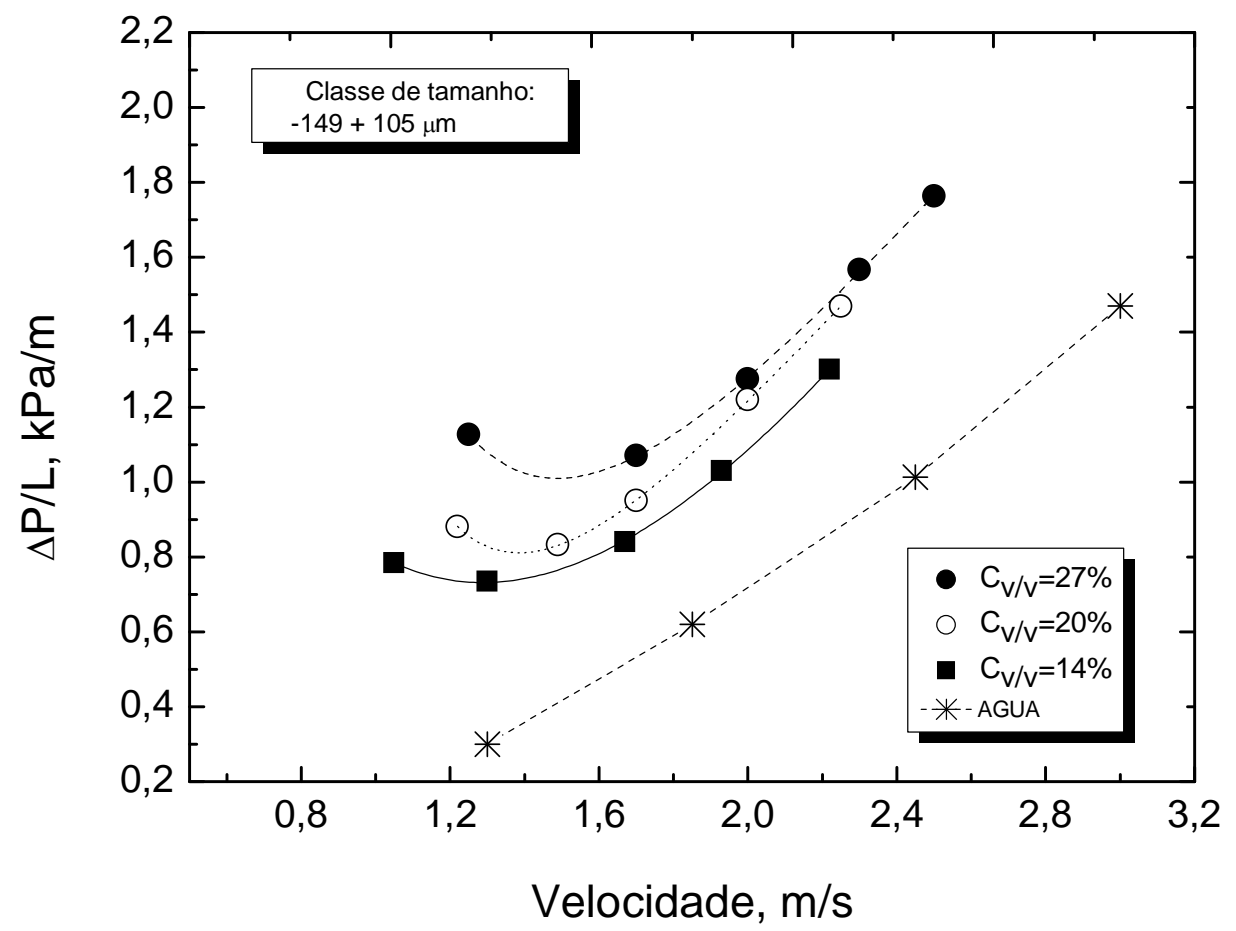

Figura 4.12- Gradiente de pressão em função da velocidade de fluxo para quartzo em dutos de 50,8mm de diâmetro.

A partir da análise das curvas de $\Delta P / L$ em função de $V$ em todas as situações estudadas, apresentaram a maior perda de carga em tubos de $25,4 \mathrm{~mm}$ de diâmetro, revelando a influência do diâmetro neste parâmetro. A magnitude da velocidade crítica apresentou maior valor para tubos de 50,8mm de diâmetro, já que a altura do leito móvel na base do tubo demanda maior velocidade de fluxo para ser transportado. Velocidade acima de $\mathrm{V}_{\mathrm{C}}$ não apresenta leito móvel de partículas, pois a intensidade da turbulência é suficiente para suspender o peso de todas as partículas imersas. Quanto maior a velocidade menor a segregação do fluxo na seção transversal do duto.

As Tabelas que apresentam os dados do gradiente de $\Delta P / L$ em função de $V$ para o concentrado de apatita, hematita e mineral de quartzo são apresentadas no Apêndice B. 


\subsection{Segregação de partículas de hematita nos tubos durante o bombeamento}

A distribuição de sólidos (apatita, hematita e quartzo) ao longo da seção transversal das tubulações de diâmetro de 25,4mm e 50,8mm é apresentada no Apêndice $A$, onde se observa que ocorre maior segregação na tubulação de maior diâmetro. A explicação para este fenômeno reside nas considerações abaixo enfatizadas:

a) As amostragens ao longo do perfil vertical do duto foram realizadas sob condições operacionais que favoreciam a ocorrência de um leito móvel, visto que seu objetivo era o de determinar a velocidade crítica de transporte $\left(\mathrm{V}_{\mathrm{C}}\right)$ da polpa naquelas condições;

b) Nesta condição de fluxo em $V_{C}$, as forças inerciais são muito superiores à gravitacional (Froude $=\frac{v^{2}}{g^{D}}>>1$ ). Deste modo, um fluxo de polpa com velocidade (v) de $1,5 \mathrm{~m} / \mathrm{s}$, correndo em um tubo de $\mathrm{D}=25,4 \mathrm{~mm}$ resulta num número de Froude (Froude $=9$ ) duas vezes maior que aquele relativo ao tubo de $\mathrm{D}=50,8 \mathrm{~mm}$;

c) A magnitude de $V_{C}$ para o tubo de $50,8 \mathrm{~mm}$ é superior à obtida para o tubo de 25,4mm nas mesmas condições operacionais (Seção 4.1). Gilles (1993) pondera que a turbulência gerada por uma maior magnitude de $V_{C}$ não é suficiente para promover uma maior distribuição dos sólidos ao longo da seção transversal. Assim, quanto maior o diâmetro, maior a segregação de massa no perfil vertical do tubo. Esta argumentação encontra respaldo no número de Froude do sistema.

Considerando-se somente a tubulação de maior diâmetro $(50,8 \mathrm{~mm})$, isto é, aquela que exibe maior segregação de massa ao longo do seu perfil vertical, verifica-se no Apêndice A que:

a) Independentemente do mineral estudado, o topo do tubo abriga somente 5$6 \%$ da massa total que passava na seção transversal durante o intervalo de tempo da amostragem; 
b) A base do tubo contém mais de $60 \%$ da massa obtida nas mesmas condições de amostragem. Uma vez que a mesma foi realizada sob condições experimentais que favoreciam o início da formação de um leito móvel $\left(V_{C}\right)$, esta segregação é, de fato, esperada.

Por outro lado, diferentemente dos minerais apatita e quartzo, o mineral hematita ocorre nos itabiritos na forma de placas (hematita especular na Figura 4.13b) ou formas arredondadas (hematita granular na figura 4.13-c). Tal hábito tão diverso se traduz, obviamente, em fator de esfericidade $(\Psi)$ diferente: espera-se que as partículas de hábito especular apresentem um fator de esfericidade muito menor do que as partículas de hábito granular. Nos minérios, devido à ocorrência de partículas com os dois hábitos (e outros intermediários), o fator de esfericidade de uma amostra de concentrado de hematita constitui um valor médio que incorpora as partículas com esfericidade mais baixa (hábito especular) e mais alta (hábito granular).

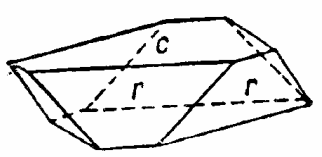

(a)

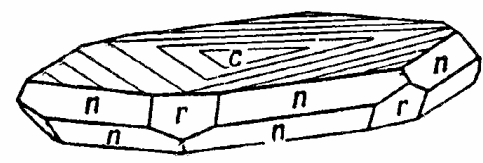

(b)

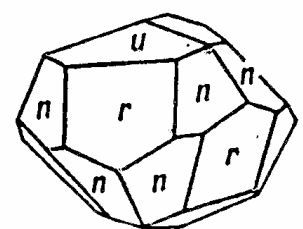

(c)

Figura 4.13 - Hábito das partículas de hematita (Dana, 1978).

Acoplando uma calha distribuidora (Figura 3.14), no ponto de descarga da tubulação, foi possível amostrar a polpa de hematita que fluía na base $(0,2 D)$, meio $(0,5 D)$ e topo $(0,8 D)$ do tubo de diâmetro $D=50,8 \mathrm{~mm}$. Determinando-se a esfericidade do material coletado em cada calha, obtiveram-se os resultados que são apresentados nas Figuras 4.14 e 4.15, onde se observa que o material coletado nas cotas mais altas da tubulação apresentava menor coeficiente de esfericidade do que as partículas situadas na base. Este fenômeno se mostrou ser independente da granulometria das partículas e da concentração volumétrica de sólidos na polpa. Um quadro geral de resultados é apresentado na Tabela 4.9, cujos valores corroboram com esta discussão. 
Tabela 4.9- Esfericidade na seção transversal do duto de 50,8mm.

\begin{tabular}{|c|c|c|c|}
\hline $\begin{array}{c}\text { Classe de tamanho, } \\
\text { Mesh Tyler }\end{array}$ & Concentração, \% & Calha & Esfericidade \\
\hline \multirow{3}{*}{$-48+65$} & \multirow{3}{*}{8} & Base $\left(^{*}\right)$ & 0,55 \\
\hline & & Meio $\left({ }^{\star \star}\right)$ & 0,35 \\
\hline & & Topo $\left({ }^{\star \star \star}\right)$ & 0,25 \\
\hline \multirow{3}{*}{$-48+65$} & \multirow{3}{*}{12} & Base & 0,51 \\
\hline & & Meio & 0,38 \\
\hline & & Topo & 0,20 \\
\hline \multirow{3}{*}{$-48+65$} & \multirow{3}{*}{17} & Base & 0,52 \\
\hline & & Meio & 0,40 \\
\hline & & Topo & 0,22 \\
\hline \multirow{3}{*}{$-100+150$} & \multirow{3}{*}{8} & Base & 0,55 \\
\hline & & Meio & 0,42 \\
\hline & & Topo & 0,30 \\
\hline \multirow{3}{*}{$-100+150$} & \multirow{3}{*}{12} & Base & 0,58 \\
\hline & & Meio & 0,42 \\
\hline & & Topo & 0,33 \\
\hline \multirow{3}{*}{$-100+150$} & \multirow{3}{*}{17} & Base & 0,50 \\
\hline & & Meio & 0,40 \\
\hline & & Topo & 0,27 \\
\hline
\end{tabular}

$\left(^{*}\right) \mathrm{h} / \mathrm{D}=0,2$

$\left({ }^{* \star}\right) \mathrm{h} / \mathrm{D}=0,5$

$\left({ }^{* * *}\right) \mathrm{h} / \mathrm{D}=0,8$

$\mathrm{h}=$ altura do centro de cada seção da calha; $\mathrm{D}=$ diâmetro do duto. 
Além do fator de esfericidade $(\Psi)$, que representa um valor médio de toda a população de partículas que formam uma amostra, fotos do material segregado na base, meio e topo da tubulação foram tiradas em MEV e são apresentadas nas Figuras 4.14-4.16, que corroboram os valores exibidos na Tabela 4.8.

Partículas que se acumularam na base da tubulação, isto é, que foram coletadas na calha A (Figura 4.14), apresentaram fator de esfericidade médio de $\Psi=0,54 \pm 0,03$. Também se verifica em tal figura a predominância de partículas arredondadas, embora seja observada uma partícula de hábito placoide (hematita especular). Interessante observar um agregado de partículas de magnetita, haja vista as bi pirâmides evidentes. Através do $\mathrm{MEV}$, observa-se que o material de coloração brilhante possui maior peso molecular, indicando a presença de ferro. $O$ material mais cinzento e opaco sinaliza a presença de quartzo.

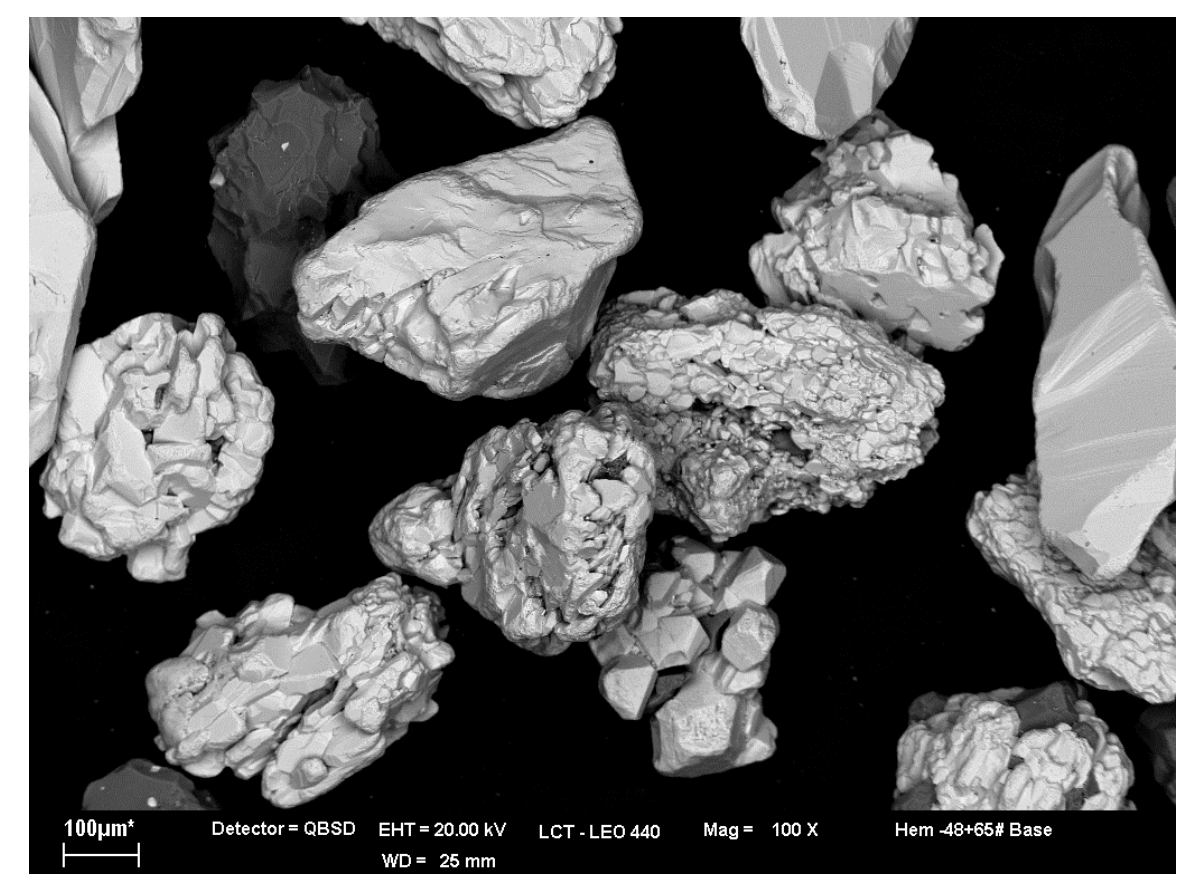

Figura 4.14-Concentrado de hematita obtido no fluxo da calha da base.

Partículas que se acumularam no meio da tubulação (Calha B) são exibidas na Figura 4.15. Elas exibem um fator de esfericidade médio de $\Psi=0,40 \pm 0,03$, que é mais baixo do que aquele que foi determinado para partículas da base. Ressalta-se na Figura 4.15 a presença de partículas alongadas de hematita (material de 
coloração mais brilhante) e arredondadas de quartzo (material de coloração mais cinza), além de uma maior presença desse último mineral quartzo.

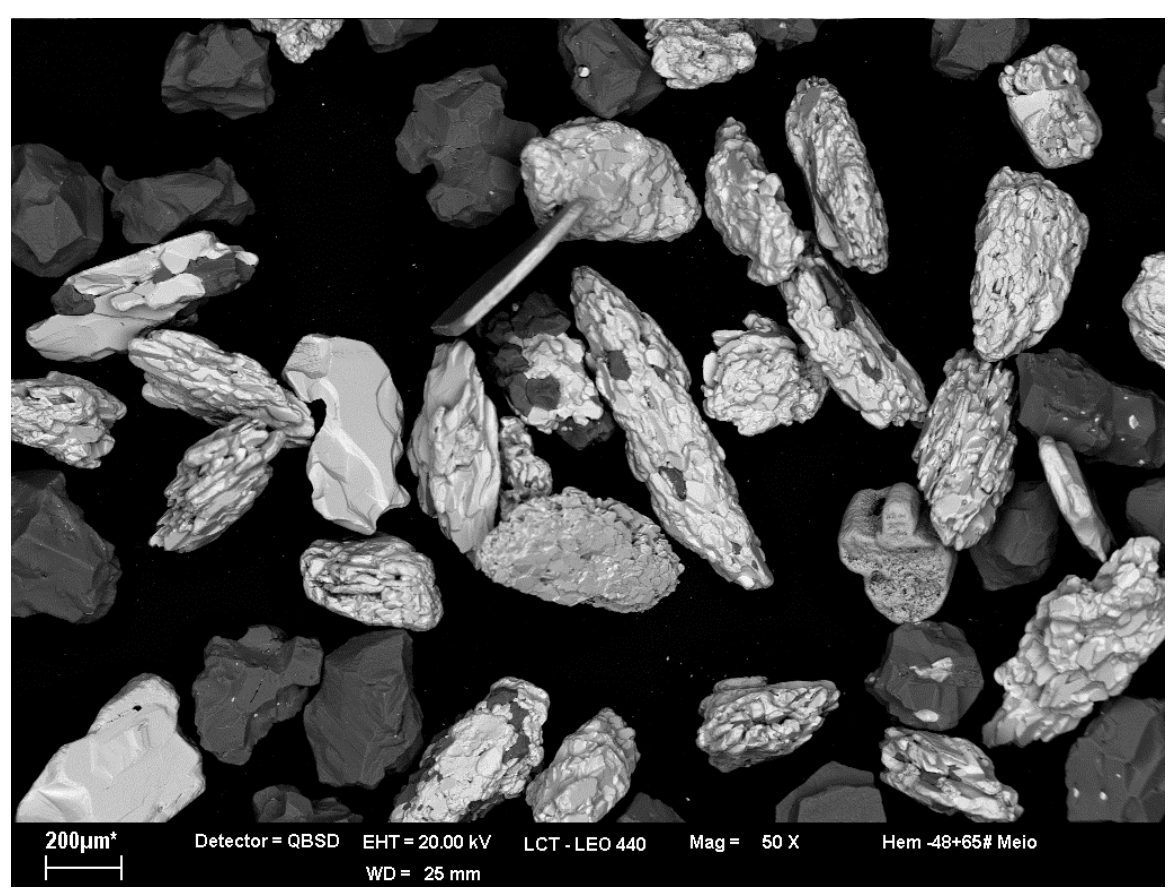

Figura 4.15-Concentrado de hematita obtido no fluxo da calha do meio.

O material que foi coletado no topo da tubulação (Calha C) é ilustrado na Figura 4.16, onde se observa a predominância de partículas alongadas e placóides de hematita. Este material exibe fator de esfericidade médio de $\Psi=0,26 \pm 0,05$. Partículas de quartzo, todavia, apresentam hábito mais arredondado.

No Capítulo 5 desta tese, ao tentar modelar o sistema, adotou-se um fator de esfericidade para as partículas de hematita na faixa de $0,39<\psi<0,40$, que reflete a esfericidade do material que alimentou os experimentos de bombeamento, cujas características químicas, mineralógicas e granulométricas foram apresentadas e discutidas no Capítulo 3. O valor de esfericidade que alimentou o modelo, todavia, constitui um valor médio entre as partículas especulares e granulares de hematita que compõem a amostra (além das partículas mais arredondadas de quartzo). $O$ experimento de bombeamento, por si, todavia, permitiu uma segregação de forma que, de algum modo, fragiliza o modelamento. 


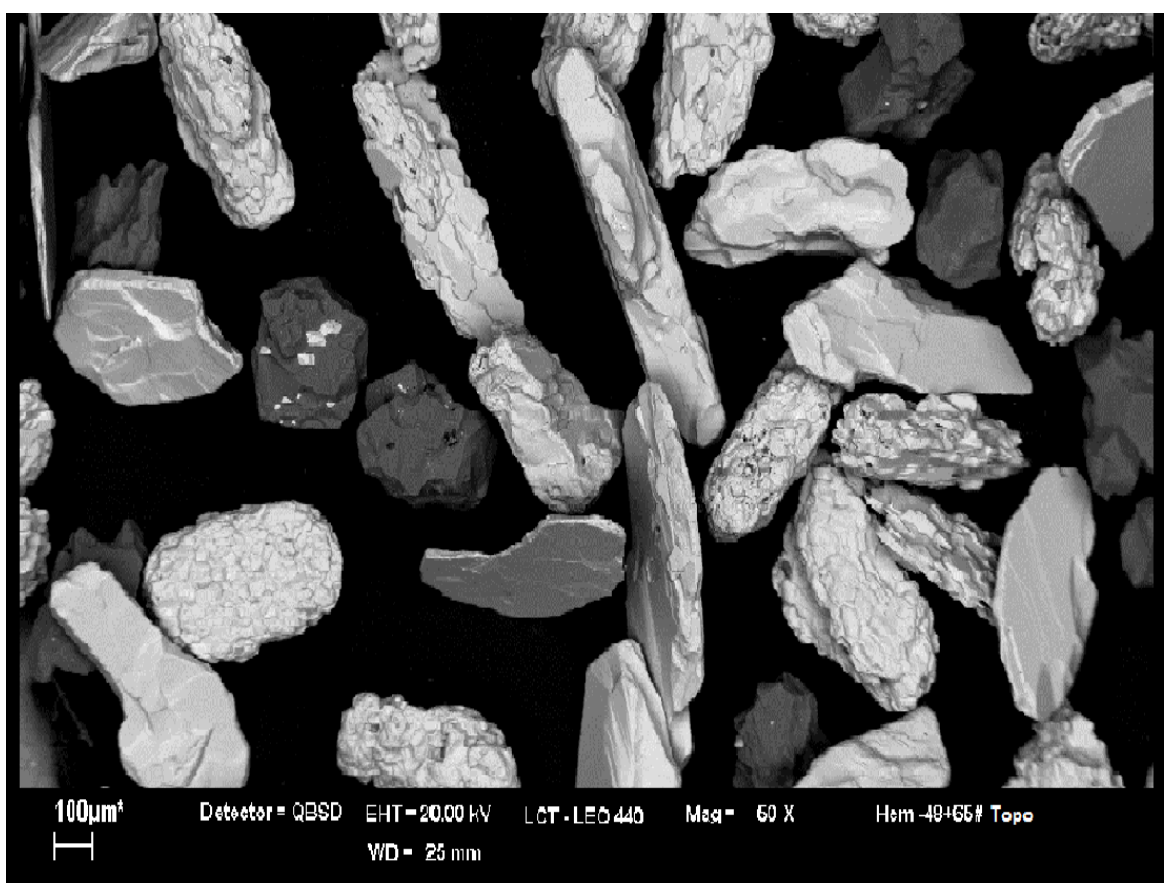

Figura 4.16-Concentrado de hematita obtido no fluxo da calha do topo.

Quando se realizaram os experimentos de bombeamento com concentrado de hematita, embora se suspeitasse da ocorrência de segregação de partículas pela forma na seção vertical da tubulação, não foi possível obter um concentrado que exibisse somente partículas placoides (hábito lamelar) ou somente arredondadas (granulares). Isto porque a preparação de polpas de hematita com $50 \%$ de sólidos em massa (ou 17\% em volume) demandava $40 \mathrm{~kg}$ de sólidos. Infelizmente, não havia disponibilidade de um material com estas características específicas no momento dos experimentos. De fato, a realidade dos concentrados de hematita produzidos a partir dos itabiritos do Quadrilátero Ferrífero é a da ocorrência simultânea de hábito granular e lamelar. $O$ material utilizado nos experimentos refletiu esta realidade e trouxe "insights" para projetos de bombeamento.

O trabalho de modelagem reportado no Capítulo 5 também é influenciado pelo fato do concentrado de hematita não ser puro, isto é, exibir de 12,9 a $15,1 \%$ de $\mathrm{SiO}_{2}$ (Tabela 3.4), o que permite inferir um teor de quartzo na faixa de $13-15 \%$. A ocorrência de outros silicatos é mínima, haja vista o baixíssimo teor de $\mathrm{Al}_{2} \mathrm{O}_{3}$ na mesma tabela. Deste modo, a cada 100 partículas que alimentavam os experimentos de bombeamento, numa inferência grosseira, 15 delas eram de 
quartzo. A massa específica do material utilizado nos experimentos (concentrado de hematita) reflete esta composição, haja vista que ficou na faixa de $4.600-4.700 \mathrm{~kg} / \mathrm{m}^{3}$ (Tabela 3.3), que é composto de hematita $\left(5.000 \mathrm{~kg} / \mathrm{m}^{3}<\right.$ densidade $\left.<5200 \mathrm{~kg} / \mathrm{m}^{3}\right)$ e quartzo $\left(2.650 \mathrm{~kg} / \mathrm{m}^{3}\right)$ (Betejtin, 1977). Tamanha diferença de massa específica entre as duas fases mineralógicas que compõem o material utilizado nos experimentos provoca uma segregação de partículas mais "leves" (quartzo) no topo, assim como mais "pesadas" (hematita) na base. 


\section{CAPÍTULO 5}

\section{RESULTADOS E DISCUSSÕES: MODELAGEM DA VELOCIDADE CRÍTICA $\left(\mathrm{V}_{\mathrm{C}}\right)$}

Nas seções de 5.1 a 5.4 deste capítulo são apresentados os efeitos das variáveis estudas em $V_{C}$, correlacionadas em grupos adimensionais. As variáveis estudas foram a concentração volumétrica da polpa, densidade do sólido e do líquido carreador, diâmetro da tubulação e das partículas, viscosidade do líquido carreador e o fator de forma das partículas expresso através da esfericidade. O modelo semiempírico proposto por Wasp e Slatter (2004) foi a base para a modelagem da velocidade crítica de transporte $\left(V_{C}\right)$, devido à sua aplicabilidade industrial e a relativa facilidade na determinação de suas variáveis. A seção 5.5 apresenta a validação estatística do modelo proposto, a seção 5.6 apresenta o ajuste dos expoentes dos parâmetros obtidos utilizando a técnica dos mínimos quadrados e a seção 5.7 apresenta o modelo semi empírico proposto na sua forma final, acompanhado do erro dos valores observados em relação aos valores previstos para $V_{C}$. 
Os resultados dos experimentos de bombeamento com polpas de quartzo, apatita e hematita, cujos resultados são apresentados e discutidos no Capítulo 4, foram submetidos a um estudo de modelamento que constitui o escopo deste Capítulo. Tal tarefa foi conduzida no Royal Melbourne Institute of Technology (RMIT), localizado em Melbourne-Austrália, sob a supervisão do professor Doutor Paul Slatter.

O trabalho teve como ponto de partida o modelo de Wasp e Slatter (2004), que organizou as variáveis em grupos adimensionais. Segundo os autores de tal modelo, este procedimento permite reduzir o número de experimentos que seriam necessários para se atingir um nível de significância aceitável $(>0,95)$ para as correlações. Assim sendo, o valor de $V_{C}$ reportado no Capítulo 4, foi correlacionado com as variáveis operacionais dos experimentos densidade do sólido, do líquido e da polpa, respectivamente $\left(\rho_{\mathrm{s}}, \rho_{\mathrm{I}}\right.$ e $\left.\rho_{\mathrm{p}}\right)$, diâmetro do tubo (D), diâmetro médio de Sauter das partículas sólidas (d), concentração volumétrica, na forma de fração $\left(C_{V}\right)$, esfericidade das partículas $(\Psi)$, viscosidade do fluido carreador $\left(\mu_{\mathrm{w}}\right)$, associadas em grupos adimensionais cuja influência na magnitude de $V_{C}$ constitui a linha mestra deste capítulo.

\subsection{Efeito do Número de Reynolds modificado}

O Número de Reynolds modificado foi apresentado conforme demonstrado na Equação 2.31, apresentada na Seção 2.5.6. O modelo proposto nesta equação visa prever $V_{D}$, o que significa a divisão do fluxo dentro da tubulação em 2 camadas, uma formada por um leito fixo na base da tubulação e outra camada de partículas que são transportadas acima deste leito. Assim, foi proposta uma alteração no Número de Reynolds modificado, inicialmente proposto por Wasp e Slatter (2004), conforme ilustra a Equação 5.1. Este novo parâmetro utiliza a viscosidade da água (fluido carreador) ao invés da viscosidade da polpa, pois a segregação das partículas em condições de fluxo em $V_{C}$ para polpas heterogêneas é mais pronunciada. A influência do Número de Reynolds modificado, para todas as condições propostas em $V_{C}$, pode ser observada na Figura 5.1, em que o valor para inclinação da reta é de 0,33. 


$$
N R_{E}=\left(\frac{d_{S} \cdot \rho_{S} \sqrt{g \cdot D}}{\mu_{A}}\right)
$$

\section{Em que:}

$\mathrm{d}_{\mathrm{s}}$ é o diâmetro médio de Sauter

$\rho_{\mathrm{s}}$ é a densidade do sólido

g é a aceleração da gravidade

D é o diâmetro da tubulação

$\mu_{\mathrm{A}}$ é a viscosidade do fluido carreador (água)

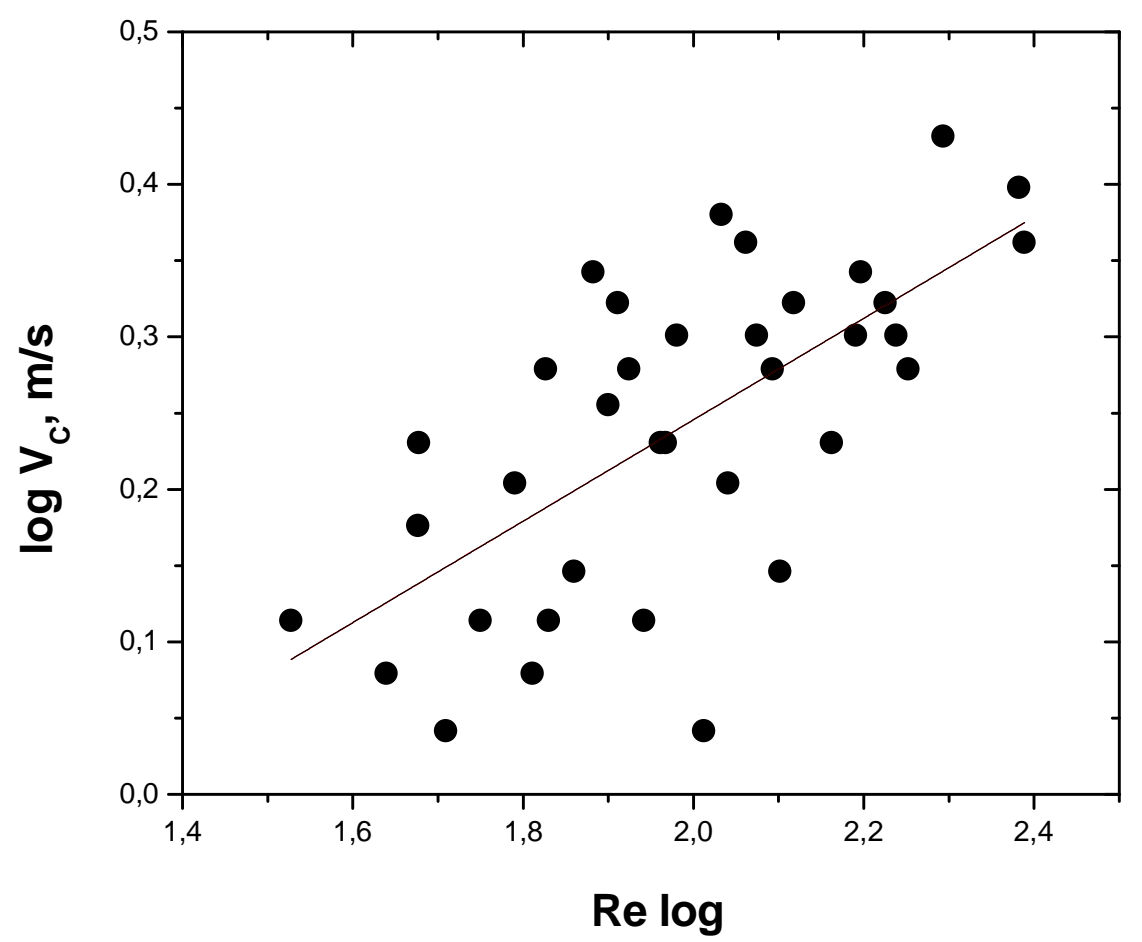

Figura 5.1-Influência do número de Reynolds modificado sobre $V_{C}$ 


\subsection{Efeito do grupo adimensional da esfericidade}

Wilson e Judge (1976) apresentam um modelo mecanístico para prever a velocidade de deposição em que utilizam um grupo adimensional baseado na razão entre o diâmetro da partícula e do tubo. A esta razão, os autores inseriram o coeficiente de arraste $\left(C_{D}\right)$, acrescentando assim um fator que se relaciona com a forma das partículas. Baseado no grupo adimensional sugerido pelos autores supracitados analisou-se a influência da relação do diâmetro da partícula e do duto utilizando a esfericidade para exprimir o fator de forma das partículas. O coeficiente de arraste foi substituído devido ao fato de se ter um leito móvel na base da tubulação e o contato partícula-partícula minimizar o efeito de arraste, por consequência seu coeficiente, e também devido à polpa mineral apresentar partículas grossas, gerando maior segregação no interior dos dutos. Uma consideração importante é a de que o coeficiente de arraste também é função da velocidade de sedimentação das partículas, sendo que sua determinação teórica só se aplica para formas esféricas, não se reportando às partículas de forma irregular. $\mathrm{O}$ efeito deste grupo na velocidade $\mathrm{V}_{\mathrm{C}}$ se encontra descrito na Figura 5.2. $\mathrm{O}$ efeito deste grupo em $V_{C}$ não apresenta relevância, pois o expoente assume magnitude de 0,039 .

Gilles et al (2000) apresentam uma discussão sobre o efeito da forma das partículas na velocidade de deposição em minerodutos. Os autores revelam que o fator de forma não apresenta relevância significativa, porém há um indicativo de que a velocidade de deposição aumente sutilmente conforme aumente a angularidade dos sólidos, fato este observado através dos ensaios experimentais. Para polpas com concentrações maiores que $30 \%$ em volume, o efeito da forma das partículas passa a ser mais pronunciado.

Muitos autores revelam (Thomas, 1965, Gilles et al, 2000, Wilson et al, 2006) que o efeito da forma das partículas passa a ter efeito significativo na viscosidade para polpas com concentração volumétrica a partir de $30 \%$ devido ao empacotamento da polpa mineral. 


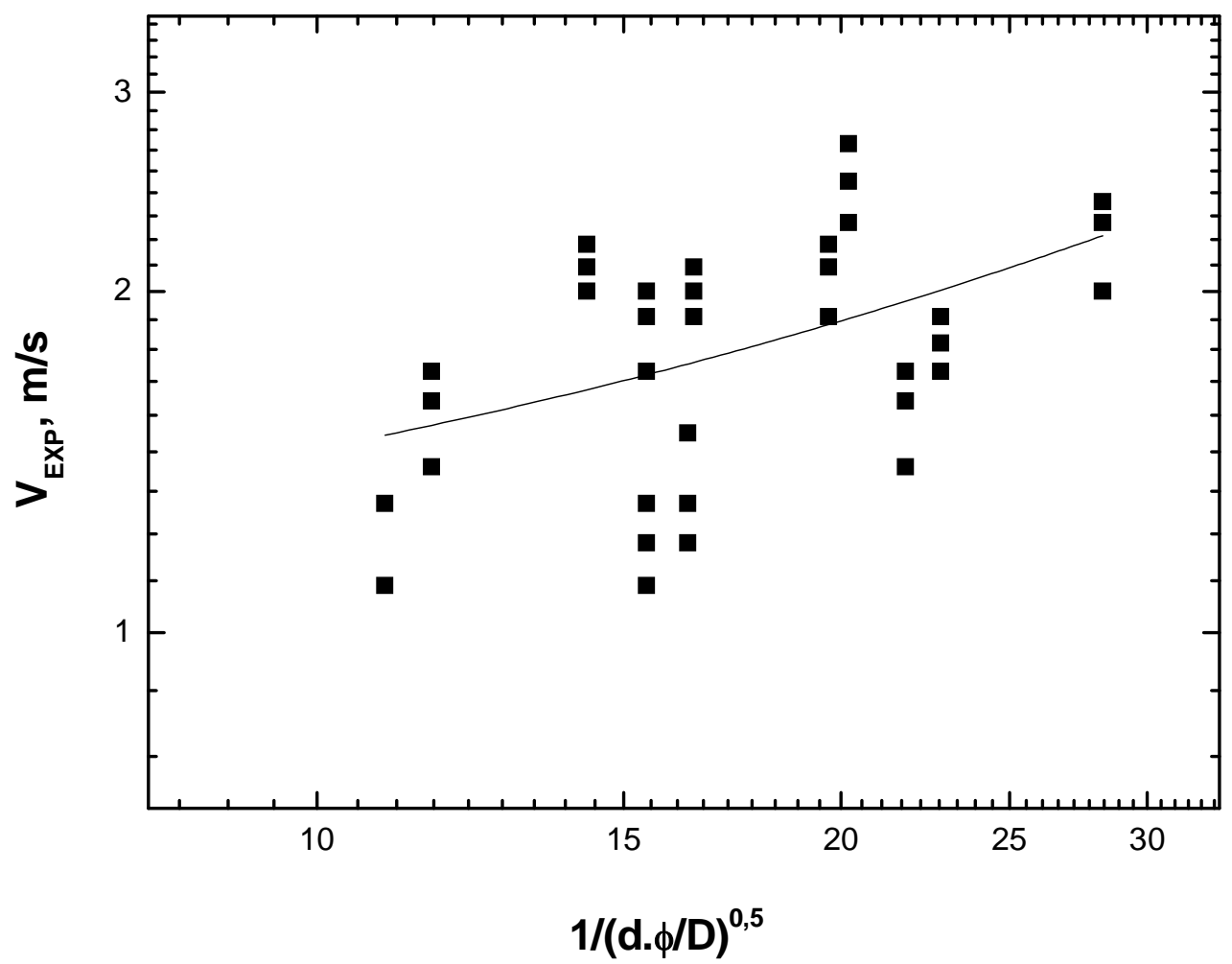

Figura 5.2-Influência do grupo adimensional da esfericidade sobre $\mathrm{V}_{\mathrm{C}}$.

\subsection{Efeito da densidade dos sólidos}

Durand e Condolios (1952) foram pioneiros ao utilizar em seu modelo a densidade relativa do sólido e do líquido carreador. Muitos autores (Davies, 1987; Wilson e Judge, 1976; Newitt, 1955; Gilles et al, 2000) verificaram a influência deste parâmetro e corroboraram com o anunciado por Durand e Condolios. A este efeito usualmente se emprega o expoente de 0,5, conforme utilizado por Wasp e Slatter (2004) e no modelo proposto nesta tese, porém a densidade dos sólidos é dividida pela densidade da polpa.

\subsection{Efeito da concentração de sólidos}

O efeito da concentração de sólidos na velocidade crítica de transporte se mostra similar para todas as observações propostas. Com o aumento da 
concentração nota-se um aumento da magnitude de $\mathrm{V}_{\mathrm{C}}$. Wasp e Slatter (2004) sugerem uma função exponencial para retratar o efeito da concentração e o mesmo procedimento foi adotado nesta tese. Cada amostra mineral apresentou uma função que retrata a sua população de partículas, e se determinou uma função média que pudesse retratar 0 efeito desta variável para todas as amostras utilizadas. Inicialmente esta função aparece de acordo com a Equação 5.2. Os efeitos para cada amostra são apresentados nas Figuras de 5.3 a 5.5.

$$
F\left(C_{V}\right)=0,14 \cdot e^{3,33}
$$

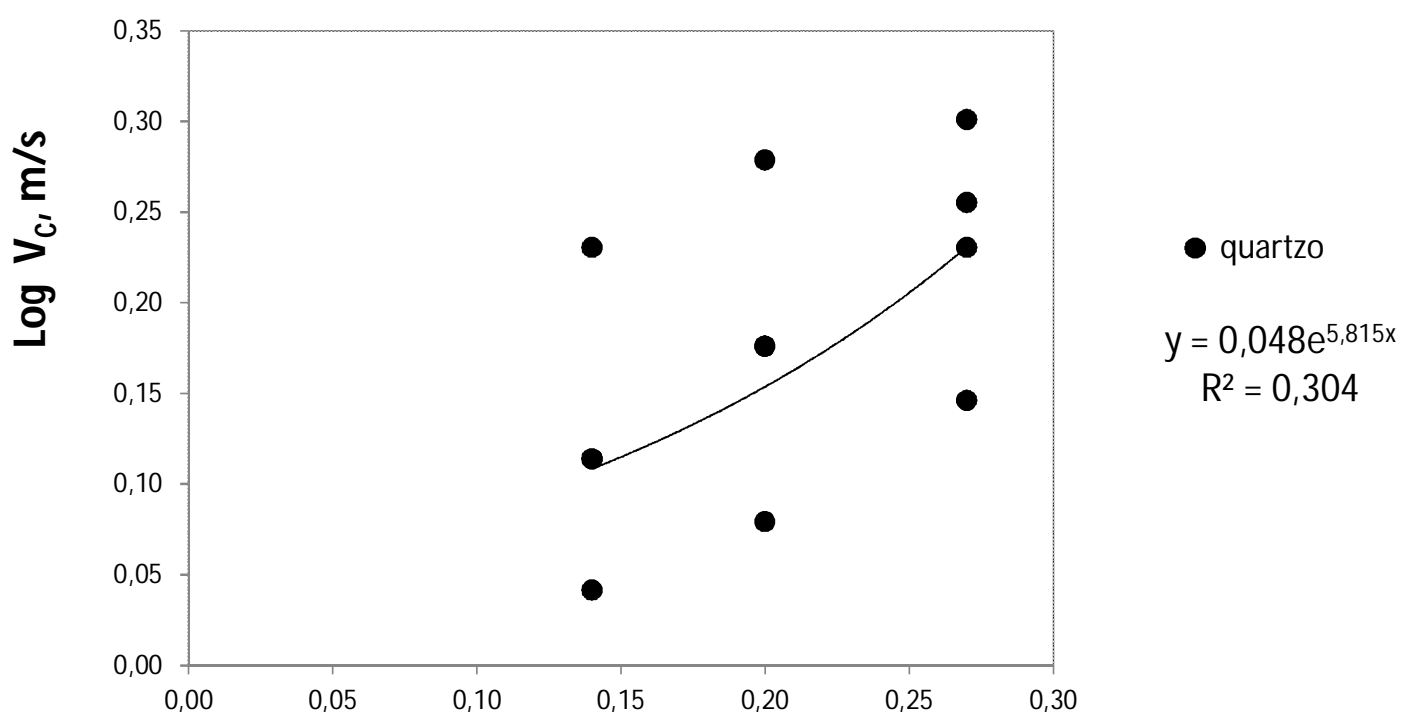

Concentração, v/v

Figura 5.3-Efeito da concentração volumétrica em $\mathrm{V}_{\mathrm{C}}$ para o quartzo. 


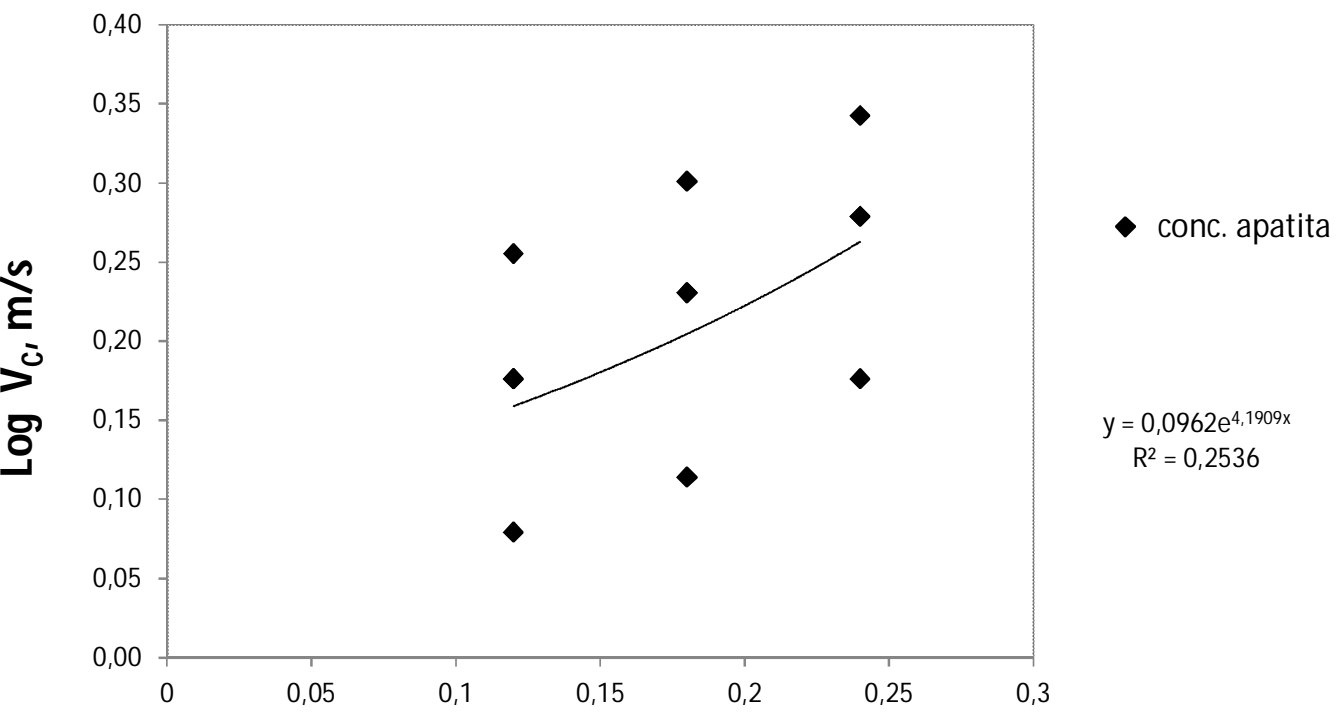

Concentração, v/v

Figura 5.4-Efeito da concentração volumétrica em $V_{C}$ para o concentrado de apatita.

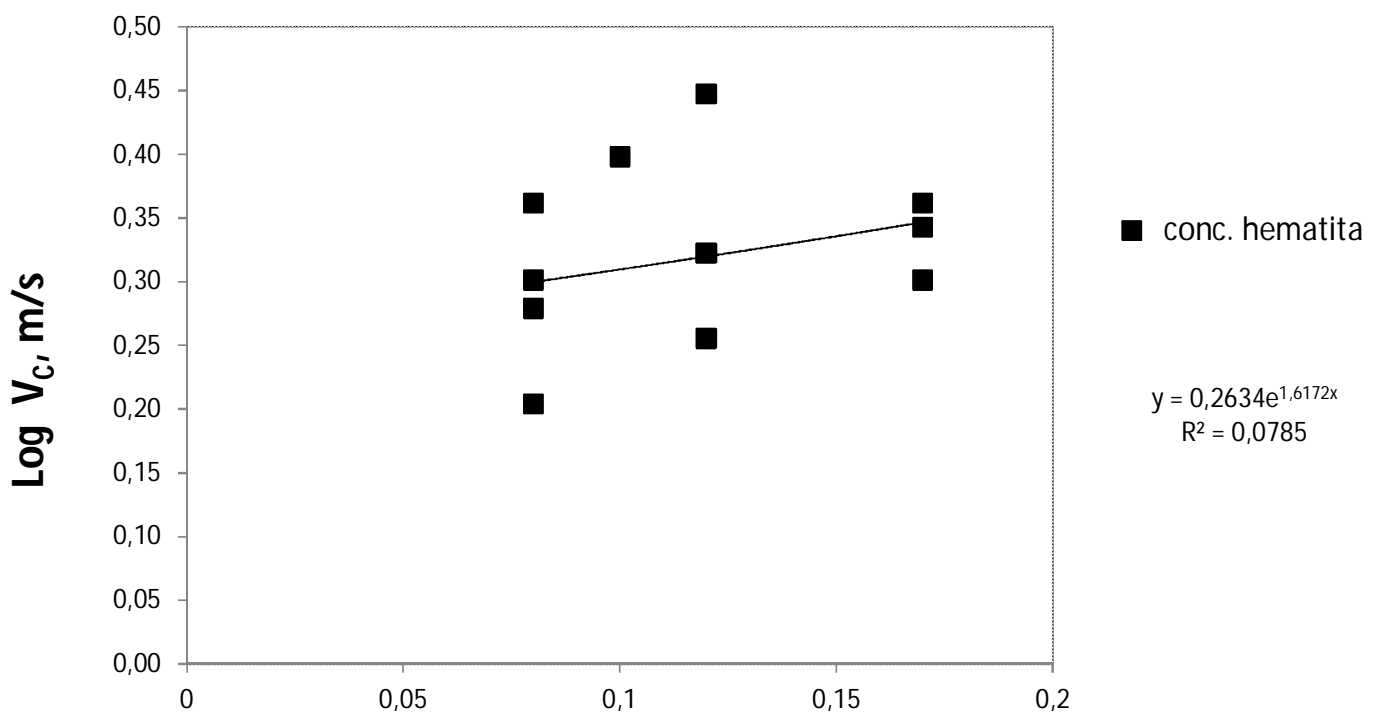

Concentracão, v/v

Figura 5.5-Efeito da concentração volumétrica em $\mathrm{V}_{\mathrm{C}}$ para o concentrado de hematita. 


\subsection{Validação estatística do modelo proposto}

Para a validação do modelo, se faz necessário verificar estatisticamente se este atende a uma distribuição normal, não apresentando tendências para os resíduos, ou seja, os resíduos devem se apresentar de forma randômica. A Figura 5.6 apresenta a distribuição dos resíduos na forma randômica, não violando as suposições assumidas para o modelo.

Para maior confiança na análise da validade do modelo, a média dos resíduos normalizados deve apresentar valor igual a zero e o desvio padrão deve apresentar valor unitário. A normalização dos resíduos é descrita conforme Equação 5.3. A Tabela 5.1 apresenta os resultados da análise do resíduo normalizado para todas as condições propostas.

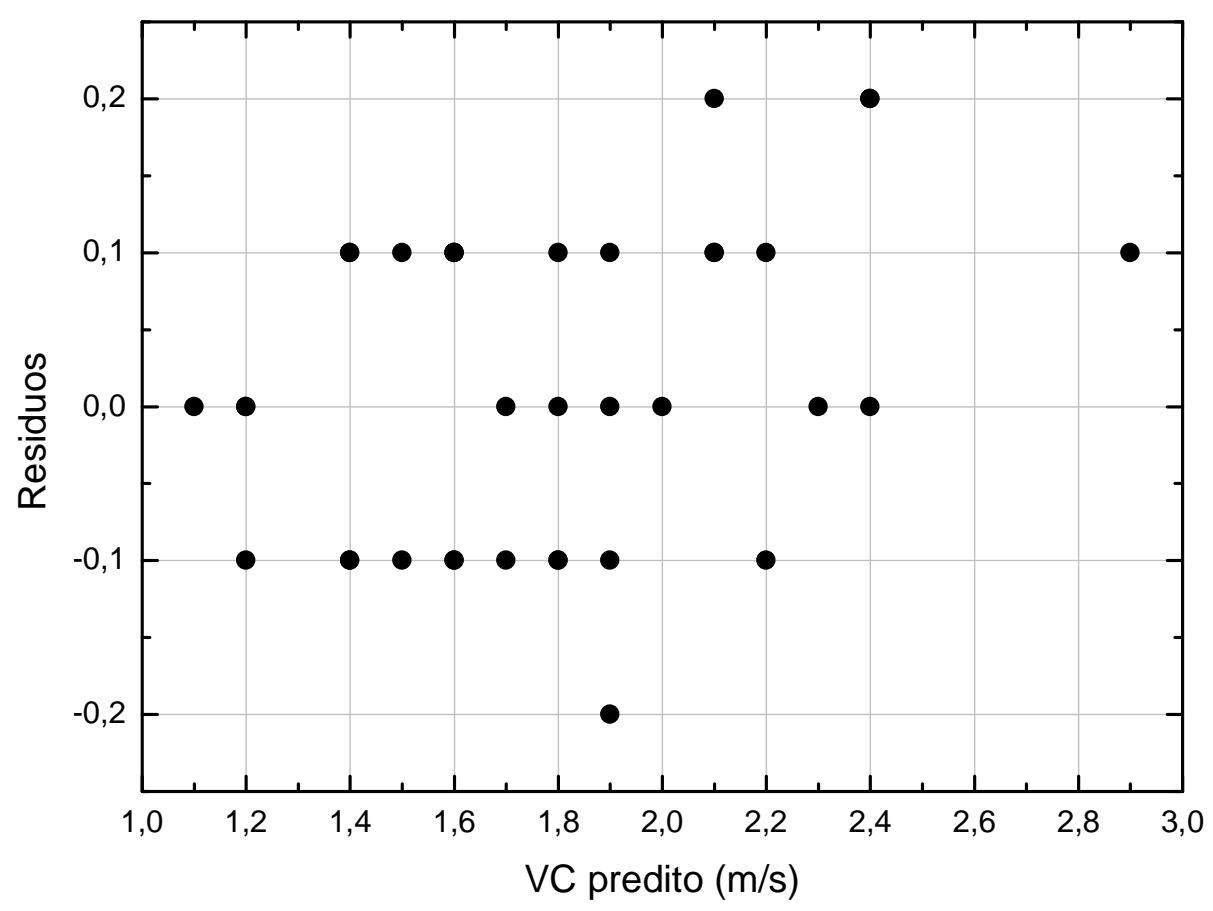

gura 5.6- Resíduos em função dos valores previstos para $\mathrm{V}_{\mathrm{C}}$.

$$
Z=\frac{\text { resíduo }-\bar{x}}{\sigma}
$$


Sendo:

Z o resíduo normalizado;

- a média dos resíduos

$\sigma$ o desvio padrão dos resíduos

Tabela 5.1- Análise do resíduo normalizado (Z).

\begin{tabular}{c|c|c}
\hline Parâmetro & Resíduos & Resíduos normalizados, $\mathbf{Z}$ \\
\hline Média & 0,0138 & 0,0000 \\
\hline Desvio padrão & 0,1046 & 1,0000 \\
\hline
\end{tabular}

Um teste de hipótese, efetuado através do teste t de Student, analisando dados pareados, em que foram comparados os valores previstos pelo modelo sugerido e o resultado obtido experimentalmente para $V_{C}$, é apresentado na Tabela 5.2 .

Tabela 5.2- Resultados para análise do teste t de Student.

\begin{tabular}{c|c}
\hline Parâmetro & Variável \\
\hline Observações & 36 \\
\hline Hipótese da diferença de média & 0 \\
\hline t calculado & 0,79 \\
\hline t crítico bi-caudal & 2,03 \\
\hline
\end{tabular}

Com base na Tabela 5.2, é possível observar que o valor para t calculado é menor que o t crítico bi-caudal, assim não sendo possível ignorar a hipótese nula, 
onde valores comparados não apresentam diferença significativa, corroborando com a análise dos resíduos e assim reforçando a validação do modelo proposto.

\subsection{Ajuste dos parâmetros do modelo proposto}

Para o melhor ajuste dos parâmetros do modelo proposto para determinação de $V_{C}$, foi aplicado aos resíduos o método dos mínimos quadrados, buscando otimizar o ajuste do modelo em relação aos dados observados experimentalmente. Como os resíduos se apresentam de forma randômica, apresentando distribuição normal, foi possível realizar a soma dos quadrados da diferença. A Figura 5.7 e a Tabela 5.3 apresentam o resultado desta análise para grupo do NRe modificado.

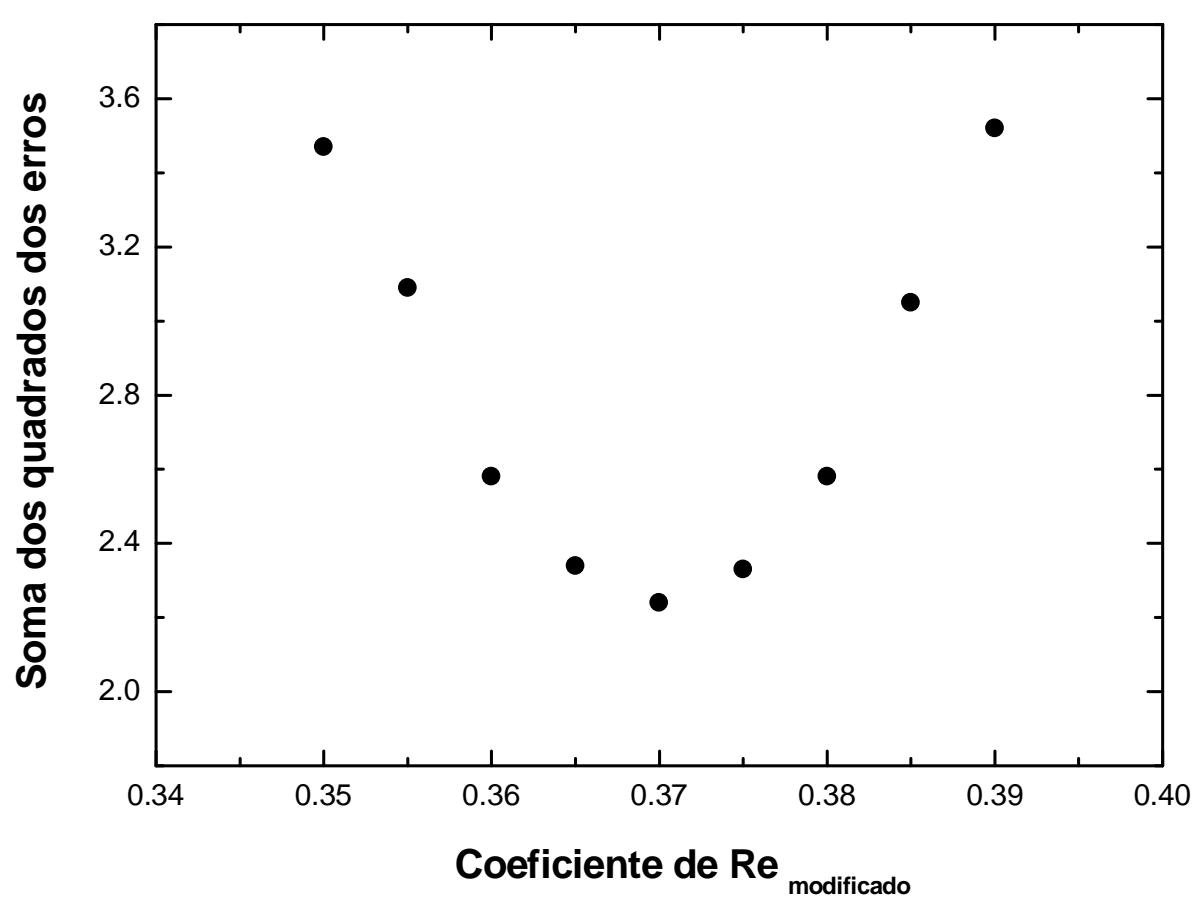

Figura 5.7- Método dos mínimos quadrados para o grupo NRe modificado.

O valor do parâmetro obtido inicialmente para o grupo de variáveis que forma o NRe modificado foi de 0,33. Com a análise da soma dos quadrados dos 
erros, o novo valor que alcança o melhor ajuste do modelo em relação aos dados observados passa a ser 0,37 .

Tabela 5.3- Método dos mínimos quadrados para o grupo NRe modificado

\begin{tabular}{c|c}
\hline Coeficiente & Soma dos quadrados dos erros \\
\hline 0,350 & 3,4755 \\
\hline 0,355 & 3,0930 \\
\hline 0,360 & 2,5820 \\
\hline 0,365 & 2,3404 \\
\hline 0,370 & $\mathbf{2 , 2 4 0 0}$ \\
\hline 0,375 & 2,3304 \\
\hline 0,380 & 2,5870 \\
\hline 0,385 & 3,0570 \\
\hline 0,390 & 3,7201 \\
\hline
\end{tabular}

A Tabela 5.4 e a Figura 5.8 apresentam o resultado para o grupo que inclui o fator de forma das partículas através da função esfericidade.

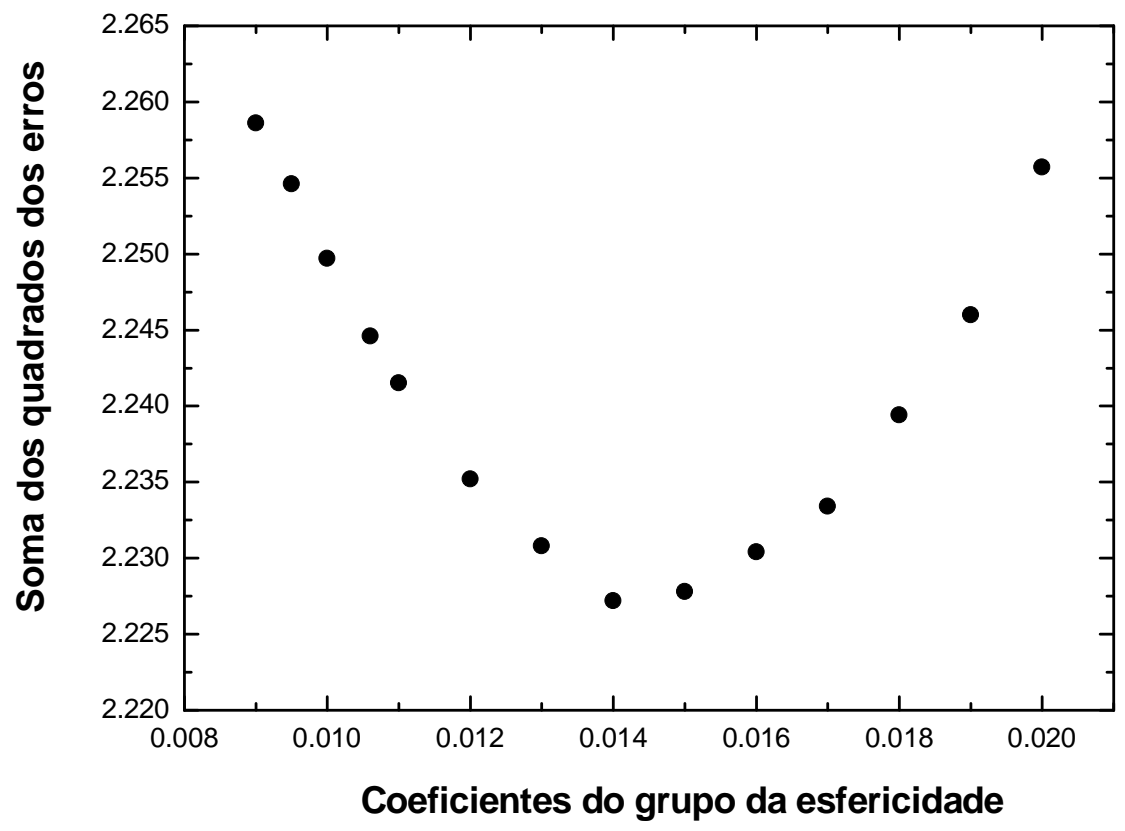

Figura 5.8- Método dos mínimos quadrados para o grupo da esfericidade. 
Tabela 5.4- Método dos mínimos quadrados para o grupo da esfericidade.

\begin{tabular}{c|c}
\hline Coeficiente & Soma dos quadrados dos erros \\
\hline 0,0090 & 2,2586 \\
\hline 0,0095 & 2,2546 \\
\hline 0,0100 & 2,2497 \\
\hline 0,0106 & 2,2446 \\
\hline 0,0110 & 2,2415 \\
\hline 0,0120 & 2,2352 \\
\hline 0,0130 & 2,2308 \\
\hline 0,0140 & $\mathbf{2 , 2 2 7 2}$ \\
\hline 0,0150 & 2,2278 \\
\hline 0,0160 & 2,2304 \\
\hline 0,0170 & 2,2334 \\
\hline 0,0180 & 2,2394 \\
\hline 0,0190 & 2,2460 \\
\hline 0,0200 & 2,2557 \\
\hline
\end{tabular}

O valor do parâmetro obtido inicialmente para o grupo de variáveis que inclui o fator de forma através da esfericidade era de 0,039. Com a análise da soma dos quadrados dos erros, o novo valor que alcança o melhor ajuste do modelo em relação aos dados observados passa a ser 0,014.

A Tabela 5.5 e a Figura 5.9 apresentam o resultado da análise para a função da concentração. Como é possível observar, o coeficiente que apresenta a menor soma dos quadrados dos erros é de 3,10, sendo inicialmente de magnitude de 3,33, com a inclinação da reta apresentada na Figura. A constante da função exponencial da concentração, inicialmente apresentou valor de 0,14. Através da análise dos mínimos quadrados, determinou-se o valor para o menor erro associado, conforme ilustrado na Figura 5.10 e na Tabela 5.6. 


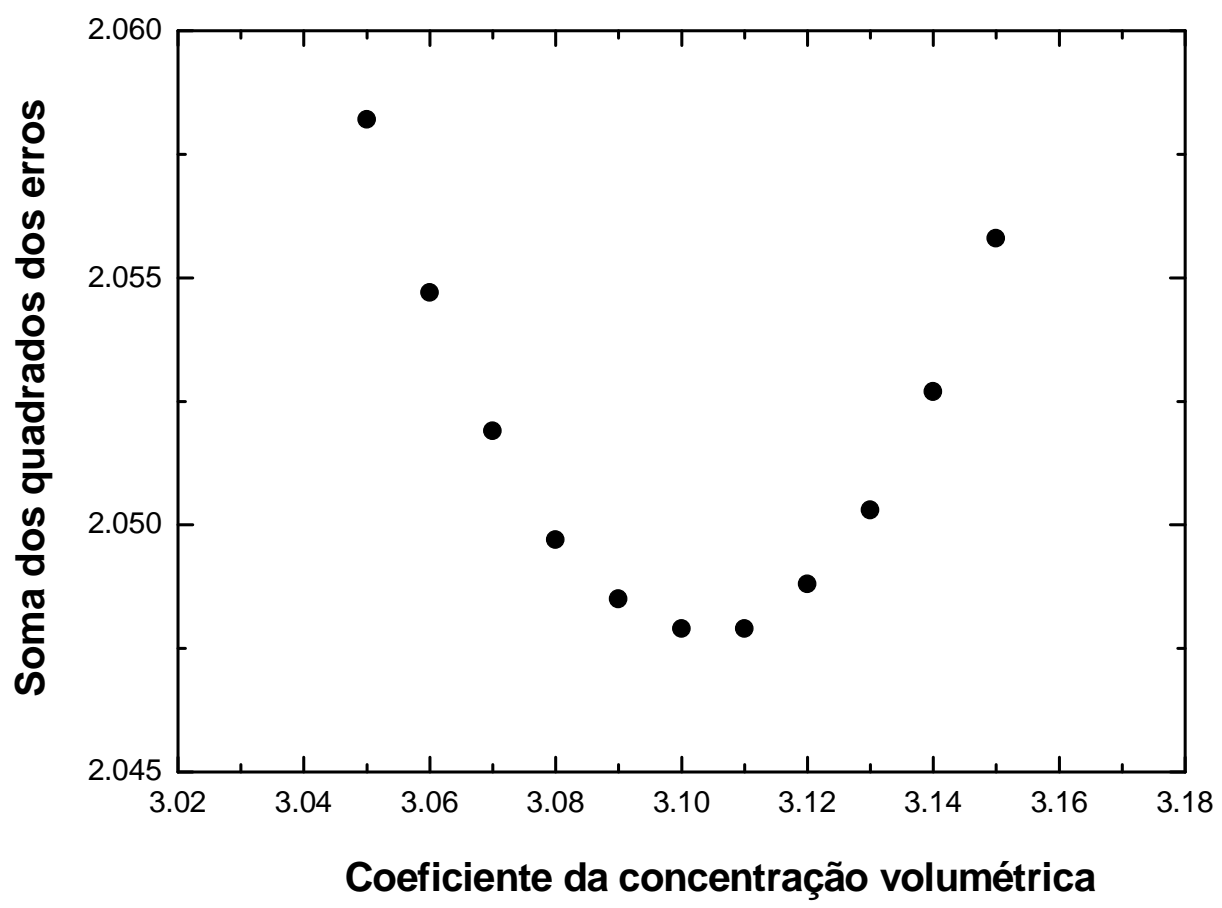

Figura 5.9- Método dos mínimos quadrados para a concentração.

Tabela 5.5- Método dos mínimos quadrados para o grupo da esfericidade.

\begin{tabular}{c|c}
\hline Coeficiente & Soma dos quadrados dos erros \\
\hline 3,05 & 2,0582 \\
\hline 3,06 & 2,0547 \\
\hline 3,07 & 2,0519 \\
\hline 3,08 & 2,0497 \\
\hline 3,09 & 2,0485 \\
\hline 3,10 & $\mathbf{2 , 0 4 7 9}$ \\
\hline 3,11 & 2,0479 \\
\hline 3,12 & 2,0488 \\
\hline 3,13 & 2,0503 \\
\hline 3,14 & 2,0500 \\
\hline 3,15 & 2,0558 \\
\hline
\end{tabular}




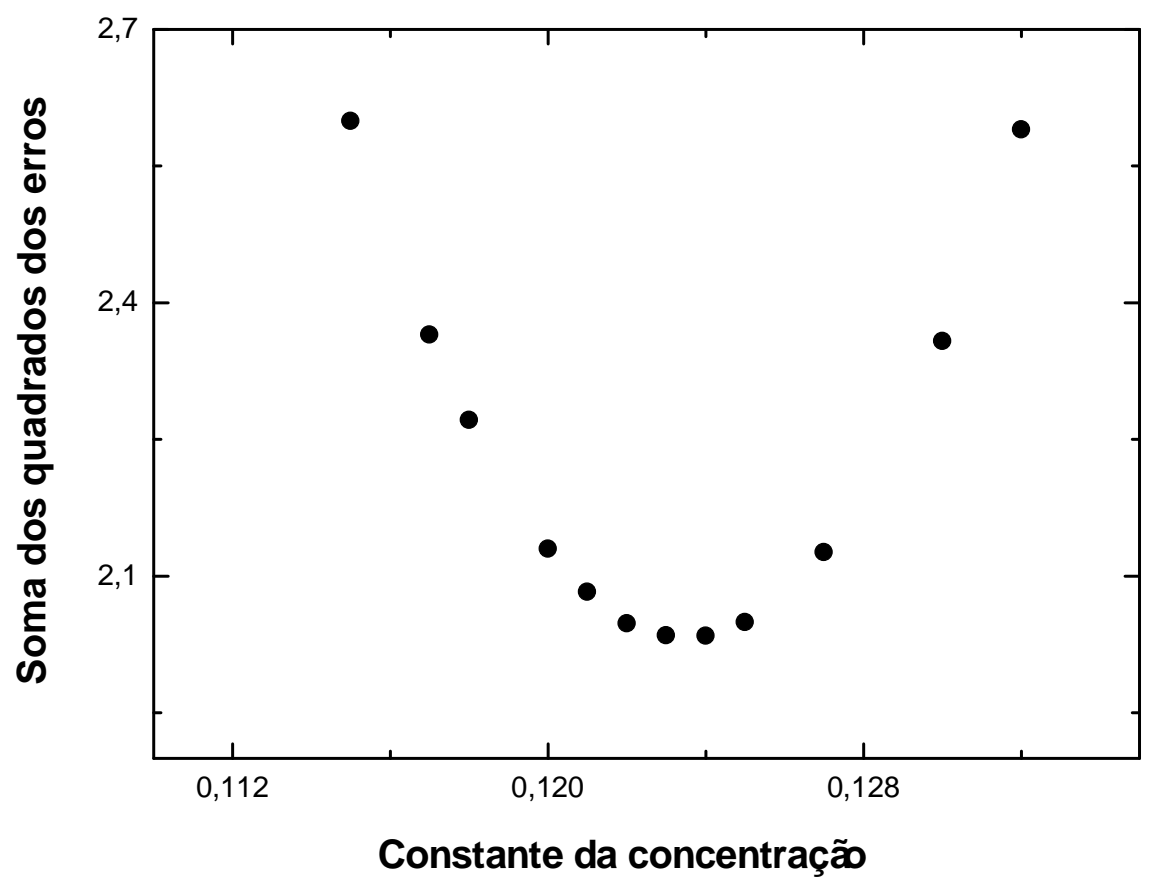

Figura 5.10- Método dos mínimos quadrados para a constante da concentração.

Tabela 5.6- Método dos mínimos quadrados para a constante da concentração.

\begin{tabular}{c|c}
\hline Coeficiente & Soma dos quadrados dos erros \\
\hline 0,115 & 2,5990 \\
\hline 0,117 & 2,3649 \\
\hline 0,118 & 2,2710 \\
\hline 0,120 & 2,1299 \\
\hline 0,121 & 2,0827 \\
\hline 0,122 & 2,0480 \\
\hline 0,123 & 2,0350 \\
\hline 0,124 & 2,0344 \\
\hline 0,125 & 2,0495 \\
\hline 0,127 & 2,1261 \\
\hline 0.129 & 2,2610 \\
\hline 0,130 & 2,3579 \\
\hline 0,132 & 2,5900 \\
\hline
\end{tabular}




\subsection{Modelo proposto final}

Com base no efeito de cada agrupamento adimensional de variáveis sobre a magnitude de $V_{C}$, (seções 5.1-5.4), assim como nos estudos estatísticos decorrentes (seções 5.5 e 5.6), chegou-se a um modelo semiempírico que é representado pela Equação 5.4. Tal modelo permite calcular a velocidade crítica de transporte $\left(\mathrm{V}_{\mathrm{C}}\right)$ de polpas minerais que contém partículas grossas. A esfericidade das partículas é abordada através do seu fator de esfericidade $(\Psi)$, que é multiplicado ao diâmetro médio de Sauter (d).

$$
V_{C}=0,124(S-1)^{0,5}\left(\frac{d \cdot \rho_{p} \cdot \sqrt{g \cdot D}}{\mu_{w}}\right)^{0,37} \cdot\left(\frac{d \cdot \psi}{D}\right)^{-0,007} e^{3,10 \cdot C_{V}}
$$

Em que:

$\rho_{s}$ é a densidade dos sólidos, $\mathrm{kg} / \mathrm{m}^{3}$

$\rho_{p}$ é a densidade da polpa mineral, $\mathrm{kg} / \mathrm{m}^{3}$

$S$ é a relação entre $\rho_{S} / \rho_{p}$

$\mathrm{D}$ é o diâmetro do tubo, $m$

$\mu_{\mathrm{W}}$ é a viscosidade do fluido carreador, Pa.s

d é o diâmetro médio de Sauter da partícula, $m$

$\mathrm{C}_{\mathrm{V}}$ e a fração da concentração volumétrica;

$\Psi$ é a esfericidade das partículas.

O erro associado aos valores previstos pelo modelo descrito na Equação 5.4 em relação aos valores de $V_{C}$ observados experimentalmente é apresentado na Figura 5.11, que indica a validade do modelo em função do desvio máximo de 10\%. 


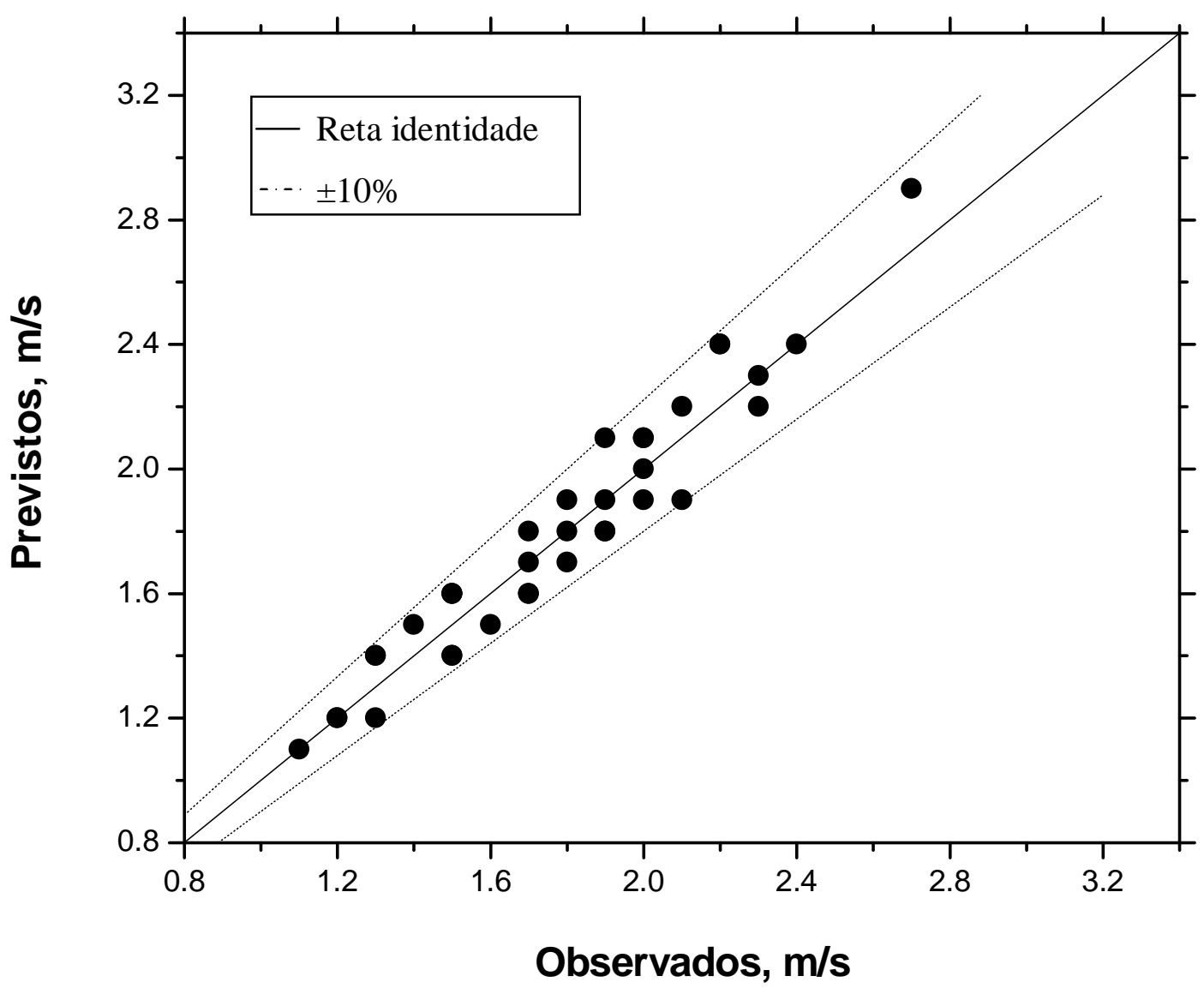

Figura 5.11- Comparação entre a velocidade crítica $\left(\mathrm{V}_{\mathrm{C}}\right)$ calculada pelo modelo proposto e a velocidade crítica observada experimentalmente. 


\section{CAPÍTULO 6}

\section{CONCLUSÕES E SUGESTÕES}

A partir dos resultados apresentados nos Capítulos 4 e 5, foi possível concluir que:

1. As unidades experimentais que foram dimensionadas e construídas para o bombeamento de polpas minerais (diâmetro de tubulação de $25,4 \mathrm{~mm}$ e $50,8 \mathrm{~mm}$ ) permitiram a realização dos ensaios e a determinação da curva de bombeamento $(\Delta \mathrm{P} / \mathrm{L}$ em função de $\mathrm{V})$ para todas condições de estudo propostas.

2. A menor velocidade de fluxo (V) em que ocorreu a formação de um leito móvel na parte inferior da tubulação, também denominada de velocidade crítica de transporte $\left(\mathrm{V}_{\mathrm{C}}\right)$, foi máxima e com magnitude de $2,8 \mathrm{~m} / \mathrm{s}$ para concentrados de hematita na concentração de $17 \%$ em volume, em dutos de $50,8 \mathrm{~mm}$ de diâmetro e partículas com diâmetro médio de Sauter de $0,336 \mathrm{~mm}$. $\mathrm{O}$ menor valor de $\mathrm{V}_{\mathrm{C}}$ foi encontrado para polpas do mineral de quartzo em dutos de 25,4mm de diâmetro em concentração volumétrica de $14 \%$ para partículas com diâmetro médio de Sauter de $0,132 \mathrm{~mm}$ e magnitude de $1,1 \mathrm{~m} / \mathrm{s}$.

3. As curvas da perda de carga por metro de tubo horizontal em função da velocidade de fluxo $(\Delta \mathrm{P} / \mathrm{L} \times \mathrm{V})$ apresentaram comportamento típico de polpas heterogêneas, que é o da ocorrência de aumento de pressão com o início da formação de um leito fixo na tubulação, à medida que se diminui a velocidade de fluxo. Deste modo, quando a velocidade de fluxo $(\mathrm{V})$ tende ao valor crítico $\mathrm{V}_{\mathrm{C}}$, a perda linear de carga $(\Delta \mathrm{P} / \mathrm{L})$ tende a um mínimo.

4. A distribuição da concentração de sólidos ao longo da seção transversal do duto apresentou uma segregação visível para todos os casos. A segregação 
das partículas se mostrou influenciada pela concentração de sólidos na polpa mineral, da densidade das partículas e do diâmetro dos dutos. Assim, quanto maior a concentração de sólidos na polpa, menor a segregação. Por outro lado, quanto maior a densidade das partículas e o diâmetro da tubulação, maior a segregação dos sólidos na seção transversal dos dutos.

5. A forma das partículas, expressa através do seu fator de esfericidade $(\Psi)$, influenciou os resultados dos ensaios de bombeamento realizados com concentrado de hematita, onde na base do duto encontrou-se um fator de forma da ordem de $\Psi \sim 0,5$, enquanto que no topo da tubulação encontrou-se $\Psi \sim 0,3$. A diferença pronunciada da forma das partículas (lamelares e granulares) do mineral hematita poderia explicar esta diferença significativa.

6. Utilizando os resultados dos experimentos de bombeamento, foi possível encontrar uma correlação semiempírica que pode ser utilizada para prever $\mathrm{V}_{\mathrm{C}}$, em função do diâmetro do tubo (D), diâmetro médio de Sauter das partículas $(\mathrm{d})$, concentração volumétrica $\left(\mathrm{C}_{\mathrm{V}}\right)$ dos sólidos na polpa, densidade relativa dos sólidos (S) e esfericidade $(\Psi)$ das partículas. Tal correlação é expressa pela seguinte equação:

$V_{C}=0.124(S-1)^{0.5}\left(\frac{d \cdot \rho_{p} \cdot \sqrt{g . D}}{\mu_{w}}\right)^{0.37} \cdot\left(\frac{d . \psi}{D}\right)^{-0.007} e^{3.10 \cdot C_{V}}$

7. O modelo proposto apresentou desvios menores que $10 \%$ entre os valores de $V_{C}$ medidos versus previstos pela correlação semiempírica. Tal constatação atesta a adequação da correlação às condições experimentais testadas.

8. Analisando a influência de cada grupo dimensional da equação do modelo na magnitude de $V_{C}$, observa-se a seguinte ordem decrescente de influência: número de Reynolds modificado $\left(\frac{d \cdot \rho_{p} \cdot \sqrt{g . D}}{\mu_{w}}\right)^{0.37}>$ densidade relativa dos sólidos $(\mathrm{S}-1)^{0,5}>\left(\frac{d . \psi}{D}\right)^{-0.007}>0,124 \cdot e^{3.10 \cdot C_{V}}$. 
9. A forma das partículas apresentou pouca influência na magnitude de $V_{C}$, haja vista a magnitude do expoente do grupo adimensional $\left(\frac{d \cdot \psi}{D}\right)$. Por outro lado, o fato de um terço dos experimentos terem sido realizados com sólidos que apresentam expressiva diferença de forma (hematita lamelar versus hematita granular) pode ter atenuado a influência do fator de esfericidade na velocidade crítica de transporte das partículas.

Como sugestões o autor propõe:

1) $O$ estudo do modelamento de $V_{C}$ utilizando diâmetros de duto maiores;

2) Utilizar diferentes condições de granulometria dos sólidos e esfericidade dos minerais;

3) Estudos de "shut down" e "start up" do bombeamento de polpas minerais nas unidades experimentais utilizadas;

4) Verificar a influência de partículas finas no bombeamento de polpas minerais. 


\section{Referências bibliográficas}

ALLEN, T. Particle Size Measurement, London, 4º ed., Chapman and Hall, 1993.

ALLEN, T. Particle Size Measurement, London, 5ํed., Chapman and Hall, 1997.

ALMENDRA, E.R. Velocidade de sedimentação de sistemas particulados. $88 p$ Rio de Janeiro, Tese, UFRJ, 1979.

BABA, J, KOMAR, P.D. Measurements and analysis of settling velocities of natural quartz sand grains. Journal of Sedimentary Petrology, V. 51, p. 631-640, 1981.

BAKKER, C.W. Numerical modeling of non-Newtonian mineral slurry in a mechanical flotation cell. 143p. Thesis (Doctor of Philosophy), University of Cape Town, 2009.

BARNES, H.A.; HUTTON, J. F.; WALTERS, K. An introduction to rheology. Amsterdam:Elsevier Science Publishers, 1989, 200p.

BARREIROS, F. M.; FERREIRA, P. J. FIGUEIREDO, M. M.; Calculating Shape Factors from Particle Sizing Data, Part. Syst. Charact., v. 13, p. 368-373, 1996.

BIRD, R.B., STEWART, W.E., LIGHTFOOT E.N. Transport phenomena. New York: John Wiley \& Sons, 1960. 780p.

BROWN, G.G. Unit operations New York, Wiley, 1950, 611p.

BROWN, N.P.; HEYWOOD, N.I. Slurry Handling: Design of solid-liquid systems; New York, Elsevier Handling and Processing of Solids Series, Elsevier Science Publishers, 1991, 680p.

BROOK, N. Fluid transport of coarse particles; Mining Science and Technology, 5 ed., 1987, p. 197-217.

CARMAN, P.C. Fluid flow through granular beds. Trans. Inst. Chem. Eng., V.23, p. 150-166, 1937. 
CARLETON, A.J.; CHENG, D.C. Design velocities for hydraulic conveying of settling suspensions. Proceedings of. Hydrotransport Conf., BHRA, Hydrotransport Conference, Cranfield, UK, Paper E5; 1974, p.57-74.

CHAVES, A. P. Teoria e prática do tratamento de minérios, São Paulo, Ed. 2, Signus Editora, 2002, cap.2.

CHATTERJEE, A. Role of particle size in mineral processing at Tata Steel; International Journal of Mineral Processing, vol. 53, p. 1-14, 1998.

CLIFT, R.; GRACE, J.R.; WEBER, M.E. Bubbles, drops and particles, Academic Press, 1978.

CONCHA, F.; ALMENDRA, E.R. Settling velocities of particulate systems, 2. Settling velocities of suspensions of spherical particles, International Journal of Mineral Processing, V. 6, p. 31-41, 1979.

CONCHA, F.; BARRIENTOS, A. Settling velocities of particulate systems, 4. Settling of nonspherical isometric particles, International Journal of Mineral Processing, V.18, p. 297-321, 1985.

COULSON, J.M., RICHARDSON, J.R. Flow of fluid through granular beds and packed columns, 2 ed, New York, Pergamon, Chemical Engineering, Vol. 2, 1968, p. 1-47.

COULSON, J.M. The flow of fluids through granular beds: effect of particle shape and voids in streamline flow. Trans. Inst. Chem. Eng., V.27, p. 237-257, 1949.

COX, R.G.; Brenner, H. The rheology of a suspension of particles in a Newtonian fluid; Chemical Eng. Science, vol. 26, n. 1, p. 69-93, 1970.

DANA, J.D. Manual de Mineralogia, New York, John Wiley \& Sons, p.313, 1978.

DRIVER, K. Slurry pump selection-what should you know before making your choice; Word Pumps, Elsevier, 2003, p. 24-26.

DORON, P; BARNEA, D. Pressure Drop and limit deposit velocity for solid-liquid flow in pipes, Chemical Engineering Science, Vol. 50, n.10, p. 1595-1604, 1995. 
DORON, P.; GRANICA, D.; BARNEA, D. Slurry Flow in Horizontal PipesExperimental and Modeling. International Journal Multiphase Flow, Vol. 13, n. 4, p. 535-547, 1987.

DURAND, R. The hydraulic transportation of coal and other materials in pipes, Conf. of National Coal Board, Londres, 1952.

ERGUN, S. Fluid flow through packed columns, Chem. Eng. Progress, vol. 48, n.2, p. 89-94, 1952.

FANGARY, Y. S.; GHANI, A. S.; EL HAGGAR, S. M.; WILLIAMS, R.A. The effect of fine particles on slurry transport processes. Minerals Engineering, Vol 10, N. 4, p. 427-439, 1997.

FERNANDEZ, L.; MARTINEZ, J.; GONZALES, A.; FUENTES, R. Flow of highly concentrated, extended particles distribution slurries in open channels in laminar, transition and turbulent flow. $\mathbf{1 8}^{\circ}$ Hidrotransport Conference, Rio de Janeiro, 2010, p.167-181.

FLEMMER, R.L.C.; BANKS, C.L. On the drag coefficient of a sphere. Powder Technology, V.48, p. 217-221, 1986.

FOUST, A.S.; WENZEL, L.A.; CLUMP, C.W.; MAUS, L.; ANDERSEN, L.B. Principles of unit operation; 2 ed., New York, John Wiley \& Sons, 1980, 578p.

FOX, R.W.; MCDONALDS, A. T.; PRITCHARD, P.J. Introdução à mecânica dos fluidos, 6 ed., Editora LTC, 2006, 798p.

GAUDIN, A. M. Principles of Mineral Dressing, 2ed, New York, McGraw-Hill Company, 1957, 573p.

GEANKOPLIS, C.J. Transport process and unit operations; 3 ed., New Jersey, Simon and Schsuter Company, 1993, 921p.

GIBBS, R.J., MATTHEWS, M.D., LINK, D.A. Relationship between sphere size and settling velocity. Journal of Sedimentary Petrology,V. 41, n.1, p. 7-18, 1971.

GILLIES, R.G. Pipeline Flow of Coarse Particles Slurries. 201p Thesis (Doctor of Philosofy) - University of Saskatchewan, 1993. 
GILLIES, R.G.;SCHAAN, J. SUMNER, R.J.; McKIBBEN, M.J.; SHOOK, C.A.; Deposition Velocities for Newtonian Slurries in Turbulent Flow. The Canadian Journal of Chemical Engineering, V. 78, p. 704-708, 2000.

GILLIES, R.G.; SHOOK, C.A.; Xu, J. Modelling Heterogeneous Slurry Flows at High Velocities. The Canadian Journal of Chemical Engineering. V. 82, p. 1060-1065, 2004.

HAIDER, A.; LEVENSPIEL, O. Drag coefficient and terminal velocity of spherical and nonspherical particles. Powder Technology, V. 58, p. 63-70, 1989.

HE M.; WANG, Y.; FORSSBERG E. Slurry rheology in wet ultrafine grinding of industrial minerals: a review. Powder Technology, V. 147, p. 94-112, 2004.

HEISKANEN, K. Particle classification, 1 ed, New York, Chapman \& Hall, 1993, $336 p$.

HEYWOOD, H. Particle shape coefficients. J. Imp. Coil. Chem. Eng. Soc., V. 8, p. 25-33, 1954.

IACOCCA, R.G.; GERMAN, R.M. A comparison of powder particle size measuring instruments. Int. Journal of Powder Metall.; V.33, n. 8, p.35-48, 1997.

JACOBS, B.E.A. Design of slurry transport systems. Elsevier Science Publishers, BHR Group, 1991, 312p.

JILLAVENKATESA, A.; DAPKUNAS S. J.; LUM L.H. GOETZEL, G. C. Particle Size Characterization, NIST Recommended Practice guide - Special Publication 960-1, Washington, 2001.

KAUSHAL, D. R.; TOMITA, Y.; DIGHADE, R. R. Concentration at the pipe bottom at deposition velocity for transportation of commercial slurries through pipeline. Powder Technology, V. 125, p. 89-101, 2002.

KELLY, E.G.; SPOTTISWOOD, D.J. Introduction to mineral processing; New York, Wiley interscience inc., 1982, 516p. 
KOTZÉ, R. Rheological characterization of highly concentrated mineral suspension using an ultrasonic velocity profiler; 223p., Thesis (Doctor of Philosophy), Cape Peninsula University of Technology, 2007.

LAREO, C.; FRYER, P.J.; BARIGOU, M. The fluid mechanics of two-phase solidliquid food flows: a review; Trans. ChemE, V. 75, part C, p. 73-105, 1997.

LEJA, J. Surface Chemistry of Froth Flotation. New York: Ed Plenum Press, 1982.

LOTH, E. Drag on non-shperical solid particles of regular and irregular shape, Powder Technology, doi: 10.1016, 2007.

MACINTYRE, A.J. Bombas e instalações de bombeamento; 2 ed., Rio de Janeiro, Editora Guanabara Dois, 1987, 667p.

MACOSKO C.W. RHEOLOGY: Principles, Measurements and Applications, New York, Wiley-VCH Inc., 1993, 568p.

MASSARANI, G. Fluidodinâmica em Sistemas Particulados - Ed. 2; Rio de Janeiro, editora e-2, Guanabara dois, 2002; 670p.

MATOUSEK, V. Research developments in pipeline transport of settling slurries; Powder Technology, V. 156, p. 43-51, 2005.

MATOUSEK, V. Predictive model for frictional pressure drop in settling-slurry pipe with stationary deposit. Powder Technology, doi: 10.1016/j. powtec. .01 .0 17, 2008.

McCABE W.L. SMITH, J.C.; HARRIOTT, P.; Unit operations of chemical engineering, 6 ed., Nova York, McGraw-Hill, 2001, 1114p.

McCABE W.L. SMITH, J.C.; HARRIOTT, P.; Unit operations of chemical engineering, 7 ed., Nova York, McGraw-Hill, 2005, 1140p.

MINGZHAO H., WANG, Y.; FORSSBERG, E. Slurry rheology in wet ultrafine grinding of industrial minerals: a review. Powder technology, V.147, p.94-112, 2004.

MOONEY, M. The viscosity of a concentrated suspension of spherical particles, Journal of Colloid Science, V. 6, p. 162-170, 1951. 
MORAES JR, D.; SILVA, E. L.; MORAES, M.S. Aplicações industriais de estática e dinâmica dos fluidos I; Edição do autor, 2011, 360p.

MUNSON, B.R.; YOUNG, D.F.; OKIISHI, T.H. Fundamentos da mecânica dos fluidos, 4 ed., Editora Edgar Bluncher;, 2004, 571p.

NAYYAR, M.L. Piping Handbook, 7 ed, New York, McGraw-Hill,1999.

NEWITT,D.M.; RICHARDSON, J.F.; ABBOT, M.; TURTLE, R.B. Hydraulic Conveying of solids in horizontal pipes; Trans. Inst. of Chemical Eng.; V. 33, p.93-112, 1955.

OROSKAR, A. R.; TURIAN R. M. The Critical Velocity in Pipeline Flow of Slurries. AIChE Journal, V. 26, No 4, 1980.

PANDA, D.; PARIDA, A.; MURTY J.S; MITRA, A.K. Transportation of coarse coal in a fine medium; International Journal of Multiphase Flow, V. 20, p. 171-177, 1994.

PAPINE, J.C. Estudo comparativo de métodos de determinação de tamanho de partículas. 130p, Dissertação de mestrado, IPEN, 2003.

Particle Size Characterization, NIST Recomended Practice guide-Special Publication 960-1, Washington, 2001.apud Papini, 2003.

PAWLIK, M.; LASKOWSKI, J.S. Evaluation of flocculants and dispersants through rheological tests. In: Polymers in Mineral Processing. 38th Annual Conference of Metallurgists of CIM, Quebec, Canada, p. 541-55,1999.

PEDEN, J. M.; LUO, Y. Settling velocity of variously shaped particles: Drilling and fracturing fluids, SPE Drilling engineering, p.337-343, 1987.

PERRY, R. H.; GREEN, D.W. Chemical Engineers Handbook, $7^{0}$ ed., New York, Mc Graw-Hill, 1999, p. 18-133.

PETTYJOHN, E.S., CHRISTIANSEN, E.B. Effect of particle shape on free settling rates of isometric particles; Chemical Engineering Progress, V. 44, n. 2, p. 157$170,1948$. 
PUGH, F.J.; WILSON, K.C. Role of the interface in stratified slurry flow, Powder Technology, V.104, p. 221-226, 1999.

RAFFI, M.; TURIAN, T. Flow of slurries in pipelines. Aiche Journal, V.23, n.3, p. 232-243, 1977.

RAWLE, A. Basic Principles of Particle Size Analysis. Disponível em $<$ http://www.malvem.co.uk>. Acesso em 17 de maio de 2002.

RICHARDSON J.F..; ZAKI, W.N. Sedimentation and fluidization part 11; Inst. Chem Eng., p. 32-35, 1954.

RITTENHOUSE, G. A visual method of estimating two dimensional sphericity. Journal of Sedimentary Petrology, V.13, p. 79-81, 1943.

SAMPAIO, C.H; TAVARES, L. M. M. Beneficiamento Gravimétrico, 1ed; Editora UFRGS, 2005, $603 \mathrm{p}$.

SCHAAN J; SUMNER R. J; GILLIES R. G.; SHOOK C. A. The Effect of Particle Shape on Pipeline Friction for Newtonian Slurries of Fine Particles. The Canadian Journal of Chemical Engineering, V. 78, p. 717-725, 2000.

SCHILLER, R. E., HERBICH, P. E. Sediment transport in pipes. In Handbook of Dredging, Editor Herbich, P. E.; New York: McGraw-Hill. 1991

SCHULZ, N.F. Measurement of surface areas by permeametry. International Journal of Mineral Processing; V. 1, p. 65-79, 1974.

SELLGREN, A.; ADDIE, G. Solids effect on the characteristics of centrifugal pumps; $\mathbf{1 2}^{\text {th }}$ International Conference on Slurry Handling and Pipeline Transport, BHR Group, Bélgica, 1993, p.3-18.

SHAHEEN, E. Rheological studies of viscosity and pipeline flow of concentrated slurries, Powder technology, Elsevier, p. 245-256, 1971.

SHOOK, C.A. E BARTOSIK A.S. Particle-wall stresses in vertical slurry flows. Powder Technology, V. 81, n. 2, p. 117-124, 1994. 
SLATTER P.T. The laminar/turbulent transition prediction for non-Newtonian slurries. Proceedings of the International Conference "Problems in Fluid Mechanics and Hydrology" Academy of Sciences of the Czech Republic, Prague, p. 247-256, 1999.

SLATTER P. T. The effect of the yield stress on the laminar/turbulent transition. $\mathbf{9}^{\text {th }}$ International Conference on Transport and Sedimentation of Solid Particles Cracow, p 547 - 561, 1997.

SLATTER P. T. The role of rheology in the pipelining of mineral slurries. Mineral Processing and Extractive Metallurgy Review; V. 20, p. 281-300, 1999.

SLATTER P.T. Pipe flow of highly concentrated sludge. Journal of Environmental Science and Health, Part A; V. 43, n. 13, p. 1516-1520, 2008.

Somasundaran, P. International Symposium on Fine Particles, in: Fine particles processing, Las Vegas, 1980, New York, Aime, 1980, V.2

SOUZA PINTO, T. C.; LIMA, O. A.; LEAL FILHO, L. S. Sphericity of Apatite Particles Determined by Gas Permeability through Packed Beds. Minerals and Metallurgical Processing Journal, V. 26, n.2, p.105-108, 2009.

Sresty, C.; Venkatesaver, R. Particle size analysis - a review, Proc. Fine Particles Processing, AIME. .V. 18, 1980.

SUNDQVIST, A.; SELLGREN, A.; ADDIE, G. Pipeline friction losses of coarse sand slurries. Comparison with a design model; Powder Technology, V.89, p.9-18, 1996.

SÜMER M.; PEKER, Ş. Ş. HELVACI, H. BANU Y., BERRIN İ., ALP A. Solid-Liquid Two Phase Flow, Elsevier, 536p, 2008.

THOMAS D.G. Transport characteristics of suspension. Journal of Colloid Science; V. 7, p.423-430, 1965.

THOMAS, D.G. Predicting the deposit velocity for horizontal turbulent pipe flow of slurries. International Journal Multiphase Flow, V. 5. p. 113-129, 1979.

TRAN-CONG, S, GAY M., MICHAELIDES, E. Drag coefficients of irregularly shaped particles. Powder Technology, V. 139, p. 21-32, 2004. 
TURIAN, R.M.; HSU, F.L.; MA, W. Estimation of the critical velocity in pipeline flow of slurries. Powder technology, V.51, n.1, p.35-47, 1987.

ULUSARSLAN, D. Comparison of experimental pressure gradient and experimental relationships for the low density spherical capsule train with slurry flow relationships. Powder Technology, V. 185, p. 170-175, 2008.

USUI, H.; HISHIMOTO, K. SUZUKI H. Non-Newtonian viscosity of dense slurries prepared by spherical particles. Chemical Engineering Science, V. 56, p. 29792989, 2001.

VALADÃO, G.E.S.; ARAUJO, A.C. Introdução ao tratamento de minérios, Ed. UFMG, 2007, 234p.

WADELL, H. Sphericity and roundness of rock particles. Journal of Geology V. 41, p. 310-331, 1933.

WADELL, H. Volume, shape and roundness of quartz particles. Journal of Geology, V.43, p. 250-280, 1935.

WASP, E. J; SLATTER, P. Deposition velocities for small particles in large pipes, $\mathbf{1 2}^{\text {th }}$ International Conference on Transport \&Sedimentation of Solids Particles, Prague, Czech Republic, 2004.

WASP, E. J.; KENNY, J. P.; GANDHI, R. L. Series on Bulk Materials Handling Vol. 1 (1975/77) No. 4; Solid-Liquid Flow Slurry Pipeline Transportation - 3.ed., Trans Tech Publications. 1977, 224p.

WHITEN, W.; STEFFENS, P.;HITCHENS, J.; An examination of pulp viscosity in tubes at higher shear rates; Minerals Engineering, v.6, n.4, p. 397-404, 1993.

WILSON, K.C. A Unified Physically Based Analysis of Solid-Liquid Pipeline Flow, in "Proc. 4th Int. Conf. On Hydraulic Transport of Solids", BHRA Fluid Engineering, Cranfield, UK, Paper A1, pp. 1-16, 1976.

WILSON, K.C.; ADDIE, G.R.; SELLGREN A.; CLIFT, R. Slurry Transport Using Centrifugal Pumps, 3 ed., New York, Springer Science+Business media Inc, 2006, 432p. 
WILSON, K.C.; CLIFT, R.; ADDIE, G.R.; MAFFET, J. Effect of Broad Particle Grading on Slurry Stratification Ratio and Scale-up. Powder Technology, V. 61; p. 165-172, 1990.

WILSON, K.C.; CLIFT, R; SELLGREN A. Operating points for pipelines carrying concentrated heterogeneous slurries. Powder Technology, V. 123, p.19-24, 2002.

WILSON, K.C.; ADDIE, G.R.; SELLGREN A.; CLIFT, R. Slurry Transport Using Centrifugal Pumps, 3 ed., Springer Science+Business media Inc, 2006, 432p.

WILSON, K.C.; JUDGE, D.G. New techniques for the scale-up of pilot-plant results to coal slurry pipelines. Proc. Int. Symp. on Freight Pipelines, Univ. Pennsylvania, p. 1-29, 1977.

YEKELER,M.; ULUSOY,U.; HIÇYILMAZ, C. Effect of particle shape and roughness of talc mineral grounded by different mills on the wettability and floatability. Powder Technology, V. 140, p. 68-78, 2004.

YOUNG, D.F.; MUNSON, B.R.; OKIISHI, T.H. Uma introdução concisa à mecânica dos fluidos, tradução da $2^{\circ} \mathrm{ed}$. Americana, Edgar Bluncher, 2005, 356p.

YOW, H.N.; PITT, M.J.; SALMAN, A.D. Drag correlations for particles of regular shape. Advenced Powder Tech, V. 16, n.4, p. 363-372, 2005. 


\section{APÊNDICE A}

\section{A1-Curvas do perfil de distribuição de sólidos}

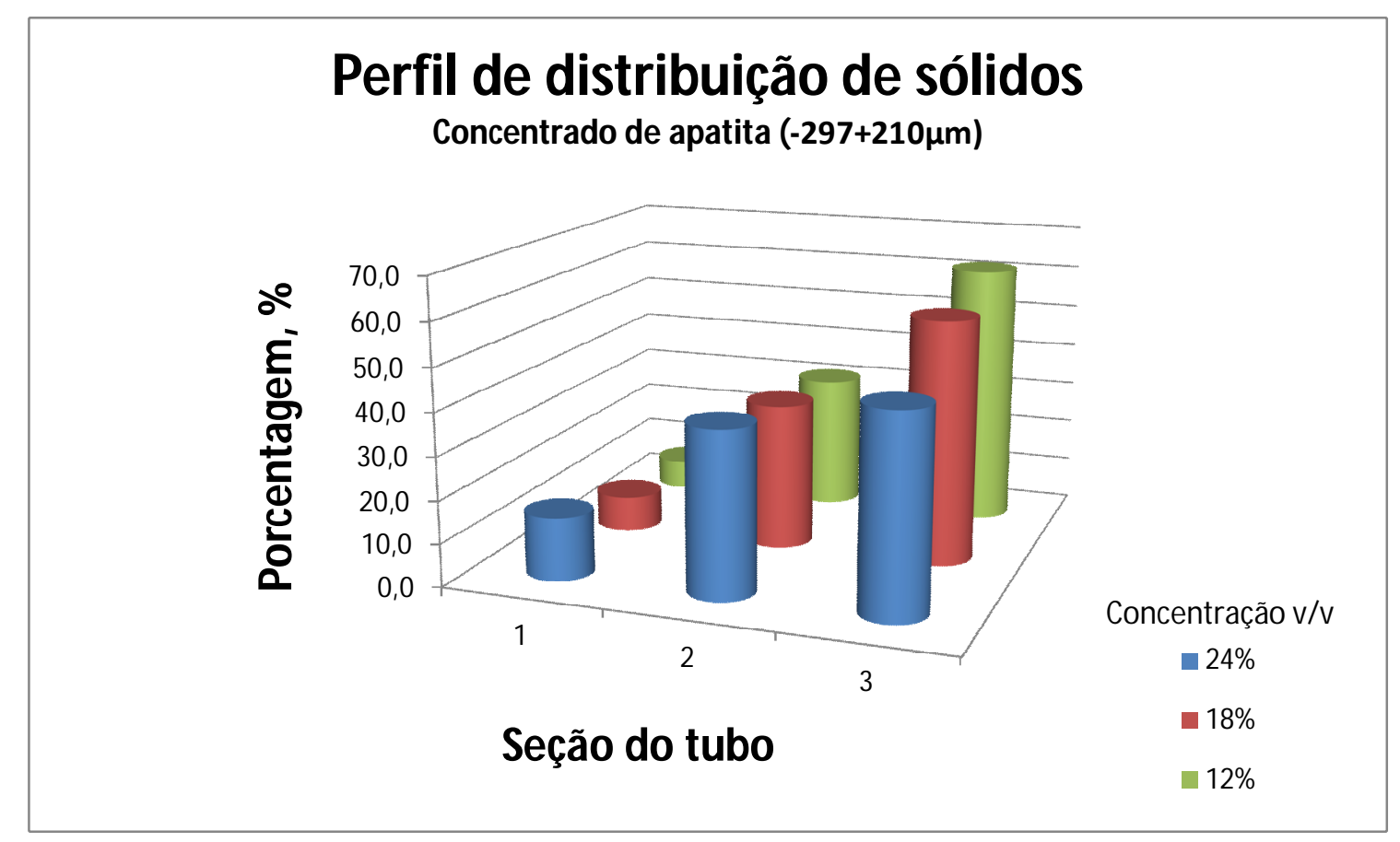

Figura A1-Distribuição de sólidos ao longo da seção transversal do duto de 25,4mm de diâmetro para concentrado de apatita.

(seção 1=topo; seção 2=meio; seção 3=base do duto).

Tabela A1-Valores da distribuição de sólidos ao longo da seção transversal do duto de $25,4 \mathrm{~mm}$ de diâmetro para concentrado de apatita $(-297+210 \mu \mathrm{m})$.

\begin{tabular}{c|c|c|c}
\hline Concentração (v/v) & $\mathbf{1 2 \%}$ & $\mathbf{1 8 \%}$ & $\mathbf{2 4 \%}$ \\
\hline Topo & 6,7 & 8,3 & 14,8 \\
\hline Meio & 31,5 & 34,3 & 38,8 \\
\hline Base & 61,8 & 57,3 & 46,4 \\
\hline
\end{tabular}




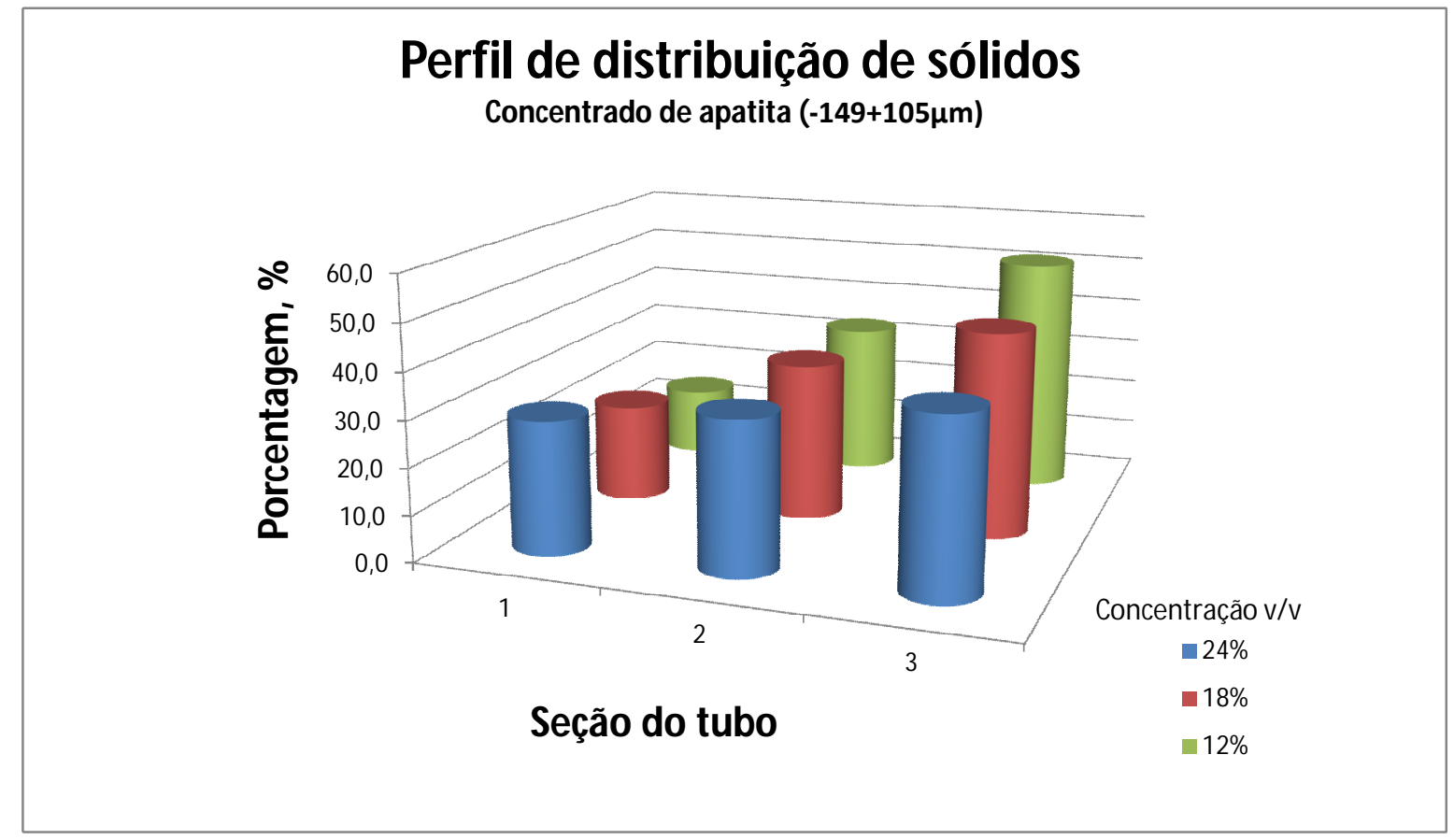

Figura A2-Distribuição de sólidos ao longo da seção transversal do duto de $25,4 \mathrm{~mm}$ de diâmetro para concentrado de apatita.

Tabela A2-Valores da distribuição de sólidos ao longo da seção transversal do duto de $25,4 \mathrm{~mm}$ de diâmetro para concentrado de apatita $(-149+105 \mu \mathrm{m})$.

\begin{tabular}{c|c|c|c}
\hline Concentração (v/v) & $\mathbf{1 2 \%}$ & $\mathbf{1 8 \%}$ & $\mathbf{2 4 \%}$ \\
\hline Topo & 14,9 & 21,3 & 28,7 \\
\hline Meio & 33,4 & 34,1 & 33,1 \\
\hline Base & 51,6 & 44,6 & 38,1 \\
\hline
\end{tabular}




\section{Perfil de distribuição de sólidos}

\section{Quartzo (-297+210 $\mu \mathrm{m})$}

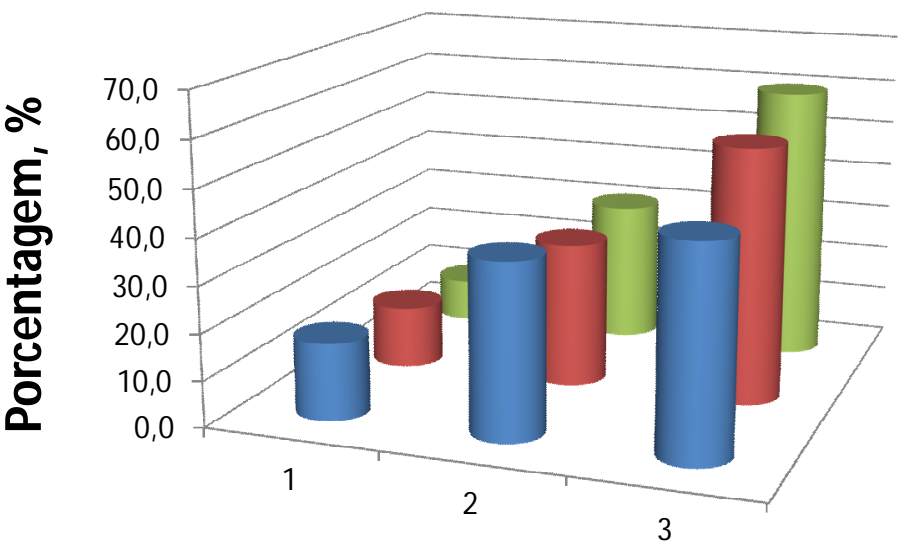

Seção do tubo

Concentração v/v

- $27 \%$

- $20 \%$

$14 \%$

Figura A3-Distribuição de sólidos ao longo da seção transversal do duto de 25,4mm de diâmetro para quartzo.

Tabela A3-Valores da distribuição de sólidos ao longo da seção transversal do duto de $25,4 \mathrm{~mm}$ de diâmetro para quartzo $(-297+210 \mu \mathrm{m})$.

\begin{tabular}{c|c|c|c}
\hline Concentração & $\mathbf{1 4 \%}$ & $\mathbf{2 0 \%}$ & $\mathbf{2 7 \%}$ \\
\hline Topo & 9,3 & 13,3 & 16,8 \\
\hline Meio & 30,8 & 31,2 & 37,7 \\
\hline Base & 59,9 & 55,3 & 45,4 \\
\hline
\end{tabular}




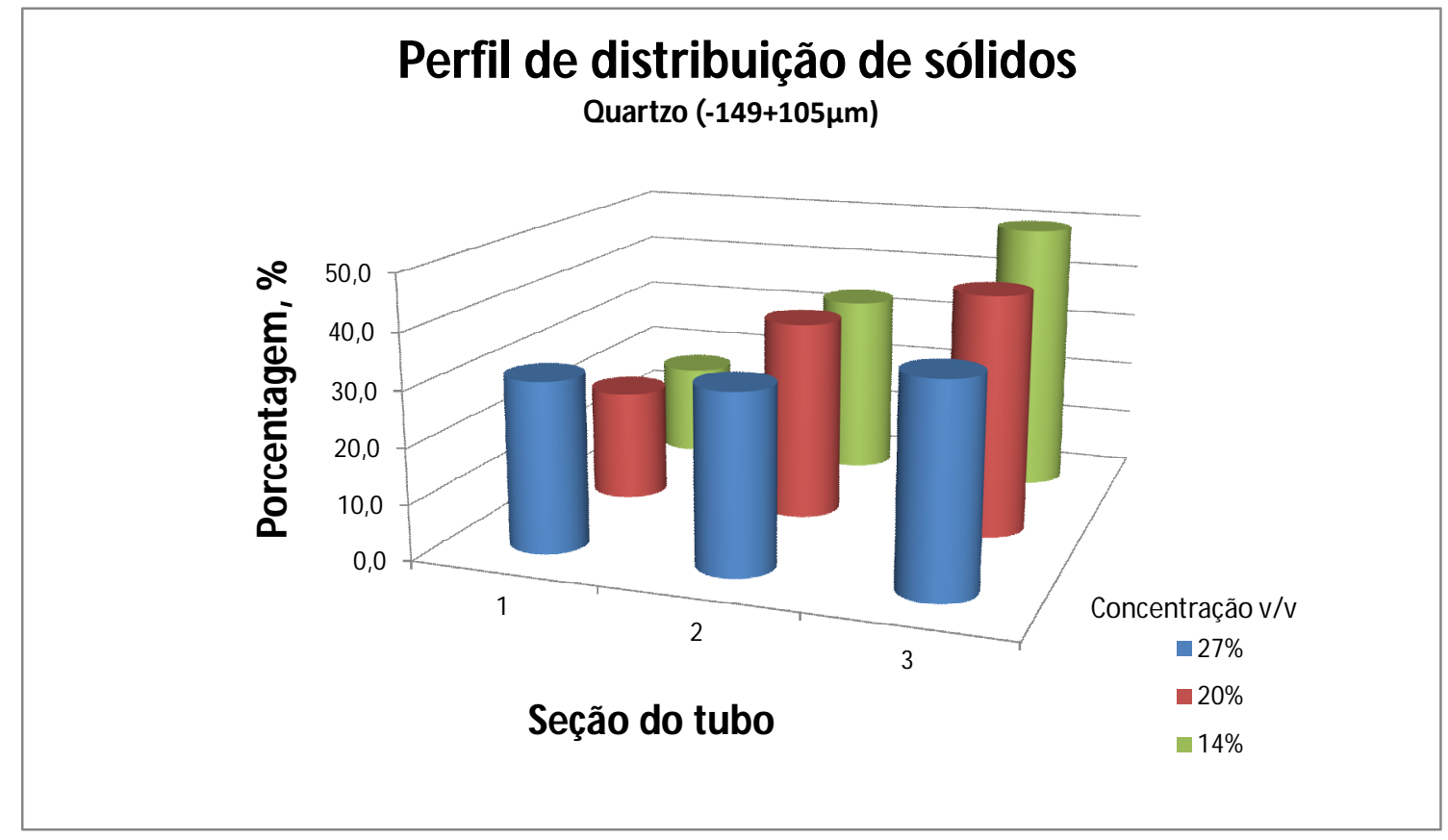

Figura A4-Distribuição de sólidos ao longo da seção transversal do duto de 25,4mm de diâmetro para quartzo.

Tabela A4-Valores da distribuição de sólidos ao longo da seção transversal do duto de $25,4 \mathrm{~mm}$ de diâmetro para quartzo $(-149+105 \mu \mathrm{m})$.

\begin{tabular}{c|c|c|c}
\hline Concentração & $\mathbf{1 4 \%}$ & $\mathbf{2 0 \%}$ & $\mathbf{2 7 \%}$ \\
\hline Topo & 16,9 & 20,2 & 30,2 \\
\hline Meio & 33,1 & 36,1 & 33,4 \\
\hline Base & 49,9 & 43,6 & 36,3 \\
\hline
\end{tabular}




\section{Perfil de distribuição de sólidos}

\section{Concentrado de hematita $(-297+210 \mu \mathrm{m})$}

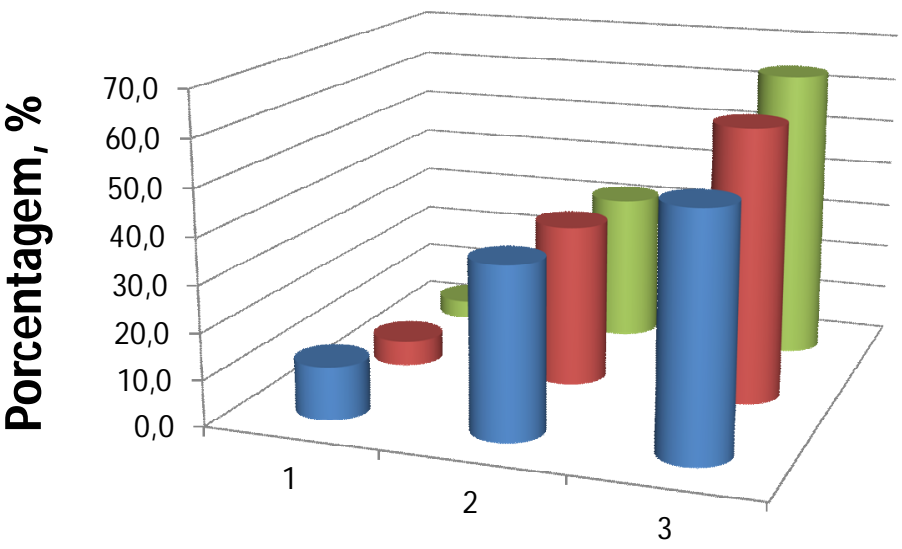

Seção do tubo

Concentração v/v

- $17 \%$

- $12 \%$

$8 \%$

Figura A5-Distribuição de sólidos ao longo da seção transversal do duto de 25,4mm de diâmetro para concentrado de hematita.

Tabela A5-Valores da distribuição de sólidos ao longo da seção transversal do duto de $25,4 \mathrm{~mm}$ de diâmetro para concentrado de hematita $(-297+210 \mu \mathrm{m})$.

\begin{tabular}{c|c|c|c}
\hline Concentração (v/v) & $\mathbf{8 \%}$ & $\mathbf{1 2 \%}$ & $\mathbf{1 7 \%}$ \\
\hline Topo & 3,9 & 5,5 & 11,5 \\
\hline Meio & 32,3 & 35,1 & 36,7 \\
\hline Base & 63,7 & 59,3 & 51,6 \\
\hline
\end{tabular}




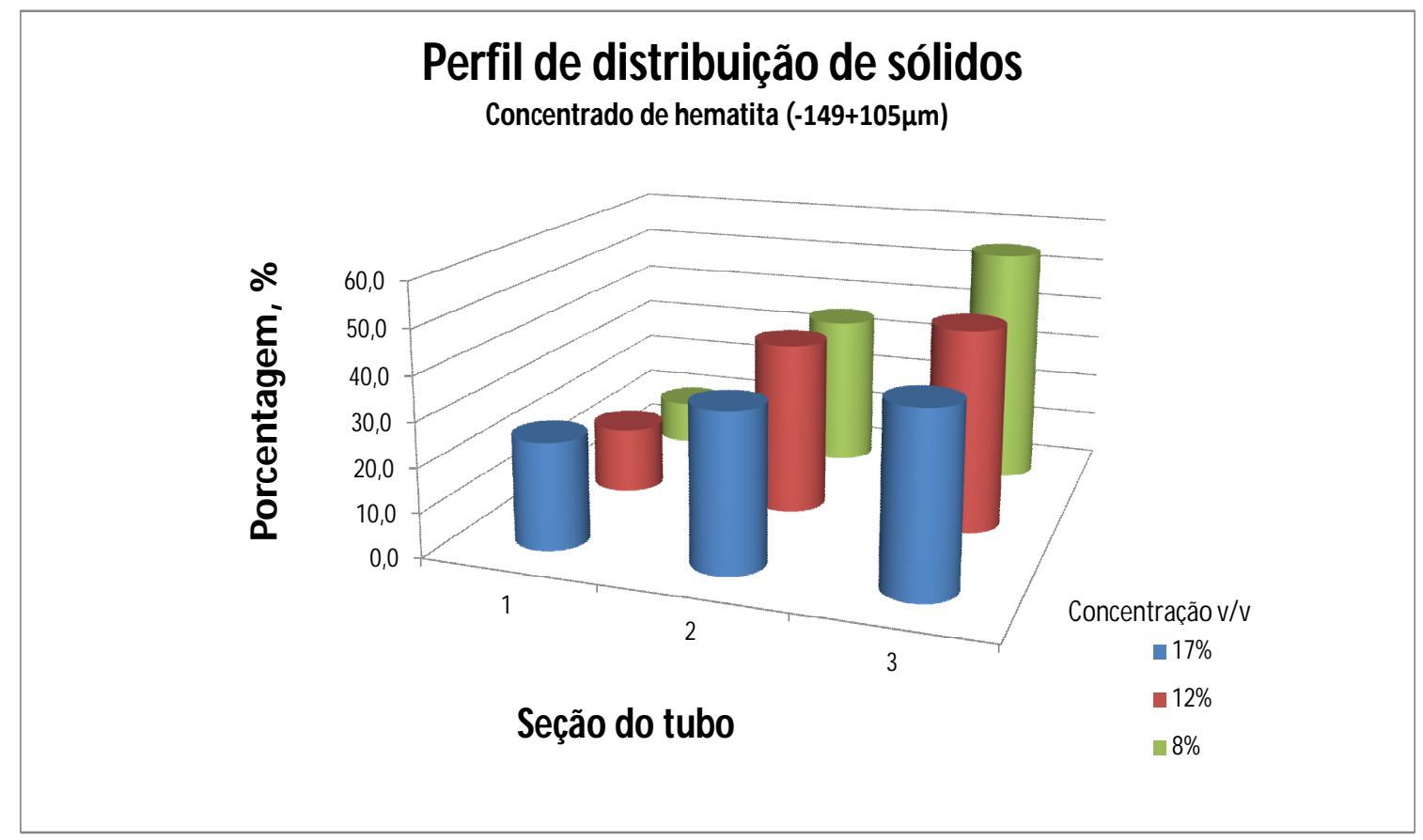

Figura A6-Distribuição de sólidos ao longo da seção transversal do duto de 25,4mm de diâmetro para concentrado de hematita.

Tabela A6-Valores da distribuição de sólidos ao longo da seção transversal do duto de $25,4 \mathrm{~mm}$ de diâmetro para concentrado de hematita $(-149+105 \mu \mathrm{m})$.

\begin{tabular}{c|c|c|c}
\hline Concentração (v/v) & $\mathbf{8 \%}$ & $\mathbf{1 2 \%}$ & $\mathbf{1 7 \%}$ \\
\hline Topo & 10,1 & 15,0 & 24,2 \\
\hline Meio & 35,1 & 38,9 & 35,4 \\
\hline Base & 54,8 & 46,0 & 40,3 \\
\hline
\end{tabular}




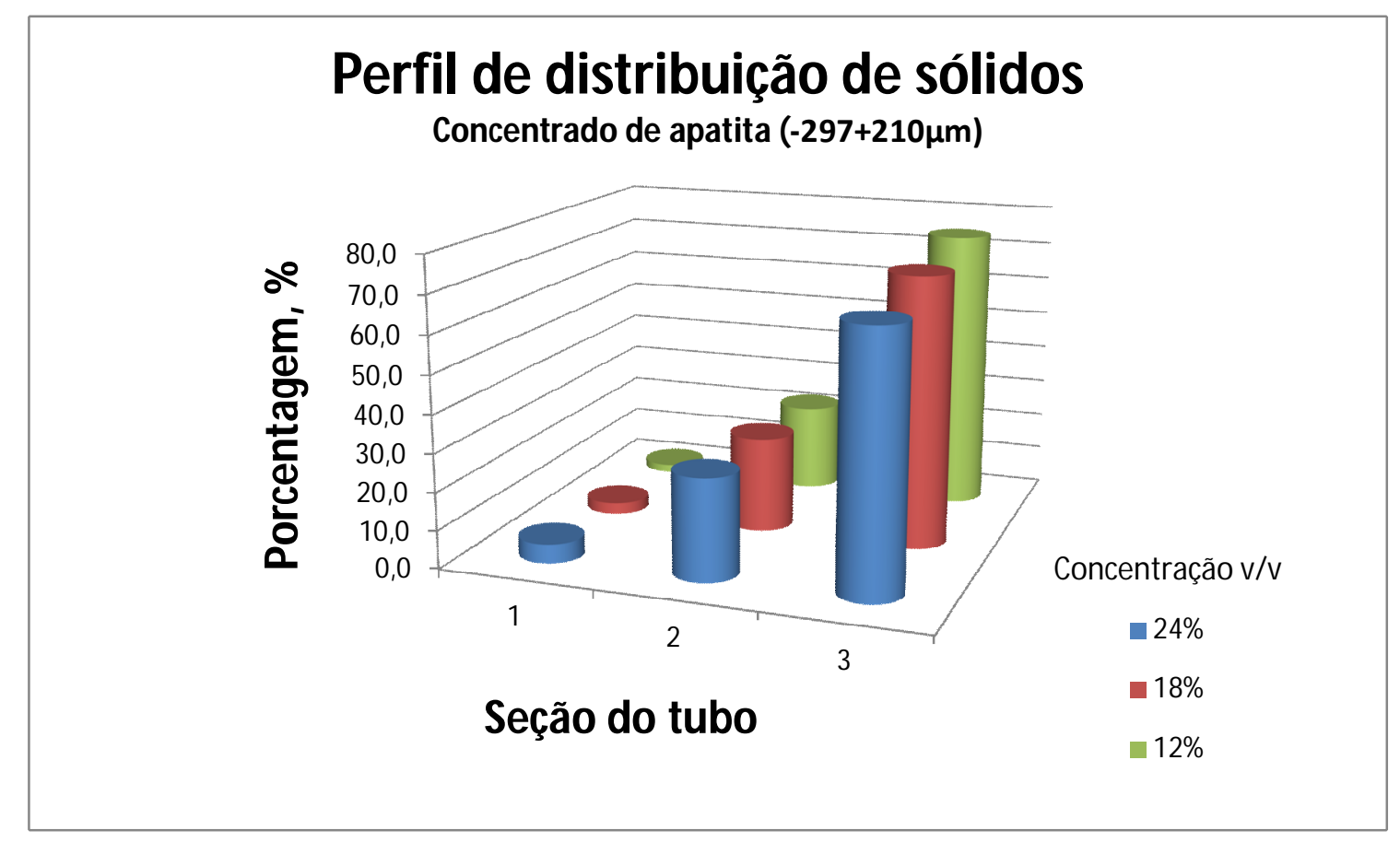

Figura A7-Distribuição de sólidos ao longo da seção transversal do duto de 50,8mm de diâmetro para concentrado de apatita.

Tabela A7-Valores da distribuição de sólidos ao longo da seção transversal do duto de $50,8 \mathrm{~mm}$ de diâmetro para concentrado de apatita $(-297+210 \mu \mathrm{m})$.

\begin{tabular}{c|c|c|c}
\hline Concentração (v/v) & $\mathbf{1 2 \%}$ & $\mathbf{1 8 \%}$ & $\mathbf{2 4 \%}$ \\
\hline Topo & 2,1 & 3,0 & 5,1 \\
\hline Meio & 23,1 & 25,3 & 27,0 \\
\hline Base & 74,8 & 71,7 & 67,9 \\
\hline
\end{tabular}




\section{Perfil de distribuição de sólidos \\ Concentrado de apatita $(-149+105 \mu \mathrm{m})$}

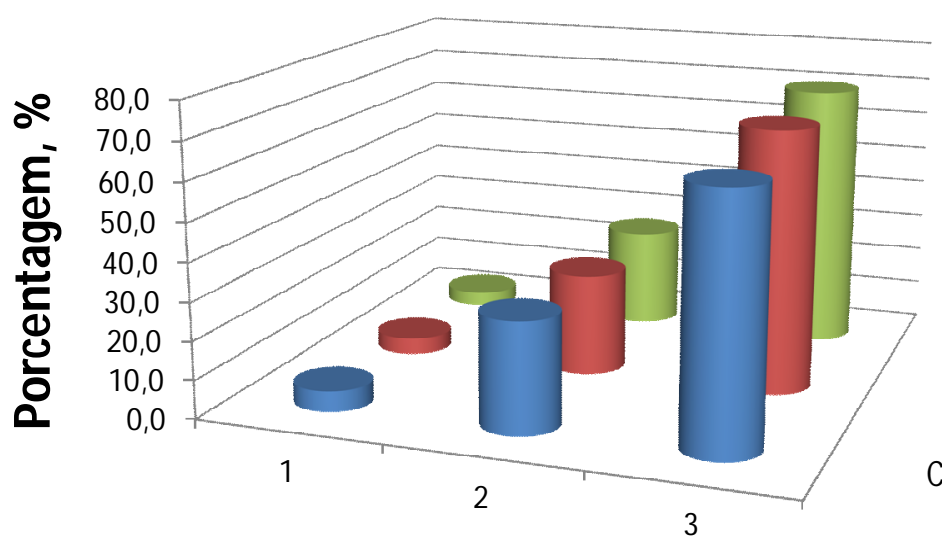

Seção do tubo

Concentracão v/v

$=24 \%$

$-18 \%$

$-12 \%$

Figura A8-Distribuição de sólidos ao longo da seção transversal do duto de $50,8 \mathrm{~mm}$ de diâmetro para concentrado de apatita.

Tabela A8-Valores da distribuição de sólidos ao longo da seção transversal do duto de $50,8 \mathrm{~mm}$ de diâmetro para concentrado de apatita $(-149+105 \mu \mathrm{m})$.

\begin{tabular}{c|c|c|c}
\hline Concentração (v/v) & $\mathbf{1 2 \%}$ & $\mathbf{1 8 \%}$ & $\mathbf{2 4 \%}$ \\
\hline Topo & 3,8 & 4,3 & 5,5 \\
\hline Meio & 26,1 & 26,7 & 29,1 \\
\hline Base & 70,1 & 69,0 & 65,5 \\
\hline
\end{tabular}




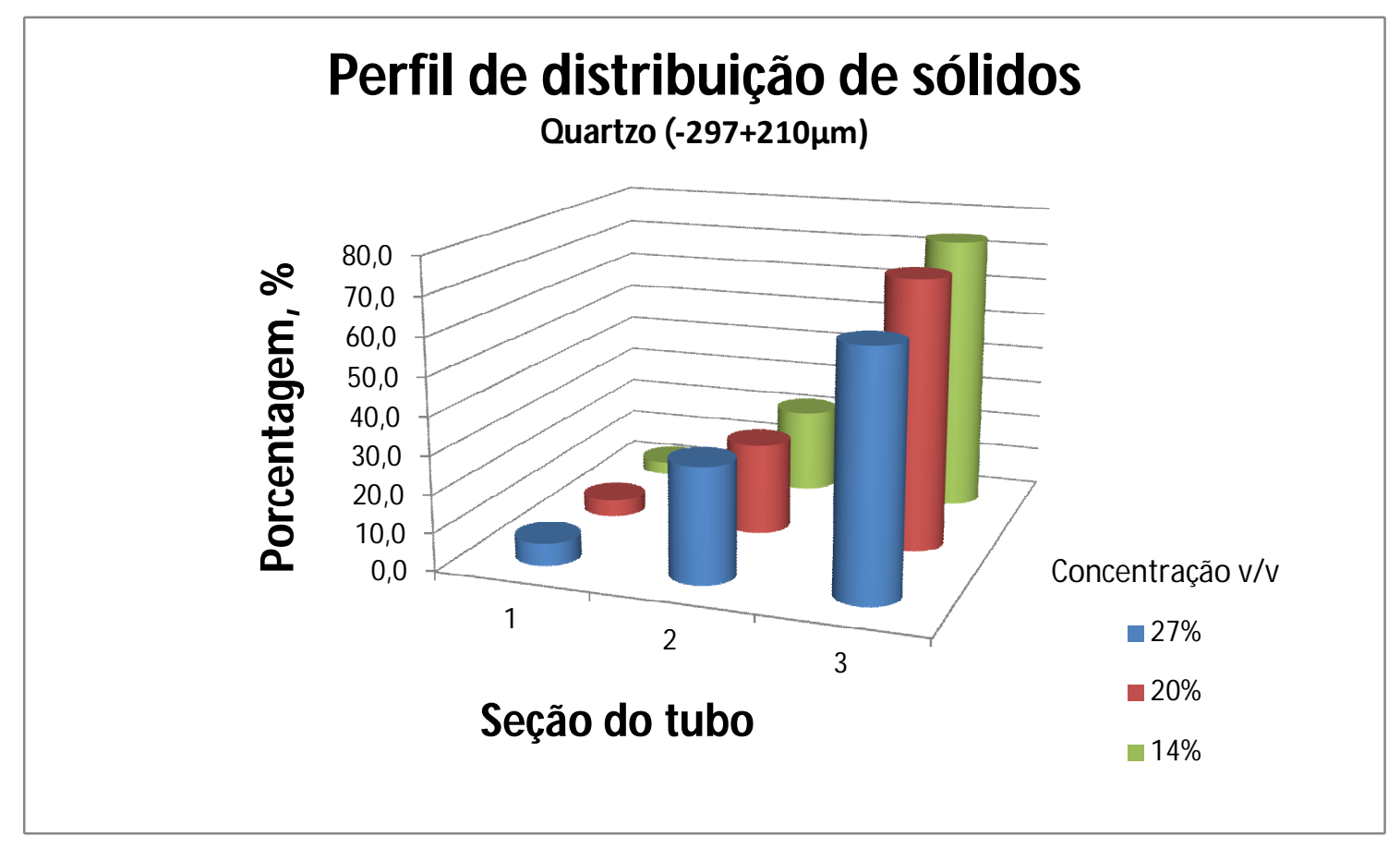

Figura A9-Distribuição de sólidos ao longo da seção transversal do duto de $50,8 \mathrm{~mm}$ de diâmetro para quartzo.

Tabela A9-Valores da distribuição de sólidos ao longo da seção transversal do duto de 50,8mm de diâmetro para quartzo $(-297+210 \mu \mathrm{m})$.

\begin{tabular}{c|c|c|c}
\hline Concentração (v/v) & $\mathbf{1 4 \%}$ & $\mathbf{2 0 \%}$ & $\mathbf{2 7 \%}$ \\
\hline Topo & 3,5 & 4,5 & 6,0 \\
\hline Meio & 22,5 & 24,1 & 30,5 \\
\hline Base & 74,0 & 71,4 & 63,5 \\
\hline
\end{tabular}




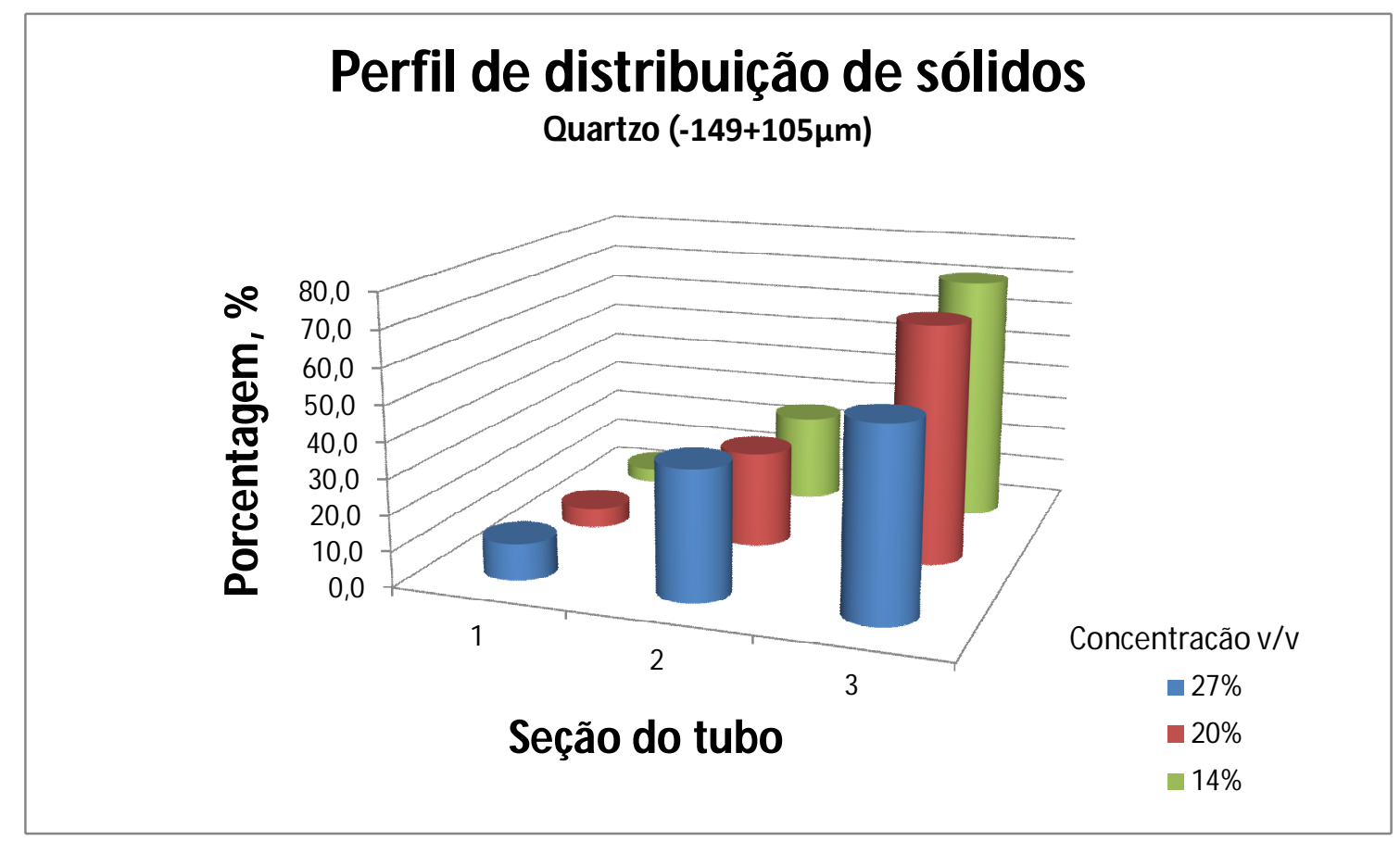

Figura A10-Distribuição de sólidos ao longo da seção transversal do duto de 50,8mm de diâmetro para quartzo.

Tabela A10-Valores da distribuição de sólidos ao longo da seção transversal do duto de $50,8 \mathrm{~mm}$ de diâmetro para quartzo $(-149+105 \mu \mathrm{m})$.

\begin{tabular}{c|c|c|c}
\hline Concentração (v/v) & $\mathbf{1 4 \%}$ & $\mathbf{2 0 \%}$ & $\mathbf{2 7 \%}$ \\
\hline Topo & 4,2 & 5,5 & 10,5 \\
\hline Meio & 25,1 & 27,0 & 36,5 \\
\hline Base & 70,7 & 67,5 & 53,0 \\
\hline
\end{tabular}




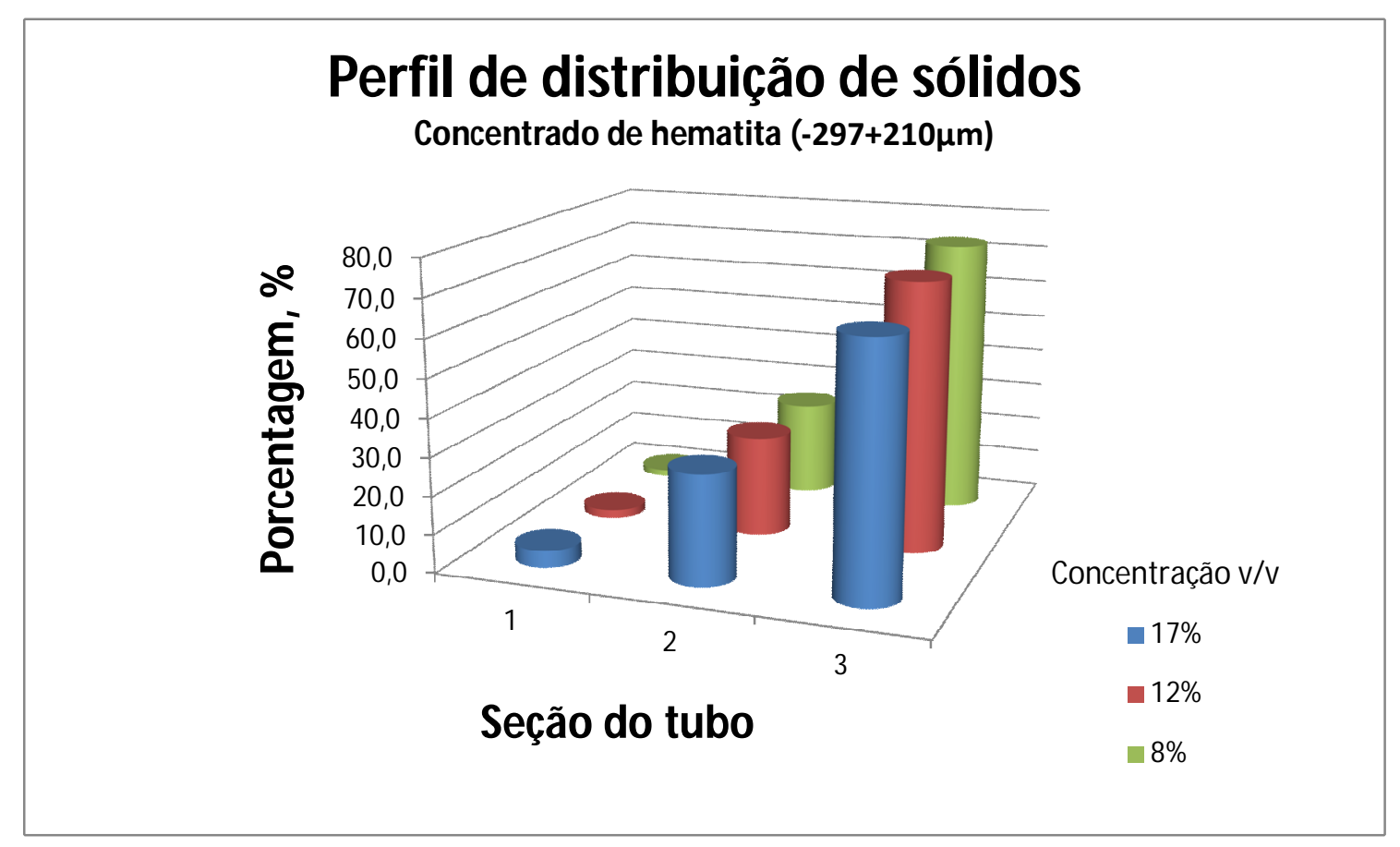

Figura A11-Distribuição de sólidos ao longo da seção transversal do duto de $50,8 \mathrm{~mm}$ de diâmetro para concentrado de hematita.

Tabela A11-Valores da distribuição de sólidos ao longo da seção transversal do duto de $50,8 \mathrm{~mm}$ de diâmetro para concentrado de hematita $(-297+249 \mu \mathrm{m})$.

\begin{tabular}{c|c|c|c}
\hline Concentração (v/v) & $\mathbf{8} \%$ & $\mathbf{1 2 \%}$ & $\mathbf{1 7 \%}$ \\
\hline Topo & 1,7 & 2,2 & 4,5 \\
\hline Meio & 25,0 & 26,6 & 29,0 \\
\hline Base & 73,3 & 71,2 & 66,5 \\
\hline
\end{tabular}




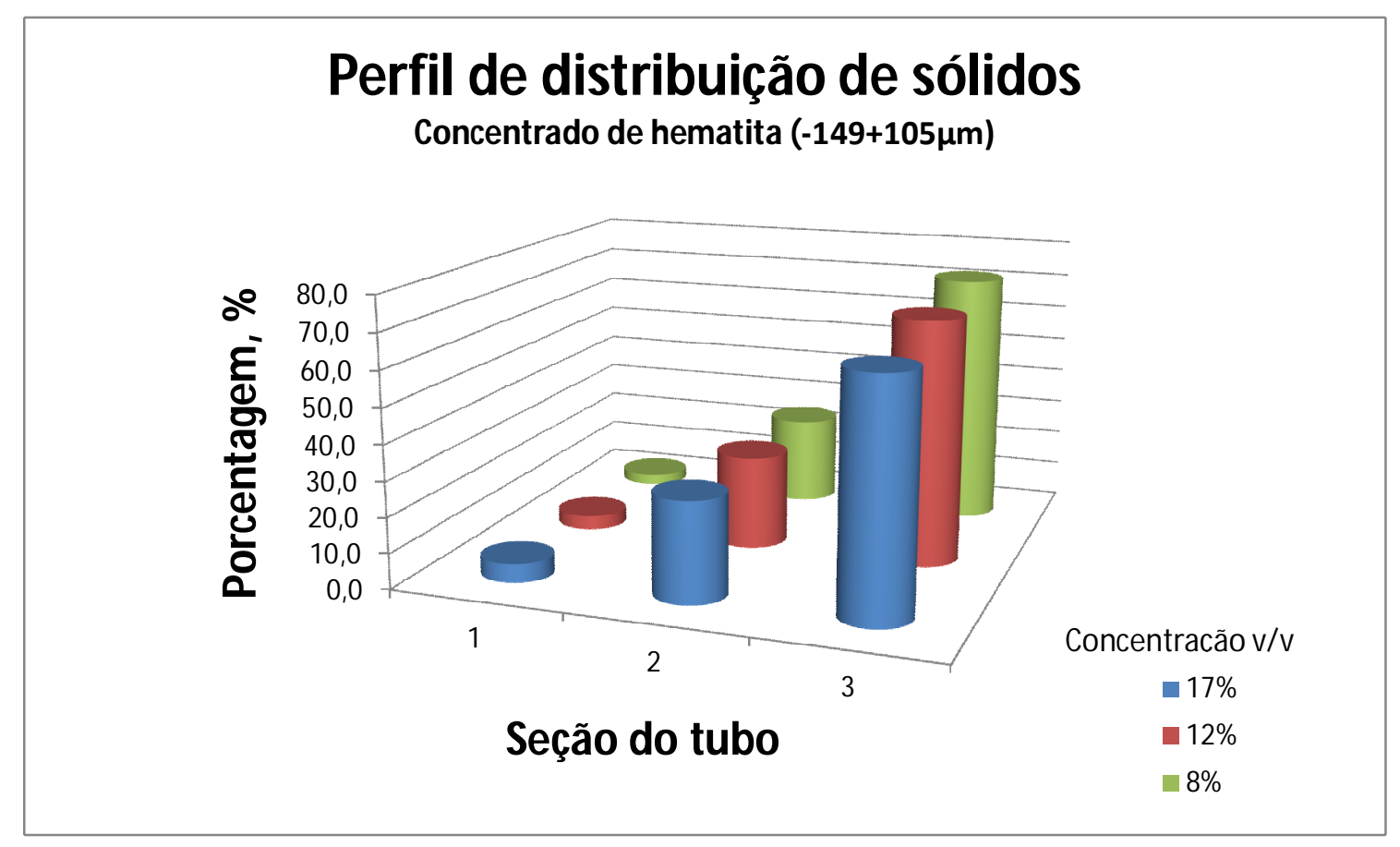

Figura A12-Distribuição de sólidos ao longo da seção transversal do duto de $50,8 \mathrm{~mm}$ de diâmetro para concentrado de hematita.

Tabela A12-Valores da distribuição de sólidos ao longo da seção transversal do duto de $50,8 \mathrm{~mm}$ de diâmetro para concentrado de hematita $(-149+105 \mu \mathrm{m})$.

\begin{tabular}{c|c|c|c}
\hline Concentração (v/v) & $\mathbf{8 \%}$ & $\mathbf{1 2 \%}$ & $\mathbf{1 7 \%}$ \\
\hline Topo & 3,0 & 3,9 & 5,4 \\
\hline Meio & 25,0 & 26,5 & 28,5 \\
\hline Base & 72,0 & 69,6 & 66,1 \\
\hline
\end{tabular}




\section{APÊNDICE B}

\section{B1-Dados de gradiente de pressão e velocidade de fluxo}

Tabela B1-Dados de gradiente de pressão e velocidade média de fluxo para polpas minerais de concentrado de apatita $(-149+105 \mu \mathrm{m})$.

\begin{tabular}{|c|c|c|c|}
\hline $\begin{array}{l}\text { Diâmetro do } \\
\text { tubo, mm }\end{array}$ & $\begin{array}{c}\text { Concentração v/v } \\
\%\end{array}$ & $\begin{array}{c}\mathrm{V} \\
\mathrm{m} / \mathrm{s}\end{array}$ & $\begin{array}{c}\Delta P / L \\
\mathrm{kPa} / \mathrm{m}\end{array}$ \\
\hline \multirow{5}{*}{25,4} & \multirow{5}{*}{12} & 1,0 & 1665 \\
\hline & & 1,2 & 1518 \\
\hline & & 1,7 & 2087 \\
\hline & & 2,1 & 2792 \\
\hline & & 2,4 & 3282 \\
\hline
\end{tabular}

Tabela B2-Dados de gradiente de pressão e velocidade média de fluxo para polpas minerais de concentrado de apatita $(-149+105 \mu \mathrm{m})$.

\begin{tabular}{|c|c|c|c|}
\hline $\begin{array}{l}\text { Diâmetro do } \\
\text { tubo, } \mathrm{mm}\end{array}$ & $\begin{array}{c}\text { Concentração v/v } \\
\%\end{array}$ & $\begin{array}{l}\mathrm{V} \\
\mathrm{m} / \mathrm{s}\end{array}$ & $\begin{array}{c}\Delta \mathrm{P} / \mathrm{L} \\
\mathrm{kPa} / \mathrm{m}\end{array}$ \\
\hline \multirow{5}{*}{25,4} & \multirow{5}{*}{18} & 1,1 & 2253 \\
\hline & & 1,3 & 1861 \\
\hline & & 1,6 & 2302 \\
\hline & & 2,0 & 2988 \\
\hline & & 2,3 & 3528 \\
\hline
\end{tabular}


Tabela B3-Dados de gradiente de pressão e velocidade média de fluxo para polpas minerais de concentrado de apatita $(-149+105 \mu \mathrm{m})$.

\begin{tabular}{c|c|c|c}
\hline $\begin{array}{c}\text { Diâmetro do } \\
\text { tubo, } \mathbf{m m}\end{array}$ & $\begin{array}{c}\text { Concentração v/v } \\
\%\end{array}$ & $\begin{array}{c}\mathbf{V} \\
\mathbf{m} / \mathbf{s}\end{array}$ & $\begin{array}{c}\mathbf{\Delta P / L} \\
\mathbf{k P a} / \mathbf{m}\end{array}$ \\
\hline \multirow{2}{*}{25,4} & & 1,1 & 2645 \\
\cline { 3 - 4 } & \multirow{2}{*}{24} & 1,5 & 2449 \\
\cline { 3 - 4 } & \multirow{2}{*}{24} & 1,8 & 2841 \\
\cline { 3 - 4 } & & 2,1 & 3526 \\
\cline { 3 - 4 } & & 2,5 & 4212 \\
\hline
\end{tabular}

Tabela B4-Dados de gradiente de pressão e velocidade média de fluxo para polpas minerais de concentrado de apatita $(-297+249 \mu \mathrm{m})$.

\begin{tabular}{|c|c|c|c|}
\hline $\begin{array}{l}\text { Diâmetro do } \\
\text { tubo, mm }\end{array}$ & $\begin{array}{c}\text { Concentração v/v } \\
\%\end{array}$ & $\begin{array}{c}\mathrm{V} \\
\mathrm{m} / \mathrm{s}\end{array}$ & $\begin{array}{c}\Delta \mathrm{P} / \mathrm{L} \\
\mathrm{kPa} / \mathrm{m}\end{array}$ \\
\hline \multirow{5}{*}{25,4} & \multirow{5}{*}{12} & 1,3 & 2254 \\
\hline & & 1,5 & 1861 \\
\hline & & 1,9 & 2302 \\
\hline & & 2,3 & 2939 \\
\hline & & 2,6 & 3620 \\
\hline
\end{tabular}


Tabela B5-Dados de gradiente de pressão e velocidade média de fluxo para polpas minerais de concentrado de apatita $(-297+249 \mu \mathrm{m})$.

\begin{tabular}{c|c|c|c}
\hline $\begin{array}{c}\text { Diâmetro do } \\
\text { tubo, } \mathbf{m m}\end{array}$ & $\begin{array}{c}\text { Concentração } \mathbf{v} / \mathbf{v} \\
\%\end{array}$ & $\begin{array}{c}\mathbf{V} \\
\mathbf{m} / \mathbf{s}\end{array}$ & $\begin{array}{c}\mathbf{\Delta P / \mathbf { L }} \\
\mathbf{k P a} / \mathbf{m}\end{array}$ \\
\hline \multirow{2}{*}{25,4} & & 1,5 & 2567 \\
\cline { 3 - 4 } & \multirow{2}{*}{18} & 1,7 & 2253 \\
\cline { 3 - 4 } & & 2,0 & 2694 \\
\cline { 3 - 4 } & & 2,3 & 3184 \\
\cline { 3 - 4 } & & 2,6 & 3821 \\
\hline
\end{tabular}

Tabela B6-Dados de gradiente de pressão e velocidade média de fluxo para polpas minerais de concentrado de apatita $(-297+249 \mu \mathrm{m})$.

\begin{tabular}{c|c|c|c}
\hline $\begin{array}{c}\text { Diâmetro do } \\
\text { tubo, } \mathbf{m m}\end{array}$ & $\begin{array}{c}\text { Concentração } \mathbf{v} / \mathbf{v} \\
\%\end{array}$ & $\begin{array}{c}\mathbf{V} \\
\mathbf{m} / \mathbf{s}\end{array}$ & $\begin{array}{c}\mathbf{\Delta P / \mathbf { L }} \\
\mathbf{k P a} / \mathbf{m}\end{array}$ \\
\hline \multirow{2}{*}{25,4} & & 1,5 & 3330 \\
\cline { 2 - 3 } & \multirow{2}{*}{24} & 1,9 & 3037 \\
\cline { 3 - 4 } & & 2,4 & 3730 \\
\cline { 3 - 4 } & & 2,7 & 4410 \\
\cline { 3 - 4 } & & 3,0 & 4800 \\
\hline
\end{tabular}


Tabela B7-Dados de gradiente de pressão e velocidade média de fluxo para polpas minerais de concentrado de apatita $(-149+105 \mu \mathrm{m})$.

\begin{tabular}{c|c|c|c}
\hline $\begin{array}{c}\text { Diâmetro do } \\
\text { tubo, } \mathbf{m m}\end{array}$ & $\begin{array}{c}\text { Concentração v/v } \\
\%\end{array}$ & $\begin{array}{c}\mathbf{V} \\
\mathbf{m} / \mathbf{s}\end{array}$ & $\begin{array}{c}\mathbf{\Delta P / L} \\
\mathbf{k P a} / \mathbf{m}\end{array}$ \\
\hline \multirow{2}{*}{50,8} & & 1,2 & 930 \\
\cline { 2 - 4 } & \multirow{2}{*}{12} & 1,5 & 835 \\
\cline { 2 - 4 } & \multirow{2}{*}{$*$} & 1,9 & 1077 \\
\cline { 2 - 3 } & & 2,1 & 1273 \\
\cline { 2 - 3 } & & 2,3 & 1469 \\
\hline
\end{tabular}

Tabela B8-Dados de gradiente de pressão e velocidade média de fluxo para polpas minerais de concentrado de apatita $(-149+105 \mu \mathrm{m})$.

\begin{tabular}{c|c|c|c}
\hline $\begin{array}{c}\text { Diâmetro do } \\
\text { tubo, } \mathbf{m m}\end{array}$ & $\begin{array}{c}\text { Concentração v/v } \\
\%\end{array}$ & $\begin{array}{c}\mathbf{V} \\
\mathbf{m} / \mathbf{s}\end{array}$ & $\begin{array}{c}\mathbf{\Delta P / \mathbf { L }} \\
\mathbf{k P a} / \mathbf{m}\end{array}$ \\
\hline \multirow{2}{*}{50,8} & & 1,4 & 1175 \\
\cline { 2 - 3 } & \multirow{2}{*}{18} & 1,7 & 1077 \\
\cline { 2 - 3 } & & 2,0 & 1273 \\
\cline { 3 - 4 } & & 2,3 & 1567 \\
\cline { 3 - 4 } & & 2,5 & 1760 \\
\hline
\end{tabular}


Tabela B9-Dados de gradiente de pressão e velocidade média de fluxo para polpas minerais de concentrado de apatita $(-149+105 \mu \mathrm{m})$.

\begin{tabular}{c|c|c|c}
\hline $\begin{array}{c}\text { Diâmetro do } \\
\text { tubo, } \mathbf{m m}\end{array}$ & $\begin{array}{c}\text { Concentração v/v } \\
\%\end{array}$ & $\begin{array}{c}\mathbf{V} \\
\mathbf{m} / \mathbf{s}\end{array}$ & $\begin{array}{c}\mathbf{\Delta P / L} \\
\mathbf{k P a} / \mathbf{m}\end{array}$ \\
\hline \multirow{2}{*}{50,8} & & 1,5 & 1371 \\
\cline { 2 - 3 } & \multirow{2}{*}{24} & 1,9 & 1273 \\
\cline { 3 - 4 } & & 2,1 & 1469 \\
\cline { 3 - 4 } & & 2,3 & 1763 \\
\hline & & 2,5 & 1959 \\
\hline
\end{tabular}

Tabela B10-Dados de gradiente de pressão e velocidade média de fluxo para polpas minerais de concentrado de apatita $(-297+249 \mu \mathrm{m})$.

\begin{tabular}{c|c|c|c}
\hline $\begin{array}{c}\text { Diâmetro do } \\
\text { tubo, } \mathbf{m m}\end{array}$ & $\begin{array}{c}\text { Concentração } \mathbf{v} / \mathbf{v} \\
\%\end{array}$ & $\begin{array}{c}\mathbf{V} \\
\mathbf{m} / \mathbf{s}\end{array}$ & $\begin{array}{c}\mathbf{\Delta P} / \mathbf{L} \\
\mathbf{k P a} / \mathbf{m}\end{array}$ \\
\hline \multirow{2}{*}{50,8} & & 1,3 & 1176 \\
\cline { 2 - 3 } & \multirow{2}{*}{12} & 1,8 & 1029 \\
\cline { 3 - 4 } & & 2,1 & 1274 \\
\cline { 3 - 4 } & & 2,4 & 1469 \\
\cline { 3 - 4 } & & 2,7 & 1764 \\
\hline
\end{tabular}


Tabela B11-Dados de gradiente de pressão e velocidade média de fluxo para polpas minerais de concentrado de apatita $(-297+249 \mu \mathrm{m})$.

\begin{tabular}{|c|c|c|c|}
\hline $\begin{array}{l}\text { Diâmetro do } \\
\text { tubo, mm }\end{array}$ & $\begin{array}{c}\text { Concentração v/v } \\
\%\end{array}$ & $\begin{array}{c}v \\
m / s\end{array}$ & $\begin{array}{c}\Delta \mathrm{P} / \mathrm{L} \\
\mathrm{kPa} / \mathrm{m}\end{array}$ \\
\hline \multirow{5}{*}{50,8} & \multirow{5}{*}{18} & 1,5 & 1371 \\
\hline & & 2,0 & 1275 \\
\hline & & 2,3 & 1460 \\
\hline & & 2,4 & 1665 \\
\hline & & 2,6 & 1861 \\
\hline
\end{tabular}

Tabela B12-Dados de gradiente de pressão e velocidade média de fluxo para polpas minerais de concentrado de apatita $(-297+249 \mu \mathrm{m})$.

\begin{tabular}{|c|c|c|c|}
\hline $\begin{array}{l}\text { Diâmetro do } \\
\text { tubo, mm }\end{array}$ & $\begin{array}{c}\text { Concentração v/v } \\
\%\end{array}$ & $\begin{array}{c}\mathrm{V} \\
\mathrm{m} / \mathrm{s}\end{array}$ & $\begin{array}{c}\Delta \mathrm{P} / \mathrm{L} \\
\mathrm{kPa} / \mathrm{m}\end{array}$ \\
\hline \multirow{5}{*}{50,8} & \multirow{5}{*}{24} & 1,8 & 1567 \\
\hline & & 2,2 & 1469 \\
\hline & & 2,3 & 1665 \\
\hline & & 2,6 & 1870 \\
\hline & & 2,8 & 2060 \\
\hline
\end{tabular}


Tabela B13-Dados de gradiente de pressão e velocidade média de fluxo para polpas minerais de concentrado de hematita $(-149+105 \mu \mathrm{m})$.

\begin{tabular}{|c|c|c|c|}
\hline $\begin{array}{l}\text { Diâmetro do } \\
\text { tubo, } \mathrm{mm}\end{array}$ & $\begin{array}{c}\text { Concentração v/v } \\
\%\end{array}$ & $\begin{array}{c}\mathrm{V} \\
\mathrm{m} / \mathrm{s}\end{array}$ & $\begin{array}{r}\Delta \mathrm{P} / \mathrm{L} \\
\mathrm{kPa} / \mathrm{m}\end{array}$ \\
\hline \multirow{5}{*}{25,4} & \multirow{5}{*}{8} & 1,2 & 1960 \\
\hline & & 1,6 & 1812 \\
\hline & & 2,1 & 2351 \\
\hline & & 2,6 & 3135 \\
\hline & & 2,9 & 3624 \\
\hline
\end{tabular}

Tabela B14-Dados de gradiente de pressão e velocidade média de fluxo para polpas minerais de concentrado de hematita $(-149+105 \mu \mathrm{m})$.

\begin{tabular}{c|c|c|c}
\hline $\begin{array}{c}\text { Diâmetro do } \\
\text { tubo, } \mathbf{m m}\end{array}$ & $\begin{array}{c}\text { Concentração } \mathbf{v} / \mathbf{v} \\
\%\end{array}$ & $\begin{array}{c}\mathbf{V} \\
\mathbf{m} / \mathbf{s}\end{array}$ & $\begin{array}{c}\mathbf{\Delta P / \mathbf { L }} \\
\mathbf{k P a} / \mathbf{m}\end{array}$ \\
\hline \multirow{2}{*}{25,4} & & 1,4 & 2400 \\
\cline { 3 - 4 } & \multirow{2}{*}{12} & 1,8 & 2253 \\
\cline { 3 - 4 } & & 2,1 & 2645 \\
\cline { 3 - 4 } & & 2,6 & 3379 \\
\cline { 3 - 4 } & & 2,9 & 4020 \\
\hline
\end{tabular}


Tabela B15-Dados de gradiente de pressão e velocidade média de fluxo para polpas minerais de concentrado de hematita $(-149+105 \mu \mathrm{m})$.

\begin{tabular}{c|c|c|c}
\hline $\begin{array}{c}\text { Diâmetro do } \\
\text { tubo, } \mathbf{m m}\end{array}$ & $\begin{array}{c}\text { Concentração v/v } \\
\%\end{array}$ & $\begin{array}{c}\mathbf{V} \\
\mathbf{m} / \mathbf{s}\end{array}$ & $\begin{array}{c}\Delta \mathbf{\Delta} / \mathbf{L} \\
\mathbf{k P a} / \mathbf{m}\end{array}$ \\
\hline \multirow{2}{*}{25,4} & & 1,6 & 3037 \\
\cline { 3 - 4 } & \multirow{2}{*}{17} & 2,0 & 2800 \\
\cline { 3 - 4 } & \multirow{2}{*}{17} & 2,3 & 3330 \\
\cline { 3 - 4 } & & 2,7 & 4016 \\
\cline { 3 - 4 } & & 3,0 & 4702 \\
\hline
\end{tabular}

Tabela B16-Dados de gradiente de pressão e velocidade média de fluxo para polpas minerais de concentrado de hematita $(-297+249 \mu \mathrm{m})$.

\begin{tabular}{c|c|c|c}
\hline $\begin{array}{c}\text { Diâmetro do } \\
\text { tubo, } \mathbf{m m}\end{array}$ & $\begin{array}{c}\text { Concentração v/v } \\
\%\end{array}$ & $\begin{array}{c}\mathbf{V} \\
\mathbf{m} / \mathbf{s}\end{array}$ & $\begin{array}{c}\Delta \mathbf{P} / \mathbf{L} \\
\mathbf{k P a} / \mathbf{m}\end{array}$ \\
\hline \multirow{2}{*}{25,4} & & 1,5 & 2457 \\
\cline { 3 - 4 } & \multirow{2}{*}{8} & 2,0 & 2155 \\
\cline { 3 - 4 } & \multirow{2}{*}{8} & 2,3 & 2596 \\
\cline { 3 - 4 } & & 2,7 & 3428 \\
\cline { 3 - 4 } & & 3,1 & 4114 \\
\hline
\end{tabular}


Tabela B17-Dados de gradiente de pressão e velocidade média de fluxo para polpas minerais de concentrado de hematita $(-297+249 \mu \mathrm{m})$.

\begin{tabular}{c|c|c|c}
\hline $\begin{array}{c}\text { Diâmetro do } \\
\text { tubo, } \mathbf{m m}\end{array}$ & $\begin{array}{c}\text { Concentração v/v } \\
\%\end{array}$ & $\begin{array}{c}\mathbf{V} \\
\mathbf{m} / \mathbf{s}\end{array}$ & $\begin{array}{c}\Delta \mathbf{P} / \mathbf{L} \\
\mathbf{k P a} / \mathbf{m}\end{array}$ \\
\hline \multirow{2}{*}{25,4} & & 1,8 & 3330 \\
\cline { 3 - 4 } & \multirow{2}{*}{12} & 2,1 & 3040 \\
\cline { 3 - 4 } & \multirow{2}{*}{12} & 2,5 & 3526 \\
\cline { 3 - 4 } & & 2,8 & 4016 \\
\cline { 3 - 4 } & & 3,1 & 4680 \\
\hline
\end{tabular}

Tabela B18-Dados de gradiente de pressão e velocidade média de fluxo para polpas minerais de concentrado de hematita $(-297+249 \mu \mathrm{m})$.

\begin{tabular}{c|c|c|c}
\hline $\begin{array}{c}\text { Diâmetro do } \\
\text { tubo, } \mathbf{m m}\end{array}$ & $\begin{array}{c}\text { Concentração v/v } \\
\%\end{array}$ & $\begin{array}{c}\mathbf{V} \\
\mathbf{m} / \mathbf{s}\end{array}$ & $\begin{array}{c}\Delta \mathbf{P} / \mathbf{L} \\
\mathbf{k P a} / \mathbf{m}\end{array}$ \\
\hline \multirow{2}{*}{25,4} & & 1,8 & 3722 \\
\cline { 3 - 4 } & \multirow{2}{*}{17} & 2,2 & 3428 \\
\cline { 3 - 4 } & \multirow{2}{*}{17} & 2,6 & 4020 \\
\cline { 3 - 4 } & & 3,0 & 4604 \\
\cline { 3 - 4 } & & 3,2 & 5100 \\
\hline
\end{tabular}


Tabela B19-Dados de gradiente de pressão e velocidade média de fluxo para polpas minerais de concentrado de hematita $(-149+105 \mu \mathrm{m})$.

\begin{tabular}{c|c|c|c}
\hline $\begin{array}{c}\text { Diâmetro do } \\
\text { tubo, } \mathbf{m m}\end{array}$ & $\begin{array}{c}\text { Concentração v/v } \\
\%\end{array}$ & $\begin{array}{c}\mathbf{V} \\
\mathbf{m} / \mathbf{s}\end{array}$ & $\begin{array}{c}\Delta \mathbf{\Delta} / \mathbf{L} \\
\mathbf{k P a} / \mathbf{m}\end{array}$ \\
\hline \multirow{2}{*}{50,8} & \multirow{2}{*}{8} & 1,7 & 1270 \\
\cline { 3 - 4 } & \multirow{2}{*}{8} & 1,9 & 1175 \\
\cline { 3 - 4 } & \multirow{2}{*}{$*$} & 2,2 & 1371 \\
\cline { 3 - 4 } & & 2,5 & 1665 \\
\cline { 3 - 4 } & & 3,0 & 2060 \\
\hline
\end{tabular}

Tabela B20-Dados de gradiente de pressão e velocidade média de fluxo para polpas minerais de concentrado de hematita $(-149+105 \mu \mathrm{m})$.

\begin{tabular}{|c|c|c|c|}
\hline $\begin{array}{l}\text { Diâmetro do } \\
\text { tubo, mm }\end{array}$ & $\begin{array}{c}\text { Concentração v/v } \\
\%\end{array}$ & $\begin{array}{l}\mathrm{V} \\
\mathrm{m} / \mathrm{s}\end{array}$ & $\begin{array}{c}\Delta \mathrm{P} / \mathrm{L} \\
\mathrm{kPa} / \mathrm{m}\end{array}$ \\
\hline \multirow{5}{*}{50,8} & \multirow{5}{*}{12} & 1,7 & 1570 \\
\hline & & 2,1 & 1430 \\
\hline & & 2,4 & 1720 \\
\hline & & 2,8 & 1960 \\
\hline & & 3,2 & 2350 \\
\hline
\end{tabular}


Tabela B21-Dados de gradiente de pressão e velocidade média de fluxo para polpas minerais de concentrado de hematita $(-149+105 \mu \mathrm{m})$.

\begin{tabular}{|c|c|c|c|}
\hline $\begin{array}{l}\text { Diâmetro do } \\
\text { tubo, mm }\end{array}$ & $\begin{array}{c}\text { Concentração v/v } \\
\%\end{array}$ & $\begin{array}{c}\mathrm{V} \\
\mathrm{m} / \mathrm{s}\end{array}$ & $\begin{array}{c}\Delta \mathrm{P} / \mathrm{L} \\
\mathrm{kPa} / \mathrm{m}\end{array}$ \\
\hline \multirow{5}{*}{50,8} & \multirow{5}{*}{12} & 1,9 & 1770 \\
\hline & & 2,3 & 1670 \\
\hline & & 2,5 & 1880 \\
\hline & & 2,8 & 2210 \\
\hline & & 3,1 & 2600 \\
\hline
\end{tabular}

Tabela B22-Dados de gradiente de pressão e velocidade média de fluxo para polpas minerais de concentrado de hematita $(-297+249 \mu \mathrm{m})$.

\begin{tabular}{c|c|c|c}
\hline $\begin{array}{c}\text { Diâmetro do } \\
\text { tubo, } \mathbf{m m}\end{array}$ & $\begin{array}{c}\text { Concentração v/v } \\
\%\end{array}$ & $\begin{array}{c}\mathbf{V} \\
\mathbf{m} / \mathbf{s}\end{array}$ & $\begin{array}{c}\Delta \mathbf{\Delta P} / \mathbf{L} \\
\mathbf{k P a} / \mathbf{m}\end{array}$ \\
\hline \multirow{2}{*}{50,8} & & 1,8 & 1764 \\
\cline { 3 - 4 } & \multirow{2}{*}{8} & 2,3 & 1568 \\
\cline { 3 - 4 } & \multirow{2}{*}{8} & 2,6 & 1790 \\
\cline { 3 - 4 } & & 2,8 & 2058 \\
\cline { 3 - 4 } & & 3,1 & 2210 \\
\hline
\end{tabular}


Tabela B23-Dados de gradiente de pressão e velocidade média de fluxo para polpas minerais de concentrado de hematita $(-297+249 \mu \mathrm{m})$.

\begin{tabular}{|c|c|c|c|}
\hline $\begin{array}{l}\text { Diâmetro do } \\
\text { tubo, mm }\end{array}$ & $\begin{array}{c}\text { Concentração v/v } \\
\%\end{array}$ & $\begin{array}{c}\mathrm{V} \\
\mathrm{m} / \mathrm{s}\end{array}$ & $\begin{array}{c}\Delta P / L \\
\mathrm{kPa} / \mathrm{m}\end{array}$ \\
\hline \multirow{5}{*}{50,8} & \multirow{5}{*}{12} & 1,9 & 1960 \\
\hline & & 2,4 & 1812 \\
\hline & & 2,7 & 2057 \\
\hline & & 2,9 & 2260 \\
\hline & & 3,2 & 2500 \\
\hline
\end{tabular}

Tabela B24-Dados de gradiente de pressão e velocidade média de fluxo para polpas minerais de concentrado de hematita $(-297+249 \mu \mathrm{m})$.

\begin{tabular}{|c|c|c|c|}
\hline $\begin{array}{l}\text { Diâmetro do } \\
\text { tubo, mm }\end{array}$ & $\begin{array}{c}\text { Concentração v/v } \\
\%\end{array}$ & $\begin{array}{l}\mathrm{V} \\
\mathrm{m} / \mathrm{s}\end{array}$ & $\begin{array}{c}\Delta \mathrm{P} / \mathrm{L} \\
\mathrm{kPa} / \mathrm{m}\end{array}$ \\
\hline \multirow{5}{*}{50,8} & \multirow{5}{*}{17} & 2,2 & 2350 \\
\hline & & 2,8 & 2250 \\
\hline & & 3,0 & 2450 \\
\hline & & 3,2 & 2700 \\
\hline & & 3,4 & 3000 \\
\hline
\end{tabular}


Tabela B25-Dados de gradiente de pressão e velocidade média de fluxo para polpas minerais de quartzo $(-149+105 \mu \mathrm{m})$.

\begin{tabular}{c|c|c|c}
\hline $\begin{array}{c}\text { Diâmetro do } \\
\text { tubo, } \mathbf{m m}\end{array}$ & $\begin{array}{c}\text { Concentração v/v } \\
\%\end{array}$ & $\begin{array}{c}\mathbf{V} \\
\mathbf{m} / \mathbf{s}\end{array}$ & $\begin{array}{c}\Delta \mathbf{\Delta} / \mathbf{L} \\
\mathbf{k P a} / \mathbf{m}\end{array}$ \\
\hline \multirow{2}{*}{25,4} & & 0,9 & 1567 \\
\cline { 3 - 4 } & \multirow{2}{*}{14} & 1,1 & 1469 \\
\cline { 3 - 4 } & \multirow{2}{*}{14} & 1,5 & 1861 \\
\cline { 3 - 4 } & & 1,9 & 2330 \\
\cline { 3 - 4 } & & 2,3 & 2918 \\
\hline
\end{tabular}

Tabela B26-Dados de gradiente de pressão e velocidade média de fluxo para polpas minerais de quartzo $(-149+105 \mu \mathrm{m})$.

\begin{tabular}{c|c|c|c}
\hline $\begin{array}{c}\text { Diâmetro do } \\
\text { tubo, } \mathbf{m m}\end{array}$ & $\begin{array}{c}\text { Concentração v/v } \\
\%\end{array}$ & $\begin{array}{c}\mathbf{V} \\
\mathbf{m} / \mathbf{s}\end{array}$ & $\begin{array}{c}\Delta \mathbf{\Delta P} / \mathbf{L} \\
\mathbf{k P a} / \mathbf{m}\end{array}$ \\
\hline \multirow{2}{*}{25,4} & & 1,0 & 1950 \\
\cline { 3 - 4 } & \multirow{2}{*}{20} & 1,2 & 1763 \\
\cline { 3 - 4 } & \multirow{2}{*}{20} & 1,7 & 2260 \\
\cline { 3 - 4 } & & 2,1 & 2743 \\
\cline { 3 - 4 } & & 2,5 & 3232 \\
\hline
\end{tabular}


Tabela B27-Dados de gradiente de pressão e velocidade média de fluxo para polpas minerais de quartzo $(-149+105 \mu \mathrm{m})$.

\begin{tabular}{c|c|c|c}
\hline $\begin{array}{c}\text { Diâmetro do } \\
\text { tubo, } \mathbf{m m}\end{array}$ & $\begin{array}{c}\text { Concentração v/v } \\
\%\end{array}$ & $\begin{array}{c}\mathbf{V} \\
\mathbf{m} / \mathbf{s}\end{array}$ & $\begin{array}{c}\Delta \mathbf{\Delta} / \mathbf{L} \\
\mathbf{k P a} / \mathbf{m}\end{array}$ \\
\hline \multirow{2}{*}{25,4} & 1,0 & 2351 \\
\cline { 3 - 4 } & \multirow{2}{*}{27} & 1,4 & 2155 \\
\cline { 3 - 4 } & \multirow{2}{*}{2} & 1,9 & 2650 \\
\cline { 3 - 4 } & & 2,4 & 3330 \\
\cline { 3 - 4 } & & 2,9 & 3820 \\
\hline
\end{tabular}

Tabela B28-Dados de gradiente de pressão e velocidade média de fluxo para polpas minerais de quartzo $(-297+249 \mu \mathrm{m})$.

\begin{tabular}{|c|c|c|c|}
\hline $\begin{array}{l}\text { Diâmetro do } \\
\text { tubo, mm }\end{array}$ & $\begin{array}{c}\text { Concentração v/v } \\
\%\end{array}$ & $\begin{array}{c}\mathrm{V} \\
\mathrm{m} / \mathrm{s}\end{array}$ & $\begin{array}{c}\Delta \mathrm{P} / \mathrm{L} \\
\mathrm{kPa} / \mathrm{m}\end{array}$ \\
\hline \multirow{5}{*}{25,4} & \multirow{5}{*}{14} & 1,0 & 1764 \\
\hline & & 1,3 & 1568 \\
\hline & & 1,7 & 1959 \\
\hline & & 2,2 & 2841 \\
\hline & & 2,7 & 3526 \\
\hline
\end{tabular}


Tabela B29-Dados de gradiente de pressão e velocidade média de fluxo para polpas minerais de quartzo $(-297+249 \mu \mathrm{m})$.

\begin{tabular}{c|c|c|c}
\hline $\begin{array}{c}\text { Diâmetro do } \\
\text { tubo, } \mathbf{m m}\end{array}$ & $\begin{array}{c}\text { Concentração v/v } \\
\%\end{array}$ & $\begin{array}{c}\mathbf{V} \\
\mathbf{m} / \mathbf{s}\end{array}$ & $\begin{array}{c}\Delta \mathbf{\Delta} / \mathbf{L} \\
\mathbf{k P a} / \mathbf{m}\end{array}$ \\
\hline \multirow{2}{*}{25,4} & 1,2 & 2351 \\
\cline { 3 - 4 } & \multirow{2}{*}{20} & 1,5 & 1990 \\
\cline { 3 - 4 } & \multirow{2}{*}{20} & 1,9 & 2450 \\
\cline { 3 - 4 } & & 2,2 & 3135 \\
\cline { 3 - 4 } & & 2,5 & 3680 \\
\hline
\end{tabular}

Tabela B30-Dados de gradiente de pressão e velocidade média de fluxo para polpas minerais de quartzo $(-297+249 \mu \mathrm{m})$.

\begin{tabular}{|c|c|c|c|}
\hline $\begin{array}{l}\text { Diâmetro do } \\
\text { tubo, mm }\end{array}$ & $\begin{array}{c}\text { Concentração v/v } \\
\%\end{array}$ & $\begin{array}{c}\mathrm{V} \\
\mathrm{m} / \mathrm{s}\end{array}$ & $\begin{array}{c}\Delta P / L \\
k P a / m\end{array}$ \\
\hline \multirow{5}{*}{25,4} & \multirow{5}{*}{27} & 1,3 & 2841 \\
\hline & & 1,8 & 2647 \\
\hline & & 2,1 & 3040 \\
\hline & & 2,5 & 3900 \\
\hline & & 2,9 & 4350 \\
\hline
\end{tabular}


Tabela B31-Dados de gradiente de pressão e velocidade média de fluxo para polpas minerais de quartzo $(-149+105 \mu \mathrm{m})$.

\begin{tabular}{|c|c|c|c|}
\hline $\begin{array}{l}\text { Diâmetro do } \\
\text { tubo, mm }\end{array}$ & $\begin{array}{c}\text { Concentração v/v } \\
\%\end{array}$ & $\begin{array}{c}v \\
m / s\end{array}$ & $\begin{array}{c}\Delta \mathrm{P} / \mathrm{L} \\
\mathrm{kPa} / \mathrm{m}\end{array}$ \\
\hline \multirow{5}{*}{50,8} & \multirow{5}{*}{14} & 1,0 & 784 \\
\hline & & 1,3 & 734 \\
\hline & & 1,7 & 840 \\
\hline & & 1,9 & 1030 \\
\hline & & 2,2 & 1300 \\
\hline
\end{tabular}

Tabela B32-Dados de gradiente de pressão e velocidade média de fluxo para polpas minerais de quartzo $(-149+105 \mu \mathrm{m})$.

\begin{tabular}{c|c|c|c}
\hline $\begin{array}{c}\text { Diâmetro do } \\
\text { tubo, } \mathbf{m m}\end{array}$ & $\begin{array}{c}\text { Concentração v/v } \\
\%\end{array}$ & $\begin{array}{c}\mathbf{V} \\
\mathbf{m} / \mathbf{s}\end{array}$ & $\begin{array}{c}\Delta \mathbf{\Delta} / \mathbf{L} \\
\mathbf{k P a} / \mathbf{m}\end{array}$ \\
\hline \multirow{2}{*}{50,8} & & 1,2 & 881 \\
\cline { 3 - 4 } & \multirow{2}{*}{20} & 1,5 & 832 \\
\cline { 3 - 4 } & \multirow{2}{*}{5} & 1,7 & 950 \\
\cline { 3 - 4 } & & 2,0 & 1220 \\
\cline { 3 - 4 } & & 2,2 & 1469 \\
\hline
\end{tabular}


Tabela B33-Dados de gradiente de pressão e velocidade média de fluxo para polpas minerais de quartzo $(-149+105 \mu \mathrm{m})$.

\begin{tabular}{c|c|c|c}
\hline $\begin{array}{c}\text { Diâmetro do } \\
\text { tubo, } \mathbf{m m}\end{array}$ & $\begin{array}{c}\text { Concentração v/v } \\
\%\end{array}$ & $\begin{array}{c}\mathbf{V} \\
\mathbf{m} / \mathbf{s}\end{array}$ & $\begin{array}{c}\mathbf{\Delta P / \mathbf { L }} \\
\mathbf{k P a} / \mathbf{m}\end{array}$ \\
\hline \multirow{2}{*}{50,8} & & 1,2 & 1126 \\
\cline { 3 - 4 } & \multirow{2}{*}{27} & 1,7 & 1070 \\
\cline { 3 - 4 } & \multirow{2}{*}{5} & 2,0 & 1275 \\
\cline { 3 - 4 } & & 2,3 & 1567 \\
\cline { 3 - 4 } & & 2,5 & 1763 \\
\hline
\end{tabular}

Tabela B34-Dados de gradiente de pressão e velocidade média de fluxo para polpas minerais de quartzo $(-297+249 \mu \mathrm{m})$.

\begin{tabular}{|c|c|c|c|}
\hline $\begin{array}{l}\text { Diâmetro do } \\
\text { tubo, mm }\end{array}$ & $\begin{array}{c}\text { Concentração v/v } \\
\%\end{array}$ & $\begin{array}{c}\mathrm{V} \\
\mathrm{m} / \mathrm{s}\end{array}$ & $\begin{array}{c}\Delta P / L \\
k P a / m\end{array}$ \\
\hline \multirow{5}{*}{50,8} & \multirow{5}{*}{14} & 1,4 & 1126 \\
\hline & & 1,7 & 980 \\
\hline & & 2,1 & 1224 \\
\hline & & 2,3 & 1371 \\
\hline & & 2,6 & 1665 \\
\hline
\end{tabular}


Tabela B35-Dados de gradiente de pressão e velocidade média de fluxo para polpas minerais de quartzo $(-297+249 \mu \mathrm{m})$.

\begin{tabular}{|c|c|c|c|}
\hline $\begin{array}{l}\text { Diâmetro do } \\
\text { tubo, mm }\end{array}$ & $\begin{array}{c}\text { Concentração v/v } \\
\%\end{array}$ & $\begin{array}{c}\mathrm{V} \\
\mathrm{m} / \mathrm{s}\end{array}$ & $\begin{array}{c}\Delta \mathrm{P} / \mathrm{L} \\
\mathrm{kPa} / \mathrm{m}\end{array}$ \\
\hline \multirow{5}{*}{50,8} & \multirow{5}{*}{20} & 1,6 & 1273 \\
\hline & & 1,9 & 1175 \\
\hline & & 2,2 & 1371 \\
\hline & & 2,4 & 1567 \\
\hline & & 2,6 & 1763 \\
\hline
\end{tabular}

Tabela B36-Dados de gradiente de pressão e velocidade média de fluxo para polpas minerais de quartzo $(-297+249 \mu \mathrm{m})$.

\begin{tabular}{|c|c|c|c|}
\hline $\begin{array}{l}\text { Diâmetro do } \\
\text { tubo, mm }\end{array}$ & $\begin{array}{c}\text { Concentração v/v } \\
\%\end{array}$ & $\begin{array}{c}\mathrm{V} \\
\mathrm{m} / \mathrm{s}\end{array}$ & $\begin{array}{c}\Delta \mathrm{P} / \mathrm{L} \\
\mathrm{kPa} / \mathrm{m}\end{array}$ \\
\hline \multirow{5}{*}{50,8} & \multirow{5}{*}{27} & 1,5 & 1469 \\
\hline & & 2,0 & 1375 \\
\hline & & 2,3 & 1567 \\
\hline & & 2,5 & 1812 \\
\hline & & 2,7 & 1960 \\
\hline
\end{tabular}


Tabela B37-Dados de gradiente de pressão e velocidade média de fluxo para água em dutos com diâmetro de 25,4mm.

\begin{tabular}{c|c}
\hline $\mathbf{V}, \mathbf{m} / \mathbf{s}$ & $\Delta \mathrm{P} / \mathrm{L}, \mathrm{kPa} / \mathbf{m}$ \\
\hline 1,4 & 615 \\
\hline 2,5 & 1470 \\
\hline 3,3 & 2450 \\
\hline 4,1 & 3420 \\
\hline
\end{tabular}

Tabela B38-Dados de gradiente de pressão e velocidade média de fluxo para água em dutos com diâmetro de 50,8mm.

\begin{tabular}{c|c}
\hline $\mathbf{V}, \mathbf{m} / \mathbf{s}$ & $\Delta \mathrm{P} / \mathrm{L}, \mathrm{kPa} / \mathbf{m}$ \\
\hline 1,3 & 300 \\
\hline 1,9 & 620 \\
\hline 2,5 & 1013 \\
\hline 3,0 & 1490 \\
\hline
\end{tabular}

